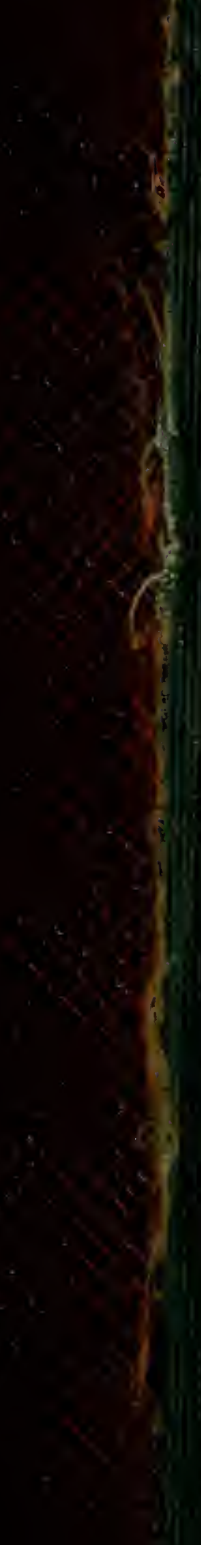




\section{G $72 \frac{\pi}{8}$}

\section{Three Splendid Aids to the Preven-

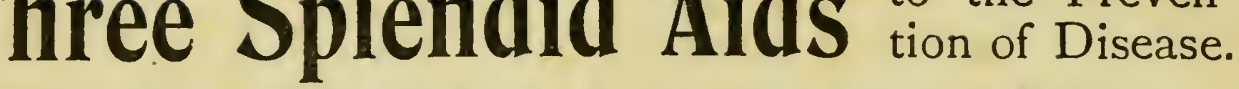

To ensure Healthy, Disease-resisting Conditions, absolute Cleanliness is of course of primary importance.

Select with greatest care

\section{THE WASHING MEDIUM}

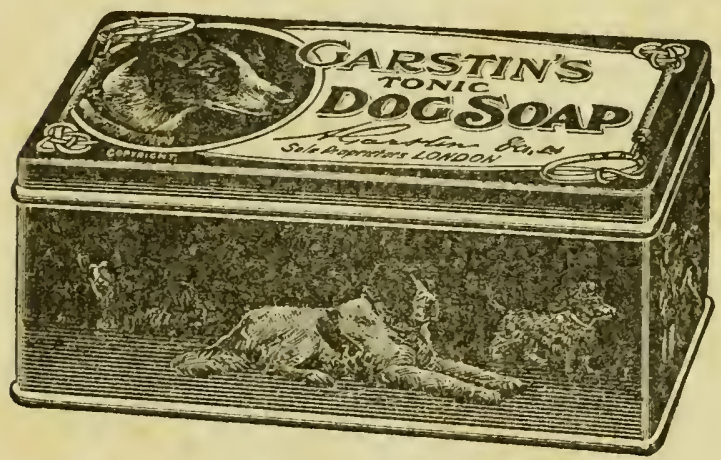

Garstin's Tonic Dog Soap is a Perfect Cleanser. It Lathers freely, $R$ inses out readily, Leaves no Residue.

IT EXTERMINATES FLEAS. Has a Wonderful Toning Effect on the Skin.

A rich gloss and an Improved Coat is quickly apparent.

Sold in Art Metal Tins containing 6 Tablets, 3s.; 3 Tablets, 1s. 6 d.; per Tablet, $6 d$.

GOOD GROOMING is also a great importance.

Obtain a Brush which is penetrating but not severe.

\section{Garstin's Registered}

\section{"Comfy" Dog Brush}

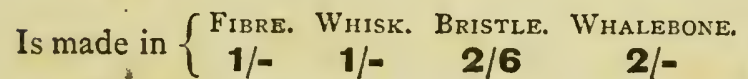

The shape is specially designed to avoid Cramp.

IT IS THE MOST COMFORTABLE BRUSH EXTANT.

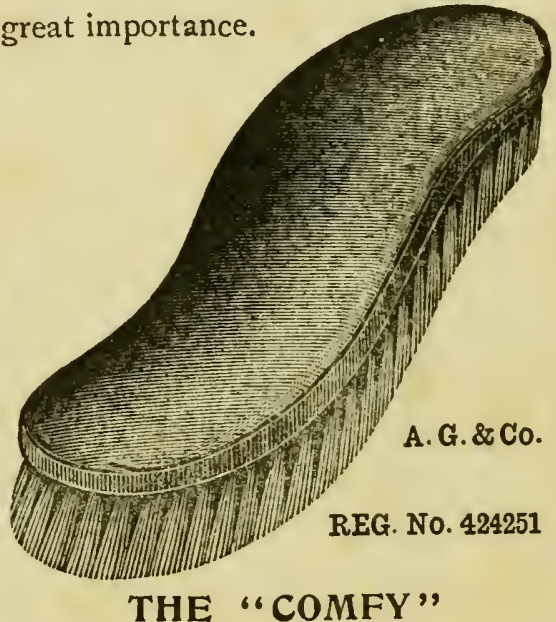

GUARD AGAINST INFECTION when taking dogs to

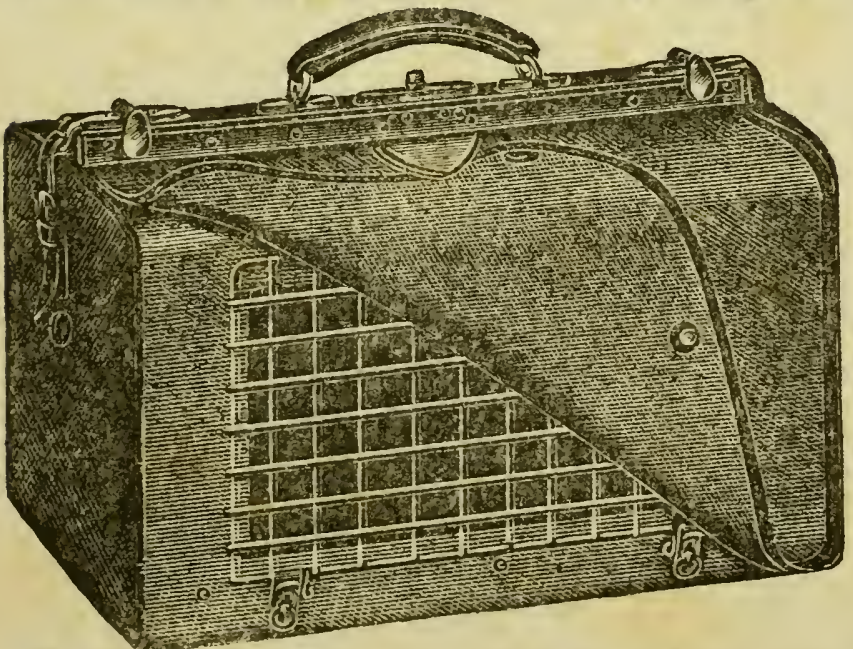
and from shows, \&c.

There is nothing better than Garstin's

\section{"Snuggery."}

It is Light, Airy, Unobtrusive.

It is exactly like a Handbag in appearance.

Made in Three Sizes.

Brown Waterproof Canvas.

$14^{\prime \prime} 18 /$-. $\quad 16^{\prime \prime} 20 / 3 . \quad 18^{\prime \prime} 22 / 6$.

Solid Cowhide.

14" 40/6. 16" 46/6. 18" 54/-.

Makers and Patentees of the Kink Hook, Bench Chain, Agreeable Dog Comb, \&c.

Stocked by all Leading Saddlers, Stores, and Retailers of Dog Collars.

Wholesale only of A.GARSTIN \& CO., Ltd., 159 Aldersgate St., London, E.C.

(District Agents' Name gladly sent on application.) 


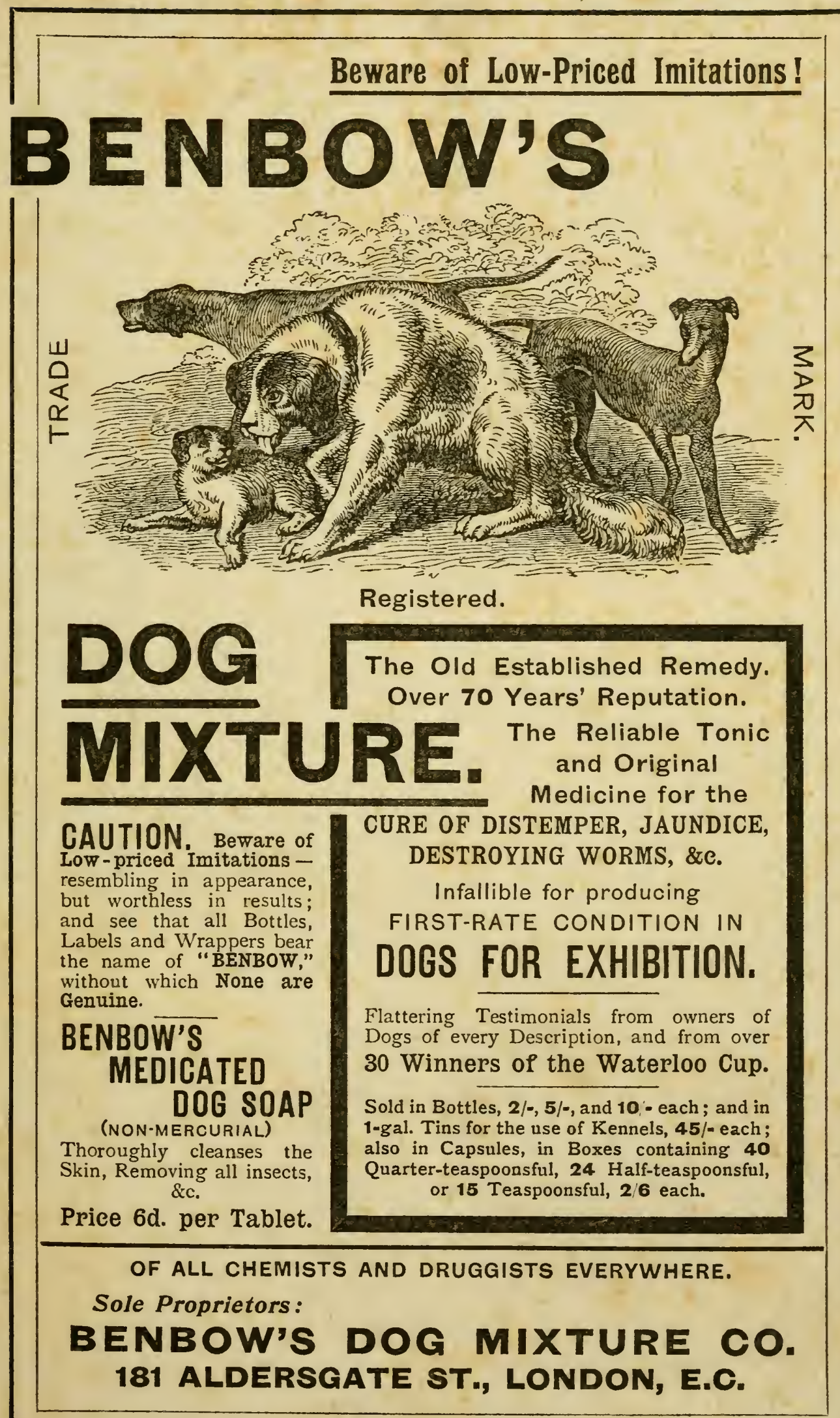




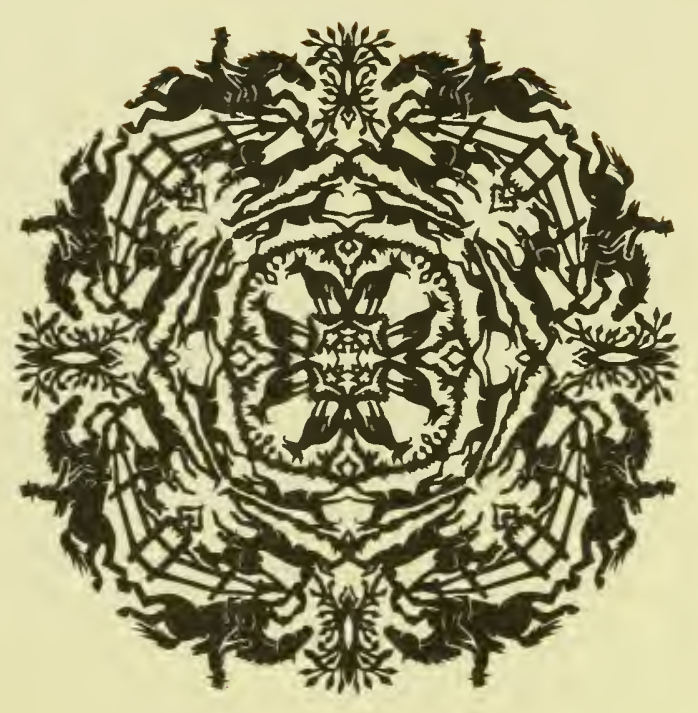

JOHN A.SEAVERNS 


\section{THE ENCYCLOPÆDIA OF THE KENNEL}


BY THE SAME AUTHOR

Uniform in size and price with this Volume

ENCYCLOP EDIA OF THE STABLE. A complete manual of the Horse, its Breeds, Anatomy, Physiology, Diseases, Breeding, Breaking, Training, and Management. With chapters on Harness, Farriery, Carriages, \&c. Fully Illustrated.

ENCYCLOP EDIA OF THE POULTRY

YARD. Fully Illustrated.

GEORGE ROUTLEDGF \& SONS, LIMITED 


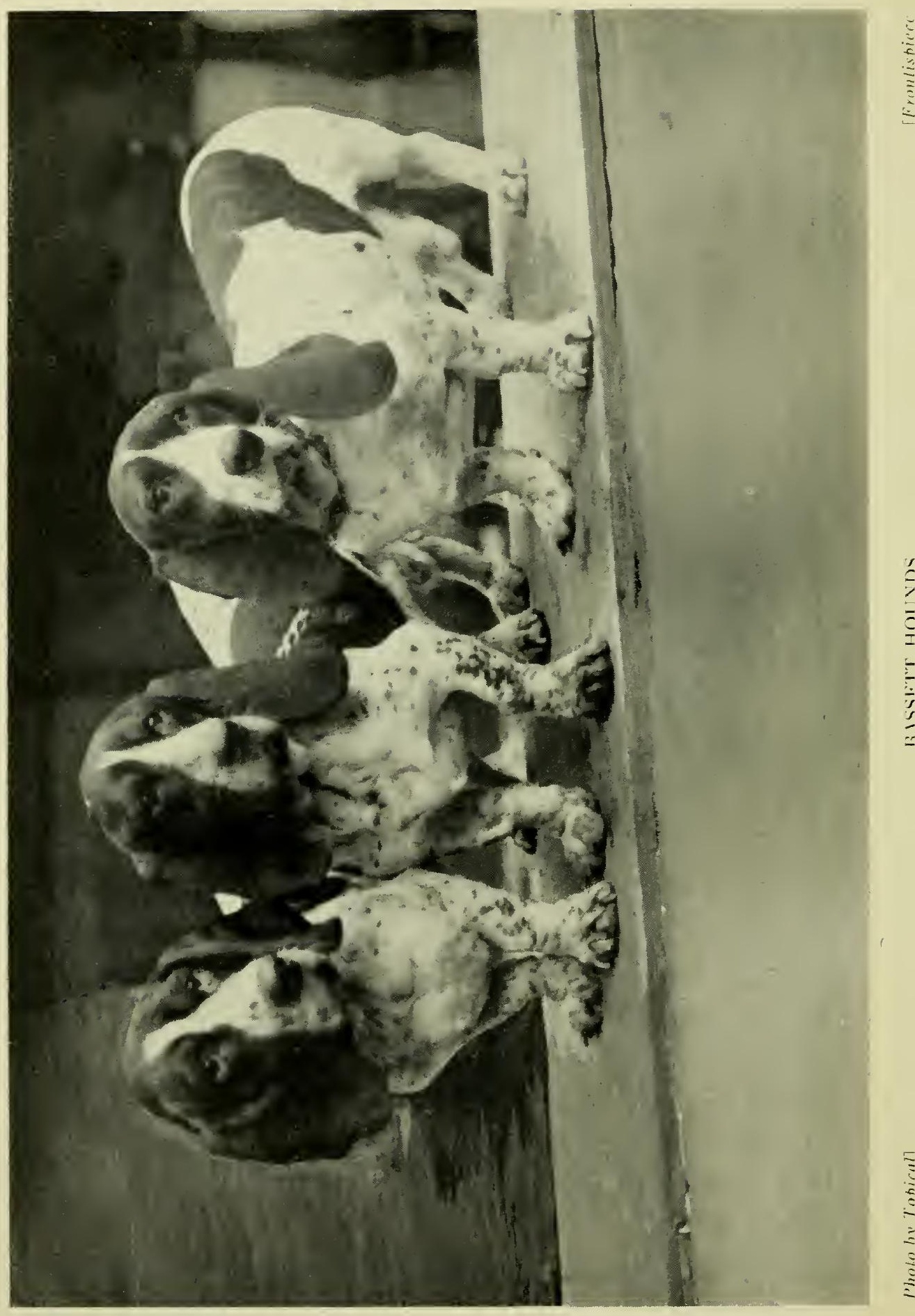


\title{
THE ENCYCLOPÆDIA OF THE KENNEL
}

A COMPLETE MANUAL OF THE DOG, ITS VARIETIES, PHYSIOLOGY, BREEDING, TRAINING, EXHIBITION AND MANAGEMENT, WITH ARTICLES ON THE DESIGNING OF KENNELS

BY

\section{VERO SHAW}

LATE EDITOR OF THE STOCKKEEPER, AND KENNEI, EDITOR OF THE FIELD

\begin{abstract}
WITH SIXTEEN FULL-PAGE PLATES AND ILLUSTRATIONS IN THE TEXT
\end{abstract}

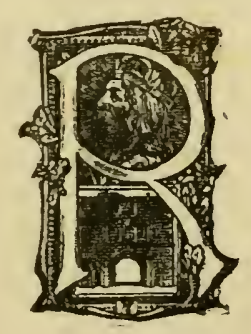

LONDON

GEORGE ROUTLEDGE \& SONS, LIMITED NEW YORK: E. P. DUTTON \& CO. I9I 3 
TO

JAMES CAPELLON TINNE

OF ARNEWOOD, SWAY, HANTS

THIS LITTLE WORK IS DEDICATED AS A HUMBLE RECOGNITION OF THE SERVICES HE HAS RENDERED TO THE CANINE RACE AND OF THE EMINENCE HE HAS ATTAINED AS A JUDGE, A BREEDER, AND

AN EXHIBITOR 


\section{P R E F A C E}

THE daily accessions to the ranks of dog owners which are taking place not only in this country but all over the world, may be regarded as a justification for the publication of a book dealing with the many intricacies of kennel management in an entirely new manner, which it is hoped may prove of assistance to the beginner as well as of service to more experienced owners in the management of their canine friends.

So many persons possess neither the time nor the inclination to attempt to master the details of the successful management of dogs as laid down in the works of imposing proportions which have appeared upon the subject, that it is hoped that the Encyclopadia of the Kennel-which is intended to be a handy work of reference for use in cases of doubt-may succeed in smoothing the path of the amateur aspirant to honours as an owner, exhibitor, or breeder.

A good, well-bred dog costs no more to keep than a mongrel, and it possesses the additional advantage of being admired by judges, and, if required, of reproducing its perfections in its offspring. But no dog, ix 


\section{PREFACE}

however perfect may be its points or how unstained its pedigree, is capable of doing justice to its merits if its few requirements are neglected or if it is improperly fed.

Perhaps I may be allowed to add that I have avoided the subject of dog-doctoring as much as possible, this subject being admirably dealt with by Mr. A. J. Sewell in the Dog's Medical Dictionary, a companion work to the Encyclopadia of the Kennel, and also published by Messrs. George Routledge \& Sons, Ltd.

VERO SHAW. 


\section{LIST OF FULL-PAGE PLATES}

BASSETT HOUNDS . • . . . . Frontispiece AFGHAN HOUND • . . . . . Face page 8 BLOODHOUND. • . . . . . " . 20 BORZOI . . . . . . . . . " . 32 BOSTON TERRIER . . . . . . . " 44 BULLDOG • • . . . . . . . . 56 BULL TERRIER . • • . • • " • 68 GREAT DANE • • • • • • • • IRISH SETTER • • • • • • " " 92 IRISH WATER SPANIEL . . . . . " 104 MASTIFF . . . . . . . . . " 120 POMERANIAN • . . . . . . . . ST. BERNARD . . . . . . . . " 152 SAMOYEDE . . . . . . . . . . . WELSH TERRIER • . . . • . . " 184 WOLFHOUND . . . . . . . . , 200 



\section{ENCYCLOPADIA OF THE KENNEL}

\section{A}

Aberdeen Terrier.-A name which is erroneously applied to the hard-haired Scottish terrier. The mistake is probably due to the fact that when the variety, which is to be met with all over Scotland, first came into prominence in exhibition circles, several of the most successful exhibitors resided in Aberdeen. The Granite City, however, possesses no claim to a monopoly of the breed, which is distributed all over Scotland. (See Hard-haired Scottish Terrier.)

Abortion.-There are few more vexatious annoyances to a dog-breeder than those which are associated with the losses incurred through a valuable brood bitch slipping her puppies. Such events are usually the result of some accident, though there are many bitches which never seem able to go through the whole period of gestation, and this tendency to abort is to a certain extent hereditary. As a rule, however, the trouble is generally due to the bitch over-exerting herself or by her constantly leaping on and off her sleeping bench, and there is naturally an increased danger of such events occurring during the later stages of pregnancy. No doubt, too, the subject of feeding enters into the question, as an imperfectly nourished animal, or one which is given improper food, is not unlikely to slip her puppies, especially if there is a natural tendency to do so. There is always the chance, moreover, of a pregnant 
bitch picking up some food which may cause her to abort, and hence the extreme importance of always burning, or in some way entirely destroying, anything that may come away from a mare, cow, or other animal which has slipped her young. (See Breeding, Brood-Bitch, Sterility.)

Abscesses comprise a form of trouble of which dogs are often the victims, as these swellings result from various causes, such as bites or injuries to internal organs through swallowing sharp-pointed bones, which are contributed to by the habits of the canine race. In all cases there is considerable tenderness whilst matter is forming, but relief can be obtained by applying poultices to the swelling if it is in an accessible position. When the abscess has become soft and "ripe" it should be opened, and after the pus has been gently squeezed out it ought to be cleansed with some antiseptic lotion. It is necessary that the wound should be kept covered if possible for a few days in order to keep it clean and wholesome, as if dirt or any foreign substance gets into it the consequences may be serious. (See Antiseptic Dressings, Poultices.)

Accidents are very fruitful sources of trouble to dogowners, as, independently of the evil effects of fighting, the animals are apt to meet with injuries through being run over, or from kicks, blows, tears, cuts, and other causes. Unfortunately, too, dogs are not as a rule at all good patients, as their natural desire to be on the move frequently retards a cure, whilst they are not easily prevented from licking wounds and thereby preventing them from healing, and they also possess a vexatious propensity for tearing off bandages. (See Bandaging, Bites, Cuts, Fractures, Nursing.)

Administering Medicine.-Some dogs give no trouble at all when they are being physicked, whilst in the case of others it is just the contrary. When medicine has to be 
given and the operator is an amateur, it is always best and safest for the latter to avail himself of the services of an assistant, and even of two, if the patient is a powerful and untractable animal. At the same time the less fuss that is made over the matter the better, as a dog is an emotional creature and very easily upset and frightened, the natural tendency to struggle being intensified when he has unpleasant substances forced upon him. The best way to proceed in the case of a large or medium-sized dog is for the owner to sit down and place the dog with its back towards him, and its head securely held between his knees, and the assistant close by to hold its feet, and, if necessary, its head. In administering liquid medicine there is no necessity at all for forcing open the mouth; all that requires to be done is to pull out the lips with a finger. at the back where the upper and lower ones join, and then to pour the liquid either from a spoon or bottle into the pouch or funnel which is thus made between the skin and the teeth. The head should be held a little upwards and the medicine poured in well at the back of the pouch, so that it can find its way into the throat; and if the dog's muzzle is released afterwards, so that he can move his tongue, he is sure to swallow the draught, provided he is unable to shake his head. When pills or boluses have to be administered, the mouth should be held open and the dose should be placed at the back of the tongue. The mouth may then be closed, and if the dog declines to swallow the pill or bolus the throat may be rubbed, which will usually cause him to do so. Powders may often be simply placed upon the tongue, and even if mixed with water very seldom cause difficulty, as they are usually small things; but many dogs possess a vexatious habit of retaining a dose in their mouths for quite a long time, and spitting them out when released. Others often return the medicine by vomiting, thereby causing themselves and their owners increased trouble; hence the value of such preparations as Spratt's tasteless aperient biscuits, 
which can be most satisfactorily administered in cases of constipation.

Afghan Hound.-This hound, which has been known as the Persian greyhound both in this country and on the Continent for many years, is a curious mixture of elegance, strength, and untidyness of appearance. The last-mentioned feature is due to the fact that although practically a smooth-coated variety, the Afghan hound usually carries a good deal of long hair of a silken texture upon his ears, tail, and legs, whilst the longer growth occasionally appears upon the belly as well. This gives him a very unkempt appearance, and suggests the idea that the long coat upon his head, neck, and body has come off-but this is not the case; and it may be added that occasionally perfectly smooth-coated specimens are met with, but these are not valued as much as the others. The general shape of the breed resembles that of a large but delicately formed greyhound, to which family it undoubtedly belongs, but the long coat above referred to makes the parts on which it grows appear somewhat clumsy. The usual colours are fawn, black, and white; the height varying from 24 to 29 inches, and the weight from 60 to 70 lbs.

Age.-The age to which a dog lives depends a good deal upon the constitution of the individual animal, and the manner in which it has been brought up. They are not long-lived creatures, however, and generally begin to show signs of declining vigour at about six or seven years old, after which old age usually overtakes them rapidly, though some robust animals hang on in comparative health for several years; but these often grow very fat, their sight almost invariably becomes feeble, whilst they lose their teeth, and their breathing and digestion is impaired. The extreme limit of canine longevity is impossible to state, but a dog of twelve or 
fourteen years old may be regarded as a very old one, though cases of a still greater age having been reached have been recorded.

Age for Breeding.-As a rule it is not desirable to breed from a dog before he is eighteen months old, or from a bitch until she has reached the age of two years; that is to say, until the sexes have become matured. This custom does not, however, suggest the fact that members of the canine race are not capable of reproducing their species at far earlier ages, indeed there are known instances of puppies having been born to parents neither of which have reached the age of twelve months. There are occasions also when it is wise to breed from quite a young bitch, as some animals seem to shoot up, and not to furnish as they ought, and in such cases if they bear a litter of puppies they mature better. In the case of big-headed breeds, such as bulldogs and mastiffs, it is sometimes desirable not to defer breeding from the bitches for too long, as the bones and muscles of the parts which are associated with the act of bringing forth puppies become set in the case of old dogs, and hence increased danger is attached to the first labour. (See Breeding.)

Air.-The practice indulged in by some owners of denying to their dogs a sufficiency of fresh air is not one that can be approved of. Air, in fact, is most beneficial to all dogs, though of course some discretion must be displayed in providing them with it, and all draughts should be avoided. There is, however, nothing that is more calculated to engender delicacy amongst dogs, or to foster disease, than compelling them to breathe an overheated or vitiated atmosphere, and it is consequently injurious to their health and development to deprive them of fresh air. (See Kennels, Nursing, Ventilation.) 
Airedale Terrier.-This old English breed is a native of the North Country, where he was originally known as the waterside dog, in consequence of his fondness for taking to the water in pursuit of vermin. It is indeed possible that the old name was more appropriate to the breed than the modern one, for the Airedale is rather a big dog to fulfil the functions of a terrier in the way of going to ground, as he stands well over 20 inches at the shoulder; on the other hand, there can be no denying either his courage, his staying powers, or his hunting proclivities, all of which have combined to render him as popular as he is. His skull is long, flat, not too wide, and tapers somewhat towards the muzzle, which in turn should be powerful, well filled up in front of the eyes and of a good length, the teeth being large, regular, and very strong, the eyes dark and rather small, and the ears small, V-shaped, and carried flat to the sides of the head. There should be no stop or indentation between the eyes, nor any superfluous skin about any part of the head, which should be long and lean, with powerful-looking jaws. The neck is of good length and free from any approach to throatiness; the shoulders long and sloping; the chest inclined to be narrow but deep, so as to provide room for the heart and lungs; the forelegs of fair length, quite straight, and heavy in bone; and the feet small and round. The back should be both level and short, showing plenty of muscle; the loins being powerful and the hind-quarters very muscular, the tail, which is usually docked, being set on high, the stifles being slightly bent and the hocks near to the ground. The coat, as in the case of all water-dogs, must be close and weather-resisting; it is also very hard and wiry, lying close to the body, so that it does not appear to be so long as it really is. The prevailing colour is tan, of a rather darker shade on the ears, but the body is either a dark grizzle or black, and there are dark markings on each side of the head. The height is about 22 inches, and the weight from 35 to 50 lbs. 
Anæmia.-When a dog goes off his feed and becomes languid and listless, and appears weak, it is probable that he is suffering from anæmia. If when his eyelids are lifted up the membrane appears pale in colour and bloodlesslooking, the suspicions of his condition will be usually well founded, and measures should at once be adopted to add tone to his system by administering tonics and encouraging bim to feed. (See Feeding, Tonics.)

Antimony or Tartar emetic is occasionally administered to dogs in the form of condition powders, but it is not a drug that can be recommended for general use, as it is poisonous in its effects. Antimony is not adapted to the uses of the amateur dog-keeper, and should not be included in his medicine-chest. If a dog is suffering from an overdose, some very strong tea should be administered at frequent intervals if the recognised antidote, tannic acid, is not at hand. (See Poisons.)

Antiseptic Dressings.-In cases of wounds in which putrefaction either has or is likely to set in, and where matter has formed, it is desirable that an antiseptic dressing or lotion should be applied. Of these, Condy's fluid (one teaspoonful to half a pint of water), boric acid in solution, or idioform are the best adapted for the use of the amateur. (See Abscesses, Bites, Cuts.)

Aperients are medicines which open the bowels, and no dog-owner should neglect to provide himself with something of the kind for use in times of emergency, as dogs are extremely liable to suffer from constipation. (See Medicines.)

Apoplexy is the result of pressure of blood on the brain, and usually attacks overfed and old animals. The symptoms are heavy breathing, fixed and bloodshot eyes, the dog lying perfectly still and not frothing at the mouth. 
In such cases professional assistance should be procured forthwith, but as time is a matter of the greatest importance, it may be stated that bleeding at the neck and rubbing the gums with undiluted spirits may bring relief. The dog should also be placed in a position where the air can reach him, and if a powerful counter-irritant, such as turpentine, is at hand, it may be well rubbed along his spine. If there is nothing else at hand for the purpose, mixed mustard may be used instead. (See Fits.)

Appetite.-The appetites of individual dogs differ amazingly, some animals being willing, if not greedy, to eat large quantities of the plainest food, whilst others refuse to be tempted by delicacies. Much depends, too, upon the state of the health, as worms, for instance, usually promote a voracious appetite, and indigestion induces a repugnance for food. (See Feeding, Gross Feeders, Indigestion, Shy Feeder., Worms.)

Applehead.-A term applied to a round head, especially by bulldog breeders.

Arsenic is a valuable drug for administration in cases of skin disease, but being a deadly poison, and cumulative in its effects, it must be used with extreme caution. Fowler's solution is a very convenient form, the dose being from two to six drops twice a day after feeding. (See Poisons.)

Arteries are the blood-vessels which convey the blood from the heart to the different parts of the body. When an artery is severed the blood spurts from the wound instead of trickling, as it does in the case of a vein being cut through, and arterial blood is lighter in colour. (See Bleeding, Capillaries, Cuts, Veins.)

Asphalt paving possesses many good points as a 


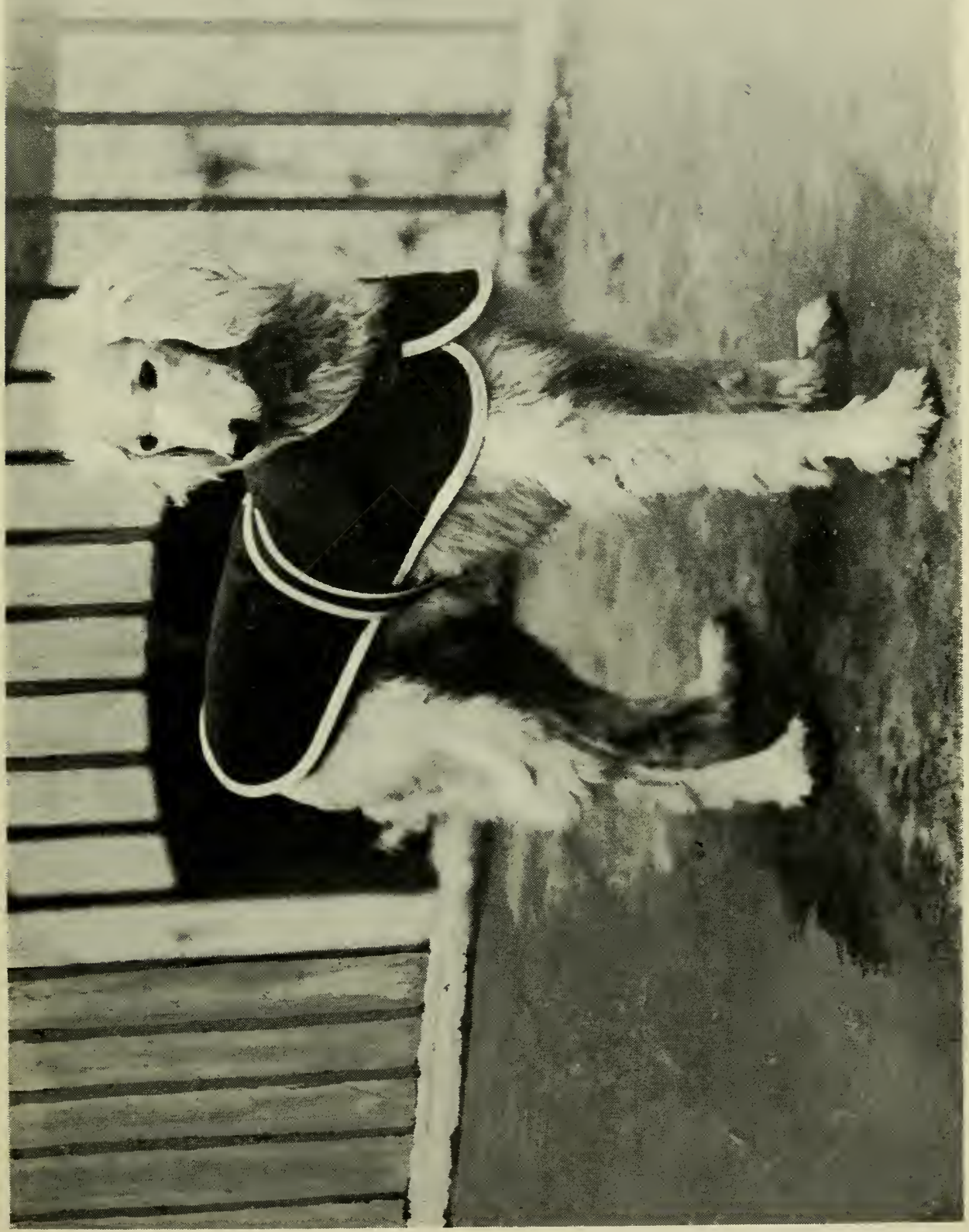

$\frac{1}{3}$
$\vdots$
$\vdots$
$z$
$\vdots$
$\vdots$
$\vdots$
$\vdots$

$\vdots$
$\vdots$
$\vdots$
$\vdots$
$\vdots$
$\vdots$
$\vdots$ 

flooring for kennels, as it is easily laid, not expensive, and is readily swilled over with water. It is not, however, so well adapted for outdoor yards, as it possesses a tendency to become soft in hot weather. In this respect it is inferior to cement, but it is warmer for the dogs to move about upon. (See Floors.)

Asthma.-The presence of this may be detected by the troubled, wheezy breathing of the dog and the crackling sound that is heard if the ear is placed to his chest. These symptoms are frequently associated with vomiting and constipation of the bowels. The treatment is to administer a mild purgative and to feed at frequent intervals on small quantities of underdone meat. For medicines, the prescriptions given by Mr. Sewell in "The Dogs' Medical Dictionary" are most efficacious.

Astringents create a contraction of tissue. (See Medicines.)

Atavism is the term applied to the tendency to "throw back" - that is, to show a resemblance to some more or less remote ancestor. (See Back Blood.)

Australian Terrier.-The fact that all dogs entering this country are subjected to strict quarantine is no doubt responsible for so few Australian terriers being seen in England, as the specimens of the breed which have appeared have been a good deal admired. In general appearance the breed somewhat resembles the working type of Skye terrier, or possibly a cross between that dog and the hard-haired Scottish terrier, the shape of the head being of the shape of the latter, but it carries a soft top-knot. The ears if uncropped are small and carried erect, but the body is rather larger than that of the Scottish terrier. The legs, too, are somewhat longer, and the lower parts and feet are smooth, whilst the hocks are slightly bent. The 
tail is always docked, the coat being flat and of a wiry texture. The colour proves the existence of a Yorkshire terrier cross, as the face and legs are tan and the top-knot either blue or silver, the remainder of the coat being either blue or grey, the former for choice. The average height is about Io inches, and the weight about 12 lbs.

\section{B}

Back Blood is the term applied to the hereditary trait which exists in a family of dogs, and which is liable to influence the conformation, constitution, and temper of its members. (See Atavism, Cross-breeding.)

Bad Breath is either caused by the stomach being out of order or by decayed teeth. In the latter case the sources of trouble should be extracted by a competent man; in the former, a dose or two of aperient medicine should be given, to be followed by a course of Spratt's tonic condition pills, whilst the feeding should be plain and plenty of exercise given. (See Exercise, Feeding.)

\section{Bad Doer. (See Shy Feeder.)}

Badger Drawing.-Not many years ago the great test of a terrier's gameness was his ability to draw a badger, but of late the custom is honoured more in the breach than by the observance; at all events, a dog's abilities in that direction are less discussed than they used to be. The test consisted of setting a terrier to drag a badger from the recesses of a barrel or artificial drain, a task which involved a good deal of pluck if the badger happened to be fresh caught and disposed to show fight; but animals kept for the unpleasant duty of being drawn very often became cunning and would come out from their retreat on the slightest provocation, knowing full well that they would be allowed to return at once. 
Balloon Brush is a specially designed brush for use when grooming long-coated dogs. It is oval in form, with a handle like an ordinary hairbrush; its peculiarity being that the bristles in the centre are the longest, the outer ones gradually becoming decreased in length as they approach the edges. (See Brushes, Grooming.)

Bandaging.-In applying bandages to a fracture or wound it is in most cases best to use a strip of rolled linen, such as may be obtained of any chemist. The way to apply a bandage is to roll it up and then to wind it tightly round the part, fixing it either by means of a safety-pin or by splitting it down the last few inches and tying the divided ends securely. In cases of fracture the bandage may be soaked in starch before being applied.

Bandogge.-An ancestor of the bulldog and mastiff, now extinct. (See Bulldog, Mastiff.)

Basset Hound.-This is a most valuable breed of French sporting hound which has attained great popularity in this country since its introduction towards the end of the 'seventies. The chief peculiarity of the breed is its short legs, which are in the case of most basset hounds more or less crooked in front, though there are some perfectly straight-legged specimens of the breed, but these are not appreciated. The short, contorted legs, moreover, possess their advantages, as they prevent their possessors from travelling over the ground too fast when tracking a wounded animal, and consequently the hunters are better able to keep up with them. In this country there are people who are apt to associate the basset hound with the German Dachshund, probably because the forelegs of each variety are short and bent. The French variety, however, is totally distinct from the German one, being unquestionably a hound, whereas the latter is more closely allied to the terrier family, as 
will be seen by referring to the description of the breed upon another page. The scenting powers of the basset hound are extremely high, and his admirers in this country have succeeded in deriving some very good sport from the fact, as the pack of drag-hounds which was established some years ago fulfilled all expectations.

The head of the basset hound resembles that of the English foxhound in many points, being long and narrow, with a somewhat lengthy and powerful muzzle, and welldeveloped flews. The occipital protuberance is strongly developed; there is some wrinkling of the skin of the skull on the forehead, the eyes being of fair size, and the red inner lining or haw being displayed in the smoothcoated variety. The ears are very long and velvety in texture, the tips curling inwards a little; the neck rather short, very powerful, and carrying a heavy dewlap; the shoulders not very long, but sloping; the chest exceptionally deep, with the chest-bone prominent in front; the front legs extremely short, very muscular, not out at the elbows, but turning inwards at the pasterns; the feet being large, splayed, and turned outwards, so as to give the desired crook of the limb. The body is of extreme length, but powerful and well ribbed up at the loin; the tail or stern being of fair length and carried upwards, like that of a foxhound; the hind legs short and bent at the stifles and hocks. The skin all over is inclined to be loose, the coat being short, fine, and glossy in the smooth-coated variety, and thick and harsh in the roughcoated breed, the forelegs of the latter being less crooked than those of the former. The average height is about I2 inches, and the weight about $50 \mathrm{lbs}$. In colour the black white and tans are mostly favoured, but red and white is often seen, and any hound colour is allowable.

Beagle.-This engaging little hound has attained a high popularity of late years, the result being that there are many more packs in existence than was formerly the 
case. It is indeed somewhat surprising that there are not even more of these now that the merits of the delightful little beagle have become better known, as the members of the hunt could easily divide the hounds between them and thereby save expense, whilst the enjoyment of the periodical runs and the value of the exercise derived from following a foot pack cannot be overestimated.

The skull of a beagle is slightly domed, rather wide, the occipital protuberance, or peak, and the stop between the eyes being well defined. The muzzle should be of a good length, showing plenty of substance, and the flews must be deep, the eyes being dark in colour, rather large, but not obtruding, and intelligent in their expression; the ears, which are set on low, being thin, long, and carried close to the sides of the head. The neck, which carries a slight dewlap, is fairly long and arched, the shoulders laid back, the chest being of moderate width and very deep, the body short, with nicely rounded ribs and strong loins; whilst the forelegs are dead straight, heavy in bone, and set on well under the body, with round, compact feet, the knuckles being considerably arched. The hind legs are bent at the stifles and hocks, whilst the tail or stern is rather long and coarse, and should be carried upwards, though free from any tendency to curl. Both smooth and rough coats are to be found amongst beagles, but the former predominate. In either case they should be dense, close, and harsh, whilst any recognised hound colour is allowable. Average height about I5 inches; average weight, 26 lbs. ; but "pocket beagles" should not exceed Io inches in height.

Bedding:-Opinions differ a good deal on the subject of bedding, some people contending that, excepting during very cold weather, the larger varieties are better if they rest on bare boards, whilst others favour all sorts of material. Taken all round, however, there is nothing to be found that is better than clean straw spread upon a 
wooden bench. Hay is not good, as it is easily beaten down flat by the dogs lying on it, and the same observation applies to shavings. The latter, however, form a very good summer bedding, especially as the odour of pine, which is associated with those most usually available, discourages insects. Sawdust and peat-moss are not to be recommended, as they work their way into the coats, and often into the eyes, noses, and water-troughs as well; but dried bracken is not at all a bad bed for the large breeds if it is spread thickly on the bench. (See Kennels.)

Bedlington Terrier.-This is a most popular breed in Northumberland and other parts of the north, but it is not held in very high favour amongst exhibitors, owing to the majority of those who show Bedlingtons indulging freely in the objectionable practice of plucking the coats of their dogs and other forms of trimming. Hence classes provided for the breed at shows are rarely well filled, and are often omitted from the schedules of important fixtures altogether. Consequently, the popularity enjoyed by the Bedlington terrier may be regarded as due to his courage, which is very great, and his ability for hunting vermin, especially in water. $\mathrm{He}$ possesses, moreover, a strong individuality of his own, and even if his temper is at times uncertain, his merits so far outnumber his failings that he deserves more support than he receives.

In general appearance the Bedlington terrier is rather a leggy, lathy-built dog, a peculiarity about him which strikes the observer at once being his flat sides, as the ribs are not at all rounded. The head is domed at the top and narrow; the muzzle is long and tapering, but well filled up under the eyes, and powerful; the eyes are small, sunken, and set obliquely; whilst the nose is large, its colour in the case of blues being black, and in the livers flesh-coloured. The ears are long and lie flat to the cheeks, the neck long and graceful, the shoulders 
laid well back, the chest narrow and deep, whilst the loins are powerful, and the back rather arched. The forelegs are rather long and quite straight, and the hind ones slightly bent at the stifles, the tail being about ten inches long and scimitar-shaped. The coat is a mixture of soft and hard hair, crisp to the touch and rough, whilst the best colours are blue and liver, or these mixed with tan. Average weight about 23 lbs.; height, 16 inches. (See Trimming.)

Beetroot is a very useful addition to a dog's food if well boiled, and forms an acceptable change, as it assists in keeping the bowels open and in adding flesh when an animal has lost condition. (See Feeding.)

Benches.-It is always a bad thing for dogs to have to lie on the floor of their kennels, and therefore, excepting in the case of young puppies and pregnant bitches, a raised wooden bench should always be provided for them to sleep upon. These should be about eighteen or twenty inches above the floor, but the height and width of the bench must of course depend upon the breed kept. It is desirable, however, to have them high enough to prevent the dogs from wetting the bedding if they lift their legs against the front of the

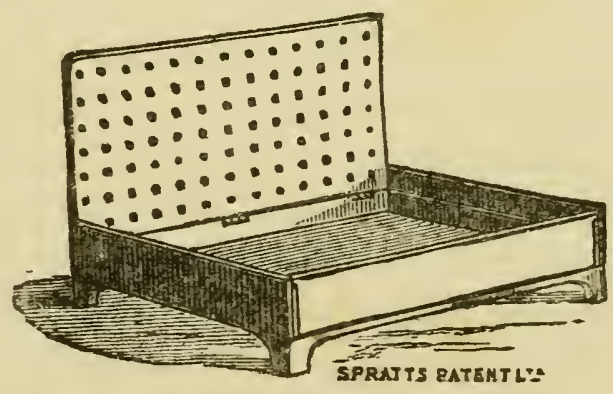

Portable Bench. benches. The fronts of the latter should be boarded down to the ground, so that the animals cannot creep under them in order to conceal bones; and there should be a strip of wood about four inches wide along the edge to keep the bedding from falling out. The benches should also be portable, so that they can be moved for cleansing purposes.

The accompanying illustration shows a very well- 
designed bench, with a hinged back to let down, if necessary, during the day. It is admirably adapted for puppies after weaning, but for adult dogs might be a little higher from the ground. (See Kenvels.)

Biscuits form an ideal food for dogs, but every care should be taken by owners to ensure their getting full value for their money. A badly baked biscuit, and still more so one that is composed of inferior materials, such as low-class meat and the sweepings out of granaries which have been ground up into meal, is not a proper food for any dog, and its use in a kennel is unprofitable in every way. On the other hand, a high-class biscuit made of the best materials, and containing a guaranteed percentage of sound flesh, is a most useful food, as it can be given both dry and soaked, and possesses the great advantage of being easily carried in an owner's pocket, so that dogs can be fed on journeys or when working away from home. It may be pointed out, too, that dry biscuits to a very great extent supply the place of bones, as if given in this form they require a good deal of gnawing, and thereby not merely keep the dogs occupied, but promote the secretion of saliva, and thus assist digestion. Reports are occasionally heard that some dogs do not like biscuits and cannot be made to eat them, but such statements are nothing more nor less than reflections upon the strength of will of those who make them. A dog can be made to eat anything by the exercise of a certain amount of firmness, but he naturally will endeavour to hold out for delicacies if he thinks that his owner is weak enough to give him what he likes and not what is good for him. (See Feeding.)

Bites.-As everybody must be aware, bites are a very common source of trouble to the owners of dogs, and the successful treatment of such injuries often causes a great deal of anxiety. Of course a great deal must depend upon 
the nature and seat of the wound; but, speaking generally, the first thing to do is to cleanse it thoroughly, and to stop the bleeding. When this has been accomplished the extent of the injury can be ascertained, and then the proper course of treatment can be decided upon. (See Bandaging, Bleeding.)

Black-and-Tan Terrier.-This very beautiful variety has unfortunately become almost extinct, owing to the lack of support it has received from dog-breeders, but happily a few enthusiastic admirers are attempting its resuscitation, and it is to be hoped that their efforts will be crowned with success. Lancashire was at one time a great stronghold of the breed, and hence some people are in the habit of referring to this dog as the Manchester terrier; but this is an absurd misnomer, as the black-andtan terrier is a national and not by any means a local variety, and is never referred to in Manchester as the Manchester terrier. There is very little doubt that supporters of this dog fell away when the practice of cropping the ears was pronounced illegal; and it must be admitted also that the black-and-tan is not so thoroughly game as are some other members of the terrier family, which fact may have had something to do with his loss of popularity. On the other hand, he is a most beautiful and engaging dog, a first-rate companion, and an excellent indoor guard for a house, as he is alert, and disinclined as a rule to make friends with strangers.

The head of the black-and-tan terrier is long, lean, flat, and narrow, the muzzle being also long and nicely filled in under the eyes, a snipey face being a nasty fault. The teeth must be white and regular, an undershot jaw being a disqualification; the eyes small, almond-shaped, rather deeply and obliquely set, and very dark in colour; the ears, which used formerly to be cropped, being small, and carried close to the sides of the head, with the tips slightly forward. The neck is rather long, and free from 
all loose skin; the shoulders sloping; the chest rather narrow; the ribs nicely rounded; the back short, and the loins not too much tucked up. The forelegs, which are an important point, must not be out at the elbows, they should be dead straight and heavy in bone, the feet being long. The tail must be fine, rather short, and carried straight out, and the thighs should show plenty of muscle; whilst the coat is short and close, and not too fine. Colour, however, is the most important point in connection with this breed, and should consist of a rich raven black relieved by rich, warm tan distributed as follows-under the lower jaw, along the throat, over each eye and upon each cheek, in the form of spots, with larger ones on the front of the breast. The legs are tanned up to just above the pasterns, but there are black lines, termed pencillings, running up the top of each toe, and a black spot called the thumb-mark on the forelegs above the pasterns. The insides of the thighs are also tanned, and so should be the hair at the vent, but the latter must not be profuse, as the tan should be hidden entirely if the tail is pressed down. Very frequently tan hairs appear behind the ears, or on the outside of the thighs-the dog is said to be breeched in the latter case-but if so, it is regarded as a serious fault, as the black hairs should be quite free of any tan at all.

Black Field Spaniel.-The popularity of the black field spaniel has increased very much of late years, and certainly the breed is entitled to all the praises bestowed upon it by its admirers, as in addition to its being a very beautiful, it is a most valuable field dog. There can be no doubt that this variety of spaniel, which is comparatively speaking a modern production, has been crossed with the Sussex by some breeders to the detriment of the latter's purity; nor is there any difference as regards its shape and make from other varieties of field spaniels, from which it is divided only by colour. 
The head is long, rather narrow, with the occipital protuberance well developed and slightly rising at the eyebrows. The muzzle is also narrow, of good length, and square; the nose large and black; the eyes dark brown in colour, rather large, and neither too prominent or too deeply sunken; whilst the ears, which are set on low, are of fair length, nicely fringed with feather, and hang flat against the sides of the head. The neck is powerful and long; the shoulders long and sloping; the body long, well let down at the chest, and very powerful about the loins, the chest being wide and the forelegs short, which makes the body appear even longer than it really is, and extremely heavy in bone, with large round feet. The hind-quarters should be powerful, the stifles being well bent, and the hocks let down; whilst the tail, which is always docked, is set on low and carried straight. The coat, which must be absolutely free from curl, though a slight waviness is allowed, is of fair length, dense and soft, the backs of the legs and tail carrying a good amount of feather. The average weight is about $35 \mathrm{lbs}$., and height about 15 inches. (See Field Spaniel.)

Blaze.-The term applied to the white streak, more or less wide, which runs up the faces of some dogs.

Bleeding.-Dogs are liable to many accidents which cause hemorrhage, and in some cases, unless the injuries receive immediate attention, a valuable animal may bleed to death. In cases in which arteries are severed-these can be detected by the blood spurting and not trickling from the wound-professional advice should be secured at once, as it is usually beyond the power of the ordinary amateur in surgery to attend to such cases. The best way to check bleeding in the case of a simple wound is to apply either very hot or very cold water to it, remembering that lukewarm water is likely to increase the flow of blood. If this course does not succeed, and the neces- 
sary appliances are not at hand, an impromptu tourniquet may be fastened above and below the seat of injury, and this can be done by fastening bandages round the parts an inch or so from the wound, and twisting them tight with a piece of stick, which can be kept in its place by another bandage or piece of cord. Should the wound be situated in such a position that a tourniquet cannot be applied, or if it is not considered desirable to adopt the latter arrangement, the bleeding may be stopped by placing a flat piece of wood, cork, or even stone wrapped up in part of a handkerchief, which has been saturated in water, over the cut, and wrapping a bandage tightly round it to close the wound. Temporary bandages can be made by cutting a stocking (a cotton one preferably, as it does not stretch) lengthways into two strips, and if one is not long enough a second can be attached to its end by safety or other pins. This, of course, can only be regarded as emergency treatment; but as it usually happens that serious cases occur when no proper appliances are available, it is best to know how to act with promptitude. The bleeding, unless the injury is a severe one, in which case professional assistance had better be secured, will usually be stopped by such means as those suggested, but the bandages should not be removed for six hours, when the injury can be properly attended to. (See Bandaging, Stitching Wounds.)

Blenheim Spaniel.-This is one of the most beautiful and engaging of all the toy varieties, and has been a favourite amongst the dog-owners of England for many years. In general shape it very closely resembles the King Charles, but it is of rather a more fragile and lathy build, and somewhat flatter ribbed. The main point of distinction between the two breeds lies, however, in their colours - that of the Blenheim being white, with markings of a lovely golden-lemon hue, neither too pale nor yet too dark in shade, and fairly distributed over the body, though 


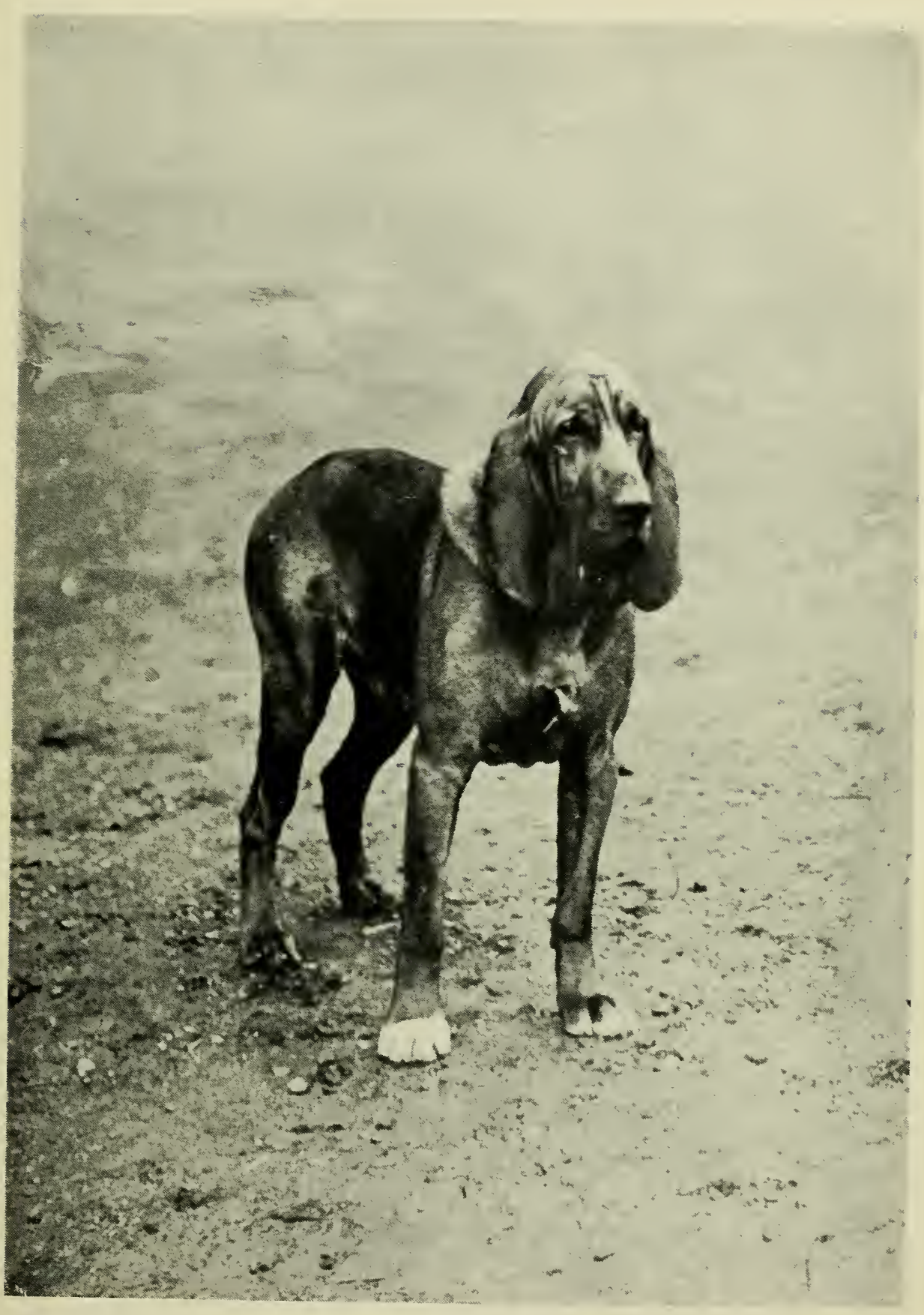

Photo by Topical] BLOODHOUND 

the white should preponderate. The ears should be of the golden-lemon colour, and there should be a spot of it on the centre of the forehead. This used to be regarded as a great point for breeders to secure, but it is difficult to produce, and hence modern admirers of the Blenheim Spaniel, who object to difficulties, profess to attach less importance to this spot than their predecessors did. As in the case of the King Charles, the Blenheim was not at one time so short in the face as he is now, and it may be added that specimens of the longer or so-called pleasant-faced family are still to be found in the neighbourhood of the Duke of Marlborough's seat at Blenheim, from which the variety derives its name. (See King Charles Spaniel.)

Blistering.-It is not often necessary to blister a dog, and when it is, the operation is not by any means a simple one to perform-nor is it easy to find something that will act as desired. Mr. A. J. Sewell, however, in his admirable work, "The Dog's Medical Dictionary," published by Messrs. George Routledge \& Sons, advocates the use of a liquid known as liquor epipasticus, which may be recommended with confidence when suggested by so eminent an authority as he. It may be mentioned, however, that this liquid is poisonous, and it must consequently be used with the greatest possible care.

The way to blister a dog, be the selected agent what it may, is to clip the hair closely from the part, which should then be thoroughly washed with warm water and soap, and dried; then the blistering liquid or ointment may be rubbed on with a brush or piece of stick, and afterwards a piece of grease-proof paper may be put over it, and the whole carefully bandaged, else the patient will get it off, and have his mouth blistered, or possibly poison himself. To prevent the latter danger, it is wise to keep a bucketmuzzle on the dog during the period (about two days) the blister is on him-excepting, of course, when he is being fed. When the blister is taken off, the place should 


\section{BLOODHOUND}

be carefully washed and dried, after which it may be dressed with boracic ointment. (See Bandaging, Bucketmuzzle, Muzzles.)

Bloodhound.-It is greatly to be regretted that this picturesque variety of hound should be in so few hands, as were he to be better understood, his merits would be appreciated as they deserve, and absurdly exaggerated stories of his ferocity would not be circulated as they often are. No doubt the bloodhound is not exactly a dog for a child to play with in all instances, but his name is derived from his remarkable powers as a tracker, and not because of the savageness of his disposition. The bloodhound is practically identical with the St. Hubert hound of France, a breed which for centuries has been valued by the huntsmen of that country; but English bloodhound owners do not use their hounds as the continental sportsmen do, probably because the opportunities are not forthcoming. At the same time, it may be observed that there have been such things as bloodhound packs used in this country for hunting purposes within, comparatively speaking, recent years, and of these that hunted by the late Lord Wolverton was by far the most famous.

The head of the bloodhound is long and very narrow, heavily wrinkled, and tapering slightly from the strongly pronounced occipital protuberance, or peak, towards the muzzle, which is of considerable depth. The eyes are very deeply sunk and small; they also show the red haw or inner membrane at the corners, and appear diamondshaped-this in a great measure being due to the weight of the flews or skin of the lips, and they should be of a hazel colour, a yellow eye, though often seen, being objectionable. The ears, which are fine in texture, should be set on low. They are very long, so long indeed that the ends lap over if brought together in front of the animal's nose, and they should lie close to the sides of the head, with the 
ends turning slightly inwards. The neck is long and carries a heavy dewlap; the shoulders are sloping and of a good length; the chest fairly wide and very deep, with wellrounded ribs. The fore-legs are set on well under the body, and are straight and extremely heavy in bone; the feet being large and round with thick soles, and the back short; the loins being both deep and powerful. The stern, or tail, is long, not too fine, set on high and carried upwards, but not over the back; the thighs being muscular, and the stifles well bent. The coat is short and hard, excepting on the head and ears, and there is a great deal of loose skin on all parts of the body. In colour the bloodhound is usually a rich, warm tan, with a black saddle on the back, and black sides and neck, there also being black on the top of the head. Occasionally the black markings are flecked with white, and white is also to be seen on the chest, the tip of the tail and toes, but though tolerated in these parts, it is not liked. Average height about 27 inches, and weight from 80 lbs. to I Io lbs.

Blood Poisoning may result from various causes, such as a wound or bite, a dead puppy remaining in the womb of a brood bitch, or diseased kidneys-in fact, the sources from which it springs are so many that dog-owners may with justice be suspicious of its existence in cases where the preliminary symptoms of a dog's illness are not clearly defined. Symptoms.-Bad breath, frequent shivers, with a high temperature, accompanied by vomiting and occasionally by extreme thirst. This is not a form of canine ill that the average amateur is competent to deal with successfully, and therefore professional advice should at once be obtained, but should the patient appear weak, restoratives in the form of spirits-brandy preferably-may be administered at frequent intervals.

Blotch.-The term applied to a form of eczema, which causes nasty sores to break out on various parts of the dog. 
Treatment, a mild course of cooling medicine and the application of Spratt's eczema lotion, which usually proves efficacious in the most obstinate cases.

Blue Eye.-When old age creeps over dogs their eyes frequently become obscured by a bluish film. For this there is no cure, but in the case of young animals the evil may arise from causes which are amenable to medical treatment if attended to at once.

Blue Paul.-An old breed of blue-coloured dog of the bull-mastiff type which has become practically extinct. The last stronghold of the variety was the south-west of Scotland, the Blue Pauls being cultivated by the patrons of dog-fighting in that part of the world for gladiatorial purposes.

Bob-tailed Sheep-dog, or old English sheep-dog, has of late established itself as a popular breed amongst those who take an interest in the exhibition of dogs. The actual origin of the variety is lost in obscurity, but there can be no denying the fact that the hardiness and intelligence of the dog, combined as they are with a perfect genius for herding sheep and cattle, have for many years rendered him a favourite amongst drovers in every part of the country.

In addition to the claims upon the regard of the community above referred to, the bob-tailed sheep-dog cannot fail to attract friends by the picturesqueness of his appearance, as he possesses attractions which are peculiarly his own. His head is large and rather square, arched over the eyes and profusely covered with hair, which in case of show specimens somewhat obscures his vision. The jaws are of fair length and very powerful, thus conveying the massive appearance to the head which is so much desired, and the nose is large and teeth very powerful. The eyes are usually dark hazel in colour, excepting in the case of 
the blue-coloured dogs, when one or both of them are usually "china" or "wall"-i.e. blue in shade. The ears are small; the neck fairly long, but very powerful; the shoulders sloping and the body rather short, but very compact, and higher at the loins than at the shoulders, thus producing the roach or wheel-back formation, as in the greyhound and bulldog. The fore-legs are straight, big, and muscular; the feet rather small, round, and compact; and the coat profuse, hard, and rather shaggy, but quite free from curl, the underjacket being very dense and sealskin-like. All old English sheep-dogs are not born tailless, but the majority are, and those which are not usually have their caudal appendages removed in early puppyhood. The usual colours are blue, grey, and grizzled, either self-colour or mixed with white, the average weight being about 60 lbs., and height 22 to 24 inches.

Bone.-Most dog-breeders seek for a liberal amount of bone in the fore-legs of their dogs, as a heavy-boned animal is naturally stronger in his limbs, and more calculated to get through hard work than one whose fore-legs are slender and weak. Hence the necessity for providing puppies with such food and exercise as will assist in the development of bone. (See Feeding, Rearing Puppies.)

Bones.-All dogs derive both pleasure and benefit from being given bones to gnaw; but it should be a care of their owners to see that all the bones are of such a size and description as not to be injurious to them. Small, hard bones, such as those of poultry, game, or rabbits, are particularly dangerous, as if pieces with sharp edges are swallowed they are apt to cause internal injuries. On the other hand, large bones with not too much meat on them will amuse a dog for hours, and are useful in the way of promoting the secretion of saliva, and thereby assisting digestion. If more than one dog is in the kennel there is always a prospect over a fight when bones are served out, 
and therefore all the débris should be collected and taken away after a sufficient time has been allowed the dogs to enjoy them. It should be remembered, too, that dogs often hide a bone under the straw on their bench, and will fight for its possession if one of their companions go near it. (See Feeding.)

Borzoi, or Russian wolf-hound, as he is also called, is beyond a doubt one of the most beautiful of all breeds, and certainly no variety of the canine race possesses more illustrious patrons, as he is a favourite of Queen Alexandra, of the imperial house of Russia, and of leading members of the aristocracy of both countries. In general appearance the borzoi somewhat resembles an elegantly built, silken-coated, light-coloured deerhound, but he is of an altogether more fragile formation, and his skull is much narrower than that of the Scottish hound. Though not by any means a brainy dog, the borzoi possesses plenty of courage, and has quite sense enough to perform all the work that is required of him. His duty is to follow wounded wolves as they break covert, and to hold them at bay until the hunters arrive upon the scene and administer the coup de grâce.

The head of the borzoi is long, narrow, and refined looking, flat on the top, the muzzle being long and tapering, which gives the dog the appearance of being Roman-nosed when he is regarded in profile. The eyes are dark, set rather close together, and possess an attractive languishing look, the ears being carried with the tips backwards, so as to show the interior. The neck is long and graceful; the shoulders laid well back ; the chest being narrow but exceptionally deep; and the back muscular, of considerable length, arched at the loins, which are powerful, though slender. The fore-legs are long and straight, but not very heavy in bone when the size of the dog is considered, the feet being long, the hind-legs being nicely bent at the hocks, but not so much so at the stifles as in the case of 
the Greyhound. The tail is long, well feathered, and carried rather low ; whilst the coat is long and rather wavy on the chest and body, with a kind of frill on the neck, but the head is smooth. The usual colour is white with fawn markings, the average height being about 28 inches and weight 90 lbs.

Boston Terrier.-This is entirely an American breed, its origin no doubt being a cross of the terrier upon the bulldog. It may therefore be accepted as being practically a bull terrier of the old style, and in many respects similar to the bull and terrier which is to be still met with in some parts of the midland counties, and which is simply a thickheaded bull terrier. The Boston terrier is a most fashionable and deservedly popular breed in America, but it is not commonly met with in this country; its importation being doubtless restricted by the rigour with which the Quarantine Act is enforced. The colour most preferred is brindle with white markings, and the weight varying from $15 \mathrm{lbs}$. to $30 \mathrm{lbs}$., but $22 \mathrm{lbs}$. is about the average.

Brace is the term used to denote two dogs of any variety, excepting hounds, which are referred to as couples.

Breaking.-Dog-breaking is an art which is not as much practised as it might be so far as non-sporting dogs are concerned, as the natural intelligence of the canine race renders it a comparatively easy matter to educate most varieties more highly than is usually the case. Of course some breeds are more easily broken than others, and individual animals differ widely in their possession of a capacity for imbibing instruction, but as general rule most dogs are capable of being taught to carry out their master's will.

As a matter of course, the various varieties of field-dogs are those which mostly come under the control of the 
breaker, and it naturally follows that their education is conducted on more advanced principles than that of animals which are only taught to retrieve or to behave themselves in an obedient manner in the streets. At the same time, the preliminary principles are similar in all cases when a dog is being brought under proper control, the first step to be taken being to teach the puppy to come to heel when ordered to, and not to run riot. In order to accomplish this the best course to take is to take a long thin line of about ten or a dozen yards in length and to fasten one end in a running noose round the pupil's neck, the other end being secured to the owner's wrist, with the slack coiled up loosely and carried in his hand. Then if the dog bolts and pays no attention to the command to return, he is pulled up sharply when he gets to the end of the line, and the running noose tightening round his neck adds to the discomfort of the position, with the result that after a few lessons most dogs abandon the practice of bolting. The check line should not be stouter than is necessary, and its thickness must depend upon the size and strength of the dog; but it may be pointed out that the thinner it is the more effectively the slip-knot will run, and hence the severer the lesson it teaches.

Thrashing a dog which possesses a disposition to bolt is a form of correction which is calculated to defeat its object, as the animal is likely to become afraid of his owner and to associate him with punishment; whereas in the case of the check line being used, he will connect the discomfort he experiences with the offence of disobedience, and be rather inclined to regard his owner, who loosens the cord round his throat, in the light of a friend in need.

When the pupil has been brought completely under control, and yet on friendly terms with his breaker, it will be time to instruct him in the art of finding birds. This, however, is best left to a professional breaker, as few amateurs are capable of the task. 
Breeching.- The term applied to the $\tan$-coloured hairs which sometimes appear on the thighs of a blackand-tan terrier, and constitute a serious fault. (See Blackand-Tan Terrier.)

Breeds.-It is unnecessary to give a detailed list of the various varieties of dogs here, as all of the important breeds are dealt with under their respective headings. It may be mentioned, however, that the canine race is divided for the purposes of classification into two categories-the sporting and the non-sporting; and speaking generally, there is not much objection to be taken to the arrangement, although in some instances the classification might be amended with advantage.

Breeding.-Most dog-lovers at one time or another develop into breeders, as the temptation to raise a few puppies is too great for them to resist. It may be therefore suggested, if it is possible so to arrange matters, that the spring is the best time of the year for the brood bitch to visit the stud dog, as the period of gestation being sixtythree days, the puppies then get all the summer to grow strong in; whereas, if they come into the world in the autumn or winter, their health and development are liable to become affected by the cold. It must be borne in mind, however, that the bitch is not at all times willing to receive the dog, the periods of her doing so being usually at intervals of six or four months, but they are irregular. The preliminary symptoms are unmistakable, the organ of sex in the first instance becoming swollen, and this being followed by a discharge tinged with blood. At the end of three or four days the latter will gradually subside, and immediately the discharge ceases is the best time for mating. Of course the bitch is willing to receive the dog before this, but if the dog is kept away until the discharge has ceased better results are likely to be secured.

As a general rule, it is unwise to mate two old animals; 


\section{BREEDING}

there should be youth on the other side if a dog or bitch of four or five years old is being bred from; but, on the other hand, two middle-aged animals may be put together without any harm coming of it. If this advice is not followed there is always a chance of the puppies being weak, and in the case of an old bitch, the yield of milk may be scanty or deficient in nutriment. In such a case the services of a foster-mother may be secured, and if so, it is necessary that she should have whelped at about the same date as the dam of the puppies, as the yield and quality of the milk becomes altered as time goes on. At all events, she should not have had her puppies a week or two before her foster-children are born.

The puppies come into the world blind, and remain so for several days, and their noses are almost invariably pink, becoming spotted at first and finally black in most cases, but not always so. If the mother has plenty of milk for them, the owner can easily satisfy himself upon this point, and if the quality of it is good, as the condition of the puppies will soon show, they will not require any extra feeding at first, and the more quiet they get the better. If, on the other hand, it is obvious that they are not thriving, and a foster-mother cannot be procured, they may be fed from an ordinary feeding-bottle on Spratt's Patent Orphan Puppy Food, or Spratt's Malt Milk with excellent results. In the case of the larger varieties, the services of a goat may be found useful, the writer having employed these animals with most satisfactory results in the case of greyhounds, by laying the goat on her side and holding her down while the youngsters sucked her, two at a time.

As the puppies become older, it is necessary that they should be supplied with food by their attendant, in order that they may learn to feed by themselves before they are weaned, and to prevent their taxing the strength of their dam too much. The best food for them in this connection is Spratt's puppy biscuits, given as directed, or Spratt's "Ovals" mixed with gravy or broth; but in any case the 
feeds should be small and frequent, the precaution being taken to leave nothing standing by them lest it should turn sour and upset their stomachs.

No doubt many puppies suffer in their youth from being allowed to roam about on a cold floor, and in order to avoid trouble in this respect the low bench upon which their bed is placed should be of wood, and the floor of their shed should be covered with peat-moss or sawdust to keep them warm. It may here be observed that it is alvays best for the bitch to be confined in a warm and dry, but well-ventilated shed whilst she is devoting her attention to maternal duties; and if the window is so placed that the sun can enter the place it will be all the better, as sunshine and fresh air are both great factors in the development of puppies. (See Brood-Bitch, In-breeding, Puppies, Selecting a Stud Dog.)

Breeders' Societies.-Of late years most breeds of dogs are honoured by having a Society-some favoured varieties have two or more-devoted to their interests, and beyond all doubt these bodies work hard in favour of their protégées, who owe much of the popularity they erjoy to the good offices of their friends. Whether the best interests of the canine race are advanced by the existence of specialist clubs is, however, another matter, upon which opinions differ, and there is certainly justification for the belief that some of the good old English breeds have suffered severely from the support given to foreign varieties which have been favoured by the influence of powerful clubs. There is, moreover, always the prospect of a specialist society developing into a clique, and by its influence compelling breeders to accept their views regarding the alteration of the points of an old-established variety which had existed and flourished long before the would-be reformers ever owned a dog at all.

Brick Paving.-This is a thoroughly bad form of paving for kennels, as not only does the porous nature of the 
bricks absorb the moisture, but unless they are very carefully laid their surface soon becomes uneven, and thus allows the water to accumulate and not run off as it should. (See Floors.)

Broken Colour.-A dog is said to be broken in colour when his otherwise dark coat is marked with white patches.

Broken Ribs are matters of not infrequent occurrence amongst dogs, and may be caused by a blow or kick. They should be attended to promptly, and pending the arrival of a veterinary surgeon may be treated by winding a wide linen bandage very tightly round the dog's body, and fastening it with safety-pins. (See Fractures.)

Bronchitis.-Many dogs which are confined in damp and draughty kennels lose their lives through an attack of bronchitis, the existence of which can be detected by a wheezy rattling in the throat and laboured breathing, accompanied by efforts to cough up phlegm. In such cases the patient should be removed to a warm-not hotand airy shed or room, and if possible a kettle should be kept as long as possible on the boil in it, so that the atmosphere will be rendered moist, as in cases in which human beings are the subject of attack. This disease is fully dealt with by Mr. Sewell in "The Dog's Medical Dictionary." (See Hospital.)

Bronzed when tan-coloured hairs appear amongst the black ones, as, for instance, they sometimes do behind the ears of a black-and-tan terrier, the dog is said to be bronzed.

Brood Bitch.-The selection of a brood bitch in cases where a person desires to make money out of her puppies is not so easy a task as the inexperienced may imagine. In 


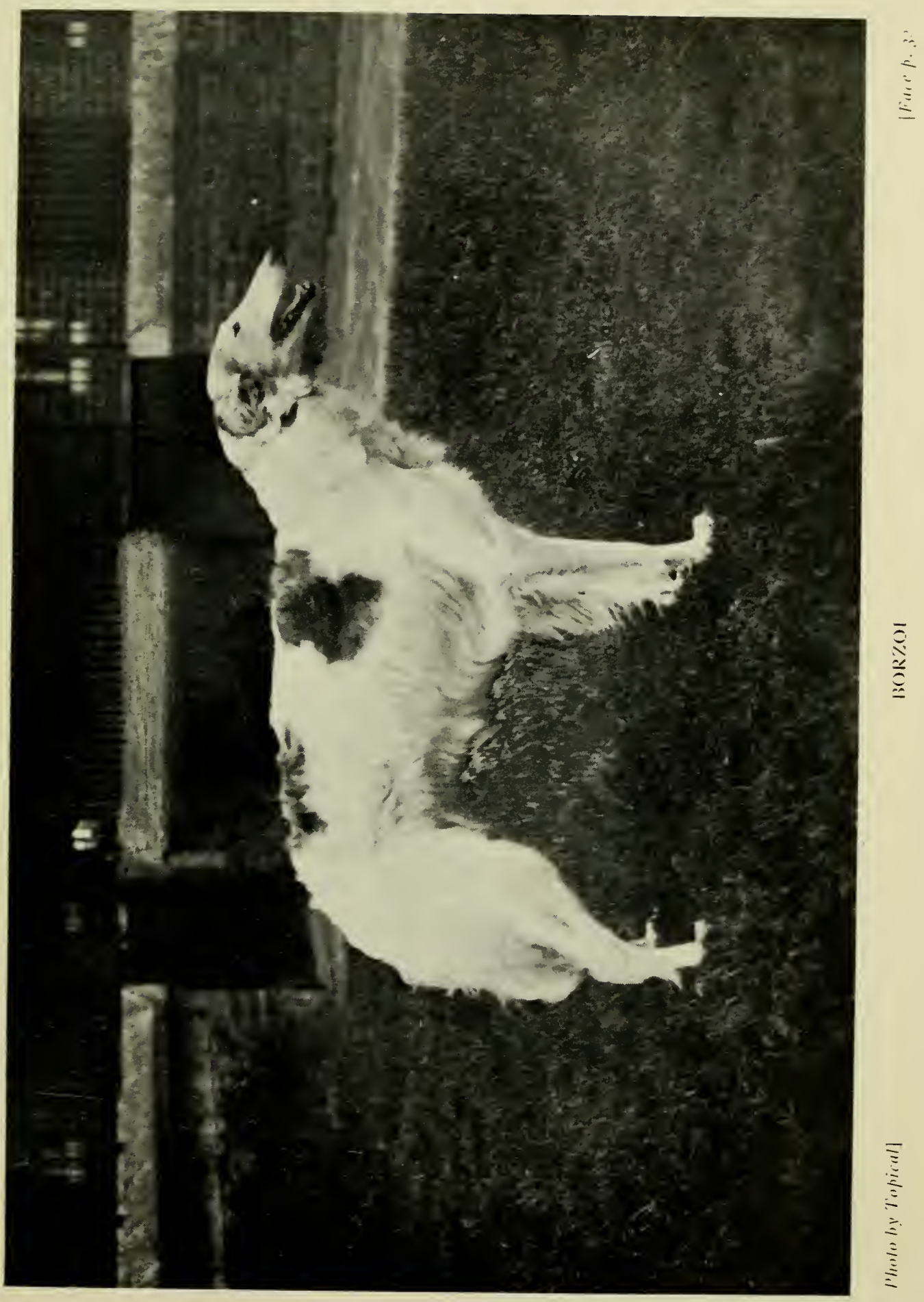



the first place, her robustness of constitution, freedom from hereditary disease, present state of health and age, are all matters which have to be seriously considered, and when these are all satisfactory, her owner will have to exercise care in providing her with a mate whose blood will " nick" with heirs. This is not always an easy matter, as it is well known to breeders that some families never cross well with each other, and it is far more important that the blood of the dog should suit the bitch, than that he should possess certain good points which she does not. Of course, assuming that the breeding of the dog is satisfactory, it is highly desirable that his perfections should be regarded from the point of view of their being likely to correct the faults she may possess; but it should always be remembered that an animal may not be a true representative of the family he belongs to, and if so, it is quite probable that certain characteristics of his strain, which he does not display himself, may appear in his offspring, and hence the importance of ascertaining what the parents and other relations of the dog are like before deciding to breed from him.

Assuming that the brood bitch is safe in pup, it is necessary to treat her carefully for the latter half of the nine weeks' period of gestation. At no part of it, however, ought she to have her energies overtaxed by too much hard work, but during the last few weeks she requires special attention. For instance, she ought not to be allowed to jump on and off a high bench, and therefore her bed should be made on the floor, care being taken to place some boards, nailed to a piece of quartering, underneath the straw if the pavement is of any cold material, such as concrete, brick, or asphalt. It is desirable also that she should be placed in the kennel in which it is intended that she shall have her pups, some time before the event is anticipated, as some animals take a long time in settling down in new quarters. The breeding kennel should be fairly roomy, well lighted, and isolated, so that 
the bitch will not be disturbed by other dogs, and if it opens on to a sunny yard where the puppies can be let run when they are strong enough so much the better. Previous to the time of whelping the bitch will be all the better for a little addition to her food, and she should be allowed a reasonable amount of exercise every day.

The day before she is due to whelp a dose of sweet-oil or of glycerine may be given to the bitch, and a plentiful supply of clean straw may be placed on her bench on the floor, so that she can prepare the bed for the expected young. This she will do by turning round and round until a circular nest is formed, with all the straw removed from the bottom of it, so that the puppies actually lie on the boards, this being no doubt an arrangement of nature to facilitate cleansing operations. It moreover proves the necessity of having a wooden floor beneath the puppies, as stonework of any kind would be too cold for them.

Provided that all is proceeding as it should, the less the bitch is interfered with at the time of labour the better; but she must be watched in case complications occur, in which event professional assistance should be secured by the amateur. A clean trough of fresh cold water should be within easy reach of her, and when her troubles are over she should be supplied with properly cooked gruel at frequent intervals. If there are any dead puppies they should be removed, this being a task of some difficulty, as the mothers often resent the act, and there is always a chance of an irritable bitch destroying her young if she is not left quiet for a few days after they are born.

The above suggestions as to the management of the brood bitch will meet any ordinary case, but it may be pointed out that there are always chances of complications arising which may lead to the loss of the bitch or her puppies. Therefore, if there are any signs of difficulty, the inexperienced owner should at once seek advice, professional if possible, if not that of some practical person. (See Breeding, Puppies, Selecting a Stud Dog, Weaning.) 
Broth is a form of nourishment to which dogs are mostly very partial, and it possesses the additional advantage of being good for them. Bullocks and sheeps' heads are the best materials of which to make it. They should be cooked very slowly, and afterwards turned out with the broth into another vessel to cool, as if allowed to remain in the copper or saucepan in which they were boiled the whole mixture is likely to turn sour. (See Feeding.)

Bruises constitute a common cause of trouble amongst dogs, and may be the result of intentional or accidental injuries. In some cases the skin is broken, in which event the part may be fomented to cleanse it and allay the inflammation, and then a soothing dressing may be applied, and if possible it should be bandaged. The treatment of a bruise when the skin is not broken consists of fomentations, after which the swelling may be gently dried with a soft cloth.

Brushes form a very important part of the requisites of a kennel which contains show dogs, as they assist the owner in keeping the coat in good order and the skin clean. Many persons, of course, use ordinary hairbrushes for the above purpose, but the following are better. For the large, smooth-coated varieties, a body brush, such as grooms use for dressing horses; for rough-coated breeds, a dandy brush, this being a longer haired one; for curlycoated dogs, a water-brush; and for the toy varieties, a so-called balloon brush, which consists of an oval-shaped long bristled one, rather soft, and so made that the bristles in the centre are longer than those at the sides. These brushes are specialities of such firms as Spratt's Patent, who manufacture them in various sizes. Brushes with wire bristles are occasionally used when obstinate patches of superfluous hair have to be removed. (See Brushing, Cleansing the Coat, Grooming, Preparing for Shows.) 


\section{BRUSHING-BULLDOG}

Brushing.-It is always better to brush a dog's coat than to comb it, as if the hair is matted the comb is liable to pull it out in tufts, and its teeth sometimes irritate a delicate skin. Brushing, moreover, if thorough, will improve the appearance and condition of the coat, and generally conduces to the comfort of the animal. (See Brushes, Combing, Grooming, Preparing for Showes.)

Bucket Muzzle consists of a leather tube, with holes pierced in it to enable its wearer to breathe, which fits over the muzzle. It is chiefly worn by whippets in training, as it provides an absolute prevention against their picking up any undesirable food. (See Muzzling, Tape Muzzle.)

Bull-baiting is a form of sport in which our ancestors incinged, but is now unknown, though the stakes to. which the bulls were fastened are still to be seen in some parts of the country. Contrary to general belief, the bull was not loose when the dogs were slipped at him, but fastened to a post by a strong line. The dogs were then encouraged to go for him and pin him by the nose, their object being to bring him on to his knees. (See Bulldog.)

Bulldog.-The so-called national dog of England is a very different sort of animal to what he was in the old bullbaiting days, or even forty years ago, as he has lost much of his old activity, though happily his courage has not been generally or materially affected by the changes which have been effected in him. There is no reasonable ground for doubting that he and the mastiff are both descendants of the ancient mastiff or bandogge which was bred by our ancestors, and highly prized by them on account of its courage and ferocity. The bulldog of a hundred years ago was, moreover, a leggier and longer-faced dog than those which are now to be seen. He also weighed a good deal heavier, and was a far more active, able-bodied animal than many of the modern cracks, some of which have such mal- 
formed limbs as to be almost incapable of jumping on or off a bench. In fact, so far as any approach to utility is concerned, comparisons are all in favour of the bygone type, the latter-day development of which has produced little else but a clumsy lap-dog.

Undoubtedly, however, the modern bulldog is more fortunate in his associations than his ancestors were, as his patrons of the past were certainly not of a very desirable type of humanity, and his connection with them brought the dog a bad name, which was not his fault. The bulldog, moreover, is regarded by many persons, who are incapable of discriminating between courage and ferocity, as a most dangerous and evil-dispositioned dog; whereas he is nothing of the sort, though of course, as in the case of every breed, there are some bad-tempered specimens to be met with. As a matter of fact, the bulldog is very slow to anger, and a most safe companion for children; but should his passions be aroused by teasing or an attack from some other dog, his immense courage renders him an extremely formidable opponent, especially as his intelligence is not great.

The head of a bulldog should be large and square, wide between the ears, and flat at the top, the temples being prominent, and there being strongly developed bumps on the cheeks at the base of the jaws. The eyes should be rather full, round, and dark in colour, with an indentation between them known as the "stop"; whilst the nose, which must be black-a butterfly or Dudley nose being a very bad fault indeed-is large, with well-developed nostrils and laid well back, the muzzle being short, and well filled up under the eyes. The under jaw, which projects in front of the upper one, is very. wide, and ought to turn rather upwards, and the lips, or "chop," should be heavy; the skin on the skull and muzzle being heavily wrinkled; whilst the ears, which should be small, are set on high and wide apart at the corners of the skull. The best shape of the 
ear is that known as the "rose," it being formed so that the tips turn backwards, and thus show the inside burr.

The neck is short and massive, and carries a double dewlap, whilst the chest is wide and deep, the ribs well rounded, and the back short and "wheel" or "roach" shaped, that is, higher at the loins-which are slender, though powerful-than it is at the shoulders, and gracefully curved, not rising in a straight line. The fore-legs are short, straight, and very heavy in bone, the muscles on the outside being so strongly developed as to produce an appearance of crookedness, but crooked fore-legs or ankles are very bad points in connection with a bulldog, and should not be encouraged. The forefeet should be round, of good size, and compact, a splayed foot being a nasty fault; the stifles and hocks of the hind-legs should be rather straight, and the latter slightly turned in; whilst the tail, which ought to be set on low, is short and fine, and incapable of being carried over the back; it is also more or less crooked as a rule.

The coat is short and rather fine, but not silky, the best colours being brindle, fawn, red, and white, but brindle-pieds, fawn-pieds, and red-pieds all have their admirers. Black markings, excepting on the muzzle, in which case the dogs bearing them are referred to as smuts, should disqualify any bulldog, and so should a lightcoloured eye, or deformed legs. The weight varies from 22 lbs. to $60 \mathrm{lbs}$., but from $45 \mathrm{lbs}$. to $50 \mathrm{lbs}$. for a dog, and from $40 \mathrm{lbs}$. to $50 \mathrm{lbs}$. for a bitch are the best weights. (See Butterfly Nose, Chop, Dudley Nose.)

Bull Terrier.-This most symmetrically built, gracefullooking breed is a relic of the old dog-fighting days, when the votaries of that abominably cruel sport produced a canine gladiator which possessed the courage of the bulldog combined with the activity of the terrier by crossing the two varieties together. The result was an animal which would face anything, and hold his own with most; but 
he was altogether lacking the grace and symmetry of the modern bull terrier, as his head was shorter and thicker, and his body more cumbersome than those of the latter.

The head of the bull terrier should be long, flat, and lean, very gradually tapering from the back of the skull and the cheeks to the nose, very powerful at the jaws, and well filled in under the eyes. There should be no approach to cheek bumps, as in the case of the bulldog; the upper and lower jaw should be absolutely level, and the nose jet-black; whilst the lips should be tight, just covering the teeth, and without any approach to the heavy chop which distinguishes the bulldog. The ears are fine, and usually carried erect; the eyes must be jet-black, small, almond-shaped, and set rather obliquely; the neck being long and powerful, but quite free from loose skin or any approach to a dewlap. The shoulders slope nicely ; the chest is wide and deep; the back being short and level; and the body well ribbed up at the loins. The fore-legs should be dead straight, of a fair length, and set well on under the dog, the feet being round and compact, whilst the hind-legs are rather straight and well let down at the hocks; the tail being fine, short, and carried straight out without any approach to a curl. The coat is short and inclined to be harsh, and the only recognised colour for exhibition purposes pure white; whilst the weight varies from $16 \mathrm{lbs}$. to $60 \mathrm{lbs}$.

Bullocks' Heads form a first-rate food for dogs. They should be gently simmered in a copper, and when cooked the meat may be cut off and mixed with the biscuits, meal, and vegetables upon which the dogs are fed. When cooked the heads and broth should be turned out into another vessel to cool, else they will turn sour. (See Feeding.)

Bumpy.-A dog is said to be bumpy in his head when the protuberances on his cheeks are prominent, as in the case of the bulldog. (See Cheek Bumps.) 


\section{$B U R N S-B U Y I N G$ A DOG}

Burns.-When a dog is suffering from the effects of a burn, the object of those in charge of him should be to keep the air from the part and to reduce the inflammation; this can be accomplished in simple cases by applying linseed-oil at frequent intervals. Severe burns should be attended to by a professional man.

Butterfly Nose.-A nose which is not all black, but disfigured by pink specks or markings.

(See Dudley Nose.)

Button Ear.-An ear the tip of which points downwards, so as to conceal the inner burr. (See Rose Ear, Tulip Ear.)

Buying a Dog.-The best advice that can be given to a would-be purchaser of a dog, who may not possess much experience of the canine race and their human friends, is to go to a respectable dealer, and never to buy a dog at a show. There are plenty of the former to be found who will serve a customer well, if only from the hope of favours to come ; but dogs which are exhibited are in so many cases shamefully trimmed, that when their coats grow again they are scarcely recognisable. Many breeders decline to part with the dogs they do not require for exhibition purposes, lest they should fall into the hands of opponents who might breed from them; but of course, if any of their superfluous stock can be purchased, a bargain may be secured, though as a rule show dogs are not worth much for working purposes.

Buying a puppy is always a rather difficult task even for an expert, as dogs change so much after they have passed the earlier stages of their existence, and some breeds do not arrive at maturity until they are two years old. If the assistance of some one who understands the variety of which the novice is anxious to possess a specimen can be secured, it will therefore be of use to the purchaser, who, however, should make it a rule to avoid 
the amateur dog-dealer as much as he can, and most particularly the person who always knows a man who happens to have for sale exactly the sort of animal his friends may require. (See Selling, Trimming.)

\section{C}

Calculus.-Dogs often suffer a good deal from stone in the kidneys, the presence of which can be detected by the evident pain they are enduring and the mixture of blood in their urine. The best thing to do is to apply flannels wrung out in boiling water and sprinkled with turpentine to the loins, and to administer opening medicine; but professional advice should be sought.

Canker in the Ear produces considerable pain if neglected, as it is caused by inflammation of the internal passages, which frequently produces a very offensive discharge. The treatment is to syringe out the ear first with warm water, and then with a zinc or alum lotion. If there are ulcers, they may be lightly touched with caustic; and in all cases a canvas cap should be worn over the head, and secured by tapes to prevent the dog from scratching the ears and increasing the inflammation thereby.

Canker in the Mouth is usually a result of decayed teeth, and if not attended to is likely to affect the dog's health, as he becomes unable to masticate his food. The decayed teeth should be extracted, and the remaining ones freed from tartar, if any has accumulated on them; but this is obviously the task of a professional man. A mild course of physic may also be given, and the food should be soft.

Cantharides is a useful stimulant for the growth of hair and as an ingredient of a blister, but should on no 
account be administered internally by the amateur dogowner unless under professional advice.

\section{Capillaries.-The small blood-vessels. (See Arteries, Veins.)}

Capsules.-The administration of medicine to dogs, and particularly castor-oil, is made much easier by the use of capsules, which also are easily carried about when journeys are being made, and hence are available for use in times of emergency. It is essential, however, that their contents should be fresh, as some drugs lose their efficiency if kept too long.

Carbolic Acid.-A most useful disinfectant for use in kennels. It is also a good lotion to apply to wounds which require cleansing, in the proportion of one part to twenty-five of olive oil.

Carlin.-The name by which the pug-dog was known in times gone by.

Castor-oil.-A most valuable medicine for use in cases of stoppage of the bowels. It may not be generally known that if it is slightly heated castor-oil becomes much more liquid, and is therefore more easy to administer to the patient. (See Administering Medicine.)

Cataract.-A cataract is a speck which forms on the pupil of the eye, and sooner or later causes blindness, as in many instances the eye which is unaffected at first becomes attacked. The treatment of cataract is altogether beyond the scope of the amateur, and hence the best course for him to pursue is to at once obtain the services of a specialist in canine diseases, as delays are often the source of serious trouble. 
Catarrh, or cold, is a common source of trouble to the dog-owner, as an attack may arise from various causes. Although not by any means a matter for anxiety in the first instance, a cold may lead to serious complications if neglected, and therefore if a dog is seen to be ill at ease and suffering from a discharge at the nose, accompanied by shivering and a loss of appetite, it is as well to move him into a warm kennel where he will be quite free from draughts and have a comfortable bed to lie upon. Keep him there upon a diet of hot slops, such as Spratt's biscuits, soaked in broth from bullock's or sheep's heads, or beef-tea, to which a little port wine may be added if he appedrs weak or refuses his food; and watch him carefully in case other symptoms develop.

\section{Cat-foot.-A round, compact foot. (See Hare-foot.)}

Cement Floors, though very good pavements for outside yards, are not nice things for dogs to lie upon-consequently, if they are in use inside, a plentiful supply of moss-litter or coarse sawdust should be spread over them; whilst if the floor of the outside yard is cemented, there ought to be a low bench, made of some pieces of board nailed on strips of quartering, for the animals to rest on. (See Floors.)

Chaining up Dogs.-If possible, a dog ought never to be chained up excepting for short periods, as if he is regularly subjected to this form of restraint he is apt to wring his shoulders out of shape in his struggles to get free, and especially so if he is a young animal. Exercise should always be given to a dog which is usually kept on the chain, it being the height of cruelty to keep him tied up all his time without an opportunity of stretching his legs. Consequently a fenced-in yard, however small, to keep him in is strongly recommended, especially as iron hurdles of various heights can be procured very cheaply. (See Fencing.) 
Chains should always be provided with swivels at each end, and one at least in the middle, in order to prevent them from becoming twisted, in which case the dog may be strangled. The condition of the spring hooks, by which

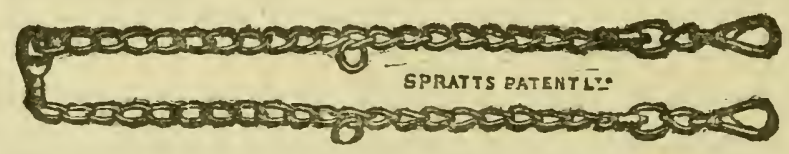

Chain with three Swivels and a Spring Hook at each end.

they are fastened to the collar and staple in the wall or kennel, should be regularly examined; and in the case of savage yard-dogs each link should be tested every now and then, as a chain wears thin through friction with the ground, and if it breaks the consequences may be serious.

Check Line.-A long line, with a running noose at one end, used by dog-breakers to teach their pupils to come to heel. (See Breaking.)

Cheek Bumps.-The protuberances on the cheeks at the base of the jaw, which are desired to be present in some breeds, such as the bulldog.

Chills.-As most dog-owners may be aware, the canine race is peculiarly susceptible to chills, which often lead to serious results. Hence if a dog is seen to be shivering and feverish, he may be moved to a warm but wellventilated kennel and given a mild dose of opening medicine to keep his bowels in proper order. Should he appear to be very cold he may be clothed, and under any circumstances a good bed of clean straw should be given him to lie upon, and his diet may consist of gruel, or slops composed of broth slightly thickened with biscuit. As he may be feverish there should be a vessel of clean cold water within his reach, and his condition should be watched in case symptoms of serious illness may arise. (See Nursing.) 


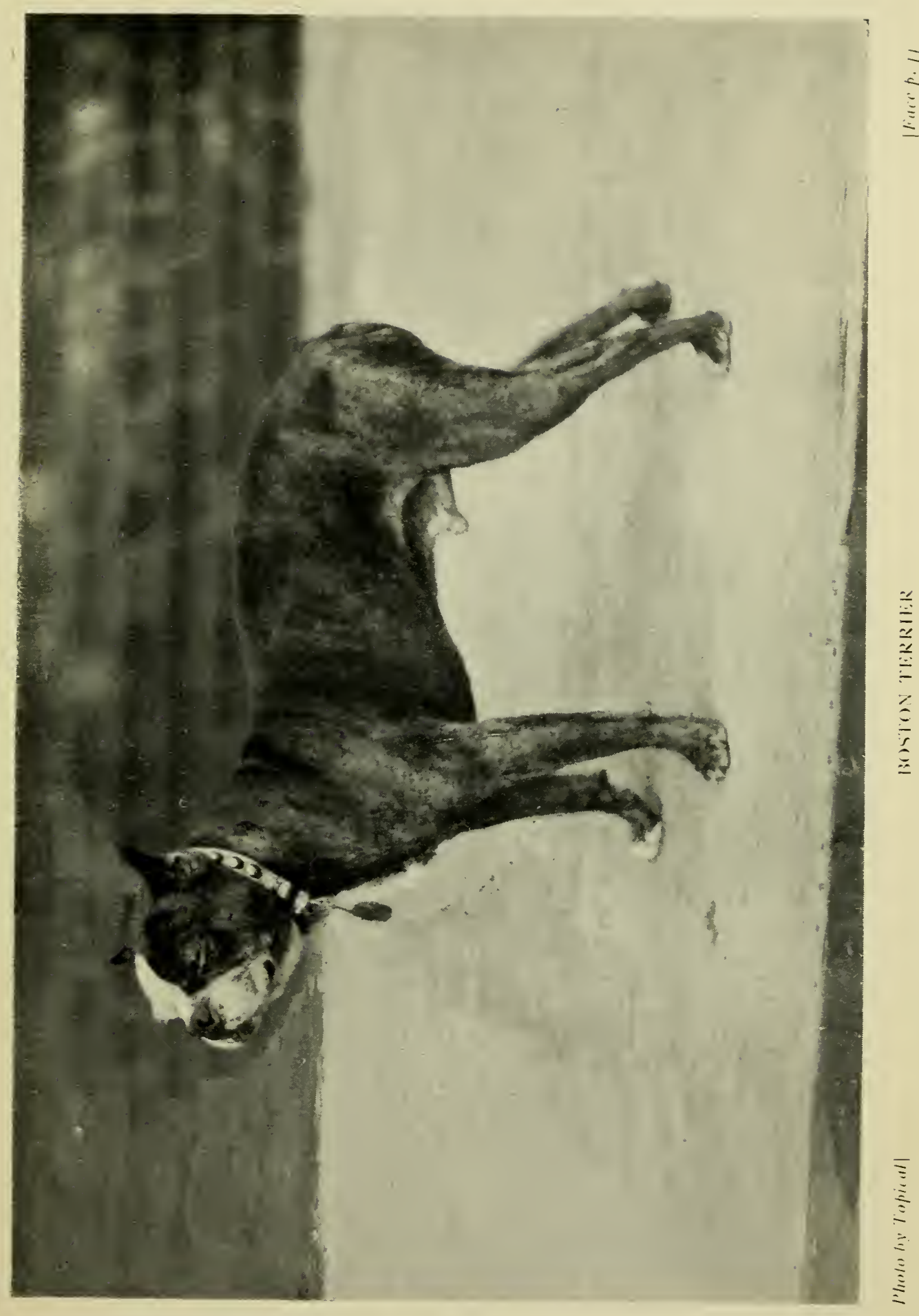



China Eye.-A blue, opaque-looking eye, which is desired in certain breeds, such as the bob-tailed sheepdog. The possessor of a china or "wall" eye can see perfectly well out of it-a fact which may not be generally known.

Chinese Dogs.-Of late years several breeds of Chinese dogs which were formerly unknown have become acclimatised in England, the most common of which are the Chow-Chow and Pekinese spaniel (which see). A peculiarity of most of the breeds hailing from the Celestial Empire is that their tongues, roofs of their mouths, lips, and gums are of a dark purple colour.

Choking.-In cases of choking, when the obstacle cannot be removed by one's fingers, the best course to pursue is to send at once for a veterinary surgeon, who may get it away by the use of forceps. Sometimes, if the dog can be made to swallow a few small pieces of meat, they will force the obstacle down, or a piece of greased rope, the end of which has been wound round by twine, may be pushed down the throat, but this operation is neither an easy or a safe one for an amateur to attempt; by far the best and most satisfactory results being obtained, if possible, by the use of the forceps.

Chop.-The pendulous lip of the bulldog is known as the "chop."

Chorea, or St. Vitus's Dance, often referred to as "Twitch," is a common result of distemper, and practically incurable. It consists of a peculiar twitching of the body and limbs, which is most usually apparent when the dog is asleep; but it does not seem to cause him discomfort or, excepting in severe cases, to affect his powers of movement $t$, any great extent. 
Chow-Chow.-The edible dog of China, which has become of recent years a great favourite in this country. The Chow-Chow belongs to the Pomeranian type of dog, but is of a more massive build, and his head is blunter. His skull is fairly large and heavily wrinkled, and the eyes rather sunken, which gives him a somewhat sullen expression; but though indisposed to make friends with strangers he is not a bad-tempered dog, and usually devoted to his master. The muzzle is blunt and of fair length; the nose large and black, excepting in the case of a light-coloured dog, where it is pink; the tongue and lips black; the eyes small and dark in colour; and the ears small, erect, and carried rather forward. The neck is thick; the shoulders fairly sloping; and the chest both wide and deep, the body being short and very powerful at the loins. The fore-legs are straight and heavy in bone; the feet small, round, and compact; and the tail is carried in a tight curl over the back. The outer coat is of fair length, very dense and coarse to the touch, the under one being sealskin-like; the most common colours being black and red, but whole-coloured blues, whites, and yellows are sometimes to be met with.

\section{Chunky Head.-A short, thick head.}

Clay Soil-_A clay soil is the worst that can be selected for the erection of a kennel, and it should therefore be avoided by dog-breeders who desire that their stock should thrive. (See Kennels, Soils.)

Cleansing Coats.-Washing is of course the best and simplest method that can be adopted for cleansing a coat, but too much soap and water is apt to make the hair too soft, and besides this, there are sometimes reasons for not wishing to wet the dog's jacket. The coats of most dogs which are regularly and systematically groomed with proper brushes are generally clean, and in the case of 46 
these it is unnecessary to bathe the animal very often. Occasionally, however, it occurs that a dog which has just been thoroughly scrubbed succeeds in getting his coat discoloured, and if so, a very effective substitute for soap and water will be found in flour which has been thoroughly baked in the oven. This can be well rubbed into the coat whilst dry, and will usually succeed in removing the dirt from the dog's jacket. (See Grooming, Washing Dogs.)

Clipping is an art which is quite beyond the capacity of an amateur, and therefore it is fortunate that, with the exception of poodles, no breed of dog is subjected to the practice in this country. It is of no use to attempt to describe the modus operandi on paper, and therefore if a dog-owner desires to imbibe knowledge in the matter, he had best engage a professional clipper to operate upon his dogs, and carefully watch the way he sets to work.

Clothing is by no means a necessity in the case of all dogs-in fact, a rough-coated terrier, or a big, strong animal of any breed, looks ridiculous when enveloped in a rug. The more delicate varieties, however, derive much benefit and comfort from being clothed if they are exposed to cold or wet, and unquestionably the coats of the smoothhaired breeds, such

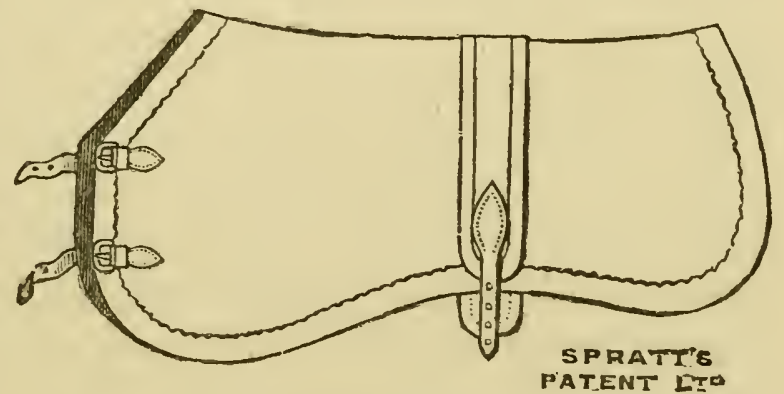

Dog Clothing. as the black-andtan terrier, are improved if the animals wear rugs in cold weather. It is the custom, too, of the trainers of greyhounds and whippets to keep their charges constantly clothed and to supply them with waterproof sheets if the weather is wet when they go out for exercise. 
Clumber Spaniel.-This is a most important member of the springer family, and its chief peculiarity is that it hunts mute. The name by which the breed is known is taken from that of the seat of the Duke of Newcastle, which has always been a stronghold of the variety, but very fine specimens have been owned by the Duke of Portland, the Duke of Westminster, and other members of the aristocracy. Apart entirely from his attractive appearance, the Clumber spaniel is valuable as a fine worker, but he has never been known as a popular dog, as, though his merits are undeniably great, his breeders have for the most part been averse to selling puppies out of their kennels, the result being that the Clumber has not been in many hands. Still all who know him best unite in bearing testimony to his value as a fielddog, although the peculiarity of the Clumber spanielthe fact that he hunts mute-is one which may not quite appeal to sportsmen who love to hear their dogs give tongue.

In general appearance the Clumber is a big dog set on very short, substantial legs, but he is far more active than he appears, and a very reliable retriever of wounded game. His head is broad and massive, with the peak well pronounced, and a decided stop between the eyes and rather heavy brows. His muzzle is very square and powerful, his flews well developed, his nose flesh-colour, and his eyes a lightish brown-a yellow eye being considered most objectionable-fairly large and deeply set. The ears are long and carried a little forward, but flat to the cheeks; the neck extremely powerful, as are the shoulders, which slope well. The body is very long and massive, broad and deep at the chest, with well-sprung ribs and powerful loins ; the fore-legs being short and very heavy in bone, and the feet large. The tail, which is always docked, is set on and carried level with the back; and the coat is thick and soft, though dense enough to keep out the weather, and free from curl. The colour should be white with pale 48 
lemon markings; the average weight being about 60 lbs. for dogs and 50 lbs. for bitches; the height averaging I7 to I 8 inches.

Clydesdale Terrier.-This is one of the most beautiful breeds of dog in existence, and it is difficult to understand why its merits have not been far more generally recognised by dog-breeders than they have been. The Clydesdale may be described as a silky-haired, prick-eared Skye terrier, and probably the beauty of its glorious steel-grey jacket is attributable to a Yorkshire terrier cross. Owing to the profusion of his silken jacket the Clydesdale terrier is not adapted for rough work, but for those who desire a beautiful canine companion, and an active, good-constitutioned dog, he may be recommended for favourable consideration. (See Skye Terrier.)

\section{Clysters. (See Enemas.)}

Coats.-The coats of different varieties of dogs differ very greatly in length, density, and texture, although the canine race is divided by some people into only two classes -namely, the rough-coated and the smooth. All the latter, of course, have a great deal in common, in spite of the fact that some of the smooth jackets are much softer, silkier, and consequently less weather-resisting than others. In the case of the rough coats there is far more diversity, as some are long and others short, some curly, some flat, and others shaggy; but almost all of them possess a second and short under-coat, in many cases as thick and close as sealskin, to protect their owners from the effects of cold and wet, for most rough coats are more or less open, and so let in the damp.

The care of coats depends a good deal upon the purposes for which a dog is kept, as it stands to reason that a show animal requires a good deal more attention than the dog that is kept. for work and not for ornamental purposes. 
At the same time, all dogs are benefited by periodical brushing, which removes the dead hair and assists in keeping the skin in good condition, thereby improving the animal's health. Combing, if it can be avoided, is not recommended, as it is liable to pull out the coat in patches if it is matted, and under no circumstances should a comb be used unless the jacket is quite dry. If the hair is matted the hard tufts should be manipulated by the fingers in order to reduce them, and it will often be necessary to comb them out, as, if it can possibly be avoided, the hair ought never to be cut, but the less combing the better. (See Brushing, Faking, Trimming.)

Cobby.-A dog is described as being cobby when he is compactly built, with a short, well-ribbed-up body.

Cocker Spaniel.-The smaller varieties of spaniels are known as cockers, to distinguish them from the springers, which are the larger breeds, the general appearance of all the cockers being similar so far as shape and make are concerned, though they differ widely in colour. They are, moreover, very useful little dogs, being merry workers which can be trusted to beat a hedgerow thoroughly; though of course, if it comes to a matter of retrieving a hare, they are not the equal of a springer, for the simple reason that they have not as much strength.

The skull is of fair length, and shows a rise at the temples, the muzzle being long and slightly pointed, with rather tight lips; the nose being large, and varying in colour according to the colour of the dog, being either black or dark liver. The same thing applies to the colour of the eyes, which should not be sunken in the head, and which should possess a soft, intelligent expression. The ears should be set on rather low, fairly broad, carried flat to the sides of the head, and well covered with hair; the neck is long and clean, and the shoulders sloping; whilst the body is long and well ribbed up; the legs short, 
heavy in bone and straight, with large, well-padded feet. The tail, which is docked, should be carried with the point a little below the level of the root; whilst the coat must be dense, not too long, and preferably flat, though a slight wave in it is permissible. The colours chiefly met with are black, liver, black and tan, roan, liver and white, but occasionally lemons and reds are seen. The average weight is about 20 lbs., and height about $\mathrm{I} 2$ inches.

Colic is a form of attack to which dogs are peculiarly susceptible, as when given their liberty even the most highly fed animals are fond of picking up and devouring garbage. The symptoms are great uneasiness, accompanied by tenderness of the stomach when it is touched, which proves that the dog is suffering pain in that region; and further evidence of discomfort is forthcoming by the moans and whines of the patient. Treatment.-A dose of castor-oil or some quickly operating aperient, and the application to the stomach of hot flannels upon which a few drops of turpentine have been sprinkled.

Collars should never be buckled too tightly; but, on the other hand, if they are too loose the dog will slip them and get away, hence the happy medium should be arrived at. In the case of some breeds, such as bulldogs, it is customary to use a very broad collar, but for the ordinary dog one of about an inch is wide enough for anything, and terriers require narrower ones. In order to avoid injuring the coats of long-haired varieties, such as collies, a round leather collar is usually worn, and these can strongly be recommended for the purpose.

Collie.-For very many years past the collie dog has occupied the position of a high favourite in the canine world; though it may be added that the patronage bestowed upon him by those who do not require dogs for work has not assisted in adding to the intelligence of the breed, but 
rather the reverse. This is because the object of breeders has been directed towards increasing the beauty of their dogs at the risk of lessening their working capacity, and hence when there arose a demand some years ago for deep-coloured "mahogany" tan markings a Gordon setter cross was introduced; whilst in more recent times the borzoi has been crossed with the collie in order to increase the length of the latter's head. It is perhaps needless to add that both these crosses were prejudicial to the interests of the true collie, as the introduction of setter blood spoiled the carriage and shape of the ear, besides injuring the character of the coat and feather, whilst the association with the borzoi most seriously reduced the intelligence of the collie.

On the other hand, there can be no gainsaying the fact that its connection with the exhibiting community has accomplished much towards popularising the collie, which thirty or forty years ago was almost exclusively utilised by shepherds and drovers. There can be no doubt, too, that the variety is a very ancient one, and that the collie is a Scottish breed, its intelligence and alertness having been highly prized by sheep-minders on the hills of North Britain for generations before such institutions as dog shows were even thought of.

The head of a collie is long, flat on the top, fairly wide at the back, and gradually tapering towards the nose, but well filled up under the eyes. The jaws should be quite level, an undershot mouth being regarded as a serious fault, as it is suggestive of a bulldog cross, which if present would be liable to make the dog unnecessarily rough when holding on to a sheep. The nose should be of a good size and black in colour; whilst the eyes are close and obliquely set, rather almond in shape and brown in colour, excepting in the case of the blue mirles, in which one or both of the eyes is "china" or "wall." The ears must be small, and should be set on at the top of the head near enough together to make the skull appear to 
be narrower than it really is; they should be carried semierect when the dog is excited, at other times backwards and almost buried in the coat.

The neck is long and graceful; the shoulders of good length, and well laid back to ensure activity; the chest being narrow, but very deep. The back is inclined to be long, but the body is powerful, being well ribbed up and strong at the loin; and the back is muscular, with a slight rise at the loin. The fore-legs should be quite straight, good in bone, and set on right under the bodya collie which is out at elbow is an impossibility-the pasterns being long, and the feet oval and compact. The tail, which is well feathered, should be carried low, excepting when the dog is excited; whilst the coat, excepting on the head and the legs where it is smooth, should be profuse, the outer coat being long, close, and harsh, and the under one soft and sealskin-like, so as to provide an ample protection from the weather. The feathering on the back of the fore-legs should not extend down to the ground, as in the case of the setter, but should cease a little above the pasterns, the hind ones being smooth; whilst the exuberance of coat on the chest and neck is called the frill. The collie is met with in all colours, but when tan markings are present they should be of a light shade, the deep mahogany tan being suggestive of a setter cross. (See China Eye, Mirle.)

Comb.-The best combs to use for a dog are those made of metal, with teeth slightly blunted at the point. Bone or vulcanite combs are apt to break and become useless, and in many of them the teeth are far too close together.

Combing.-It is never wise to comb a dog's coat unless there are tangles in it which renders the use of the comb imperative. The reason of this is that new hair is often pulled out or the skin of a delicate animal injured by the 
teeth of a comb, which under no conditions should be used when the coat is wet. If, however, there is a quantity of dead hair which has to be removed, it will often be found that a comb has to be used. (See Brushing, Cleansing the Coat, Trimming.)

Condition.-The best way to get a dog into conditionin fact, it may be said to be the only one-is to provide him with a sufficiency of wholesome food, a good kennel, and plenty of exercise. On the other hand, neglect of the above advice will assuredly produce loss of condition sooner or later, and very probably a loss of health as well; but it may be added that animals which are required for show purposes require different treatment to those which are wanted for work; and, of course, the toy varieties and delicate dogs will not be suited by a course of management which is beneficial to more robust members of the canine race. (See Exercise, Feeding, Kennels, Preparing for Show.)

Constipation.-Many dogs appear peculiarly predisposed to be constipated in their bowels, and as a consequence require very careful feeding, as though medicine will doubtless remove the trouble temporarily, it will arise again in chronic cases, and stronger doses will have to be administered. The addition of a reasonable proportion of green vegetable food to the dog's allowance at meal time, and compelling him to eat it, will materially assist in keeping his bowels in order, and if this fails a little flowers of sulphur may be given him in his food for a period, and will often be found more beneficial than powerful aperients. A periodical feed of liver will assist in keeping the bowels open.

Contagious Diseases may be briefly described as those which are conveyed from one dog to another by personal contact, or by coming in contact with people or articles 
which have been touched by a diseased animal. (See Infectious Diseases.)

Cooked Food is generally better for healthy dogs than raw flesh, though the latter, if sound and from a healthy animal, forms a very welcome change, and in the case of some weakly dogs is highly beneficial to their health. All meals and vegetables should be thoroughly boiled before being given to dogs, and it may be added that no food should be allowed to stand for long in the copper or vessel in which it is cooked, as it is liable to turn sour. (See Feeding.)

Corrugated Iron, even when laid upon boards, is not a good roofing for a kennel, as, though it is perfectly watertight, it is very cold in winter, and correspondingly warm in summer. Sheets of corrugated iron laid horizontally, with wirework or railings above, are, however, very useful if used as divisions between kennels, as they prevent dogs from fighting.

Coughs, like colds, are very frequent sources of annoyance to dogs and their owners, but fortunately they are generally amenable to treatment, though, as in the case of distemper, a cough may be the precursor of something more serious. Some excellent advice on the treatment of coughs is given by Mr. Sewell in his "Dog's Medical Dictionary," published by George Routledge \& Son.

Counter Irritants, such as liniments or blisters, are used in cases of bruises, rheumatism, and inflammation, to draw the inflammation away from the affected part by setting up a greater or less degree of inflammation. They should be used with discretion, and not when the skin is broken; and it should be borne in mind when they are applied that some injuries of the kind referred to require 
far less drastic treatment than others. (See Blisters, Liniments.)

Couples.-(I) A term that is applied to pairs of hounds. (See Braces.)

(2) The short length of chain, which should be provided with a swivel in the middle and a spring hook at each end, for attaching two dogs to each other when they are being led.

Couplings.-The term applied to the middle of the dog, which, as it were, couples the two ends together.

Coursing, which has been very appropriately styled the king of sports, a few years ago appeared likely to languish into obscurity, owing to the, happily futile, attempt to establish enclosed gate-money meetings, in which captive hares were chased by greyhounds, and which were only a degree removed above rabbit coursing meetings so far as real sport was concerned. Happily, however, the good sense and sporting feelings of coursing men proved so averse to this burlesque of the genuine thing that the enclosed meetings were quickly abandoned as being unprofitable, and with their extinction a fine, manly pastime productive of good sport and plenty of healthy exercise, took a new lease of life.

The popularity of coursing, in fact, is made apparent by the large number of small meetings which take place in every part of the country where hares are to be found in sufficient numbers to enable them to be held, and the important fixtures, such as the Waterloo Cup and the Border Union gathering, attract as many good greyhounds as they ever did. It is to be hoped, too, that it will be a long time before coursing ceases to exist as a great English sport, as it provides an ample fund of healthy recreation to thousands of people, and undoubtedly is the 56 


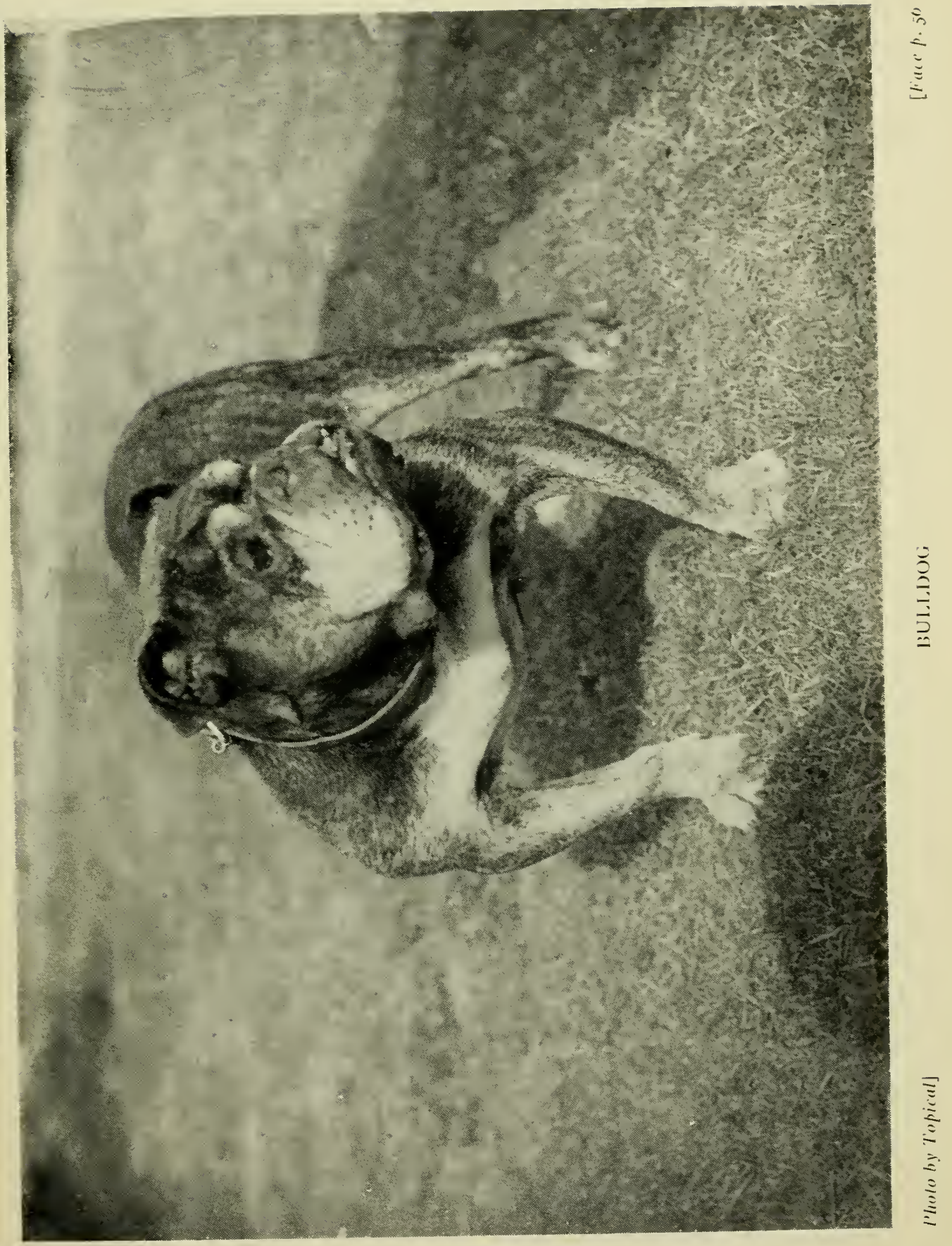



means of causing a good deal of money to circulate in the districts in which meetings are held.

The technical terms applied to coursing are :-

The lead, which includes speed, and is valued at from one to three points.

The go-by, when a dog that is a length behind at the slip is a length in front at the hare.

The turn is where the hare is turned at a right angle.

The wrench is where the hare is turned at less than a right angle.

The kill.

The trip, where the greyhound touches the hare in trying to kill, but fails to hold her.

Cow Hocks.-Hocks which turn inwards, with the result that the stifles and feet are turned outwards. This is a source of weakness to their possessor, and in many instances is the result of bad rearing. The hocks of some breeds, however, such as bulldogs, are naturally turned inwards. (See Hocks, Stifles).

Crooked Legs.-In the case of most breeds of dogsDachshunds, basset hounds being notable exceptionscrooked fore-legs are the result of constitutional weakness or bad rearing. Consequently, when the legs of a puppy display a tendency to become crooked, an attempt should be made to meet the danger by feeding the animal generously, and giving him a sufficiency of slow, healthy exercise. It is essential, too, that his kennel should be warm and absolutely dry, and a course of Parrish's food is likely to be accompanied by beneficial results.

Cropping Ears.-This practice is now alike condemned by law and by the usages of the show ring, and consequently as all dogs whose ears are cropped are debarred 
from exhibition is both unnecessary and inexpedient to describe the operation.

Cross Breeding, in the sense of mating two animals of different breeds, is productive of no good results in these modern days, though unquestionably many popular varieties have been manufactured by this means. The latest production of the kind is the so-called Irish wolf-hound, and the bull terrier is another case in point, so too is the dropper, which is a cross between the pointer and setter; whilst beyond all doubt several other well-known varieties are indebted for some of their attractiveness to other breeds.

Crosses are, however, imperatively necessary for a breeder to employ from time to time, as unless some desirable outside blood of the same breed is introduced into his strain it is certain that the constitutions and value of his dogs will suffer from the effects of inbreeding. The greatest care should, however, be taken in selecting such crosses, as the taint of an unworthy sire may appear in his descendants generations after his blood came into the strain, and hence not merely the appearance of a sire, but his breeding and the peculiar characteristics of the family he belongs to, must be the care of every careful breeder. (See Brood Bitch, Inbreeding.)

Curled Tail.-A curled tail is regarded as a great disfigurement to most dogs, but of course there are notable exceptions, such as the pug, the Pomeranian, the ChowChow, and the Esquimaux. Very few breeds, however, possess absolutely straight tails, nor as a matter of fact should they do so; but there is a very great deal of difference between the graceful, scimitar-shaped caudal appendages of such varieties as the setter, collie, and many beautiful breeds and the frightful curled tails which disfigure mongrels.

Curly-coated Retriever.-This old breed of sporting 58 
dog is not by any means as popular amongst shooting men as he was some years ago, for the position he then held is now occupied by the flat-coated variety, which outnumbers the curly-coated dog in the proportion of about fifty to one. This is to a certain extent unfair on the latter, for even if the allegation brought against him by his opponents, who declare that he is hard-mouthed and so liable to mangle the game he retrieves, be correct, there can be no gainsaying the fact that he was very highly thought of by our fathers, or that he is a most handsome, intelligent, and sound-constitutioned dog.

The origin of the curly-coated retriever is rather obscure, but undoubtedly the poodle had a good deal to do with it, and so also had the Irish water-spaniel.

Generally speaking, the formation of the curly-coated retriever is similar to that of the flat-coated variety; but the former, owing to the comparative shortness of his coat, conveys at a first glance the impression that he is a lighter-built and more active dog. The head, too, does not appear to be so massive, and the muzzle not so blunt; the skull is also flatter than that of the flat-coated variety, and the eyes are smaller and darker in colour. Another point of distinction exists in connection with the shoulders, which as a rule are less sloping in the case of the curlycoated breed, not that they can be described as being straight, and the ribs are rounder and the chest broader by comparison.

Of course, however, the great point of distinction between the two varieties lies in the coat, which in the curly breed consists of a mass of tight, crisp curls all over the body, the head and muzzle alone being covered with short hair of a rather crisp texture. The legs and tail are also covered with small curls, which like those on the body should be quite close together, so as to form a weather-resisting jacket. The prevailing colour is jet-black, but occasionally livers are met with, but not so frequently as used to be the case. (See Flat-coated Retriever.) 
Cuts may be either punctured, such as stabs: incised, which are the results of a clean wound: contused when they are associated with bruises, or lacerated when the flesh is torn. The first thing to do in either case is to stop the bleeding, which may usually be accomplished by applying either cold or very hot-not tepid-water to the wound either by gently dabbing it with a clean piece of soft linen or sponge, or else by allowing the water to trickle down on to it from above. This will also assist in cleansing the cut from any grit or other foreign substance which may have got into it. In the case of a deep wound it may be necessary to use a syringe for the same purpose, and in a severe one stitches may have to be put in. When the bleeding ceases a bandage may be applied. (See Bandaging, Bleeding, Stitching. Wounds.)

Cutting Nails.-A dog which gets plenty of exercise, especially if it is taken on the road, will generally wear his nails as short as it is necessary to keep them. When, however, animals which enjoy very little running about are concerned, the best sort of scissors to use are the short, plier-like apparatus which are provided with a spring. If the dog is fidgety when his nails are being cut he should be held by an assistant, and in any case every care should be taken to avoid removing too much, as if the nail bleeds the consequences may be serious, for the wound may fester.

Cutting Teeth.--Puppies as a rule do not suffer much from teething troubles, though unless care is taken to remove the first or milk teeth when they become loose they are liable to interfere with the second ones being cut properly, and so the latter may grow uneven, which will prejudice the value of the dog. The first set of teeth commence to appear when the puppies are a few weeks old, and generally commence to become loose and fall out when they are between six and seven months of age, but the times vary in the case of different animals, though 
most dogs get their full second mouth about the time they arrive at the end of their ninth month. (See Puppies.)

\section{D}

Dachshund.-This breed is essentially a German production, its name signifying badger dog, and it may be regarded as being allied to the terrier family, as a good deal of its work is performed underground. At all events there is nothing of the hound about it, though its earlier English admirers appear to have regarded the affix "hund" as implying that there is; for from the first they devoted their energies to developing a houndy type of head, with a high-domed skull and long ears, whereas the true type of German Dachshund represents a flat-skulled, short-eared dog. It may be added also that English breeders seek for a light-coloured nose in the red Dachshund, whereas in Germany a black one is the correct thing; but beyond these points of difference the two breeds are of very similar appearance.

That the Dachshund is a very game dog and a capital worker underground is a fact that admits of no doubt, and the British visitors to some continental shows at which Dachshund trials are held unanimously praise the pluck of the little dogs which they have seen tackle fresh-caught foxes and badgers in artificial earths which have been specially constructed with the view of testing their working capacity and gameness. At the same time, his curiously contorted fore-legs must to some extent affect the activity of a Dachshund; but of him it may be truthfully observed that he is both capable and willing to do all that the German sportsmen require of him.

According to the English ideas of the breed, the head of a Dachshund should be long and narrow, with the peak at the back well pronounced ; the muzzle long, strong, and 
square; the nose being black in the case of black-and-tan specimens, and yellowish or liver in the case of red or liver-coloured dogs; whilst the eyes follow the colour of the coat. 'The ears, which are long, wide, and soft, are set on low and carried close to the sides of the head; the neck being of fair length; the shoulders rather short; the chest narrow but deep, with the bone very prominent, and the ribs well rounded in front and very short at the loins. The body is of great length, and the fore-legs proportionately short, heavy in bone, well clothed with muscle, and decidedly crooked at the pasterns, which causes the feet, which are of a large size, to turn outwards. The hindlegs are longer than the front ones, which causes the loins to be arched, and thick at the thighs; whilst the tail, which is long and tapering, should be carried low, excepting when the dog is excited. The chief colours are red and black-and-tan, but livers, liver and tans, tricolours and mirled-coloured Dachshunds are also to be seen, the latter often possessing a china eye. The average weight is about 20 lbs. (See Mirle.)

Dalmatian Dog.-No doubt a good many people regret the fact that fashionable people have for the most part ceased to make it a custom of having a Dalmatian dog in attendance upon their carriages, as there can be no denying the fact that he added considerably to the picturesqueness of the best turned-out equipages of a bygone generation. It is remarkable, too, that more people who exhibit dogs have not devoted their attention to this variety, as a good Dalmatian is a marvel of symmetry and a most intelligent animal, whilst, though his spotted coat may appear a little singular, there must be very few who can deny that there is an attractiveness about it. The breed, as its name suggests, is of continental extraction, and in its native country the Dalmatian has been, and frequently still is, used for finding game, as the nose of a Dalmatian is naturally good, though his scenting powers 
have never been cultivated in this country, which is somewhat remarkable, as the close resemblance which exists "between him and the pointer, so far as shape and make are concerned, is rather suggestive of a remote family relationship between the two breeds. At all events, the description given of the pointer on another page may be referred to as conveying an accurate idea of the shape and make of the Dalmatian dog, but the colours of the two breeds vary entirely. In the Dalmatian the groundcolour must be a pure white, relieved by round, black or liver-coloured spots, varying in size from a sixpence to a two-shilling piece. These spots ought not to run into each other, but be quite distinct, and should appear on the ears, tail, and legs, as well as upon the body; but it often happens that the ears are almost black and the legs almost white. It may be added that Dalmatian puppies are born white, the spots beginning to show when they are a few weeks old. (See Pointer.)

Damp is extremely bad for dogs, and the precursor of many serious evils. Consequently the kennels must be made waterproof and the bedding kept dry, whilst the space outside the kennels should be paved. (See Kennels.)

Damp Food.-It is desirable that dogs should be allowed a certain proportion of damp food, as when they are so fed they do not consume so much water, which is not good for them. Moreover, as most damp forms of food include amongst their ingredients broth, they provide an opportunity of supplying dogs with some of the strengthening properties of flesh, which if given them too liberally is apt in some cases to produce eczema or foul breath. (See Dry Food, Feeding.)

Dandie Dinmont. - Although beyond all doubt Sir Walter Scott accomplished much in the way of popularising the Dandie Dinmont terrier by the references made 
to them in the pages of "Guy Mannering," the breed possesses so many admirable characteristics, conspicuous amongst which are courage and a delight in hunting vermin, that it must always have been a favourite with all who love a good terrier. Hence the large number of friends and admirers the Dandie Dinmont possesses in this and his own country, though, as is only natural, he is in greater request north of the Tweed than he is in England.

The head of the Dandie Dinmont seems rather large for the size of the dog; it is wide and domed, of a good length, and gradually tapers towards the eyes, the muzzle being very powerful, and the teeth strong and regular. The eyes are set wide apart, and are rather inclined to be full, in colour they should be a dark brown, and the expression they convey very intelligent. The ears, which are long, lie flat to the sides of the face and are rather thick; they carry a short, velvety coating of hair, and occasionally a slight fringe of feather at the tips. The neck is short and muscular; the chest wide and deep, and well let down between the fore-legs; the back being rather long and well arched at the loins, from which point it falls towards the shoulders and tail. The fore-legs should be very short and heavy in bone, with a suspicion of turning inwards at the pasterns; and the feet of good size, with thickly padded soles. The hind-legs are longer than the front ones, very muscular about the thighs, and nicely bent at the hocks; whilst the tail is of fair length, and carried gaily but not over the back. The coat is not very long, is thick, close, and pily in texture, and there is a topknot of silky hair upon the head which adds considerably to the beauty of the dog. The colours are pepper, a sort of dark bluish-grey; or mustard, a yellowish-red shade; and the average weight is from $22 \mathrm{lbs}$. to $\mathrm{r} 8 \mathrm{lbs}$., according to size. It may be added that Dandie puppies come into the world black-and-tan in colour, changing to the orthodox shade after a few weeks. 
Dandy Brush.-A long, bristled, rather hard brush, which is strongly recommended for grooming the coats of dogs. (See Brushing, Cleansing Coats.)

Dare-devils. - A title bestowed upon the Irish terrier by some of his admirers. (See Irish Terrier.)

Deafness may be the result of varying causes, but if a dog is born deaf it is not likely that any treatment will relieve him of the infirmity. It may be observed that the belief exists amongst some people that white dogs are more often deaf than those of any other colour, but it is difficult to realise that there is any solid foundation for this superstition, although no doubt many bull terriers were so afflicted, but probably this was due to the practice of cropping. Any attempt to cure a dog that is born deaf is hopeless, but should the infirmity attack one in after life professional skill will in many cases alleviate the evil, if even it does not entirely remove it ; but the successful treatment of deafness is quite beyond the skill of the amateur practitioner.

Debility.-When a dog is run down, or is constitutionally weak, it obviously becomes the duty of his owner to endeavour to set him up by the aid of good strengthening food and tonics. It does not at all follow, however, that the animal should be placed upon a rich or heating dietrather the reverse-as if he is he may be incapable of digesting or retaining the food, which in consequence will not nourish him. If the appetite remains fairly good the dog may be given Spratt's biscuits, or if he belongs to one of the larger breeds, Spratt's Rodnim soaked in strong broth made from sheep's heads, to which some of the meat may be added. An occasional change to raw, lean meat cut up small will be found beneficial, but the meals should be small and frequent, as well as varied, as it is a mistake to overload the stomach. In the case of small or very 65 
delicate dogs, some lean, raw meat may be cut up small and left to soak in sufficient water to cover it for a few hours, after which the liquor may be given the patient, who will often be tempted by this when he will refuse other nourishment. In severe cases, when a dog seems to be on the point of collapse, a raw egg beaten up with a little port wine or brandy-the former is best-will often prove a valuable restorative, and it will always be necessary to place the dog which is suffering from debility upon a course of tonics. Spratt's Patent supply a most effective tonic preparation, which is alike beneficial to the very largest dogs and the toy varieties.

Deerhound.-The origin of the Scottish deerhound is a question that has involved a good deal of argument, as some persons contend that it is a descendant of the Irish wolf-hound, whilst others believe that it is indigenous to Scotland, the balance of authority being rather in favour of the latter theory. The question, however, need not be entered into here, though the regret may be expressed that so picturesque and attractive a variety of dog should not possess more supporters than it does. Still its value as a sporting hound is appreciated as keenly as ever by those who enjoy the excitements of deer-stalking, provided the deerhounds are not of a too large size, as many show specimens undoubtedly are.

The head is rather wide between the ears, gradually tapering towards the muzzle, which ought to be rather pointed. It is long and flat, showing a slight rise over the eyes, and is covered by long silky hair, whilst there is a sort of beard under the muzzle. The eyes, either brown or a dark hazel in colour, are soft in expression; the ears being set on high, and carried with the tips turned backwards, so as to show the insides, and sometimes when the dog is excited they are raised far enough to be semi-erect. The neck is rather long, neatly set on to long, lean, sloping shoulders; the chest very deep but rather narrow; the body

$$
66
$$


being slightly arched, with not too much roundness at the ribs, but powerful at the loins. Fore-legs rather long, dead straight, and heavy in bone, with round, compact feet, the knuckles of which are well developed. Hind-legs well bent at the stifles and hocks, with plenty of length from the latter upwards, the stern being scimitar-shaped and carried downwards. The coat is hard and wiry on the neck and back, but softer on the head and belly; the favourite colour being blue-grey, but fawns are not uncommon, and any white markings are faults. Average height about 28 to 30 inches; weight about 90 lbs. The bitches being less in both instances.

Dewclaws are the superfluous claws which appear on the legs of some dogs above the pastern. There is no use for these, and in fact they constitute an element of weakness, as they are apt to get torn, and so cause ugly wounds; and should therefore be removed. The way to do so being to pull the skin as far back as possible from the roots and then to sever the ligature which connects the dewclaw with the bone by the aid of a sharp pair of scissors. Very little blood is shed if the operation is carefully conducted, and the skin on being released will close up over the wound, which under ordinary conditions will heal rapidly.

Dewlap.-The loose skin which adheres under the neck of some breeds of dogs.

Diarrhœa is a common form of ailment amongst dogs, and a fruitful cause of death to puppies. In simple cases a little powdered chalk mixed with their food and ricewater to drink will put matters right, but when the diarrhœa continues long enough to cause weakness, and especially if blood appears in the motions, professional advice should be obtained. (See Rice Water.) 
Diehards.-A name applied to hard-haired Scottish terriers by their admirers. (See Hard-haired Scottish Terrier.)

Dingo, or Warragal.-The indigenous wild dog of Australia, a few specimens of which have been seen in this country. There is not, however, much that is attractive about the dingo, which is usually of a more or less unsociable disposition, though he adapts himself fairly well to civilisation. In his wild state he does not bark as an ordinary dog does, but after he associates with human beings and other members of his species he frequently begins to imitate the voices of the latter. In shape the dingo somewhat resembles the wolf, but the colour of the former is red when he reaches the adult stage of his existence, though the puppies are born very dark in colour, in fact, almost black.

Dish-face.-When the muzzle of a dog turns upwards at the nose, so as to leave the suggestion of a dip between that organ and the eyes, he is said to be dish-faced. (See Dowen-face, Frog-face.)

Disinfectants should be in use in every large kennel, not merely in order that the atmosphere of the place should be kept sweet, but with the view of preventing infection spreading if disease should suddenly break out amongst the inmates. For general purposes there is nothing to beat carbolic acid, but many persons object to the odour of this fluid, and the same may be said of chloride of lime. If this is the case an efficient substitute will be found in permanganate of potash liberally diluted with water, and this will be found to be far cheaper than Condy's fluid, which it strongly resembles. Whatever form of disinfectant is used it is always desirable that it should be kept in a vessel out of reach of the dogs, as some of the remedies employed are poisonous, and none of them are beneficial to the animals that drink them. 


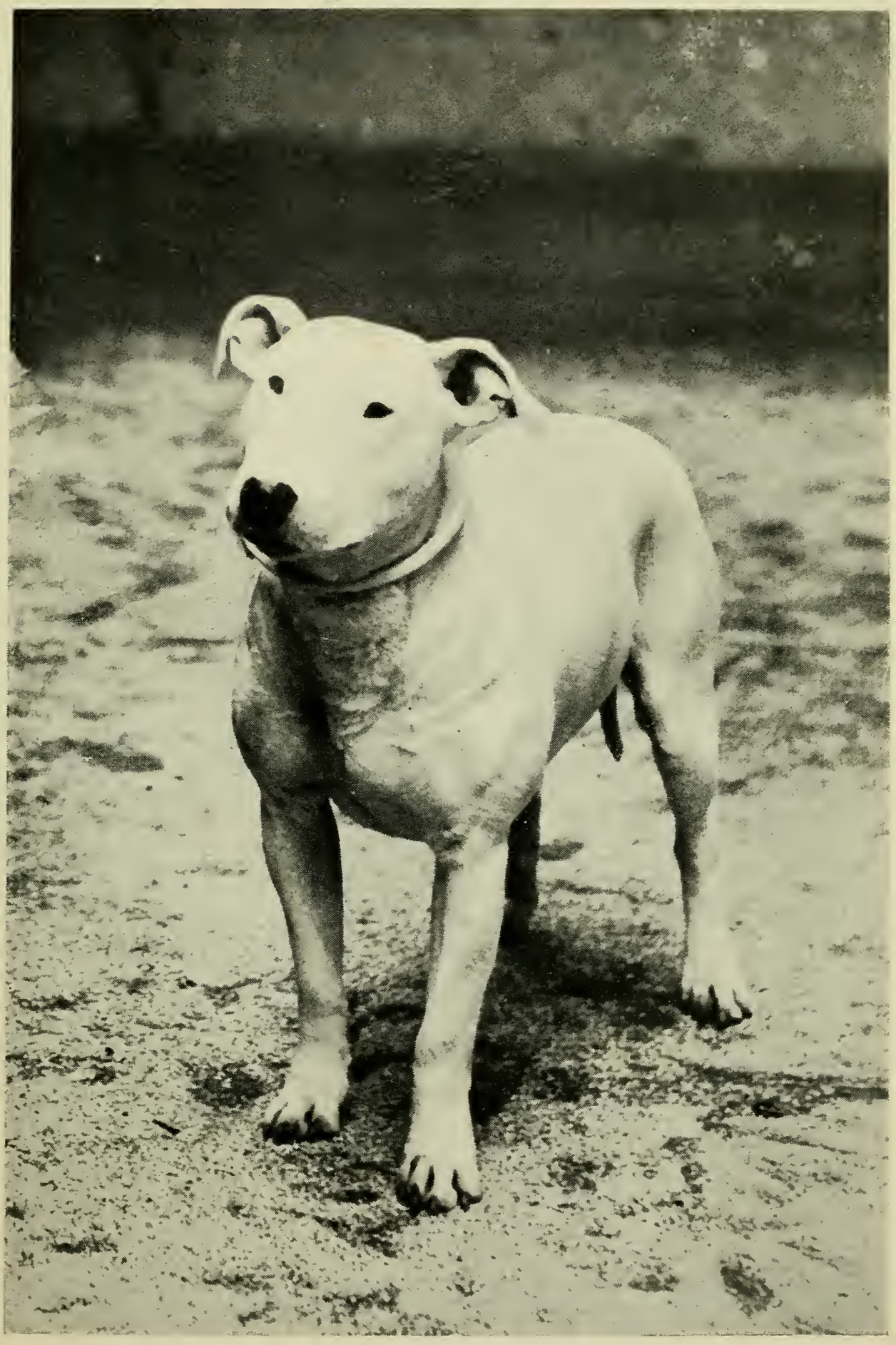



Dislocations are not matters that the amateur surgeon can attend to with any reasonable hope of success, and therefore in cases of this sort of injury the only course for him to adopt is to send at once for professional assistance and meantime do the best he can for the patient. This consists of keeping the dog as quiet as possible, as naturally if he moves about the pain and inflammation extend, and the labours of the surgeon are increased, with additional suffering to the animal. The part affected may be kept cool by the application of wool or soft cloths which have been soaked in cold water; and pieces of flat, thin wood may be collected in order that splints can be ready without any unnecessary delay should it be necessary to use them. For the same reason it is wise to have starch at hand, and bandages also, if there are any on the premises. (See Bandages.)

Distemper.-This is undoubtedly a most fatal disease if it is not taken in time, and many dogs which recover from it bear traces of its effects for the rest of their lives. It is both infectious and contagious, and hence very easily conveyed from an affected animal to a healthy one. As a consequence most dogs suffer from distemper. The disease usually attacks puppies; but it is not correct to believe that all dogs must have it, and in rare instances an animal has been known to suffer from it more than once.

The first symptom of distemper to be detected by the dog-owner who is not familiar with the diagnosis of diseases is a peculiar husky cough, accompanied by a loss of appetite and retching. The temperature rises rapidly, indeed the dog has been feverish from the first, but the fact has probably not been noticed, and acute diarrhœa is usually present. The dog loses condition fast, and frequently the breathing becomes laboured. Occasionally fits occur, and if so the case at once becomes most serious, if not positively hopeless, and even if the 
patients recover they usually suffer from chorea in after life.

A dog suffering from distemper should be kept in a warm-not hot-dry, and airy room or shed, the object of those in charge of him being to keep it as nearly as possible at one temperature, and their patient beyond the reach of draughts and damp, a stuffy, ill-ventilated place being very bad for him. He should stay in it; his evacuations being cleared away as soon as possible, and either buried deeply or disinfected thoroughly. A nice warm bed should be given him to lie upon, and it is a wise thing to put some warm clothing on him, keeping it on day and night whilst he is ill, and destroying it when done with.

The patient will lose flesh rapidly, and frequently becomes painfully weak, and if so, he may be given a little port wine or brandy to revive him. The appetite is usually bad, but under any circumstances solid food should not be given to a dog suffering from distemper. Broth made of heads, in which biscuits are soaked, is a good thing if he will take it, but some dogs prefer rice or pearl-barley as a thickening. A strengthening dish, and a very favourite one with some dogs, is made of fresh haddocks' heads, which can be obtained easily of any fishmonger, covered with water and gently simmered on the hob for some hours until they attain the consistency of a jelly when cold. If thoroughly cooked the bones will become quite soft and jellified, so as to cause the dog no inconvenience when swallowing; and this food is quite easy to prepare, but it takes some time. When the patient declines to feed, he may be given strong beef-tea and port wine, or eggs beaten up with port wine, which may be poured into his mouth from a bottle in small quantities at frequent intervals.

As regards medicine, there are many remedies for distemper, all more or less efficacious ; but there are few, if any, superior to those dispensed by Spratt's Patent, a supply of 
which should always be at hand for use in times of emergency, as the sooner a distemper patient is treated the better.

Good nursing, a warm, dry place to rest in, proper ventilation and fresh air, strengthening food of the kinds recommended above in sufficient quantities, and plenty of fresh milk to drink, are all most important factors in the successful treatment of a disease which if neglected may cause the death or lifelong injury to a valuable dog. It may also be added that the patient should be fed and made comfortable the last thing at night and the first thing in the morning. (See Nursing.)

Docking Tails.-A very great deal of well-intentioned nonsense has been spoken and written against the alleged pain that is produced through docking a dog's tail. Whether there is anything but custom that can be quoted in support of the practice is another matter, but certainly if conducted on intelligent principles, the operation is practically painless. The best age to dock the tail is when the puppies are about a month old, that is, before they are weaned, the way to proceed being to draw up the loose skin of the tail towards the body of the pup, to feel for a joint, and to cut through at that part with a sharp, strong pair of scissors. It is usually the custom to remove about two-thirds of the entire length, but this must be a matter for the operator to decide. After the scissors have done their work there will be very little bleeding, and the loose skin which has been drawn up will fall back and cover up the wound, which in the case of a healthy animal will heal very quickly.

Dog Baskets should always be used when valuable dogs are travelling by rail, as they prevent injuries from articles falling on the canine traveller, and when they are used he cannot slip his collar and bolt. (See Dog Boxes, Journeys.) 
Dog Boxes are not so strongly to be recommended for the use of dogs on their travels as baskets, for they naturally do not admit so much air, besides which, should they unfortunately fall off a height, they are liable to break or come open. Some dogs, however, will eat their way out of any basket, and in their case boxes must be used. If so, there should be ventilators covered with perforated iron on the front, sides, and top; and these should be protected by projecting iron guards, so as to prevent any other boxes or luggage from being packed close up against the dog boxes in the guard's van, as if this is done the animals stand a great chance of being suffocated. (See Journeys.)

Dog Racing, which must not be confounded with that abomination rabbit coursing, is a form of sport which appeals far more to north countrymen than to residents in the south of England. The method in vogue is to have each dog held on its mark (the competitors are handicapped according to their weights and performances) by an attendant, whilst their trainers or owners proceed nearly to the end of the track and attract their attention by waving handkerchiefs, the wings of birds, or other objects which are likely to be easily seen. On the pistol being fired the attendants let their charges go, and the race proceeds. (See Whippet.)

Dogue de Bordeaux.-This is a French breed of a decidedly bull-mastiff type which it was attempted to popularise in this country a few years ago, but without success, as the breed is neither attractive nor useful, whilst many dogues de Bordeaux possess most ferocious tempers, which in the case of dogs of their size renders them as dangerous as they are unattractive.

Doors. - The doors of kennels should always be made to open outwards, as in event of a dog being ill and lying 
against the door it is not an easy matter to get to him; and besides this, the opening of the door, if it comes close to the ground, as it should do, will disturb the lay of the sawdust or peat-moss which is on the floor of the kennel. Doors should be secured by two sliding bolts, one a few inches above the ground, and the other four feet from it. (See Kennels.)

Down-faced is a term chiefly in use amongst the admirers of bulldogs and other breeds whose muzzles should be of the retroussé order, to describe an animal which fails to show the desired conformation. (See Dishface, Frog-face, Lay Back.)

Drains.-All kennels in which a large number of dogs are kept should be well drained, and if, as is usually the case, sawdust or peat-moss is spread on the floor, means should be taken to prevent the drains from getting choked up. It is most desirable, too, that the outside exercising yards should be drained, a gutter will do if it slopes, so that the water will run off, as when the yard is swilled out the water is likely to remain in places unless it is removed by a broom, in which case the path outside the kennel will always be muddy if there is no drain to carry it away. The best arrangement is to have the inside drains connected by short pipes with a gutter running along the front of the kennel, which is an easy thing to arrange if the floor of the inside kennel is raised a little above the exercising yard, as it should be. The outside gutter can in turn be connected by pipes with the cesspool or drains of the establishment, but the pipes must be well trapped, and if a cesspool is used, it should be some distance from the kennels.

Draughts are a most potential source of danger to dogs, as even the most hardy breeds, which can stand almost any amount of ordinary cold, are liable to suffer 
in their health if exposed to a cold current of air. As a consequence, the sides of the kennel should be rendered draught-proof, and the ventilators placed well above the dogs, in fact, as near the roof as possible. (See Kennels, Ventilation.)

Dry Food is a very good thing as a change for dogs, especially if it takes the form of a big bone for him to gnaw. Spratt's biscuits given dry form an excellent substitute for the latter, as by gnawing them the dog secretes a quantity of saliva which assists digestion, and bones also assist in cleansing the teeth. (See Damp Food, Feeding.)

Dropper is the name by which a dog, the result of a cross between the pointer and setter, is known. (See Cross Breeding.)

Dudley Nose.-A yellow or flesh-coloured nose. (See Butterfly Nose.)

Dumb Madness. - A form of rabies in which the lower jaw becomes paralysed, so that the mouth remains open. (See Rabies.)

Dyeing.-It is, of course, a most reprehensible action to dye a dog, but plenty of cases occur in which unscrupulous persons conceal a faulty patch of colour by such methods. The most common offenders are perhaps a certain class of people who cultivate black-and-tan terriers, which often show tan-coloured hairs on the thighs and behind the ears. Intending purchasers of these dogs should therefore be careful when dealing with strangers. (See Trimming.)

Dysentery may be briefly described as aggravated diarrhœa, in cases of which blood is mixed with the motions. (See Diarrhoca.) 


\section{E}

Ears.-The shape, carriage, and position of a dog's ears mean very much in the case of show animals, and hence the importance of only breeding from parents which are good in these points, as a faulty ear is frequently hereditary. Occasionally the edges and tips of the ear become thickened and scurfy, which is annoying to the dog, as he is perpetually shaking his head or attempting to scratch the places affected, from which the hair often comes off, leaving unsightly bare patches. The application of a dressing of oxide of zinc and glycerine will usually produce good results, and a course of cooling medicine will assist a cure. (See Button Ear, Canker of the Ear, Rose Ear.)

Eczema is a form of skin trouble which is frequently confounded with mange, but it is not the same disease. It consists of little patches of very small pimples, which set up great irritation and cause the dog to scratch himself until sore places are formed. The best treatment is to wash the dog thoroughly in warm water, using tar-soap, and then to apply a lotion of laudanum, 2 oz.; glycerine and carbolic acid, I oz. each; carbonate of potash 2 drams; and water, $1 \frac{1}{2}$ pints. The dog should also be given a course of cooling medicine.

Eczema, unlike mange, is not contagious. (See Mange.)

Elbow.-The joint at the top of the fore-leg where it joins the shoulder.

Elk Hound.-This Swedish variety is occasionally met with in England at shows, but the breed is in few hands, though it has both good looks and intelligence to recommend it. It is very like the Esquimaux dog in shape, but its ears are finer and more pointed; and the coat lies flatter to the body. (See Esquimaux Dog.) 


\section{Embrocations. (See Counter-Irritants.)}

Emetics.-As a general rule it is not a difficult matter to make a dog vomit, and this has been a fortunate thing for many an owner when his favourite has managed to pick up poison. Salt, about half a tablespoonful in a dessertspoonful of tepid water, will generally accomplish what is wanted.

Enemas should be more often used in kennels than they are, for they are much more speedy and effective in cases of stoppage of the bowels or constipation than doses of powerful medicine, which do not act so quickly and often cause severe straining, and so may cause internal injury. Warm soap-suds, or warm water mixed with some sweet-oil or glycerine, in the proportions of about six parts of the former to one of the latter, may be referred to as constituting useful enemas, the amount of the above varying according to the size of the dog. The end of the instrument should be greased or smeared with oil before it is passed up the rectum, and care should be taken to see that the contents of the instrument pass out as soon as the bag is squeezed, else air will be forced into the bowels, which must be avoided if possible.

English Setter.-Opinions differ a good deal as regards the origin of the setter, but it is to the highest degree probable that at one time spaniel blood was largely introduced into the race-indeed, some persons believe that to the spaniel the setter owes his existence. At the present time there are three distinct varieties of setter recognised, namely, the English, Irish, and Gordon; but the latter has of recent years fallen behind the others in popular esteem, whilst the English is by far the most favoured by sportsmen. No doubt, however, the demand for all the breeds of gun-dogs has declined somewhat of late owing to the practice of driving game having become more 
generally practised; but still the setter is in considerable request amongst sporting men, and it will be long before he ceases to be regarded as a leading British breed and a most valuable field-dog. At the same time, it may be observed that the constitutions of some English setters are inclined to be delicate, this being no doubt a result of the inbreeding to which certain strains have been subjected; but the good sense of breeders renders it unlikely that such a system will be continued in the future.

The head of this most beautiful and intelligent dog is of the most exquisite grace, the chiselling of the outline being a constant source of admiration to those who can appreciate the refinement of the model and the wealth of intelligence portrayed by the expression of a well-broken specimen of the breed.

English Springer Spaniel.-At the time of writing the English springer is more popular amongst sportsmen than the exhibitors of dogs, and it is to be trusted, for the sake of the breed's working powers, that this may long continue to be the case, as it is a first-rate field-dog that has not had its abilities affected by the introduction of fancy points.

The skull is long and broad, slightly domed, and fairly developed over the eyes; the muzzle of a good length and breadth ; the eyes of a dark-brown colour and large, without being of the goggle order; and the ears long, set on low, and carried flat to the sides of the head. The neck is of a good length, and the shoulders slope nicely, the chest being deep and fairly wide, the body short, well ribbed up, and strong about the loins. The fore-legs, which are moderately long, must be straight and heavy in bone, with big, round feet; and the tail, which is usually docked, is carried low. The coat is not of great length, but there must be plenty of it, and a slight tendency to waviness is not seriously objected to, whilst there is feathering on the legs all the way down to the ground, and a slight fringe upon the dges of the ears; the most usual colours being 
liver, black, or sandy, either marked with white or tan, or red. The average weight is about $35 \mathrm{lbs}$. (See Springer.)

English Water Spaniel.-This breed is not by any means a common one, as most spaniels take well to water, and hence the merits of the ancient variety have been sadly neglected, though they were very highly esteemed by our fathers, who shot game under different principles to those now employed.

The head of this dog as he at present exists is long, rather narrow, with a pointed muzzle. The eyes are dark in colour and inclined to be small; the ears, which are of medium length, being well covered with hair and set rather forward. The neck is long; the shoulders broad; the chest wide and deep ; the body being round, well ribbed up, and compact; the fore-legs of good length and heavy in bone, with big feet heavily supplied with hair ; the hindlegs a good deal bent at the stifles; and the tail is carried rather high. The coat, excepting on the skull and muzzle, is covered by a series of thick curls of an oily texture, smaller curls being on the tail and ears, the favourite colours being liver and white, liver roan and white, or plain liver, and the average weight about $35 \mathrm{lbs}$.

Entering Puppies.-All puppies should be taught what is expected of them in after life at an early age, and the rule specially applies to such varieties as terriers which are used for the purpose of destroying vermin, and this is what is known as entering a puppy. In the case of a terrier the practice is to commence when he is big enough to face a certain amount of punishment, but it is nevertheless most undesirable that he should be seriously hurt, as if he is it is quite likely that his courage may be affected for the rest of his life. At the same time there should be no idea of sparing him the consequences of any mistakes he may make; but in order to avoid his incurring unnecessary risks through inexperience, it is a 
good plan to let the puppy first see some old dogs at work and then for him to accompany them when facing vermin, as this will teach him how to proceed, and give him courage to face and take his share of punishment. In short, it is necessary to proceed slowly at first with the work of entering a puppy; for though some young dogs appear to know at once what they should do, others of undoubted gameness seem absolutely ignorant of all that is expected of them, and in some cases do not even think of attacking their opponents until the latter tackle them. Consequently no owner need despair of a puppy which at first appears to show the white feather or a disinclination to work, as many of such puppies prove to be the most plucky and determined of all when they once understand what they have to do and how to do it. (See Breaking.)

Enteritis (or Inflammation of the Bowels) is most dangerous to dogs, and is usually the result of improper feeding. An attack usually comes on suddenly, and is attended by fever, shivering, and a very hot nose, whilst the stomach is swollen, hot, and hard, and tender if touched, and the urine very scant in quantity. The best thing for the amateur to do is to give the dog an enema in order to open the bowels, and to send at once for a veterinary surgeon. (See Enema.)

Epilepsy.-When a dog is subject to epileptic fits, his value is considerably impaired, as he is always liable to renewed attacks, and under the best of conditions such seizures are dangerous, both to himself and not infrequently to those about him. The symptoms are as follows: the dog falls suddenly on his side, often at the same time giving a shriek of pain, his lower jaw works convulsively, the tongue being frequently bitten, and the animal foams at the mouth. The limbs twitch convulsively, and during the spasms water is sometimes passed and the bowels operate. Of course, professional advice should at once 
be sought for, but pending its arrival the treatment to pursue is to place the dog in the open air, dash cold water on his head, and hold a bottle of ammonia to his nostrils. The spine may also be rubbed with turpentine, mixed mustard, or some powerful counter irritant. When the fit is over the dog appears dazed, and occasionally endeavours to break away or bite those around him, his behaviour during and after the attack sometimes causing people who do not recognise the symptoms to form the erroneous opinion that he is suffering from rabies. (See Fits, Rabies.)

Ergot of Rye is fortunately not a form of vegetation that dogs are likely to eat, as partaking of it is likely to produce abortion in the case of a bitch in whelp. Still, animals which enjoy their liberty encounter some risks, as ergot is a fungus which attacks grass, and therefore may be eaten by them. It is a poison which, if swallowed in large quantities, produces violent abdominal pains and purging, which frequently result in paralysis, so it may be regarded as a potential source of danger to all dogs.

Esquimaux Dog.-Of recent years the Esquimaux dog has become familiar, as a breed, to many people, owing to the frequent references that have been made to him by the chiefs of exploring expeditions in Northern latitudes. His appearance, moreover, is pretty well known to visitors to dog shows, as numerous good specimens of the race have been imported into this country from time to time. It can scarcely be claimed for the Esquimaux dog, however, that his intelligence is great or his sociability conspicuous, and he may therefore be regarded more in the light of a curiosity here, and a very useful animal for draught purposes in his own country, than as a companionable animal.

The general appearance of the Esquimaux dog is decidedly foxy, as his head, adorned as it is by prick ears, 80 


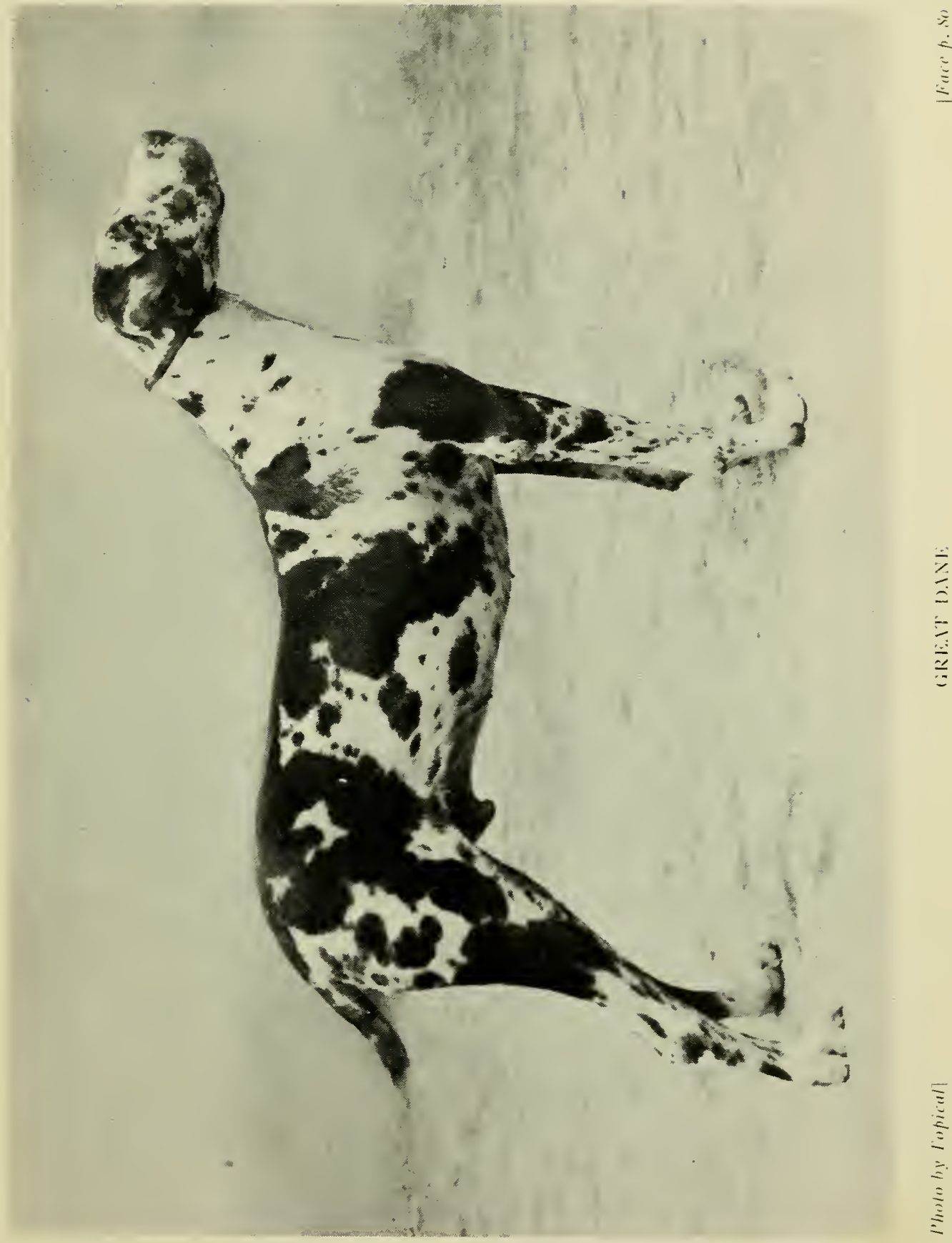



resembles that of the animal referred to. The dog is, however, the larger animal, and much more powerfully built, and he stands on longer legs. His body is compact and powerful, and his tail is carried in a curl over his back. As may be supposed in the case of an animal that is used for draught, his fore-legs must be straight and stout, with compact feet and thickly-padded soles; whilst the hind-legs are muscular and well let down at the hocks. The outer coat is of fair length and very thick, the under one of the close, sealskin-like character which is carried by all dogs that are indigenous to cold climates. The colour of the Esquimaux is a sort of yellowish grey, and the average weight about 35 lbs.

Evolution.-Many theories have been expressed regarding the evolution of the canine species, but the consensus of opinion appears to be that the wolf, jackal, and dog have sprung from a common root, though some eminent authorities entertain the belief that the wolf is the direct ancestor of the dog. The fact that wolves, jackals, and wild dogs do not bark is held by some to suggest the probability that these races are not allied to the domestic dog; but against this theory it can be argued that these animals frequently attempt to bark, and occasionally actually do so, after long association with ordinary members of the canine species. Other opponents of the suggestion that the wolf is the ancestor of the dog maintain that it is impossible that the dog in its almost infinite varieties could possibly have descended from an animal in which certain strongly defined characteristics have been developed for centuries; but such a contention is surely negatived by the immense changes and innumerable fancy points which have been introduced into the different varieties and sub-varieties of dogs by modern breeders who have devoted their energies to the production of show specimens. On one point, however, the authorities are unanimous, as they all agree that from time immemorial 


\section{EXERCISE}

the dog has been the constant and faithful companion of mankind, that he has proved himself to be the invaluable associate of the latter in the pursuit of game, and a most vigilant guardian of his home and property. In fact, all records tend to prove the estimation in which the canine race was held by the earliest races of humanity, strong evidence of this being forthcoming through the discovery of ancient graves containing the bones both of men and dogs. (See Dingo.)

Exercise.-If more owners could realise the beneficial results of healthy exercise upon their pets, there would be far fewer unhealthy dogs. There can be no two opinions regarding the truth of this, but it unfortunately happens that many people who agree with it cannot, or at all events do not, give their dogs the proper amount of exercise the animals require. A very general impression appears to exist, moreover, that a dog should be given violent exercise in the form of long runs after vehicles if he is to derive any benefit from his outing, whereas the fact remains that there is nothing like long, slow walks along the road if it is desired to have the dog lay on muscle and keep himself in good health and condition. It should not be forgotten, moreover, that a dog that is taken for a constitutional by his owner travels over a far greater extent of ground than the latter does, as he is always tearing about and running backwards and forwards, the result being that he covers several miles to his owner's one. This, it may be repeated, is the kind of work which keeps him thoroughly fit, but he should be given an occasional gallop after a vehicle if it is desired that his speed should be increased. At the same time, few things are more cruel than to chain an unfortunate dog behind a dog-cart or carriage, thereby compelling him to keep on at a uniform pace in the cloud of dust that is raised by the horses and without having the opportunity to rest for a single instant.

Of course it is not within the power of all dog-owners 
to give their animals as much exercise every day as they should have. But there are very few people who cannot spare a half-hour daily to indulge their favourites with runs after a ball, which the animals delight to do, and the habit of retrieving it for their owners to throw away again is generally acquired very soon. Another way of giving a dog exercise in a small space is to suspend a cat's skin, a rat in a trap, or some object that will attract him at the end of a pole just out of his reach, so that he may be induced to persist in jumping up at it. Some dogs will keep on trying to reach the object for hours at a time if allowed to do so, but of course the amount of this sort of exercise must be limited. Small toy dogs can always be exercised in a room by being encouraged to run after a ball, and certainly will be better for it, as no animal however delicate it may be can be kept in health if it passes its existence in a life of laziness. (See Preparing for Shoze, Training Greyhounds.)

Exhibiting.-Of late years the popularity of dog shows has increased so greatly that there is scarcely a town of any importance in the country which does not enjoy the privilege of having its annual show. Whether this is entirely for the welfare of the canine race is a matter of opinion, as the extension of the show system has unquestionably led to increased attention being paid to fancy points and to the neglect of others which are associated with working ability. No doubt shooting men have to a considerable extent contributed to the decadence of many of the old sporting breeds, as the tendency of the times is to largely dispense with the services of dogs in the field, and hence exhibitors who breed for the purpose of winning prizes at shows cannot be blamed if they attach supreme importance to the improvement of the appearance of their dogs, without regard to their working capacities. On the other hand, it may be argued that the constant change that is going on in connection with the development of fancy 
points, and the abandonment of others which used to be prized by breeders, is an unjustifiable usurpation of authority on the part of those who tamper with old standards in their'desire to effect changes under the cloak of improvements. In one respect at all events those who support the modern view are entitled to plead justification for their actions, as dogs of most varieties which can win prizes have vastly increased in value. Whether this fact provides proof that they are better animals than those of a generation or more ago, is a matter for doubt. They certainly possess many new properties as they have lost old ones, and as mediums for attracting the favourable notice of modern judges, many of whom possess no knowledge of what former breeders aimed at producing, they must be pronounced to be distinct successes. The only debatable question, in short, is, can the alterations which have been effected, and which in some instances have practically changed the whole character of a breed, be honestly regarded as improvements? (See Faking, Preparing for Show, Trimming.)

Eyes.-A great deal of difference exists in the colours and shapes of the eyes in dogs of different breeds, and also in the manner in which they are set in the head. These matters are, however, referred to in the descriptions of the various varieties; but it may be laid down that, excepting in a very few instances, a yellow eye is a disfiguration which detracts considerably from the value of its possessor. (See China Eye.)

\section{F}

Faking.-This expression is one that is generally adopted by exhibitors when alluding to certain dishonourable practices which unprincipled persons resort to with the object of improving the appearance of their dogs or of 


\section{FAT-FEEDING}

concealing blemishes. As a matter of course, detection leads to disqualification and other penalties, but the fact remains that faking does exist, though possibly not to so great an extent as formerly. Amongst the practices which constitute this offence against honesty are-severing the muscles of faultily carried ears to make them lie properly, manipulating badly carried tails, removing patches of objectionable colour and superfluous hair, filing teeth, dyeing coats, and applying resin or other such substances to soft coats in order that they may appear harsh. In former days the lip-strings of bulldogs used to be severed to encourage the lay back of the nose, but of late the practice has been discontinued. (See Trimming.)

Fat.-A fat dog is never a healthy one, and a stud dog or a brood bitch which bears the burden of adipose tissue to an abnormal extent is seldom likely to produce puppies. Some dogs, however, appear to lay on flesh in defiance of all the precautions their owners may adopt to prevent it; but if they are given plenty of exercise, and fed sparingly but sufficiently on wholesome food, their bulk may be reduced. Raw flesh and dry biscuits are the best things to feed them on, and if the dog is in the habit of drinking a large quantity of water his allowance may be limited. (See Feeding:)

Feather is the term applied to the fringe of hair which grows on the back of the legs, on the lower side of the tail, and on the edges of the ears of some breeds of dogs.

Feeding.-Upon the question of feeding much of the success of the breeder depends, as from the first mouthful a dog eats to the end of his life his health, condition, activity, and general well-being will largely be affected by what he gets to eat. The puppy will not develop if he is improperly fed, the sporting dog or the terrier will not be capable of doing the work expected of him if he is in- 
sufficiently nourished, and the toy will become a trial and an eyesore to its owner if its diet is not based upon correct principles. Hence the importance of proper feeding.

It is not by any means a difficult matter to attend to the subject properly if a little common sense and fairness is brought to bear upon it, and to commence with, two important facts ought always to be borne in mind-first, that all dogs do not require the same course of feeding; and secondly, that a dog's diet should be regulated by the work he has to do and the amount of exercise he gets. There can be no doubt that, excepting the state of his health ordains it otherwise, all dogs are benefited by having meat to eat, but the quantity should be regulated judiciously, and the quality must be good. For instance, an animal which enjoys a great deal of exercise can consume more flesh with benefit to itself than one which lies all day long in front of a fire; and it may here be added that a constant diet of flesh, especially if it is in the form of a stew and mixed with fat, is sure to be injurious to its consumer.

Hence the necessity of providing a supply of farinaceous food for all dogs. This can be given to them in the form of meal well boiled in the broth of bullocks' or sheep's heads and mixed up with green vegetables (also boiled), and if desired, a portion of the meat from the heads chopped up small. The above is a very good food for the large breeds, and if variety is desired, bread, ship's biscuits, rice or pearl-barley may occasionally be substituted for the meal. There can, however, be little doubt that for most dogs Spratt's biscuits form an ideal form of food, as they contain meat in different guaranteed proportions, and hence the owner knows exactly how much flesh his dog is getting, and is able to regulate the quantity as occasion demands. These biscuits are equally nutritious if given soaked in broth or dry, and in the latter form if placed whole before the dogs they fulfil the purpose of a bone, as by gnawing 
them digestion is assisted by the secretion of additional saliva, and the teeth are cleansed by the removal of the tartar which may have collected on them.

Horse-flesh, provided of course that it comes from a healthy animal, is appreciated as a change, especially by the larger breeds; but there is a great deal of truth in the belief entertained by many persons that too much meat impairs the scenting powers of gun-dogs, such as pointers and setters. Boiled liver is excellent if given now and

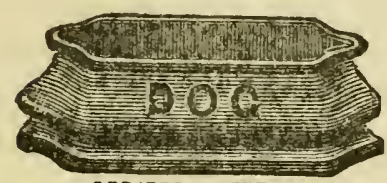

SPRATTS PATENTL":

Drinking Trough.

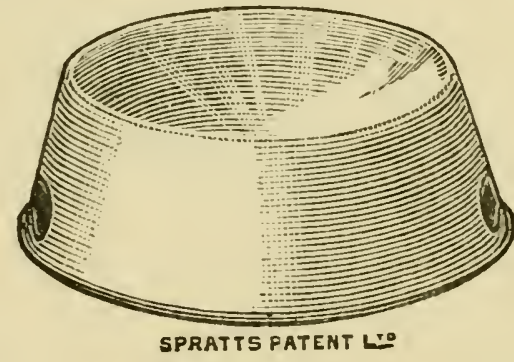

Feeding Tin.

then, as it assists in keeping the bowels in proper order; but though sheep's paunches and bullocks' tripes are liked by most dogs, they are not a very strengthening form of food, and when given they must be thoroughly cooked. If boiled up with Rodnim-a speciality of Spratt's Patenthowever, they can be recommended, as rodnim is most nutritious, and especially adapted for the food of hounds and the larger breeds of dogs. Fish as an occasional change is very good, but it must be thoroughly boiled so that the bones will become soft, else there may be cases of choking in the kennel; and bones, provided that they are large ones and precautions are taken to prevent fighting for the possession of them in cases where several dogs are kept together, also provide a welcome variety of diet.

The feeding of toy dogs is an easy matter if owners would only temper common sense with their solicitude for the pleasure of their pets, and thereby deny the latter things which they know full well will make them ill. 
Scraps from the table, consisting of a little meat minced up with green vegetables and bread crumbs, will form an excellent dinner for the most delicate of toys, whilst a few of Spratt's "Ovals"-a form of biscuit specially prepared for the smaller breeds-either given dry or soaked in malt milk cannot be surpassed for the other meals of the day.

In the case of most healthy dogs two meals a day is amply sufficient to keep them in health-in fact, many animals thrive better upon only one, but toys and invalids demand more. As regards quantity, it must be remembered that some dogs require more food than others, whilst there are greedy creatures which will always be ready to devour more than is good for them. The owner will therefore have to regulate the allowance made to each dog by what he sees is best for it; but it may be added that when two meals a day are provided, the morning one should be light and the evening one the larger. (See Biscuits, Bones, Preparing for Show, Puppies, Shy Feeders, Training Greyhounds.)

Feet.-The feet of a dog are an important point about him if he is expected to be active, as a weakness in this region naturally incapacitates him from getting about. A splay, open foot with thin soles and flat knuckles is usually a weak one; a compact one with well-developed knuckles and a thick sole is always the reverse. If dogs are expected to work on stony ground a thick sole is indispensable, and if there is hair between the toes, the foot will be all the better able to stand the strain. (See Cat-foot, Hare-foot.)

Fencing.-The fencing which encloses the exercising yard of a kennel should always be high enough to keep the dogs in; six feet being quite low enough for the larger breeds. The top should be rounded off in order to prevent a dog wounding himself if he succeeds in getting his feet on it, and if there is a sheet of corrugated iron laid 88 
horizontally along the bottom, shelter from cold winds will be provident, and fights between the members of adjoining kennels will be prevented. (See Kennels.)

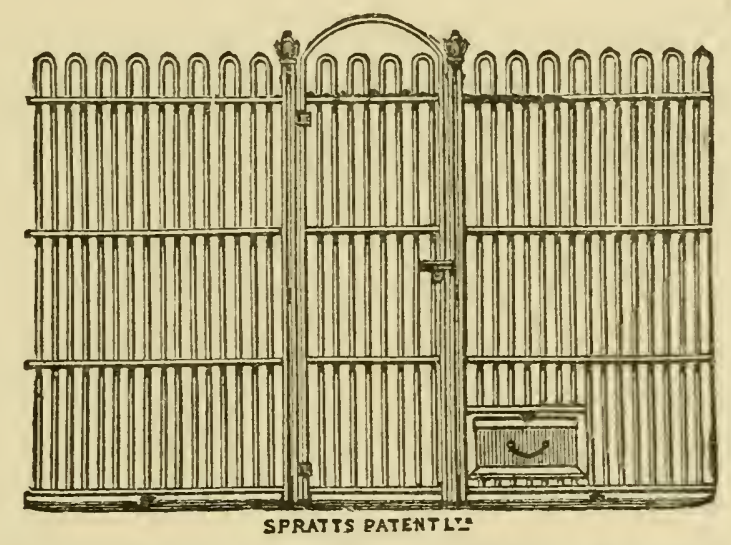

Kennel Fencing, with Gate and"Water Trough.

Fever.-The presence of fever is associated with a high temperature, loss of appetite, and shivering, all of which are usually to be regarded as signs of some approaching sickness, but it may also be the result of an accident, such as a severe wound, in which case there may be less anxiety as regards the cause. The reduction of the fever as quickly as possible should be attempted; the most reliable agent being, in the opinion of Mr. Alfred J. Sewell in "The Dog's Medical Dictionary," published by Messrs. Routledge and Sons, phenacetin, to be administered as directed by him in that work. (See Temperature.)

Field Spaniels are divided into two groups, namely, the springers, which are the larger-sized varieties, and the cockers or small ones. The former category includes the clumber and Sussex, Norfolk and Welsh spaniels, and the members of the spaniel family of various colours which are of the larger size, and do not belong to one of the above four breeds. Hence it has become the custom to designate as a field spaniel a springer, which is not a Sussex, clumber, Welsh, or Norfolk. Various colours are 
met with in this variety, including black, roan, liver and white, black-white-and-tan, but their points are all the same. (See Black Field Spaniel.)

Field Trials are the meetings held annually in different parts of the country for the purpose of testing the working abilities of gun-dogs over birds. They provide admirable tests of the merits of the competitors, and have contributed greatly towards sustaining the interest taken in training pointers, setters, retrievers, and field spaniels. The oldest established meeting is that held at Shrewsbury, it having been established over a generation ago, under the patronage of Lord Hill and Sir Vincent Corbett, with Mr. S. Ebrall as secretary. The popularity of the fixture quickly became established, with the result that the owners of the principal pointer and setter kennels all sent representatives to compete in the various stakes; a win at Shrewsbury being regarded as the supreme test of a dog's merits in the field. Of more recent years many other fixtures have sprung up, including that of the Kennel Club and those devoted to spaniels and retrievers, all of which are movable gatherings.

Fighting.-When two dogs conceive an animosity for each other it often becomes a very difficult matter to prevent their fighting whenever they meet, and it is therefore most unwise to leave them together in the same kennel. Bones left lying about are a very fruitful source of trouble amongst dogs, and especially in such cases as when one animal discovers the treasure which another has buried under the straw on the benches. In ordinary street fights the best way to separate the combatants is to drag them from off each other by their tails, but if one has got a firm hold of his opponent it may become necessary to choke him off. (See Bites.)

Fistula is not an uncommon form of trouble amongst dogs, and especially if they are fed upon constipating 
foods. The services of a properly qualified veterinary surgeon should be obtained to treat cases of fistula. (See Piles.)

Fits are not at all uncommon sources of concern and loss to owners of dogs, as in one form or another they are liable to attack animals of all ages. Puppies, for instance, frequently suffer from them as a result of teething troubles or from the presence of worms; whilst older dogs are liable to be attacked by epilepsy and apoplexy. The successful treatment of fits is, however, a subject which is far beyond the powers of the ordinary amateur practitioner to deal with, as much depends upon the constitution of the individual dog. It is best, therefore, to obtain the assistance of a qualified veterinary surgeon, or to peruse the pages of Mr. A. J. Sewell's admirable work, "The Dog's Medical Dictionary," in which much valuable advice is given. (See Apoplexy, Epilepsy.)

Flag.-A name given to the tail of some breeds, such as the setter.

Flat-coated Retriever.-Of late years the flat-coated retriever has become by far the most popular member of the family, as he has completely ousted the curly-coated variety from the position he formerly enjoyed. The origin of the flat-coated dog was probably a Labrador or Newfoundland and setter cross, and very possibly all the three varieties were concerned in his production. At first the coat was far denser and more wavy than it is now, and this is suggestive of a Newfoundland cross, which, however, is not at all noticeable in the modern and fashionable flatcoated dog.

The head in this breed is long and wedge-shaped, flat on the top of the skull, and tapering gradually towards the nose; the muzzle being long, powerful, and fairly blunt. The eyes are of a gond size, but not too full, the correct colour 
being a dark brown, a yellow eye being a very bad fault; and the ears, which should be V-shaped, lie close to the sides of the head. A long, powerful neck is a characteristic of the breed, and the shoulders should be long and well laid back, as the retriever must be an active dog, else he will be useless for work. The chest is deep, but not too wide; the back very broad and muscular ; the ribs not being too much sprung; but the loins, which are slightly arched, should be muscular. The fore-legs are set on well under the dog, of fair length and heavy in bone; the feet being large and compact, with thick soles, and the hindquarters extremely powerful, with very muscular thighs; whilst the tail, which is well feathered, is slightly arched near the root. The outer coat is moderately long, perfectly flat and dense, with a close, sealskin-like jacket underneath to keep out the cold and damp. The prevailing colour is black, but light, golden-liver specimens are to be found. (See Curly-coated Retriever.)

Flatulence.-Dogs often suffer from this to a very objectionable extent, the most usual cause being indigestion, the result of improper feeding and inadequate exercise. The remedy is to remove the cause. (See Indigestion.)

Fleas are very troublesome to dogs which are not kept properly clean and have not their beds changed often enough. The best means of eradicating these pests is to wash the dogs with carbolic soap in water in which quassia chips have been soaked. A small handful of the chips, which may be obtained of any chemist, should be tied up in muslin and placed in a jug of boiling water until it is cold. The water may then be added to that in which the dog is washed. (See Ticks, Washing Dogs.)

Flesh.-Raw flesh is occasionally a very good change of food for dogs, provided that it is fresh and comes from a healthy animal. (See Feeding.) 


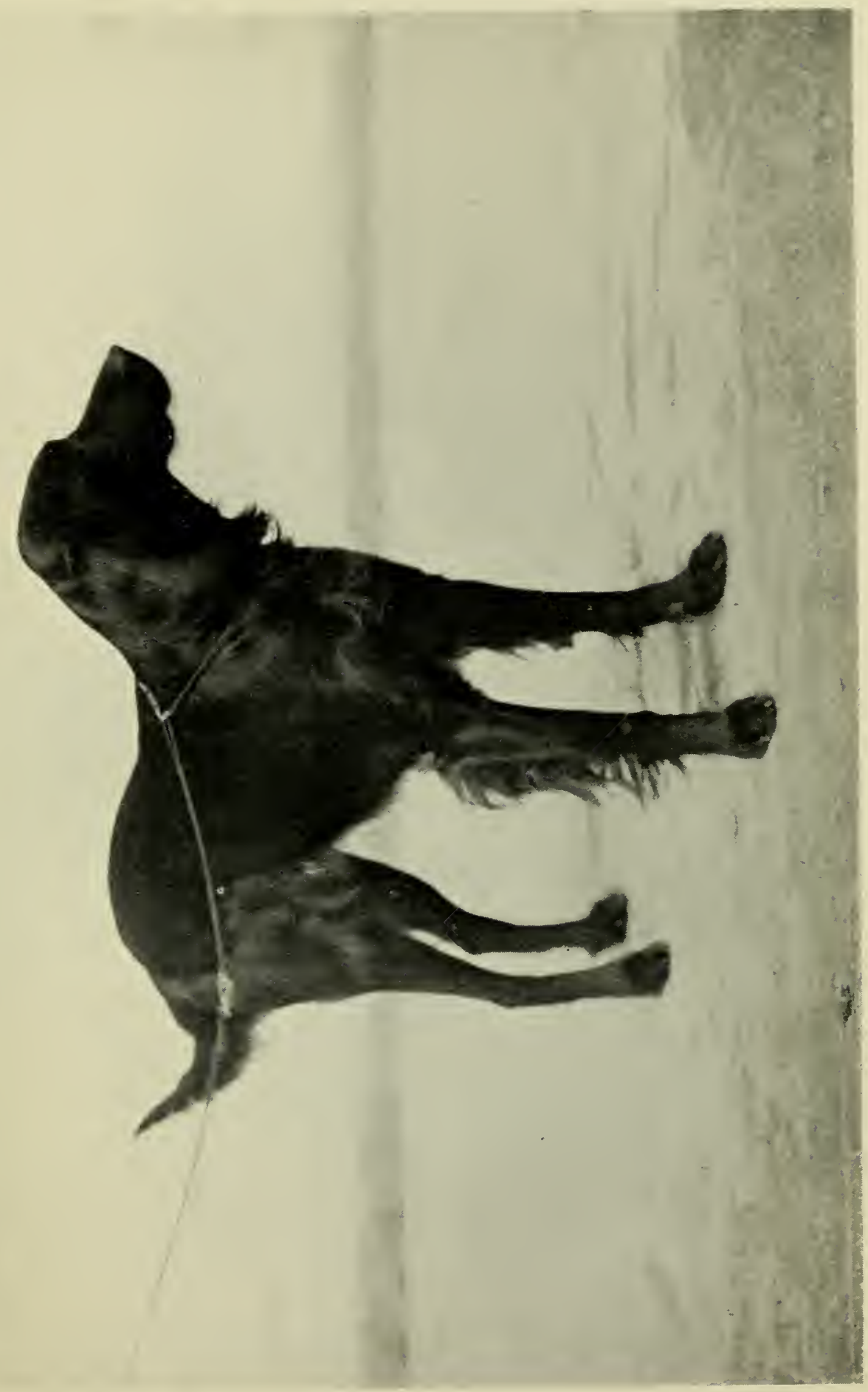

1
$\vdots$
$\vdots$
$\vdots$
$\vdots$
$\vdots$

$\frac{1}{-}$
$\frac{1}{5}$
$\frac{5}{5}$

$\vdots$
$\vdots$
$\vdots$
$\vdots$
$\vdots$
$\vdots$ 

Flews.-The name given to the pendulous lips of bloodhounds and some other breeds.

Flies often cause discomfort to a sick dog, and their presence in a kennel is always unwelcome. They can be kept away by placing a vessel containing a weak solution of carbolic acid in a position out of reach of the dogs.

Floors.-Of whatever materials the floors and pavements of kennels are made, they must be perfectly smooth ; and it is as well for cleansing purposes if they gently slope, so that the water can run off. If made of boards or brick they are liable to absorb the moisture, which is a disadvantage; but the former is the warmest of all floors, and the difficulty referred to can be got over by covering it with a layer of coarse sawdust or peat-moss. Concrete is a very cold flooring for a kennel, though it is an excellent paving for exercising yards, and asphalt is preferable, though if in use out of doors it is liable to become soft in hot weather. Flagstones are in use in many large kennels, though they are more costly and no better than concrete or asphalt; but in the case of small breeds a wooden floor is by far the best. It may be added that it is desirable that peat-moss or coarse sawdust should be thickly spread on the floors in all cases. (See Kennels.)

Flour:-Flour which has been well baked in an oven will be found very useful for cleansing the coats of dogs which it is not desired to wash. (See Preparing for Show, Washing Dogs.)

Fore-arm.-The upper part of the fore-leg below the elbow.

Foreign Dogs.-The rage for foreign dogs which has 
possessed the admirers of the canine race in this country for the last few years has undoubtedly been the cause of injury to the interests of many a fine old English breed in which our fathers took delight. The increase in popularity of the former has, moreover, been coexistent with the change that has come over the usages of shooting men, who now support the practice of driving game more generally than before, though it can scarcely be suggested that the appearance of hundreds of foreign dogs amongst us is wholly responsible for this; but the fact is worthy of attention. It may also be pointed out that many a breed which is now claimed as an English one is of foreign extraction, and therefore the expression foreign dog is more generally applied to the more recently imported varieties, such as Chow-Chows, Japanese and Pekinese spaniels, Esquimaux, and other northern dogs.

Fore-legs.-The fore-legs possess two joints-the elbow, or upper one, and the pastern, which is the lower.

Foster-mother.-It is occasionally necessary to obtain the services of a foster-mother for puppies. When this is the case it is necessary that the foster-mother should have whelped as nearly as possible on the same date as the dam of the puppies, and if she is of the same size so much the better. When a foster-mother is used she should be carefully watched when the puppies are first placed with her, as some bitches do not take readily to their charges. As a rule, however, all danger is over after the puppies have been allowed to suckle. (See Breeding, Brood Bitch, Puppies.)

Fotor, or Comforter.-The name applied to the smaller varieties of spaniel in bygone days.

Founder.-(See Kennel Lameness.) 
Fractures can be detected by the sound of the grating of the edges of the bones when the part affected is moved. These injuries are of four kinds-namely, simple, that is, when the bone is broken without piercing the skin; compound, when the skin is pierced; comminuted, when the skin is pierced in more than one place; and complicated, when the surrounding tissues are injured by the fracture. The setting of a fractured limb is quite beyond the powers of most dog-owners, and therefore surgical aid should be at once procured, whilst pending its arrival the injured animal should be made to keep as quiet as possible. The precaution of getting together bandages, cotton-wool, starch, and materials for splints for use later on will save time subsequently.

French Bulldogs.- The attempts made to popularise this variety of dog in England have not been associated with success, which is not surprising, as the French bulldog is not particularly prepossessing in appearance.

Frill.-The luxurious growth of hair on the neck and breast of some varieties is known as the frill.

Frog-face.-A muzzle which turns downwards instead of upwards is thus described. (See Down-face, Lay Back.)

Full Mouth.-A puppy is said to have got his full mouth when all his second teeth have been cut. This usually takes place when he is about nine months old. (See Puppies.)

Furnished.-A dog is said to be well furnished when he is well filled out all round. (See Made Up.) 


\section{G}

Gall-stones.-Many dogs suffer greatly from the presence of gall-stones, which cause considerable pain and tenderness in the belly. Hot linseed poultices may give temporary relief, but the treatment of gall-stones is rather beyond the powers of an amateur practitioner, nor is it at all an easy matter for him to discriminate between them and colic. Mr. A. J. Sewell's advice in "The Dog's Medical Dictionary" will, however, be of much service to owners.

Gastritis is a very common source of trouble to dogs and their owners, as in addition to its being the result of eating improper food or poison, it may be the result of a blow or kick. The chief symptoms are violent retching and diarrhœa, considerable fever, accompanied by rapid breathing, a weak, quick pulse, and sometimes considerable thirst. The dog should be made as comfortable and quiet as possible, and his bowels be given as much rest as possible, his diet being a limited one of milk and beef-tea. This disease is treated of very fully in "The Dog's Medical Dictionary" (George Routledge \& Sons, Ltd.).

German Boarhound.-A few years ago this dog was to be met with far more frequently than it is now, the reason for this being that it has been practically merged into the great Dane, which variety it resembles in many respects, though the boarhound is the far heavier headed, more massively built, and less active dog of the two. (See Great Dane.)

Gestation.-The period of gestation in the bitch is sixty-three days. (See Breeding, Brood Bitch.)

Girth.-The girth of a dog's body is taken round the chest behind the forearm. 
Glassy Eye.-The eyes of many dogs when the animals grow old assume a bluish, glazed appearance, and the vision becomes impaired. There is nothing that can be done to remedy it, though in the case of younger animals similar trouble occasionally appears as the result of a cold, in which case professional advice should be sought.

Gordon Setter.-To the infinite regret of many shooting men of the old school, the Gordon setter has of late years steadily lost ground in the estimation of the sportsman of the day. Forty or fifty years ago he occupied a very different position, and was in especial request amongst elderly sportsmen, as though his powers of scent are of the highest, and he is a paragon of staunchness, the Gordon lacks the pace of his English and Irish relatives, and therefore is peculiarly adapted to shooting men whose forte is not activity. The breed derives its name from the Scottish seat of the Duke of Richmond, and a century ago no setter was more highly prized than one which came direct from Gordon Castle. The prevailing colours were black tan and white, and black-and-tan, though of late years only the latter are to be found ; and it may be added that a former Duke of Richmond, in the earlier part of the nineteenth century, introduced the blood of the collie into his strain through the medium of a remarkably clever bitch, whose intelligence attracted him.

The head of the Gordon setter is heavier than that of either the English or Irish breeds, and rather broad between the ears, slightly rounded, and with the occipital bone well pronounced; the muzzle being long and large. The eyes are very bright, and sometimes show the haw; the correct ear being of fair length, covered with silky hair, and carried close to the sides of the head, but in some wellbred dogs they are, comparatively speaking, short. The neck is of fair length, and rather heavy looking; the chest fairly wide and of good depth; the body large and massive looking when compared with that of the English or Irish 
varieties; the fore-legs straight, heavy in bone, and nicely feathered right down to the ground, and the feet large. The tail should be short, well feathered, and carried straight. The coat is long and silky, and the prevailing colour of late years a rich black and deep mahogany tan; the latter appearing on the muzzle, on two spots 'over the eyes, on the points of the shoulder, on the fore-legs up to the knees, and on the inside of the hind ones. The average weight is about $65 \mathrm{lbs}$.

Great Dane.-None of the breeds of big dogs has made such progress of late years as the great Dane, which is undoubtedly a descendant of the ancient Danish dog, a variety which was known to, and eulogised by, several of the most reliable writers of the past. Some thirty years ago a good deal of confusion existed in the minds of enthusiasts in dog flesh between the German boarhound, which was also an undoubted descendant of the Danish dog, and other varieties possessed of somewhat similar characteristics. The German breeders of these varieties, of which Germany was the acknowledged stronghold, however, very wisely decided to unite them all so far as possible under one type and name, the result being the great Dane or German dog, as he is styled in the Fatherland, now one of the most popular breeds in existence, and rightly so, as a fine specimen of the variety is the beau-ideal of a combination of strength, grace, and activity. No doubt a certain amount of prejudice exists against the great Dane, which is believed by many people who do not know him to be by nature a savage and unreliable tempered dog. This is not the fact, but it was so in the case of the German boarhound. If, however, the great Dane is properly trained and disciplined when a puppy-this does not imply that he should be knocked about or ill-treatedhe will in ninety-nine cases out of a hundred be found to be a most companionable dog and easy to keep under control. Perhaps the chief objection that can be brought 98 
against him is the tendency he possesses to become weak and crooked about the legs and joints, this being in the majority of cases the result of a want of proper food and exercise when he was young, as his limbs were not able to carry the great weight of his body. Hence the necessity that exists for bestowing much care upon a great Dane in the earlier stages of his existence.

The head should be long and flat, with a rise at the eyebrows, and a slight groove between them; the muzzle long and of uniform substance, well filled up under the eye, and yet free from any approach to coarseness; the lips, though showing no deepness of flew, coming well down in front of the nose, so as to present a very square appearance. The teeth should be level, the nose large and dark, excepting in the case of the harlequin-coloured dogs, when they may be butterfly or flesh-coloured; the ears are small, set on high, and carried with the tips forward. In Germany it is the practice to crop the ears of great Danes, but the custom is prohibited here. The neck must be long and gracefully arched, quite free from any approach to loose skin or dewlap, and neatly set on to the shoulders, which should be long, lean, and laid well back. The chest is rather narrow when compared with the size of the dog, but very deep; the back being of fair length, but extremely muscular and powerful about the loins; whilst the fore-legs, which should be set well on under the dog, are of medium length, very heavy in bone, and dead straight; the pasterns being straight, and the feet large, round, and compact. The hind-quarters are powerful, showing plenty of muscle, and the hocks, which are let well down towards the ground, should not be at all turned inwards. The tail, which is rather thick at the root, tapers towards the tip, and should be carried almost in a line with the back, with a very slight curve towards the end. The coat is short and fine, though very thick, and the principal colours are brindle, blue, fawn, and harlequin, the latter consisting of black markings upon a white 
ground. (See Butterfly Nose, Exercise, Feeding, Rearing Puppies.)

Green Food is necessary to keep dogs in health, and if accustomed to eat it from their early puppyhood there is no difficulty in making them take it. The best form of vegetable food is cabbage, but some people give their dogs quantities of the heads and tender shoots of nettles when these can be obtained; but whatever the green diet consists of, it must be thoroughly boiled and cut up before mixed with the other food. (See Feeding.)

Greyhound.-In the opinion of many authorities well qualified to express their views the greyhound is the most ancient breed of dog in the world, and certainly there appear likenesses of a dog of very similar appearance on some of the old friezes which have been excavated in Eastern countries. There are undoubted proofs forthcoming, however, to show that the ancient Egyptians possessed a dog resembling the greyhound, which they used for hunting purposes, and the speed of which they highly prized. Arrian - the younger Zenophon-who wrote in the second century, moreover, referred to dogs which hunted by sight and not by scent, and it is certain that in his day a sport conducted on very similar lines to modern coursing was popular in the East. Referring to more modern times, it may be observed that Dame Juliana Berners of Sopwell Priory, St. Albans, in her "Booke of St. Albans," the earliest work of the kind published in English, gave expression to a description of the greyhound which has become historical. To quote a portion of that immortal standard of the breed :-

"A grehounde should be heeded lyke a snak

And neckyd lyke a drake,

Footed lyke a catte,

Tayllyd lyke a ratte,

Syded lyke a teem,

And chyned lyke a beem."

\&c. \&c. \&c.

100 
The above represents a very fair description of the modern greyhound, the head of which should be long, rather wide between the ears, and gently tapering towards the muzzle, which is powerful, though a little chiselled out under the eyes. The nose is large and fairly prominent; the eyes bright and rather small; and the ears fine, small, and carried with the tips turned backwards, so as to show the inner burr, but when the dog is excited they become semi-erect. The neck is long, light, and slightly arched; the shoulders very clean, long, and sloping; the chest narrow, but very deep; the body rather long, muscular, and arched at the loins, which are deep and powerful; the fore-legs set on well under the dog, dead straight, and heavy in bone; whilst the feet are round and compact, with the toes well arched. The quarters are very muscular, the hind-legs being bent at the stifles, the hocks being well let down. The tail is long, fine, slightly curved, and carried low; whilst the coat, though short and fine, is thick and weather-resisting. Almost all colours are met with in the greyhound, the most common being black, fawn, blue, brindle, and red, either self-coloured or marked with white. Weights vary immensely, as first-rate specimens have been seen which only scaled a little over $40 \mathrm{lbs}$. -Coomassie, who won the Waterloo Cup twice, only scaled $44 \mathrm{lbs}$. in training-up to $70 \mathrm{lbs}$., but about $60 \mathrm{lbs}$. for a dog and 55 lbs. for a bitch is a good weight. (See Training Greyhounds.)

Grooming.-All dogs which are required for show purposes should be groomed regularly at least once a day, and even in the case of others the practice is most beneficial, as it assists in keeping the skin in good order and therefore promotes health. In grooming, a liberal use of the brush is recommended, and the less of the comb the better. The faces may be sponged over, and subsequently carefully dried, whilst after the brush has been well applied the coat may be well gone over with a hair glove, towel, 


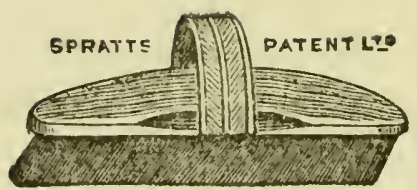

Slanting Bristle Brush.

An excellent brush for removing dead hair and cleansing the skin. It is most useful in the case of wirehaired varieties, the coats of which would be proof against the ordinary brush.

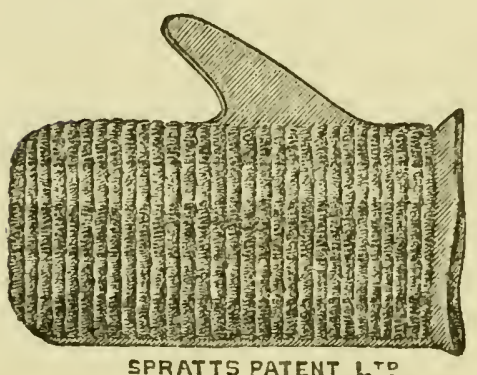

Grooming Glove.

The best design of glove for imparting a gloss to the coats of smooth-haired dogs after"brushing.

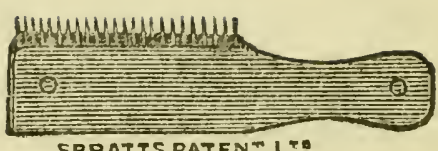

SPRATIS PATEN" LI:

Steel-toothed Comb.

This comb should only be used in cases where a dog's coat has become so hopelessly tangled that it is necessary to remove a considerable portion of it.

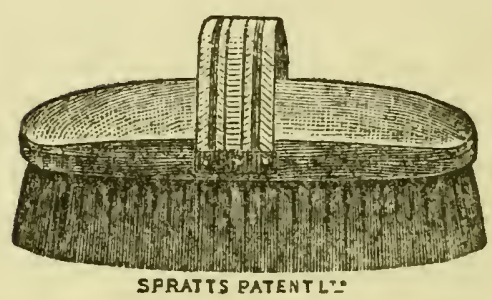

Dandy Brush.

For general 'use when a shortbristled brush is not required. It is also made with whalebone bristles for the purpose of grooming the long-coated breeds.

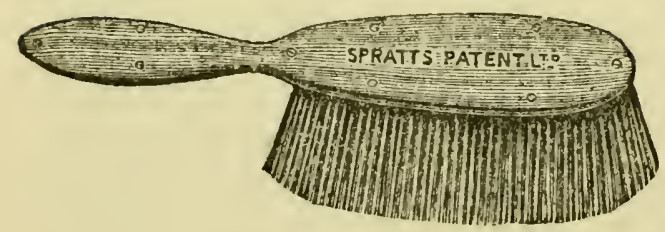

Toy Dog Brush.

The long bristles of this brush assist in producing a brilliant lustre of the coat without injuring the delicate skin beneath it.

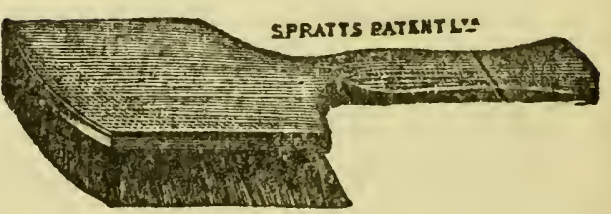

Short-Bristled Brush.

A capital brush for general use in the case of short-haired varieties. 
or chamois leather, rubbing the hair the right way. (See Brushes, Cleansing the Coat, Combs, Preparing for Show.)

Gross Feeders.-Many dogs are great gluttons, and will not only eat far more than is good for them, but will pick up and devour any street garbage they come across if allowed to do so. In the latter case the propensity is often due to a disordered condition of the stomach, which can be cured by a course of medicine, such as Spratt's Alterative Powders; in the former, the owner has it in his power to check the greediness by feeding the dog by itself and only providing it with a proper allowance of food. (See Feeding, Shy Feeder.)

Gruel is one of the best diets for sick dogs which are suffering from diseases which engender a high temperature, and a few basinsful should always be given to a brood bitch after she has whelped. It may be mentioned, however, that oatmeal possesses a tendency to relax the bowels or heat the blood of some dogs if given them regularly, but in most cases they become accustomed to it after a while, and this effect wears off. The gruel should be carefully made with fresh milk, as if it is lumpy or not sufficiently cooked the taste of the raw meal will cause a sick dog to refuse it. It must be given fresh and sweet, as if allowed to stand about too long it will turn sour and cause more harm than good. (See Brood Bitch, Nursing.)

Gun Shy.-A term applied to a dog which bolts at the sound of a gun being fired. It is next to impossible to overcome this feeling of timidity, and a gun-shy dog being useless in the field he is best destroyed, or if good-looking, kept for show purposes. (See Breaking.) 


\section{$\mathrm{H}$}

Hæmorrhoids, which are often mistaken for piles, are not an uncommon form of trouble amongst dogs which suffer from constipation, and especially so in the case of old animals. To obtain relief the bowels should be kept relaxed by proper food, and if constipated an enema may be administered, whilst a soothing ointment should be applied. (See Enema, Piles, Suppositories.)

Handler.-The description by which the professional keepers who take charge of exhibition dogs and show them for their owners are known. (See Exhibiting.)

Hand-rubbing is very useful in assisting to impart polish to a dog's coat after grooming. It also is most efficacious in cases of rheumatism if applied carefully and in the direction the coat naturally lies.

Hard-bitten.-A term used in describing a plucky dog who will accept punishment without flinching.

Hard-haired Scottish Terrier or Diehard.-The above very cumbersome name is used to describe a most valuable breed of terrier, but its adoption has become necessary in order to avoid the absurd mistake into which some English people fall when they refer to this dog as the Aberdeen terrier. As a matter of fact the breed is distributed all over Scotland, and although the dog lovers of the Granite City have possessed some excellent specimens of it, they have never claimed the honour of being regarded as the originators of the variety. On behalf of the hard-haired Scottish terrier it may be claimed that there is no gamer, better-constitutioned, or more devoted companion in the canine world than he, and hence the popularity which 


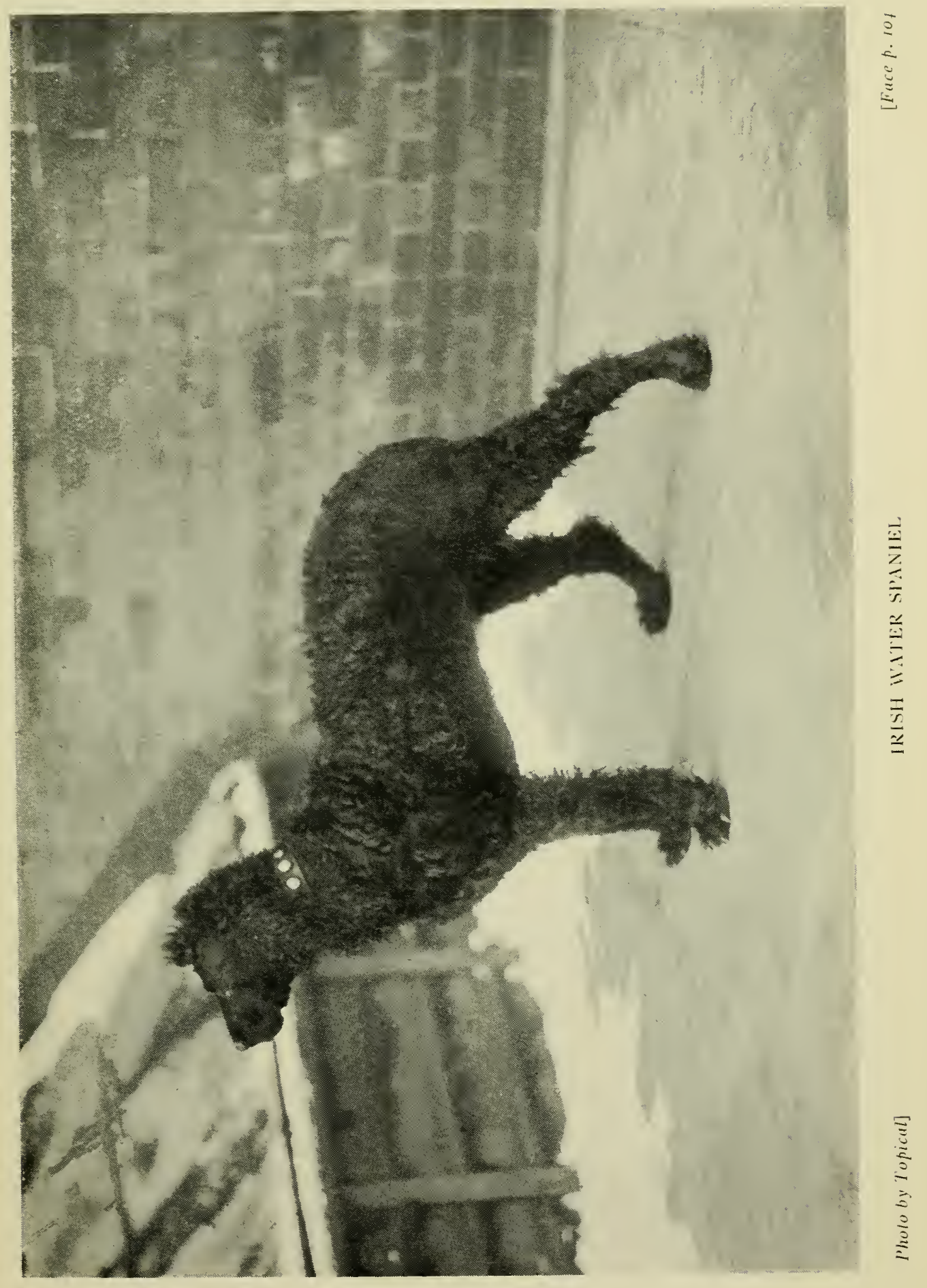



he enjoys is thoroughly justified. Some thirty years ago, however, the breed was very little known in England, and the few specimens which appeared were extremely moderate in quality, and most had huge bat ears, which are (and were) regarded as serious faults by those who understand the points of a diehard. At that time, too, there was a good deal of feeling between the northern and southern breeders of Scotland, but Mr. Vero Shaw was fortunately able to effect a reconciliation by drawing up a scale of points which was acceptable to each party, and this led to the establishment of the Scottish Terrier Club, since which time the breed has never looked back.

The head of the Scottish terrier should be fairly long, a little domed, with a slight drop between the eyes; the powerful muzzle tapering gradually towards the nose, any signs of weakness being a serious fault. The teeth should be large and absolutely level; the eyes small, dark hazel, and very bright; the ears small, pricked, and sharp at the points; the neck short and muscular, and the shoulders fairly sloping; the chest not too wide but deep-if too wide the terrier cannot enter a narrow earth or drain; the body only moderately long-some show specimens have far too much length of back-and well ribbed up at the loin, though the front ribs are not sprung. The fore-legs must be straight and short, very heavy in bone, and set on well under the dog, with fairly large, compact feet, which carry very thick soles; the hind-legs moderately bent; and the tail, which is rather thick and bushy, carried gaily but never curled. The coat should be as hard as pin wire, very dense, and not too long all over the body, excepting on the ears, which are velvety, and the head and muzzle, where the hair is short and close. The best colours are steel-grey and dark brindle, but lighter shades of these are permissible, wheaten, sandy, and black, but white markings should disqualify; the average weight being $\mathrm{I} 8 \mathrm{lbs}$. for a dog and I6 lbs. for a bitch, and specimens of 20 lbs. or over should be disqualified. 
Hardiness.-Some breeds are naturally more hardy than others, and the constitutions of the members of the same variety will always differ; but the fact remains that as a rule the dog which is not pampered and improperly fed in its youth, and which gets plenty of fresh air, exercise, healthy food, and proper housing, is a far more hardy creature than the one which leads a life of luxury. (See Exercise, Feeding, Kennels.)

\section{Hare Foot.-A long, narrow foot. (See Cat Foot.)}

Hare Lip.-An upper lip that is partially split is so described.

Harrier.-Of late years the harrier has approached the foxhound far more closely in conformation than formerly and in fact in some cases it is a very difficult matter to distinguish the two breeds. In days gone by, however, there were special points of distinction between these two varieties of hound, the head of the harrier, as a case in point, being far heavier than that of the foxhound, whilst he was, comparatively speaking, a heavier-built dog and a much slower hunter. The old blue-mottle colour now so seldom seen was likewise a characteristic of the harrier; but it may be added that the type of hound favoured in different countries varied a good deal, as, in fact, it does at the present day. One thing, however, may be claimed for the harrier of the past, and this is, that though he might not have the grace and the galloping powers of the harrier of the present day, he was a great hunter and possessed extraordinary scenting powers.

Haw.-The red inner membrane of the eye, which is shown in the bloodhound, St. Bernard, and some other breeds. It is sometimes referred to as "sealing-wax," which it somewhat resembles. 


\section{HAY-HOLLOW BACK}

Hay is not an ideal form of bedding for dogs, as it soon becomes beaten down when they lie upon it. Besides this, it gets brittle and dusty, and so works its way into the coats. (See Bedding.)

Heat, or œstrum, is the name by which the period during which the bitch is in a condition for breeding purposes is known. (See Breeding, Brood Bitch, Selection of Stud Dog.)

Height.-The height of a dog is measured from the top of the shoulders to the ground by means of a graduated sliding standard, provided with a cross-piece, similar to that employed for measuring horses. It is not always an easy matter to get the animal to stand up properly, but in this matter, as in others, the exercise of patience accomplishes much, and it may be added that the best way to proceed is to stand the dog on a flat surface against a wall.

\section{Hemorrhage. (See Bleeding.)}

Heredity.-There is an undoubted tendency on the part of all varieties of animals to display the characteristics of some ancestor more or less remote, and hence the necessity of studying pedigrees carefully in thinking out crosses.

Hocks. - The middle joint of the hind-legs, between the stifles and the pasterns. (See Corv Hocks.)

Hollow Back, sometimes referred to as a dipped back, is one which drops sharply behind the shoulders and rises slightly at the loins. This formation is usually a sign of weakness, and must not be confounded with a roach or wheel back, which see. 
Horse-flesh is a good food for big dogs as a change, provided it is fresh and comes from a healthy animal. (See Feeding.)

Hospital.-All large kennels of dogs should have a well-ventilated but warm hospital attached, so that sick animals may be isolated from their companions, to the benefit of the latter, and enjoy the comfort of rest and quiet. When possible there should be two hospitalsone (well isolated) for the reception of infectious and contagious cases, the other for accidents and ordinary complaints. These should be divided into compartments and pens, so that each invalid should be by himself and loose, as a sick animal should never be fastened up if it can be avoided. The hospital should also possess means of being being kept warm and well lighted, and a supply of water should be at hand. If it is possible to arrange double doors, so that a current of cold air will not be brought into the place each time the attendant enters, it will be all for the best; and if this can be done, the inner one should have a glass panel in it, so that he can see his patient without disturbing it. In kennels lighted by electricity, if the switch for turning on the light is outside the inner door, the above arrangement will be still further facilitated. There should always be a thermometer in the hospital, so that the temperature can be properly regulated; and all feeding vessels and other articles which are used in it should be kept away from healthy dogs. (See Nursing.)

\section{Housing. (See Kennels.)}

Humours are usually the result of improper feeding, and the best means of curing them is to give the dog plain food and a course of Spratt's Patent Alterative Powders, whilst a dressing of carbolic acid one part and glycerine twenty parts may be applied to the sore places. 
Husk.-A short, harsh cough, which frequently becomes chronic unless attended to, as it should be. It usually is associated with distemper, worms, or indigestion. (See Cough, Distemper, Indigestion, Worms.)

Hybrids.-Canine hybrids are not common, for the simple reason that when produced there is no use for them, and they are not usually prepossessing in appearance. The dog, however, will breed freely with the wolf or jackal, to which he is undoubtedly allied, but not with the fox, in spite of the stories received relating to the existence of such hybrids. The latter are doubtless the result of some impression being made on the imagination of a pregnant bitch by a fox, as no naturalist has been found to substantiate the existence of a dog and fox hybrid. All stories which refer to dog and fox hybrids should be accepted with the strongest suspicion. This hint is rendered necessary by the frequency with which alleged instances have been told of. (See Evolution.)

\section{I}

In-breeding or Sibbing is a fruitful source of constitutional weakness and loss of size amongst dogs, and if carried on too far is therefore a practice to be deprecated. No doubt, however, some of the toy varieties owe their existence to a system of close in-breeding, and to this much of their delicacy is unquestionably due. At the same time in-breeding, if judiciously carried out, is most useful in assisting to fix certain characteristics which belong to a family and which it is desired to retain, and no doubt many strains have benefited by it, the Laverack setter being a case in point, but when it was carried too far the dogs became weaker and lost size. Still, in-breeding is to be recommended when out-crosses are being prepared; but once more the advice may be expressed that caution must be exercised. (See Breeding.) 
Incisors.-The middle front teeth situated between the canines. (See Teeth.)

Indigestion is a trouble to which many dogs are subject, the chief causes being improper feeding, bad teeth, and want of exercise. It is usually associated with loss of appetite, considerable thirst, bad-smelling breath, and flatulency, and sometimes with a husky cough, vomiting, and looseness of the bowels. A dose of opening medicine to clear away intestinal obstructions may be given, and this should be followed by a light diet of digestible food, such as Spratt's biscuits, broken up very small and boiled in milk, whilst if there is much flatulency green vegetables should not be given for a week or so. A small quantity of charcoal in the food may also prove beneficial, and the dog should be left quiet if the attack is a severe one. (See Feeding.)

Infectious Diseases are those which can be communicated from one dog to another without the two animals coming into contact. (See Contagious Diseases.)

Inflammation of the Bowels. (See Enteritis.)

Inflammation of the Lungs. (See Pneumonia.)

Inflammation of the Stomach. (See Gastritis.)

Injections are frequently the means of saving a valuable dog's life in cases of severe obstruction of the bowels. (See Enema.)

Inoculation.-Opinions differ somewhat regarding the value of inoculation against distemper, but there can be little reason to doubt that the advocates of the practice are fewer than formerly, as the balance of the experiments which have been made has not been favourable. (See Distemper.) 
Insects.-The coats of dogs naturally provide attractive harbours for insects in general and fleas in particular. The latter form of pest is unavoidable, as a dog which is kept under the very best conditions as regards cleanliness is always liable to be attacked by them when out of doors. (See Fleas, Lice, Ticks.)

Irish Setter. - This very elegantly built, attractive member of the setter family has increased a good deal in popularity during the past few years, and it is quite safe to offer the opinion that there are now more good specimens of the breed to be found than was formerly the case. It is certainly a more recent production than either the English setter or the Gordon, but its origin is unascertainable, and all that can be said about the Irish setter in that respect is that the breed was doubtless in existence some eighty years ago or thereabouts. Since that comparatively remote period the improvement of the Irish setter has been the object of many breeders, the result being that sortiness has increased. As a field-dog the Irish setter excels in pace and possesses a very good nose, but he is apt to be hot-headed and flush birds, so if not kept under control he may upset the steadiness of other dogs working with him. Still, with all his faults, he is a wonderfully good dog on game, and perhaps no greater tribute to his worth has ever been paid than the statement made by the late Mr. Edmund Laverack to a friend, that he contemplated introducing a cross of Irish blood into the famous breed of English setter which bears his name.

The head of the Irish setter is long and lean, rather domed at the top, the occipital protuberance being well developed, and showing a slight stop between the eyes. The muzzle is long and beautifully chiselled; the nose, which is large, projecting somewhat, and being of a darkbrown colour; whilst the eyes, which are rather inclined to be small, are a brownish-hazel; and the ears, which are set on low, should be fine and hang close to the sides

\section{I I}


of the head. The neck is long, muscular, and very graceful, with no lumber about it; it is slightly arched, and neatly set on to long, sloping shoulders. The chest is rather narrow, but very deep; the body being of a good length, with nicely-sprung ribs and powerful loins, which are just a little arched. The fore-legs are of a good length, dead straight, well under the dog, and heavy in bone, the hind ones being well bent at the stifle and hocks, so as to ensure pace; the tail being well feathered and carried almost straight. The coat is rather long, fine in texture, and flat; it is shorter on the head, and there is a nice silky feather on the legs and ears. The accepted colour is a rich chestnut, a little white on the forehead, chest, or toes being permissible, though it is not liked. The average weight is about 65 lbs.

Irish Terrier.-A generation or so ago the Irish terrier was often contemptuously referred to as the tinker's dog, now his admirers claim for him the sobriquet of daredevil, and his popularity is scarcely inferior to that of the fox and Scottish terriers. Doubtless much of the success of the breed is due to the energy of his friends, conspicuous amongst whom was the late Mr. William Graham of Belfast; but there was good material for them to work upon, as the Irish terrier is a game, companionable, handsome dog, and those who once take up the breed very rarely transfer their patronage to other varieties.

The head of the Irish terrier is long, rather narrow between the ears and flat, tapering gradually towards the nose; the muzzle being very punishing, and the teeth quite level. The nose is black; the eyes rather small, dark hazel, and bright; and the ears small, V-shaped, and carried with the tips forward, but never cropped, as was formerly the custom. The neck is rather long, and quite free from any superfluous loose skin; the shoulders long and sloping; and the chest of moderate breadth, but deep. The body is of fair length, but not too long, the back straight, and 
the loins powerful; the fore-legs being rather long, dead straight, and heavy in bone, with round, compact feet, the hind-legs being long from the stifles to the hocks; whilst the tail, which is always docked, should be carried high. The coat must be hard, wiry, and flat, the best colours being bright red, red, wheaten, and yellow-red, a little white sometimes appearing on the chest or feet, but it is much disliked. The best weight for dogs is 24 lbs., and for bitches, 22 lbs.

Irish Water Spaniel.-Thanks to the efforts of the members of the club which has been established in its interests, the position of the Irish water spaniel is far better than it was a few years ago. Still the breed, picturesque looking and valuable as a water dog though it be, is not widely bred; and the future before it does not appear to be exceptionally bright, as for some unascertainable reason the dog-loving public do not seem to take very kindly to this most useful, engaging, and intelligent member of the canine race, which is an invaluable field-dog and a very tender-mouthed retriever of wounded game. Very probably the poodle had a good deal to do with the production of the Irish spaniel, which in turn was doubtless concerned in the establishment of the curly-coated retriever; but the precise sources from which it sprang cannot be traced, and it is therefore sufficient to say that the breed has existed for many years.

The head is rather large and rounded, the forehead being prominent, and the muzzle long and square. The eyes are dark brown in colour; the ears very long, set low, and carried against the sides of the head; whilst the neck is long and muscular; the shoulders long, sloping, and strong; the chest not too wide, but deep; the body powerful, with well-sprung ribs, and muscular, slightly arched loins. The fore-legs are long, straight, and very heavy in bone, the feet being large and thickly clothed with hair; the hind-legs being rather bent at the stifles; 
and the tail short, thick at the root, tapering, and covered with short hair. The coat is one series of short, crisp curls, varying in size on different parts of the body and limbs, the face being smooth; whilst on the head there should be a characteristic top-knot. The only recognised colour is a rich, deep liver without any white, and the average weight is about 40 lbs. (See Curly-coated Retriever.)

Irish Wolf-hound.-Beyond all doubt the genuine Irish wolf-hound is a thing of the past, as the modern dog which masquerades as such is admittedly a cross between the Scottish deer-hound and German great Dane, and it has been produced within the last thirty years or thereabouts. There can, however, be no doubt that the gigantic proportions and picturesque appearance of these dogs appeal very strongly to many persons, and provided that they do not take too much after their Teutonic progenitors about their heads, as some unfortunately do, they are very handsome dogs; though why they should be called Irish wolfhounds is not very clear, as they certainly are not Irish, having been manufactured in England, nor have they ever been used for hunting wolves.

The head of this dog is long, rather narrow for the size of the breed, slightly prominent at the brows, and tapering towards the nose, the muzzle being long and inclined to be pointed. The eyes are dark hazel in colour; the ears small, and carried with the tips thrown backwards, so as to display the burr; the neck being long, clean, muscular, and arched, whilst the shoulders are laid back. The chest is both wide and deep; the back strong, and arched at the loins, which are muscular, though a little tucked up; the fore-legs being of a good length, quite straight, and very heavy in bone, with moderately large feet, the hind-legs carrying a good deal of muscle on the thighs; whilst the hocks are well let down and rather straight; the tail being long, rather coarse, and carried in a slight curve. The 
coat is of a good length and hard, the chief colours being grey, brindle, and fawn, though reds, whites, and even blacks are to be met with. The minimum weight of a dog sh suld not be less than $\mathrm{r} 20$ lbs., and of a bitch $90 \mathrm{lbs}$; whilst the respective heights should be at least 3 I and 28 inches. (See Deerhound, Great Dane.)

Italian Greyhound.-As its name suggests, this most elegant, though delicate, little dog is a native of Italy, but it has become well established in this country; though its admirers are fewer in numbers than formerly, owing to many breeders of toy dogs having transferred their affections to foreign breeds.

The head of the Italian greyhound is long, narrow, and flat on the top; the muzzle being very delicate; the eyes large, but not goggle, and usually of a hazel shade; the ears set well back, and carried with the tips thrown backwards; the neck long and arched; and the shoulders sloping. The chest is narrow, but very deep; the back arched; the ribs nicely sprung, and the loins rather tucked up; whilst the fore-legs are long and straight, with long feet, the hind ones being bent at the stifle, and well let down at the hocks; and the tail long, fine, and carried low. The coat is short and fine, all greyhound colours being recognised, though the most popular is a golden fawn; whilst white markings are objected to, though permissible. The average weight is about $8 \mathrm{lbs}$.

\section{$\mathrm{J}$}

Jacks.-The instrument-a sort of vice-which was used in days gone by to hold in position the noses of bulldogs which had been forced back after the lip-string had been severed. The object of all this was to develop an artificial shortness of face, and it need scarcely be added that it was illegal as it was cruel. (See Faking, Lay Back.) 
Japanese Spaniel:- The importation into this country of numbers of these engaging and attractive little dogs a few years ago was hailed with enthusiasm by the majority of those who are interested in the fortunes of the toy varieties. As a result, the Japanese spaniel has been largely bred in England, and possibly to its advantage, as the puppies reared here are for the most part less delicate than those which were imported. At the same time, the showy little Jap is not a dog of robust constitution, and he is somewhat liable to fits, as indeed are all toy spaniels after they attain a certain age. Perhaps the chief reason for regret that he has appeared amongst us in such large numbers is that some breeders, inspired by an insane thirst for what they term "improvement," have been silly enough to perpetuate a cross of Japanese and the English varieties, to the detriment of both, as differences exist between them, and very undesirable traces of the cross have developed in subsequent generations.

The head of the Japanese spaniel is large, broad, and rounder in front than at the back; the muzzle short, wide, and broad at the nose, which is black, excepting in the case of the red and white specimens, when it is sometimes of a dark liver shade. The eyes are not so full as those of the English varieties of toy spaniel, and darker in colour; whilst the ears, which are set up wide apart on the corners of the head, are small, $\mathrm{V}$-shaped, and carried with the tips pointing forward. The neck is short and thick, the chest wide, and the body short, square-looking, and compact ; whilst the fore-legs, which must be straight, appear to be shorter than they really are because of the wealth of feather they carry, as do the feet. The coat is profuse and flat, covering all the parts of the body, but on the head and muzzle it is short; and the tail, which is curled over the back, is very heavily feathered. The recognised colours are black and white, and red and white, the former being the more common and the better liked; and the average weight is about $7 \mathrm{lbs}$. 
Jaundice, or Yellows, is due to an accumulation of bile in the blood, which may be caused by a chill, improper feeding, or even by chronic constipation. The symptoms are unmistakable, as in addition to loss of appetite, a disinclination to move, and other common indications of liver trouble, there is a yellow appearance of the eyes and lips, and often a paleness of the motions to betoken the existence of jaundice. The patient should be kept warm and dry, and carefully dieted upon plain food. Calomel enters largely into the treatment of the disease, which is not an easy one to deal with, as cases differ widely. A reference is therefore recommended to Mr. A. J. Sewell's work, "The Dog's Medical Dictionary," published by George Routledge \& Sons.

Joints.-The possession of a good set of joints is a matter of importance in the case of most breeds, as no matter how good-looking an animal may be he is useless - unless he be a Dandie Dinmont, Basset hound or Dachshund-if he has not got a straight set of legs to carry his head and body. As a rule the joints of the heavier breeds give far more trouble than those of the lighter ones, owing to the strain which is put upon the limbs of immature puppies by the weight of the body; hence the larger proportion of cow-hocks, twisted pasterns, and cases of out-at-elbow which are found amongst big dogs. Good wholesome food and a sufficiency of slow exercise are the best safeguards against joint troubles, as weakness naturally disposes a dog to develop such. Parrishes' Food is often found a useful adjunct to the above, but mechanical appliances, such as irons or starch bandages, which have been resorted to by owners in sheer desperation, have not usually produced beneficial results. The best thing, therefore, to do is to bear in mind the old adage"Prevention is better than cure," and to endeavour to provide against crooked joints by attending to the puppies carefully and managing the dogs properly all through their 
careers. (See Cow-hocks, Exercising, Feeding, Pasterns, Stifles.)

Journeys.-A good deal might be written on the subject of dogs on their journeys, as the absurd solicitude displayed by some owners for the comfort of their pets is only equalled by the reckless carelessness on the part of others. Between these two extremes there is a great gulf fixed, and as in most other things in this world, the middle course is the best and wisest to adopt. Hence it may be briefly laid down that a dog which is being sent on a journey by rail is usually better off if conveyed in a basket or box, if his size will permit of this, than if he is merely secured by a chain, and if the weather is cold he should be clothed. Under all circumstances, however, he should have a chain attached to the collar, and the latter should be buckled tight enough to prevent his slipping it over his head, but not so tight as to cause him inconvenience. A chain is preferable to a leather lead, as the traveller cannot gnaw it through; it should possess three swivels-one at each end and one in the middle - and when the dog is placed in the box the end not attached to the collar is best left loose, as if it is hooked on to the side of the basket the dog may possibly get hung up, through the straw which is given him to lie upon becoming twisted up in the chain. Under all circumstances a parchment luggage label with an eye at each end should be attached to the collar in such a way that the dog cannot get at it to gnaw; and this should show the address to which the animal is being sent, and also the name and address of the owner on the reverse side, as dogs often succeed in escaping in spite of all precautions to the contrary. If the dog is not despatched in a basket, he should be given into the charge of the guard, and it may be added that a shilling bestowed upon the latter is usually money very well laid out. Some companies provide excellent I 8 
dog boxes in the corners of their luggage vans for the accommodation of canine travellers, and these should always be utilised if possible; for no matter how careful a guard may be, there is always a chance of luggage falling upon the dog if he is chained up in the van. Unless the journey is a very long one it is best, for

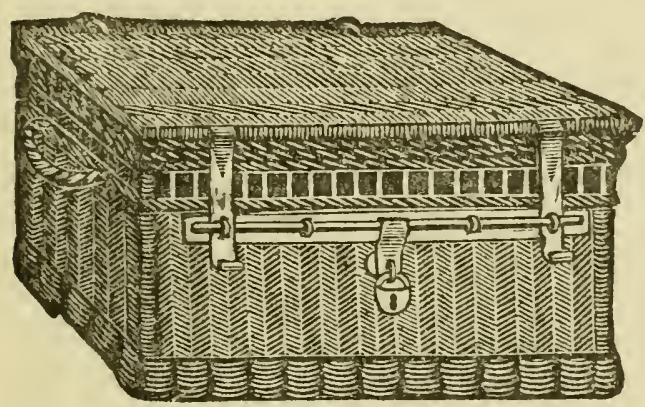

Travelling Basket.

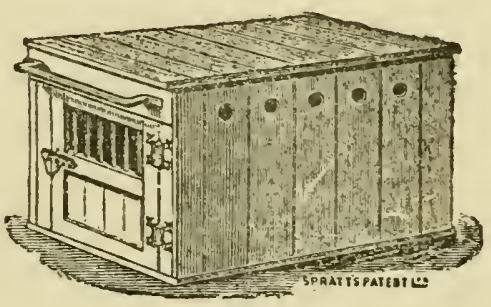

Travelling Box.

obvious reasons, not to give the dog food or water just before he starts, and an opportunity should be given him to relieve himself at the last moment, and if possible at any stopping places on the road. The accompanying designs represent a thoroughly good basket and box for the use of dogs on their journeys. (See Dog-Basket, DogBox, Chains, Clothing, Lead.)

\section{$\mathrm{K}$}

Kennel Lameness, or Founder, is the result of exposure to cold and wet, and is in reality a form of rheumatism which attacks the shoulders. At times it causes great pain, and when the attack is on the joints affected become stiff. The application of some counterirritant in the form of a liniment will often bring relief, but if kennel lameness is permitted to become established it is incurable. (See Counter-Irritants, Liniments.) 
Kennel Man.-A good kennel man is a most valuable person, a bad one is a constant source of embarrassment to his master and a danger to his charges. Unfortunately, however, many dog-owners are completely under the influence of their servants, who affect airs, and act in a manner not at all in accordance with the positions they should hold. A hard-working, honest, sober man, even if he may not possess an extensive knowledge of the breed he is called upon to look after, is therefore far more valuable to his employer than one who deputes his duties to a subordinate and apes the manners of his superiors; for the former is always willing to learn, whereas the latter, who is not infrequently as ignorant as a man can be, is perfectly hopeless in that respect, and cannot be relied upon to carry out the orders of his master. Above all things, the kennel man who possesses a penchant for dosing his charges is a man to be avoided. (See Breeding, Exhibiting, Preparing for Show.)

Kennels.-Whatever breed of dog is kept one thing is absolutely necessary, and this is, that proper accommodation is provided for sleeping purposes. Of course we all know that a dog can sleep anywhere-in fact many do - but if health, strength, condition, and a capacity for work are sought for in him, the owner who supplies him with a damp or draughty kennel will surely be disappointed in the long run. Kennels, of course, vary immensely in design, and many of such designs are admirably adapted to the purposes to which they are devoted; but, on the contrary, some of themand these are not necessarily the least expensive-are veritable death-traps for the dogs which inhabit them. It would, for instance, be hard to imagine a more inappropriate shelter for a dog or any other animal than the old-fashioned kennel, with an aperture for ingress and egress which occupies almost the whole of the front. Such a den allows the cold winds and rain to beat upon 


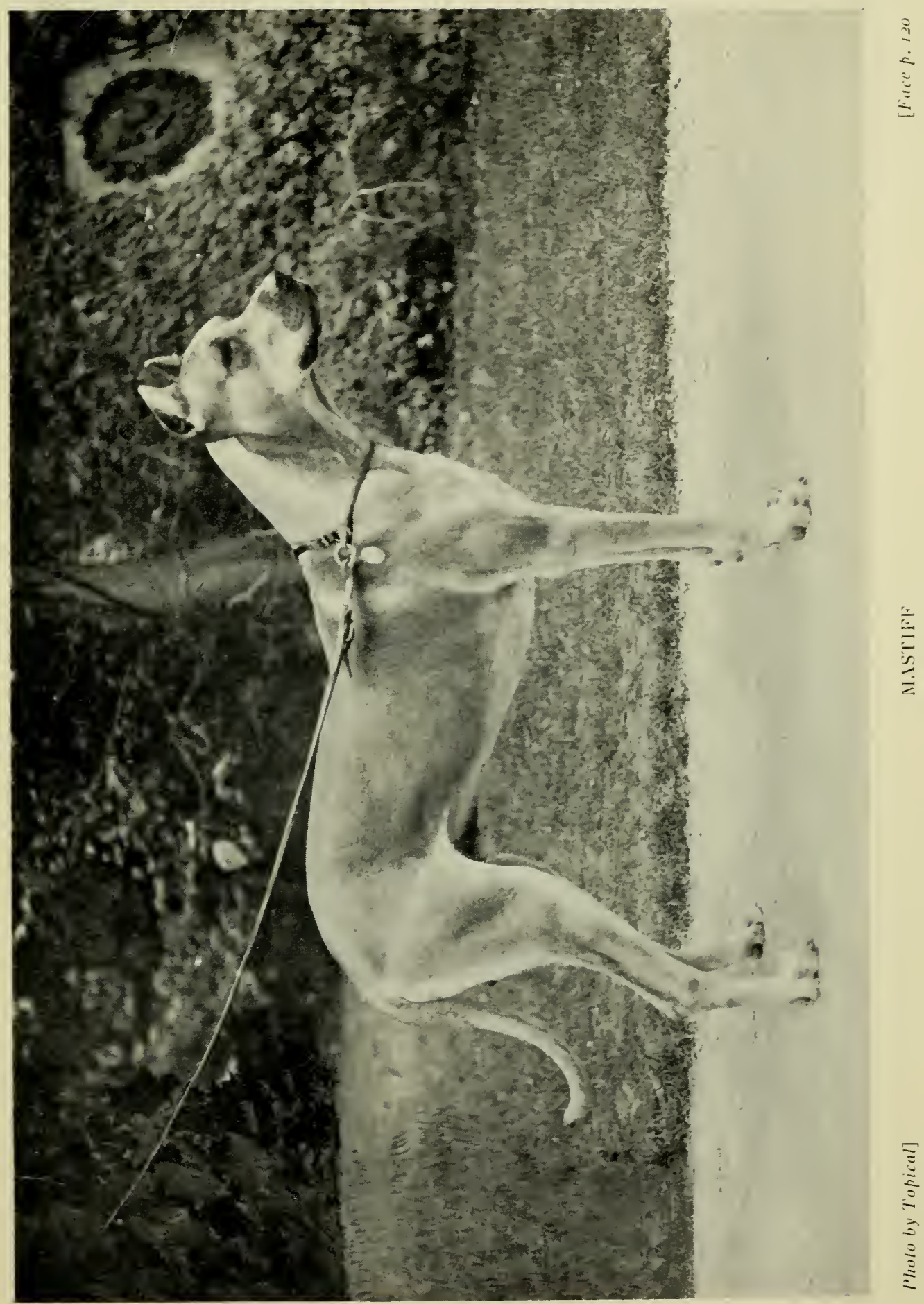





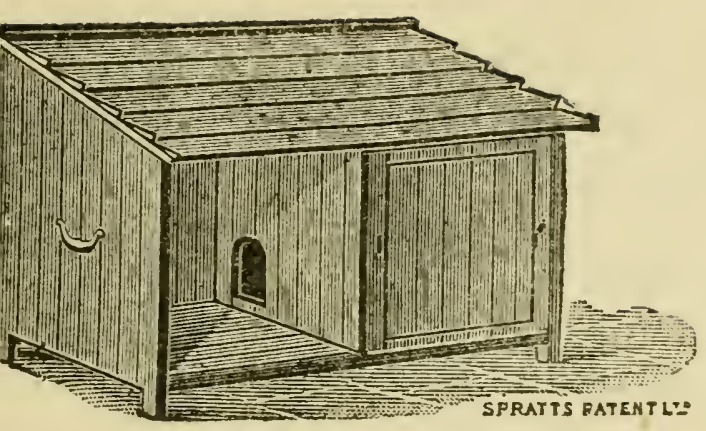

Portable Kennel, with Covered-in Bench. A first-rate design for use in winter.

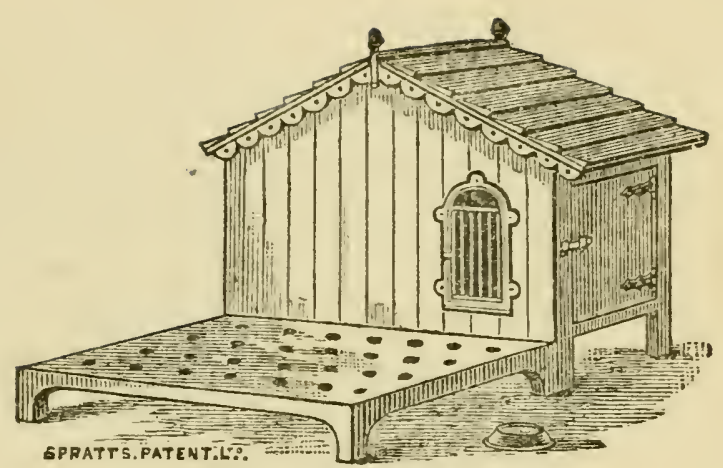

Portable Kennel, with Bench.

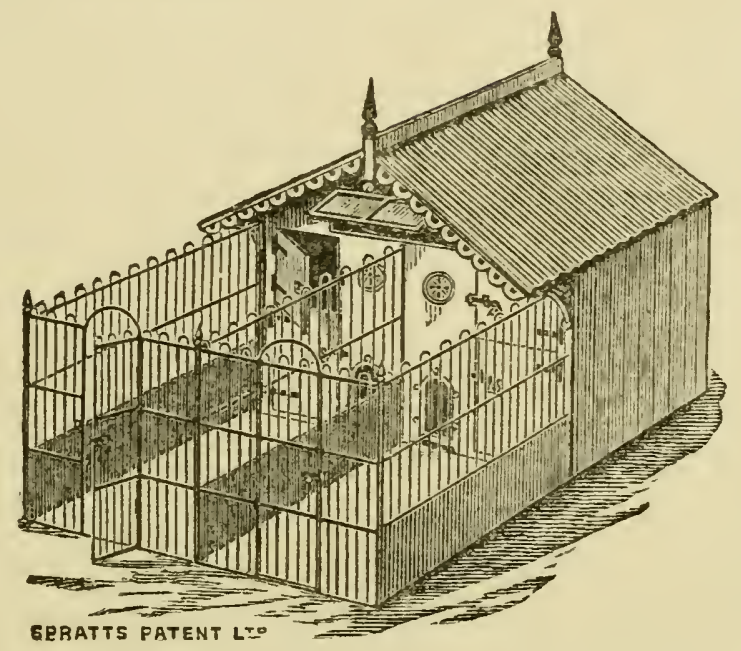

Span Roof Double Kennel, with Yard.

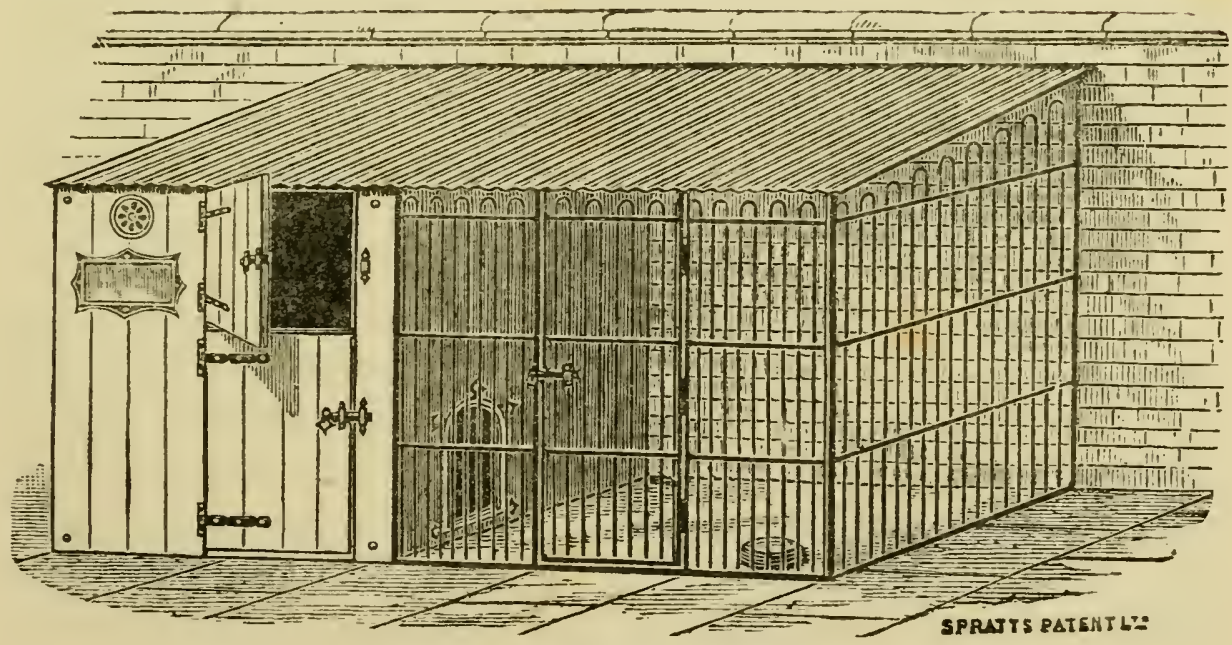

Lean-to Kennel and Covered Yard. 
its inmate, and is practically no shelter at all; whereas it would be quite a different affair were the entrance to be at one side near the end, so that the dog can escape the fury of the elements. The best sort of kennel for the average dog lover who keeps one or two animals is one or other of the portable designs, which are tenants' fixtures, and if purchased of a good firm, possessed of a reputation to lose, will often be worth as much as was originally given for them after being in use for years. A dry shed in the garden or yard is often capable of conversion into an excellent kennel; but if it happens to be of the "lean-to" order, and a wall forms one side of it, it often happens that it is damp, as the brickwork holds the moisture, and therefore in such cases the wall part of the shed should be covered by match-boarding to keep the place dry.

It is always desirable that there should be a yard attached to the kennel or shed, in which the dogs can obtain the fresh air and sunshine that is so essential to their health, as it is never good to keep them chained up for longer than is necessary. The questions of ventilation, draining, and suchlike matters, are all of the utmost importance, and therefore should be most carefully attended to, as it cannot be too strongly impressed upon the doglover that a dry, comfortable kennel which is free from draughts, though properly ventilated and capable of being kept clean, is absolutely necessary if the animal is to be kept in health. (See Benches, Fencing, Floors, Roofs, Ventilation.)

King Charles Spaniel.-This breed is the oldest and, in the opinion of many people, the most delightful of all the varieties of toy spaniels. At all events the Merry Monarch has earned the gratitude of modern dog-lovers for having popularised so charming a breed, which has been eulogised by every writer upon canine subjects. As far back as the reign of Queen Elizabeth Dr. Caius referred 
in high terms to the variety of spaniel known as fotor or comforter, which was used by the medical men of the period for drawing the fever out of their patients by lying on the breasts of the latter! Although the latter-day lovers of the King Charles claim no such ridiculous powers for their favourites, the fact remains that there is no more engaging or beautiful variety of $\mathrm{dog}$ in existence, and if not coddled up and overfed, the breed is a very hardy onein fact, cases have been known of King Charles having been employed in beating hedgerows for game with complete success. No doubt the original King Charles possessed white markings, as the first advertisement for the recovery of a lost dog, which dates back to the reign of the Merry Monarch, refers to a black and white spaniel, "the property of His Majesty the King," which was lost in the Green Park. Hogarth's paintings also support the above statement as regards colour, but until some thirty years ago the vast majority of the King Charles spaniels which were met with were black-and-tans. The first really good specimen of the tricolour that was shown about that time was Conrad, the property of Miss Violet Cameron, and the same lady exhibited a red bitch named Clare with considerable success. Both these colours have always been recognised as belonging to the King Charlesindeed the reds were utilised many years ago for crossing with the black-and-tans, in order to improve the richness of their tan markings. Consequently, many old breeders deeply resented the action of some modern exhibitors of toy spaniels, who subdivided the breed now under consideration into King Charles, which were the black-and-tans; Prince Charles, which were the tricolours; and Rubies, which were the reds. Of course this was an absolutely ridiculous and indefensible action, and therefore there is some satisfaction in adding that the name Prince Charles has been abandoned, but that of Ruby remains as a testimony to the folly of some modern breeders.

The general appearance and shape of the King Charles 
spaniel is so similar to that of the Blenheim that the description given of the latter breed may be referred to as in the main applying to the former. The King Charles, however, is a more substantially built dog, and the hair on its ears is usually longer. (See Blenheim Spaniel.)

Kissing Spots.-The name by which the bright tan spots on the cheeks of black-and-tan terriers are known. (See Black-and-Tan Terrier.)

\section{L}

Labrador Dog.-It is surprising that this very valuable breed of sporting dog is not better known and appreciated than he is, for he has been bred in this country for nearly a hundred years; and in addition to his exceptional merits as a retriever he is one of the very best water dogs in existence, and a most intelligent and valuable companion. Many people, however, confound him with the Newfoundland, and others with the flat-coated retriever; but it is incorrect to do so, for the Labrador is a distinct breed, and what is more, a very valuable one indeed for all sportsmen who use the gun.

The head is long and flat; the muzzle being square and of a good length; the eyes rather small, dark in colour, and set well apart; whilst the ears, which are set on high, are of a good size, and carried flat to the sides of the head. The neck is longer than it appears to be, as its substance conveys an erroneous impression of shortness; the shoulders slope nicely, and the chest is fairly wide and deep. The back is rather long, the loins powerful, and the fore-legs straight and heavy in bone; the feet being round, compact, and large. Powerful hind-quarters and muscular thighs are characteristics of this breed, the tail of which is stout, of good length, straight, free from feather, and carried low. The outer coat is short, flat, and dense, the under one soft 
and sealskin-like; whilst the only recognised colour is a rich jet-black. The average height is about $2 \mathrm{I}$ inches, and the weight $60 \mathrm{lbs}$.

Lameness attacks many dogs without any tangible reason being forthcoming for its appearance, and in such cases it is very often the result of rheumatism, the seat of which may be hard to locate. If the foot has been cut or pierced by a thorn, inflammation and lameness may supervene if the wound is not attended to in time; hence it is a wise precaution to examine the feet and legs of dogs when they come in from exercise, and if a cut or thorn is discovered to thoroughly cleanse the place-after extracting the thorn with a pair of pincers-and then to apply some healing dressing of a non-poisonous nature. Locurium, a liquid only supplied by Spratt's Patent, being a first-rate thing to use. (See Rheumatism.)

\section{Landseer Newfoundland. (See Newfoundland.)}

Laryngitis, or inflammation of the larynx, is often a result of cold, the chief symptoms being a nasty dry cough, hoarseness if the dog barks, a difficulty in breathing, and frequent retching. If not attended to in time, laryngitis may develop serious symptoms and cause the patient its life, and as it is highly contagious the animal should be isolated. Should there be much pain in the region of the throat hot linseed poultices should be applied, and an emetic will often provide temporary relief. For subsequent treatment "The Dog's Medical Dictionary" (George Routledge \& Sons) should be consulted. (See Nursing.)

Laverack Setter.-A breed of English setter made famous some fifty years ago by the late Mr. Edward Laverack of Whitchurch, Salop, from whom it derives its name. (See English Setter.) 
Lay Back.-When the nose recedes and the lower jaw turns upwards, as in the case of the bulldog, the formation is referred to as lay back.

Leading Dogs.-More art is required to lead a dog in such a manner that he will show himself off to the best advantage than some people may imagine; and it is always difficult to get a puppy to trot beside one when he is being led. Patience and the exercise of a little firmness are, however, sure to triumph in the end; but it is the worst possible policy to hit or scold a dog that hangs behind when he is on the lead or slip. Coax him and he will soon understand what is required of him, and above all things be careful not to tread upon his foot, else he may be lamed for days to come. In very obstinate cases the experiment of coupling the offender to a dog that leads well may be attempted with satisfactory results. (See Couples.)

Leather.- The term applied to the solid flap of the ear to distinguish it from the hair or fringe upon the tip.

Leathers.-Chamois leathers are useful in imparting the desired gloss and smoothness to the coats of shorthaired dogs after they are brushed and dressed. (See Grooming, Preparing for Show.)

Leads. (See Slips.)

Lean Head.-A graceful, well-proportioned head which is free from coarseness is thus described. (See Chunky Head.)

Leonberg Dog.-A variety somewhat of the St. Bernard type, but smaller and less majestic-looking, which has admirers in some parts of Germany. It is usually of a yellowish colour and free from white, and undoubtedly has 
been crossed by some breeders with the St. Bernard, to the detriment of the latter.

Level Mouth.-A dog is said to have a level mouth when the upper and lower front teeth meet without one row projecting in front of the other. (See Overhung, Underhung.)

Lice.-Sometimes dogs which are not kept clean, or which come into contact with affected animals, are attacked by these most offensive insects. If the dog is a strong animal, a dressing or two of paraffin will usually accomplish their extermination. White precipitate powder dusted into the coats is a certain exterminator of lice, but it is a most dangerous remedy, being a deadly poison, whilst it is capable of being absorbed into the system if the coat becomes wet. Its use therefore is not recommended, excepting under very exceptional circumstances, when the utmost care must be taken. The dog should be effectively muzzled and kept absolutely dry for a few hours, after which the powder must be thoroughly brushed out of the coat with a dry brush and destroyed. On no account should the coat be wetted whilst any powder is on it.

Licences.-All persons who keep dogs are required to take out a licence at the cost of $7 \mathrm{~s}$. $6 \mathrm{~d}$. for each animal. Such licences are transferable from one animal to another, which means that if the owner sells his dog he can buy another one, and the licence may be used for it. It is a mistake, however, to imagine that the licence can be handed over to the purchaser of a dog with the animal, and that the possession of it will release him from the obligation of taking out a licence to keep a dog himself. Indeed, it has been decided that a professional handler who keeps dogs belonging to other persons on his premises as boarders is bound to take out a licence for each animal, and that the fact that the owner of the dog has sent him the licence 
he holds is not sufficient. Whether this is good enough law to run the gauntlet of the Court of Appeal is a matter of opinion, and happily the police in most districts are considerate enough not to prosecute a man who has another person's dogs under his care if the owner holds licences to keep them and has sent them with the dogs. On the other hand, it may be pointed out that the licence specifically states that the person named on it may keep a dog, and it may therefore be a question of opinion whether the privilege is extended to another person who may keep the animal. If so, there can be no doubt that there would be a good deal of trafficking in licences on the part of people who have taken them out and who could sell or lend them to others who own dogs, but had omitted to conform to the law. Licences, according to law, expire on December 3ist in each year, but a month's latitude is usually allowed to renew them in.

Light.-All sheds in which dogs are confined should be lighted, but if the windows are low enough down to enable the dogs to reach, the precaution should be taken to protect them with strong wire-netting.

Liniments are a form of counter-irritant which is most useful in cases of rheumatism, bruises, or sprains, but reasonable care should be exercised in applying them, as the skins of some dogs are more sensitive than others; and if the bruise happens to be broken, an application of a soothing nature and not a counter-irritant is required. The ordinary soap liniment and Elliman's Embrocation are both excellent things to keep ready at hand in the kennel. (See Counter-Irritants, Rheumatism, Sprains.)

Linseed is a very valuable constituent of poultices which are applied to reduce inflammation either in cases of bronchitis, pneumonia, and kindred attacks. It is not, however, a material that can be given to dogs as food, 
but in the form of oil it can be used as an enema. (See Enemas, Poultices.)

Losing Flesh.-When a dog is found to be losing flesh it is necessary to discover the cause without delay, as it is often the precursor of serious trouble. If it is proved to be simply due to debility, which causes a loss of appetite, the diet should be strengthened and food given to the dog daily in smaller quantities and more frequently; indeed, it may be necessary to tempt him by offering him pieces from the hand. Of course tonics must be given to stimulate the appetite, and the advantages of fresh air and gentle exercise must not be forgotten. A tempting food which attracts many dogs consists of sheep's windpipes, slowly boiled until they are soft, chopped up very small, and mixed in a little pearl-barley which has been boiled with them, and some of the broth. To this a few currants can be added before placing it before the dog; and it may be added that, unlikely as it may appear, a very small quantity of dry curry powder will attract some animals, but only a few grains should be given. (See Debility, Indigestion, Shy Feeder, Tonics.

\section{M}

Made Up.-A dog is said to be "made up" when he is fully developed. (See Furnished.)

Mahogany Tan.-The rich dark shade of tan, such as is characteristic of the markings of the Gordon setter and black-and-tan terrier.

Maize in the form of meal is not a good food for dogs, even if they can be got to eat it, which is not always the case. It is both fattening and heating, and therefore should be avoided. 
Maltese Dog.-For some reason best known to themselves many people persist in calling the delicate little Maltese dog a terrier, whereas he is nothing of the kind, but a fragile member of the toy family, which would no more think of going to ground than a terrier does of flying. Whether the island of Malta is really entitled to the honour of being regarded as the birthplace of the breed is not certain, but there can be no doubt that the variety has enjoyed the prefix Maltese for very many years.

The head of the Maltese dog is fairly wide, and the muzzle is rather short and substantial for the size of the dog. The eyes are almost black; the ears fairly long and set on low; the chest being narrow, the back short, and the body well ribbed up. The legs are short, and the bushy tail is carried well over the back; the coat being long, silky, and quite free of curl, whilst the colour must be pure white. The average weight is about $7 \mathrm{lbs}$.

\section{Manchester Terrier. (See Black-and-Tan Terrier.)}

Mange.-It is the custom of many people to describe any breaking out of the skin of dogs as mange, but this is wholly incorrect, and as a matter of fact mange exists in more than one form, differing totally from each other.

COMMON, or SARCOPTIC, MANGE is, comparatively speaking, an easy disease to cure ; but it is very contagious, and in addition to being carried from dog to dog is capable of being communicated to man, so persons having dogs afflicted by it should be extremely careful in handling them. It takes the form of a number of very small pimples, which discharge a fluid. Violent irritation follows, and the dog scratches himself until he causes sores to form, which when they dry up leave bare places where they have been. The cause of this form of mange is an insect which forces its way under the skin, and the dog will not be cured until these insects are killed, the head, or the parts just inside the forearms, being the places 
usually first attacked. Spratt's Patent dispense a very effective cure for this form of mange, but if the owner desires to treat his dog himself, he may try the effects of a dressing of flowers of sulphur 8 ounces, oil of turpentine and oil of tar each $\frac{1}{2}$ ounce, olive-oil 2 quarts, which will possibly lead to good results.

Follicular MANGE is most difficult to cure, as it continues to break out long after it is believed to have been driven out of the dog, and in many cases the patient either dies or has to be destroyed. Its chief victims are young dogs, but adults are not exempt, and its existence can be detected by the hair coming off in patches, which leave the skin dark in colour and upon which pimples form, which if not promptly dealt with become very painful sores. These may be dressed with zinc ointment, but follicular mange is a disease which taxes the ability of even the most skilful veterinary surgeon, and hence owners who have dogs affected by it will do well to consult Mr. A. J. Sewell's "Dog's Medical Dictionary" (George Routledge and Sons), in which the subject is very ably and exhaustively dealt with. (See Red Mange.)

Mask.-A term applied to the muzzles of some breeds, such as the mastiff, when the colour is referred to.

Mastiff.-Of late years this good old English breed, which doubtless shares a common ancestry with the bulldog, and which was highly prized by our forefathers, has sadly fallen off in repute amongst dog-fanciers. That his loss of popularity is mainly due to the patronage that has been bestowed upon such foreign varieties as the St. Bernard and great Dane is a fact beyond contradiction. But in spite of the apathy of the public, the efforts of the few staunch supporters which still remain true to the mastiff have been successful in producing some very fine specimens in recent years; so if Britons should ever return to their allegiance, the complete resuscitation of the mastiff 
would not be difficult to ensure. The breed, moreover, in addition to the possession of a most majestic appearance, is fully entitled to claim the distinction of being the best and most reliable watch-dog of all the large varieties, and as such is surely worth preserving.

The head of the mastiff is broad, flat, of a good length, showing a stop, and rather raised at the brows; the muzzle being short, powerful, and square. The jaws are not always level, but if they are, so much the better; the eyes are small, set wide apart, and of a dark hazel colour; the ears being set on high and wide apart, they are fine in texture, and hang flat to the sides of the head. The neck is long, rather arched, and carries a dewlap; the shoulders are sloping and muscular; whilst the chest is both wide and deep, and the ribs well sprung. The body is rather long, the back being extremely powerful and slightly arched in the case of dogs but flat in bitches; whilst the loins are deep and powerful, a slack loin being a bad fault. The fore-legs are of fair length, quite straight, and very heavy in bone, with large round feet; the hind ones being very muscular about the thighs, with hocks fairly bent, and neither turned in nor out; whilst the tail is rather coarse and hangs downwards. The coat is short, thick, and inclined to be harsh to the touch ; the principal colours being brindle, or a clear fawn, with a black mask and ears. (See Mask, Stop.)

Maturity.-Different breeds of dogs do not all mature at the same age, some taking longer than others, but from about eighteen months to two years is the usual average.

\section{Maw Worms. (See Worms.)}

Meal.-Oatmeal is the best of all meals for dogs if given them well boiled and mixed with broth and a little cooked flesh, as it unquestionably assists in the develop- 
ment of bone and muscle, and is most nutritious. It does not, however, suit all animals at first, as in some cases it is apt to produce looseness of the bowels and heat of the blood; but after they have become accustomed to this food, such troubles usually wear off. (See Feeding.)

\section{Measuring Height. (See Height.)}

\section{Meat. (See Feeding, Flesh.)}

Medicines.-Happily for the canine race the physicking of dogs is conducted upon far less barbarous principles than was the case in days gone by, when all sorts of most abominable concoctions were forced down unwilling throats by ignorant persons. In short, the science of veterinary surgery is far better understood than it used to be, and dogs as well as other animals have benefited thereby. Owners of kennels, and their servants too, are displaying less inclination to follow out their own opinions in the treatment of canine diseases, and in cases where they do not seek professional advice direct, they procure the medicines they may require from firms such as Spratt's Patent, who make a speciality of dispensing reliable remedies in forms which enable them to be kept at hand for emergencies, and with full directions attached to each. The custom of administering physic in the form of capsules is also one that is worthy of general support, provided, of course, that the drugs themselves are of kinds that can be contained in such coverings. (See Administering Medicine.)

Membrane.-A thin but strong tissue which covers the cavities of the body.

Milk.-Many experienced dog-breeders object to giving their animals cows' milk, and much prefer that of goats; 
but if the latter is used, it should previously be boiled and have a little sugar added. Quite recently a most valuable preparation in the form of malt milk has been placed on the market by Spratt's Patent in the form of a powder. This forms not merely a very nourishing food for puppies and sick dogs, but is an excellent addition to the diet of all toys and delicate varieties, the digestions of which have to be studied, and therefore should be given to them with biscuits broken up in it.

Milk Fever is a not inirequent result of pupping, and will cause much suffering to the brood bitch which is oversupplied with milk, or when her puppies are taken from her. The teats in such cases will usually become inflamed and her belly extremely tender, but relief may be obtained by drawing off some of the milk and dressing the parts referred to with camphorated oil. Sometimes the teats are so tender that they cannot be touched by the hand, and if so, a soda-water bottle may be filled with the steam from a kettle and the mouth placed over the teat and gently pressed. By this means the teat is softened, and it usually happens that some milk can be drawn off. It is necessary that milk fever should be taken in time to avoid complications, and therefore if it seems as though there is a superfluity of milk, some should be drawn off in order to prevent the tenderness of the teats which will otherwise ensue. The diet should be cooling, and she should be subjected to a gentle course of medicine, such as flowers of sulphur mixed in milk.

Milk Teeth.-The name by which the first set of teeth the puppy cuts are known. These are usually shed at about eight months old. (See Teeth, Teething.)

Mirle.-The grey-bluish colour which appears in some breeds, and particularly collies. It is usually associated with a wall eye. (See China Eye.) 
Molars.-The back teeth. (See Teeth.)

Molossus.-The molossus was an ancient breed of a powerful type which was highly valued by our forefathers many centuries ago as a guardian of their homes and property. No doubt the mastiff and bulldog are descended from it, and in appearance it somewhat resembled a gigantic bull-mastiff of the present day. (See Bulldog, Mastiff.)

Moss Litter is an excellent covering for the floors of kennels, as it absorbs moisture, and consequently renders it an easy matter to keep them clean and sweet. The chief objections to it are that it is difficult to break up fine, and that it is apt to become dusty and work its way into the eyes and coats of the dogs; but its many excellent properties render it a very valuable covering for the floors of kennels. (See Flooring.)

Mouth.-The expression "mouth" is frequently applied to the teeth of dogs. For instance, a dog is said to have his full mouth when he has got all his second teeth; or a bad one or good one, as the case may be, when the teeth are bad or good.

Muscle.-The production of muscle is the inevitable task of everybody who is entrusted with the care of a show or working dog. The only way to produce muscle is by providing the animal with proper food and exercise, as it is hopeless to expect that a dog which is neglected in such matters can attain the state of condition that a healthy animal should be in. (See Exercise, Feeding, Preparing for Show, Training Greyhounds.)

Mutilation.-The question of mutilating dogs with the object of improving their appearance in accordance with the dictates of fashion is one upon which so much has 
been spoken and written, that it is unnecessary to devote much space to it here. That the practice is practically indefensible is undeniable; but it is difficult to reconcile the professions expressed by those who have it in their power to put an end to the mutilation of dogs with their actions as societies and individuals who have adopted measures to put an end to the cropping of ears, continue to permit the docking of tails. Of course the former operation is the more serious one, but the principle involved is the same; and hence the very natural surprise that many people experience when they see many breeds of terriers, spaniels, schipperkes, and other varieties which have their tails docked competing for prizes at shows under the rules of which cropped dogs are disqualified. (See Cropping Ears, Docking Tails.)

Muzzling.-In spite of the strong objections which are entertained against the practice of muzzling dogs by many people, it is occasionally necessary to use such restrictions upon the absolute freedom of some dogs in order to protect them from themselves. For instance, it occasionally occurs that a poisonous dressing has to be applied to the skin, or that a dog will persist in licking a sore which irritates him, with the result that it becomes worse. Sometimes, too, if there is a fear that poison has been laid in a district, it is only an act of common sense on the part of an owner to adopt measures to prevent his dogs picking it up when enjoying their daily exercise. It is, moreover, quite certain that the wearing of a well-fitting muzzle does not inflict as much discomfort upon a dog, after he has worn it a few times, as many people imagine-this fact being rendered obvious by the anxiety displayed by the dogs to have their muzzles put on them when they associate the action with a run out of doors. A good deal, of course, must depend upon the design and fit of the muzzle, the best being those made of wire, which effectively prevent the dog opening his mouth to feed or bite, whilst they allow him to drink. 


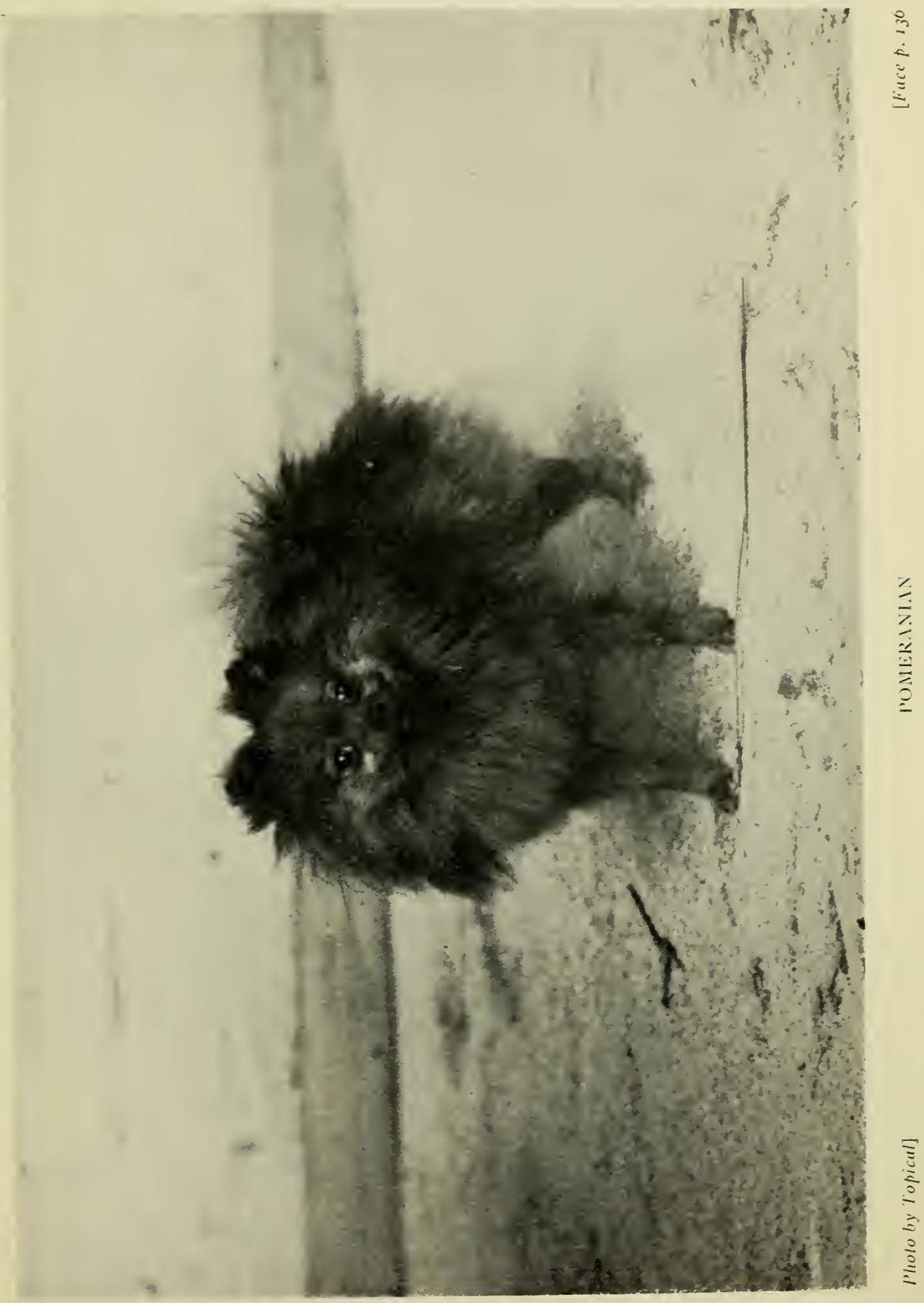



They are also light, and in every way superior to the arrangement of leather straps which were formerly in use. Another design is the "bucket muzzle," which consists of a round leather case, punctured by many holes for ventilat-

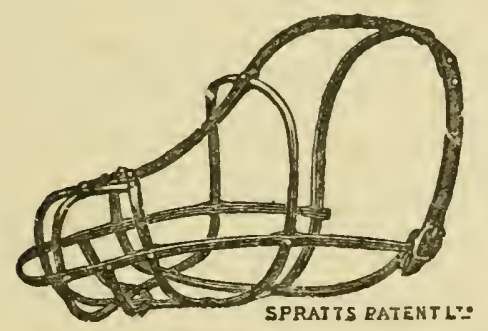

Leather.

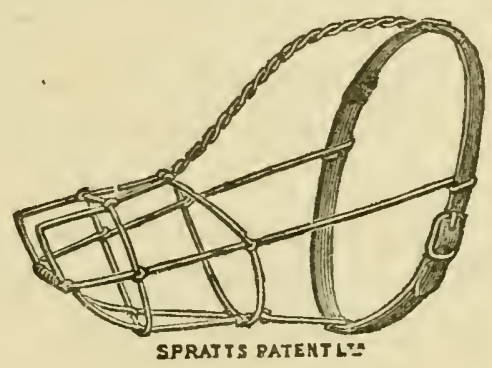

Wire.

MuzzLES. - The above represent the most humane design of muzzle that is manufactured.

ing purposes, which encloses the entire muzzle of the dog and places it absolutely beyond his power to eat or drink. This bucket muzzle is mostly used by trainers of greyhounds and whippets, and cannot be recommended for general use. (See Training Greyhounds.)

\section{$\mathrm{N}$}

Nervous System.-Nobody who has had much experience of dogs will be disposed to dispute the statement that their nervous system is very highly strung, as their behaviour when excited affords convincing evidence that it is. Of course some breeds are more phlegmatic in disposition than others, the larger varieties being as a rule far less excitable than the small ones, which for the most part are less easy to control.

Newfoundland.-The Newfoundland dog, as known in England, is a far larger and more imposing-looking 
animal than the dogs to be discovered in the country from which he takes his name, and he moreover differs from the majority of them in colour, as his coat is jet-black, or black and white, whereas theirs is usually of a rusty hue. This tinge, it has been suggested, is probably due in some measure to the fact that the native dogs spend a good deal of their time in the sea, and that the salt water has an effect upon the colour of their coats; but whether this is the case or not, the fact remains that a rusty jacket is seldom seen in England. The black and white variety is of course a modern and British production, as it owes its origin to the great painter Sir Edwin Landseer, from whom it derives its name, who selected an imposing-looking mongrel of this colour for his famous painting, "A Distinguished Member of the Humane Society," which animal quite erroneously came to be described as a Newfoundland.

The head in this breed is flat on the top, wide, and very massive, the occipital protuberance being well marked; whilst the muzzle is rather short and moderately blunt. The eyes are small, deeply set, and dark in colour, a yellow eye being a most serious fault; and the ears set well back, small, lying close to the sides of the head. The neck is longer than it appears to be, as it is very thick and well coated with hair, which makes it seem shorter than it actually is; the shoulders rather sloping, and the chest very wide and deep; whilst the body is rather long, with well-sprung ribs and very powerful loins; the feet being large and compact. The hind-quarters are extremely powerful; and the tail, which is of moderate length and thickness, is carried low, with a slight curve near the tip. The hair on the coat must be dense, flat, rather coarse, and like that of most water-dogs, inclined to be oily, the inner jacket being thick, soft, and sealskin-like. The most commonly found colours are black, and black and white; but bronze, rusty, and even yellowish jackets are to be found, the latter occasionally occurring as sports in blacks of unimpeachable pedigrees. The average height is about I 38 
27 inches, and weight $\mathrm{I}_{40} \mathrm{lbs}$. in dogs; bitches being about a couple of inches smaller and $2 \mathrm{I}$ lbs. lighter.

Nits are the eggs of lice, which the latter deposit on the coats of dogs. (See Lice.)

\section{Norfolk Spaniel. (See Springer.)}

Nose.-A term applied to the scenting powers of a dog. Thus an animal well endowed in this respect is said to have a good nose.

Nursing.-In canine, as in human diseases, good nursing is the means of saving many a valuable life, and hence owners who may happen to be far removed from professional assistance should never despair-excepting, of course, in cases which from the first are obviously hopeless. A good nurse must in the first place possess a natural liking for the care of sick animals, else the duties in an obstinate case may prove intolerable, and unintentional neglect of details may cost the patient its life. A good nurse must also be patient and observant, gifted with a power of moving about quietly, so that the sick animal is not unnecessarily disturbed, and tactful. A bustling, loudvoiced person who hauls his patient about as if it had no sense of feeling is not qualified for a nurse, nor is he who is not capable of realising the importance of punctuality in feeding an invalid and administering medicine. Good nursing, combined with warm yet airy accommodation, is what is required when a dog is ill, in addition to proper medical treatment; and in the majority of canine ailments the nurse is quite as responsible for the recovery of the patient as the professional attendant. (See Hospital.) 


\section{O}

Occipital Protuberance, or Peak.-The projection at the back of the head which is conspicuous in many breeds, notably the bloodhound and setter.

Estrum, or Heat.-The period during which the bitch is in a state to receive the male dog. It usually lasts for about three weeks, the middle one being the best for service, and appears for the first time at about ten or twelve months of age. (See Breeding, Brood Bitch.)

Oil in Coat.-The coats of most varieties which can claim to be included in the category of water-dogs shows more or less trace of oiliness, this being a provision of nature to render them impervious to water.

\section{Old English Sheep-dog. (See Bobtailed Sheep-dog.)}

Old Man.-A term applied principally by bulldog breeders, but by others also, to an animal that has matured. Thus a backward puppy is sometimes referred to as one that is likely to be all that is required when he has a little more of the old man about him. (See Furnish, Made Up.)

\section{Orphan Puppies. (See Breeding, Puppies.)}

Ophthalmia is an inflammation of the mucous membrane of the eye, and may be the result of a damp kennel, injuries from the effects of blows, or something having got into the eye, or from constitutional tendency. It can be detected by the presence of a nasty discharge from the eyes, which are a good deal inflamed, and extreme sensitiveness to light. The disease is not one for an amateur to treat, but as a preliminary measure pending professional assistance the dog may be placed in a darkened room, fairly warmed and free from draughts, and the eyes may 
be bathed in warm water, the lids being gently rubbed with vaseline or cold-cream afterwards, as the discharge becomes caked on them if this precaution is not taken.

Otterhound.-It is unfortunately a fact that this most picturesque variety is not so much in favour amongst breeders as was the case a few years ago, as not only have the packs of otterhounds become fewer in number, but the masters of these are not so particular regarding the sort of hound they use so long as the animals can hunt, and consequently their packs are more or less of the nature of scratch ones. Still the slow, but none the less sure, extinction of the old breed must be a source of regret to many people, for it is an old English variety, though its origin is not precisely known, but probably the old southern hound and the water spaniel had a good deal to do with it.

The head of the otterhound is long, domed, and broad, the forehead being raised, and the muzzle long and powerful, the eyes being dark and the ears long and thin, well fringed with hair, and lying close to the sides of the head. The neck is of fair length, the shoulders sloping and muscular, the body powerful and very strong at loins. The chest is rather wide, the legs straight, and the feet large; the stern, which is of fair length, being carried gaily. The prevailing colour is grizzle, and the coat is very hard. Average weight, 75 lbs.

Out-at-Elbow.-A dog is said to be out-at-elbow when his fore-legs are not set on straight under him, but turn outwards below the shoulder.

Overhung.-The expression used to describe a dog's mouth when the upper front teeth project beyond the lower ones. Pincher, pig, and overshot jaws are synonymous terms. (See Level Mouth, Teeth, Underhung.)

\section{Overshot. (See Overhung.)}


Paving.-All outside yards in which dogs are confined should be paved in order to facilitate cleansing operations and to prevent sickness, owing to the absorption of their evacuations. The best form of paving for ordinary purposes is concrete, as asphalt is apt to become soft and boggy when exposed to a hot sun, and flagstones cost money and have to be very carefully laid, as otherwise the moisture will penetrate the cracks between them. Bricks are bad, as they are porous, even if set edgeways, and are liable to be scratched up by the dogs, the latter objection being also applicable to tiles. (See Flooring, Kennels.)

Paralysis is usually due to some affection of the brain, and occasionally is a result of distemper, sometimes the whole body being attacked by it, but usually it is confined to the limbs. In most cases the appetite is not affected, but the bowels are almost invariably very constipated. This disease, which is quite beyond the powers of the amateur, is exhaustively dealt with by Mr. A. J. Sewell in "The Dog's Medical Dictionary" (George Routledge and Sons), and a careful perusal of this work is therefore recommended, as contrary to general belief paralysis in the dog is not always incurable. (See Chorea, Distemper.)

Parsnips are occasionally given to dogs boiled and mashed up in their food. They are not recommended for general use, however, as they are fattening, produce flatulency, and are not particularly nutritious. (See Feeding.)

Pasterns or ankles are the lowest joints of the legs above the foot. (See Fore-legs.)

Paunches.-Sheep's paunches and bullocks' tripes are a very good food for dogs if given them well boiled and mixed with meal, but they are better regarded as an occa- 
sional food; for though they assist in keeping the blood cool and bowels nicely open they are not a very strengthening form of diet. If not well boiled, paunches are liable to introduce parasites, which have lodged in them, into the stomachs of the dogs. (See Feeding.)

\section{Peak. (See Occipital Protuberance.)}

Pekinese Spaniel.- This very quaint looking, but most attractive and intelligent little dog has achieved a remarkable popularity since its importation into this country; so much so that it bids fair to usurp the position occupied by the native varieties of toy spaniels before very long. It is undoubtedly a very ancient Chinese breed-so ancient, in fact, that its origin is quite lost in obscurity; and it, in addition to other merits, possesses the great one of being endowed by nature with a very robust constitution, though it is to be feared that the pampering it receives from some of its feminine admirers in this country will result in the Pekinese developing into a delicate breed.

The head of this dog is broad, flat between the ears, and slightly domed in front, the muzzle being short and broad, the eyes large; the ears, which are set on high, being $\mathrm{V}$-shaped and rather small. The neck is rather short, as are the shoulders; the body long, deep, and big in front, the sides being flat and the loins deep. The fore-legs turn out at elbow, and are short and big for the size of the dog, the hind ones being slightly longer than those in front, which makes a Pekinese higher at the quarters than at the shoulders; but the back is not arched, and the bushy tail is carried in a curl over the back. The coat is soft, long, and free from curl, there being a well-defined frill on the chest; whilst the ears are fringed with silky hair, and all the legs are well feathered, but the head and muzzle carry shorter hair. The favourite colour is red, but fawns and other colours are also found; and the average weight is about ro lbs. 
Pencilling.-The streaks of black which run up the toes of some breeds, such as black-and-tan terriers and some Gordon setters.

Peritoneum.-The membrane which covers the abdominal cavity, and encloses the bowels and its other contents. (See Peritonitis.)

Peritonitis, or inflammation of the peritoneum, usually results from a blow or kick, but a chill may cause it, and it is also by no means uncommon amongst bitches at whelping time. The symptoms are great tenderness of the belly, which causes the animal to lie on its side, quick breathing, and faint pulse, associated with high fever and a white, slimy tongue. Hot linseed poultices or warm fomentations should be applied to the belly, and doses of opium of from $\frac{1}{2}$ to 2 grains, according to the size of the dog, may be given in water every six hours, the nourishment given being strong beef-tea if the patient will take anything. Absolute quiet, warmth, and good nursing are essential in cases of peritonitis. (See Hospital, Nursing.)

\section{Pig Eye.-A small, sunken eye.}

Pig Jaw.-A jaw in which the upper front teeth project over the under ones. Also known as overhung, overshot, pincher jaw.

Piles are not uncommon amongst dogs, and especially amongst those whose bowels are apt to be constipated, as the piles result from straining. Frequent diarrhœa may also produce them, and so will indigestion, as a result of improper food and insufficient exercise. The existence of piles may be detected from the swollen condition and heat of the anus, the appearance of blood in the motions, and the irritation of the part displayed by the animal dragging it along the ground. If an examination is made 
small red swellings will be found, and to these cold water may be applied to afford relief, and afterwards some soothing ointment. If the bowels are constipated, an enema may be given, and in some cases suppositories can be used with good results. The diet should be of a non-heating nature. (See Enemas, Hamorrhoids, Suppositories.)

Pily.-The term applied to a close, soft coat.

Pincher Jaw. (See Overhung, Pig Jaw.)

Pleasant Face.-An old-fashioned expression used to describe a dog belonging to a short-muzzled breed which possesses a long muzzle or face.

Pleurisy, or inflammation of the pleura, which is the lining of the membrane of the chest, usually results from exposure to cold, but a blow or fracture may cause it. The symptoms resemble those of pneumonia, but in cases of pleurisy there is a characteristic heaving of the flanks. The treatment in the case of both diseases is practically the same, but pleurisy is not a thing that the amateur practitioner can deal with satisfactorily, and therefore professional assistance should be obtained without delay. (See Pneumonia.)

Pneumonia, or inflammation of the lungs, is a result of exposure to damp or cold, the symptoms being a high pulse, quick breathing, shivering, and tenderness of the chest if it is pressed, whilst if the ear is placed to the latter a sort of murmuring sound is heard, which increases as the disease proceeds, and the dog often stands with his legs wide apart. For treatment the dog may be placed in an airy room, but out of the reach of draughts, and linseed poultices, to which a little mustard has been added, should be applied to the chest and sides behind the forearms. 
The diet should be strengthening, such as strong beef tea with some port wine or brandy in it. Pneumonia is a disease which demands the best medical treatment, and if this cannot be at once procured, Mr. Sewell's "Dog's Medical Dictionary" should be consulted. (See Nursing, Poultices.)

\section{Pocket Beagle. (See Beagle.)}

Pointer-Although he has been recognised as an English breed for generations there can be no disputing the fact that the pointer is of foreign extraction, and traces back to the cumbersome Spanish variety. Opinions, however, differ as regards the breeds with which he was crossed, some authorities expressing the conviction that the French pointer, a much lighter variety, was used, whilst others believe in the existence of a foxhound cross. Probably both views are correct; but be this as it may, the fact remains that the English pointer has existed for many years as an acknowledged distinct breed. As a gun-dog he knows no superior, his only rival being the setter, and between the two the rivalry has always been most keen. The pointer, however, is not as thirsty a dog as the setter, and therefore is capable of getting through a hard day in places where water is scarce better than the latter, which nevertheless is the better dog on stony ground, as the hair between his toes protects them from injury, and as in other respects the two breeds are equally reliable, honours may be regarded as being divided between them.

The head of the pointer is wide and long, with a stop between the eyes, and a drop at the set on of the muzzle, which must be massive, truncated, and rather dished. It should, in fact, be powerful without being coarse, and well chiselled, the cheeks being flat, and the lips well developed but not pendulous. The nose is large, and either dark liver or yellow in colour, as depends on the colour of the dog, a black nose being disliked. The eyes are of moderate 
size, often inclined to be sunken, and of a light hazel colour; the ears, which are set on high, being of medium length, fine in texture of the leather and hanging flat to the sides of the head. The neck, which must be clean and free from dewlap, is long and slightly arched ; the shoulders thin, long, and sloping; the chest rather narrow but of considerable depth; the back short and level, the ribs nicely sprung, and the loins deep and powerful. The fore-legs must be dead straight, heavy in bone, muscular, and of fair length, with large, round, compact feet. The hindquarters should be very powerful; the thighs well covered with muscle, and the hocks neither turned in nor out; the tail being short, thick at the root, and fine at the point, set on high up, and carried straight. The coat is short and close, whilst the usual colours are liver and white, and lemon and white, the former having dark noses and the latter light ones; black-ticked, black, liver, and self-coloured lemons also appear occasionally, but a tricoloured one is objected to, as it suggests the foxhound cross. Weights vary from $35 \mathrm{lbs}$. to over $60 \mathrm{lbs}$. (See Dish Face, Leather, Stop.)

Poisoning.-Dogs, unhappily for themselves and their owners, are so frequently the victims of poison that the subject of successful treatment in cases of such emergency is one of the highest importance. The great difficulty that besets the amateur practitioner in cases of poison is that the symptoms and the treatment vary, and so the remedy which may be efficacious in one instance may be absolutely useless, even if it is not injurious, in another. The best advice that can be given, therefore, is that owners who are suspicious that their dogs have picked up poison should at once repair to the nearest chemist and consult him, always provided that qualified veterinary assistance is not promptly available. A list of common poisons, their symptoms and antidotes, is given under a separate heading; but the advice may be repeated, that in the absence of a veterinary surgeon that 


\section{POISONS}

of a respectable chemist should be obtained without delay, and care must be taken to regulate the amount of the doses to the size of the dog. (See Poisons.)

Poisons. - The following is a list of poisons which most commonly are fatal to dogs, together with their symptoms and antidotes for immediate use.

Aconite is used in cases of lockjaw and as a sedative. Symptoms.-Continuous retching, extreme exhaustion, and a difficulty in moving the hind-legs. Antidote.-Emetics, and repeated doses of strong brandy and water.

ANTIMONY, or tartar emetic, used as a counter-irritant, an emetic, or by some people in small quantities to improve their dog's coat. Symptoms.-Violent sickness, diarrhœa, thirst, a difficulty in breathing, and coldness of the limbs and ears. Antidote.-Tannic acid, or if this is not at once available, repeated doses of the very strongest tea that can be made.

ARSENIC is frequently given to dogs as a tonic and in cases of skin trouble. Symptoms.-Diarrhœa and vomiting, the evacuations being usually tinged by blood, great thirst, difficult breathing, bloodshot eyes, and convulsions. Treatment.-An emetic of salt and water, from ro to 30 grains of magnesia if it is at hand. Moist hydrated peroxide of iron should at once be obtained for immediate administration. If the strength fails an egg beaten up in milk may be given at frequent intervals pending the arrival of professional advice.

BELladonna is given as a sedative. Symptoms.-Dilation of the eyes, coma. Antidote-Strong brandy and water, or ammonia in frequent doses; a dog suffering from belladonna poisoning should be kept moving if possible, and may derive benefit from smelling-salts held under his nose.

CARBOLIC ACID, when used for disinfecting purposes, is occasionally drunk by dogs, the flavour not being unpleasant to some of them. Symptoms.-A feeble irregular 148 
pulse, difficult breathing, the lips hard and white, great prostration. Antidote-A good dose of sweet-oil or Epsom salts, followed by the whites of eggs beaten up in sweet or salad oil at frequent intervals.

LEAD.-Many lotions containing lead are used in the treatment of canine diseases, and it occasionally happens that these are administered internally by mistake. Symptoms.-Blueness of the gums, diarrhœa, evil-smelling breath, severe pains in the belly, and sometimes swelling of the joints, followed by paralysis. Antidotes.-Iodide of potassium, sulphuric acid. Whilst aid is being sent for, give the dog a strong dose of Epsom salts, or if none can be obtained at once the white of an egg beaten up in milk. Small doses of chlorodyne will alleviate the intestinal pains.

OPIUM is in common use as a sedative, but if given in too large quantities it is a dangerous poison. Symptoms.Great drowsiness, slow breathing and pulse, coma. Antidotes.-Strong tea at frequent intervals, the stomach having been previously emptied by a strong dose of Epsom salts. The dog should not be allowed to sleep, but should be encouraged to move about.

PRUSSIC ACID is not a poison that is commonly given to a dog in the form of a medicine, but occasional cases of animals picking it up occur. Symptoms.-Collapse, as the action of prussic acid paralyses the heart. Antidotes.Ammonia and brandy, cold water should be dashed on the dog's head and spine; he should also be given plenty of fresh air, and made to inhale ammonia.

STRYCHNine, or nux vomica, is valuable in small doses as a nerve stimulant and tonic, but it is a deadly poison. Symptoms.--Severe muscular twitching, extreme stiffness of the limbs, and a difficulty in breathing. Antidotes.Chloral hydrate, or very large doses of brandy or whisky if the former is not available for use at once.

$Z_{\text {INC }}$ is contained in most cooling lotions which are recommended for use in kennels, and which are sometimes administered internally in error with disastrous results. 
Symptoms.-Falling away in condition, great thirst, loss of appetite, paleness of the lining of the eyes and lips, and loss of spirits. Antidotes.-Oil and chalk to follow a strong dose of opening medicine.

It may be repeated that the above suggestions as to treatment are only to be regarded as offering assistance in times of emergency, pending professional advice. (See Poisoning.)

Pomeranian.-The advance made by the Pomeranian in popularity of late years has been so great that the variety which a generation ago was in very few hands is now one of the most admired and sought after of all the fancy varieties. This, no doubt, is due to the production of the toy pomeranian, which is the result of a steady course of persistent in-breeding, and has brought into existence a most exquisite, alert little dog, but unfortunately a very delicate one. On the other hand, the larger-sized specimens of the breed, which is undoubtedly of German origin, though there is a handsome Italian offshoot of the family, usually of a golden-lemon colour and not so dense in coat, are quite hardy animals, and being extremely sharp of hearing, acute on the approach of strangers, and given to barking when alarmed, they may be regarded as exceptionally good watch-dogs for indoor purposes.

The head of the pomeranian is sharp and foxy-looking, the skull being flat-though in the case of the toys it is somewhat rounded-and the muzzle rather fine and tapering at the nose, which is black or brown in colour, as depends upon the shade of the coat. The eyes are of medium size, set obliquely in the head, dark in colour and very bright; the ears small, pointed, and carried erect. The neck is short, and appears to be very thick, as it should carry an immense frill; the shoulders are rather straight; the back short and cobby-looking, the chest being deep and the loins strong. The fore-legs should be straight and not too long, and like the thighs must be heavily feathered; 
whilst the tail, which is very bushy, is carried over the back in a curl. The outer coat, excepting on the head and face, is very long, flat, and profuse, especially on the neck and at the back of the thighs, the under one being soft and thick. The best colours are black, sable, brown, blue, or white; parti-colours, although allowed, not being liked. Weights vary from 6 lbs. to I4 lbs. (See Cobby, Frill.)

Poodle.-Owing possibly to the practice which prevails of clipping the poodle's coat in the region of the loins and hind-quarters, the breed is not infrequently the subject of ridicule amongst people who do not appreciate his wonderful intelligence and adaptability for useful purposes. Such persons may be surprised to learn that he is capable of being broken to the gun, and when this is so, that he is a capital field-dog; whilst it may be added that he unquestionably is a past ancestor of the Irish water spaniel and the curly-coated retriever. For a great many years the poodle has been a most valued variety on the Continent, especially in Russia, France, and Germany, and as his merits have become more widely recognised in England his popularity has increased, but as really first-rate specimens are most difficult to procure, the breed is not in many hands. This is particularly the case in connection with the corded variety, whose coat consists of a series of long rope-like tresses, which sometimes are of such length as to trail upon the ground from the body, and almost from the ears as well. The curly-coated variety, however, is more easy to obtain, and of late recognition to some extent has been bestowed upon a fluffy sort of coat, which, however, is neither typical of the poodle nor attractive in appearance.

The head of this dog is long and beautifully chiselled, having no approach to coarseness. There is a peak at the back, and the head tapers gradually towards the nose; the muzzle being strong, but not coarse or clumsy. The eyes are dark brown in colour, and of medium size; the ears 
long, wide, and lying close to the head; the neck long and muscular, and the shoulders powerful and sloping, the poodle being a very active dog. The back is short, the loins powerful and slightly arched, and the ribs nicely sprung. The fore-legs are rather long, quite straight, and heavy in bone; the feet small and compact, and the hindlegs bent at stifles and hocks; the tail, which is usually docked, being carried gaily. The question of coat has been alluded to above, but it may be added that it should be harsh in texture, the most common colours being black and white, but brown, grey, red, and blue are also seen, parti-coloured specimens not being liked, though they are not liable to disqualification. Average weight, $45 \mathrm{lbs}$. (See Occipital Protuberance.)

Potatoes are frequently given to dogs, and if they are thoroughly well boiled and mashed up they form a useful change when mixed with broth and a little meat or paunches, but as a staple food they are not to be recommended. (See Feeding.)

Poultices, as in the case of human beings, are often very useful in reducing pain in cases of inflammation. The most serviceable is a poultice made of linseed in the following way: Take a sufficiency of linseed meal, place it in a basin, cover it with boiling water, and stir with a table-knife until it is thoroughly mixed, when it may be applied. Of course it must not be put on if it is so hot that the dog will be scalded, but it ought to be quite warm. It is best to enclose the poultice in a piece of linen or muslin, in order to keep the meal from clinging to the hair of the dog; and if the poultice is applied for the purpose of drawing the matter out of a wound, a little oil may be smeared on the cloth beforehand to prevent it sticking. Mustard poultices are useful in cases of bronchitis, pneumonia, and the like, but it is best to add a little linseed meal to them. (See Nursing.) 


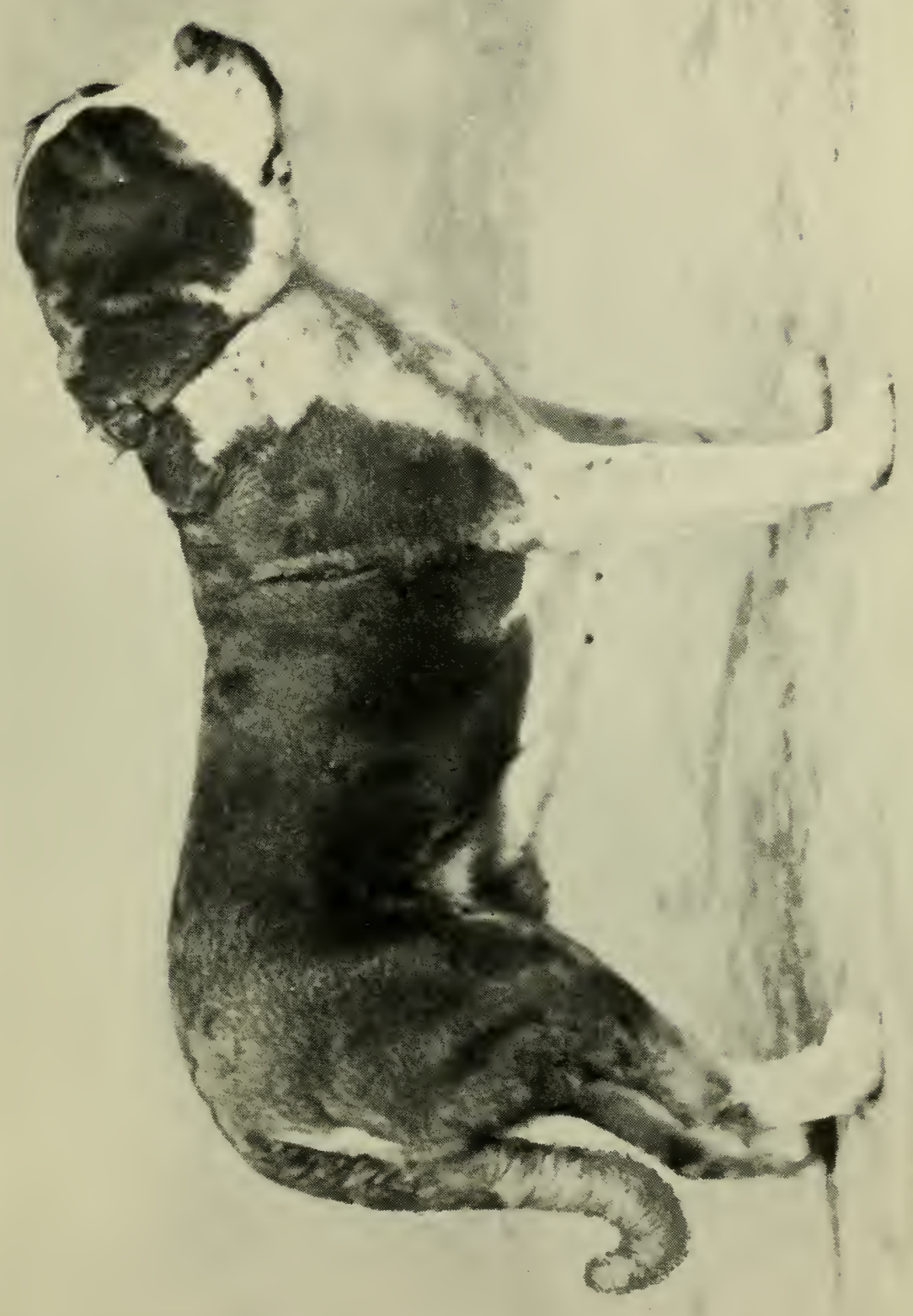

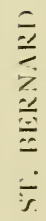

$\Xi$
$\vdots$
$\vdots$
$\vdots$
$\vdots$
$\vdots$ 

Poverty of Blood may be a result of constitutional weakness or bad feeding, and the only course to pursue in such cases is to provide the dog with a sufficiency of strengthening nourishment, such as beef-tea and boiled mutton mixed with pearl-barley, plenty of fresh air, gentle exercise, and a tonic. For the latter purpose Spratt's Patent Tonic Condition Pills will be found most efficacious. (See Debility.)

Preparing for Show.-There is not very much art required to bring a dog into the show-ring in good condition, provided that the person entrusted with the duty has good material and a healthy animal to work upon, and that proper attention is paid by him to the questions of feeding, exercising, kennelling, and grooming. A dog that is intelligently cared for under normal conditions will not require much tuning up for exhibition, but his owner will naturally be anxious that he should look smart and hard, that his muscles should show up well, and that his coat should be at its best. Under such circumstances the importance of plenty of exercise, not necessarily of a violent nature, but long and slow, cannot be overestimated, as this is the sort of thing to lay on muscle and promote a healthy appetite, and when the dog feeds well he usually looks well. It may here be pointed out once and for all, that a quantity of stimulating, fattening food is bad for a show dog, as it renders him soft and flabby and liable to breakings out of the skin, which may ruin his coat ; consequently, though an additional allowance of flesh may be given him, the extra quantity to be regulated by the amount of exercise he gets, all heating foods should be taboo. On coming in from exercise his legs and feet should be carefully examined in case they have been cut, or that thorns or splinters may have run into them, as it would be awkward if he was lame on the eventful day. If necessary, they should be washed and dried, and his coat should be gone over with a brush and linen cloth before he is allowed 
into his kennel. Of course, too, the daily routine of grooming should not be relaxed, in fact a little extra time may be devoted to his toilet; for grooming not merely stimulates the growth of hair, but adds to its brilliancy, and therefore suggests good health. It should also be remembered that the dog should rest well, and therefore his bed should be a good one, and his kennel ought to be kept clean; and an occasional dose of mild medicine may be necessary if the bowels appear constipated, as some dogs are constitutionally disposed to suffer in that way. This may take the form of a little flowers of sulphur given in milk, this being a mild aperient and a capital purifier of the blood. An occasional bone to gnaw is very good for dogs which are being prepared for show, provided always that there are no kennel companions to fight for possession of it; and if there are any signs of loss of appetite a few doses of Spratt's Tonic Condition Pills will usually put matters right very quickly. Of course toy dogs will not require so much exercise as animals of more robust constitution, but air and exercise will benefit them as well. They should not, however, be overfed and stuffed with delicacies and a superabundance of rich food. If they are, a catastrophe is very likely to occur in the form of a breaking out of the skin or disarrangement of the bowels. Spratt's malt milk and oval biscuits soaked in it is an excellent food for toy dogs when being prepared for show, and the value of constant attention to the coats of the long-haired breeds must not be overlooked. The question of washing is one that causes many exhibitors a good deal of anxiety, as soap and water is liable to make the coat soft, and therefore it is not wise to make the dog undergo his ablutions just before he has to leave home. On the other hand, he is apt to get his coat dirty if he is washed too long before he does so; but the best thing to do is to wash him the morning before he has to start, and to give him a clean bed to lie upon. If he soils his coat in the interim the application of baked flour, well rubbed in and then brushed out, will usually remove 
the stains, but if it does not, he must of course be washed over again. (See Cleansing the Coat, Exercising, Feeding, Grooming, Kennels, Washing.)

Prick Ear.-An erect ear, such as that of the Scottish terrier or pomeranian. (See Tulip Ear.)

Prince Charles Spaniel.-The name which was given to the black white-and-tan, or tricolour King Charles spaniel a few years ago. It has now been abandoned, and wisely so, as there never was the slightest justification for calling two dogs of the same breed by different names simply because they differed in colours, and it was impossible to discover the reason for the breeders of the King Charles spaniel acting so foolishly as to suggest such a course. (See King Charles Spaniel.)

Pug.-The pug-dog no doubt is a native of Holland, but the breed has been established in this country for so long a time that it has become a recognised British breed. It has always been most popular, too, amongst dog lovers here, and in spite of its asthmatic gruntings, the result of its shortness of face, can rank amongst its supporters some of the leading members of the aristocracy. A generation or so ago, when there were fewer varieties of toy dogs in England to divide the affections of the community, there were two distinct families of pug that were recognised, namely, the Willoughby and the Morrison, each of which was jealously protected by a strong following of dogfanciers, who religiously refrained from crossing the two varieties. Of late years, however, the barrier that formerly existed has been broken down, and one rarely hears the expression Morrison or Willoughby used in describing a pug; nor does there seem to have been any valid reason for keeping them distinct, as the main difference between them was one of colour, the Willoughbys being of a pale fawn and the Morrisons of a richer or apricot-coloured 
fawn, whilst the coveted dark trace down the back was not as sharply defined in the latter variety. Some twenty years ago, or rather more, the late Lady Brassey established a breed of black pugs in this country, and these have achieved considerable popularity, though as a rule they are inclined to be higher in the leg and less massive and compact in body than the fawns.

The head of the pug should be large and inclined to be round, somewhat resembling a man's fist in shape, and hence probably the name he bears, as suggestions have been made that it is derived from the Latin word pugnus, which signifies a fist. The muzzle is short and blunt; the eyes large, round, and prominent; the ears small and fine, carried close to the head, with the tips down. The neck is short and thick, the shoulders rather inclined to be straight, the chest wide, the body very short and compact, with well-sprung ribs and strong loins. The fore-legs should be of fair length, quite straight, set well under the dog's body, and heavy in bone, with fairly round feet having black toe-nails, the latter being a point which some modern judges appear to be ignorant of. The hindlegs are strong, the hocks being straight, whilst the tail is carried in a tight curl over the back. The coat is short, close, and of moderate hardness, the colours being either fawn or black, the former having black markings distributed as follows-the muzzle, a mole on each cheek; ears, a thumb-mark on the forehead, and in the form of a trace, as clearly defined as possible all down the back. The forehead should show a good deal of wrinkling; and the average weight is about $\mathrm{I}_{4}$ lbs.

Pulse.-The pulse of a fully-grown dog varies from 90 to roo beats a minute, but it becomes considerably slower in old and feeble animals, sometimes falling as low as 65 . The best place to take it is inside the thigh.

Puppies.-The successful rearing of his puppies is a I 56 
source of considerable anxiety to the dog-owner who is in possession of a well-bred litter, and undoubtedly many a valuable life is lost from causes which are no fault of his. An irritable, nervous bitch may destroy her young; the dam may have an insufficiency of milk, or if the supply is plentiful it may be of poor quality, and so the puppies may starve, even though their stomachs are full; one or other of them may get out of the nest and die of coldin fact, there are many things which may happen to cause the loss of, or injury to, the helpless puppies. Assuming, however, that all has gone on well with the litter, the owner will not have much to do until the puppies open their eyes on the ninth day, by which time they will have become strong enough to begin to try and crawl out of the nest. He will be able then to ascertain whether they are getting sufficient nourishment from the dam, as some bitches' milk begins to give out or become inferior in quality after the puppies have been on her for a while; and if this is the case, means will have to be adopted to meet the difficulty. Under any circumstances, it is desirable that the puppies should be given some extra nourishment when they are about a fortnight or three weeks old, so the question of additional food is only anticipated by a few days. The best thing to commence on is Spratt's Malt Milk, prepared as directed, and in this some small pieces of puppy biscuits may be soaked. Later on, when the youngsters are about a month old, gravy may be substituted for the malt milk for some of the daily meals, which should be frequent; and still later some tiny pieces of well-minced meat may be added if the puppies appear to require additional nourishment, but this is rarely necessary before they are weaned, which will be when they are six weeks old. At first their food may be given them in shallow saucers, so that they can get at it easily, as there is sometimes a difficulty in getting them to feed until they understand how to proceed, but when once they do so a litter of healthy puppies will cause no further trouble 
in that respect. The food should be supplied to them at frequent intervals in small quantities, and the saucer should be removed when they have finished, as if it is left beside the puppies the contents may become sour or contaminated by dirt getting into it. The owner need not trouble himself as regards keeping the nest and the puppies clean at first, for the dam will see to all that for him; but when they begin to move about the shed it will be advisable to attend to the matter carefully, and to assist matters the floor had better be thickly covered with coarse sawdust. It may be necessary to change or renew the bed from time to time; but at first most bitches are very jealous of having their puppies interfered with, and if so, unless the bed is very badly soiled, it had better be left alone. In the case of breeds the tails of which it is customary to dock, the operation had better be performed whilst the puppies are about two weeks old. (See Brood Bitch, Docking Tails, Rearing Puppies, Weaning.)

\section{Pupping. (See Brood Bitch.)}

\section{Q}

Quality of Food.-No dogs can be expected to thrive upon food of an inferior quality, and therefore meal which is all husks, weevily, or badly baked biscuits, and, in fact, cheap food generally, is usually found to be by far the dearest in the end. In short, the best food is invariably the best, as it goes further and nourishes the dogs, which eat it far better than that of an indifferent quality. (See Biscuits, Feeding.)

Quantity of Food.-Some dogs are extremely greedy, and if given as much as they will eat soon suffer in health. The owner should therefore endeavour to ascertain how much each animal requires to keep it in health, and regulate its allowance accordingly. (See Feeding.) 
Quarantine.-In compliance with a possibly wise, but undoubtedly extremely irritating, order of the Board of Agriculture, all dogs coming into this country from foreign parts are compelled to be kept in quarantine for a fixed period. They are placed under the care of veterinary inspectors during such period, and all expenses have to be paid by their owners.

Quarrelling.-Some dogs are by nature so quarrelsome that it is impossible to keep them in the kennels with others, in which case isolation is absolutely necessary. A very fruitful source of quarrels amongst most peaceable dogs is, however, a bone or bones, and therefore if there are two or more animals in the kennel it will be necessary for someone to be at hand if bones have been served out to them. If so, a search should be made in the bed and in the corners of the kennel to see if any bones have been hidden by the dogs, as if so a free fight will very likely take place when the owner's back is turned unless he has collected all the bones the dogs have done with.

\section{R}

Rabies is unquestionably the most serious danger to which the canine race is exposed, and as it is easily communicated to mankind it is naturally a constant source of terror to timid people who entertain a dislike to dogs. It is extraordinary, therefore, that the public know so little regarding the symptoms of rabies, which are popularly believed to consist of violent struggles accompanied by profuse frothing at the mouth. These, it may be said, are characteristic of the attacks which from time to time take possession of a rabid dog, though they are not by any means symptoms of the disease, but rather a result of it. The primary symptoms are restlessness, a wild look, a desire to creep into dark corners, and a morbid appetite, 
which causes the dog to swallow coals, pieces of stick, hair, and other substances which he would otherwise decline to eat. Although he seeks quiet he is usually as affectionate as ever to those he loves, in fact, often more demonstrative than is his wont, and in this there is an additional source of danger to those about him; for the saliva of a dog which is in a rabid state is capable of communicating the disease to other animals and to men for many days before the acute symptoms appear if it comes into contact with a cut or scratch, and hence the danger of a lick from the tongue of a dog which is suffering from rabies. When the acute stage is reached the dog turns from sullenness to ferocity, and will often attack strangers and other dogs though his ordinary nature is quite gentle; but it may be added that he is usually affectionate to his owner and those he knows. His bark changes into a sort of snappish howl, and the restlessness increases to such an extent that in some instances he will endeavour to gnaw his way out of his kennel and stray away for miles, returning to his home if he can find his way back, quite exhausted by his tramp. In the course of his march he usually takes little notice of people he may meet, but will readily attack dogs, which of course may become affected by rabies, though the danger may be quite unsuspected by their owners. He does not rush wildly about, as many people imagine, but proceeds at a slouching gait, with his head and tail hanging down, the very picture of extreme dejection. In due course paralysis sets in ; but in most instances the sufferer endures paroxysms of violence, in which he will endeavour to tear to pieces all the things about him. $\mathrm{He}$ is also consumed by thirst but cannot swallow, which fact is doubtless responsible for the popular fallacy that a rabid dog has a hatred of water. There being no cure for rabies, a dog which is known to be suffering from it should be promptly destroyed, as he is a source of serious danger to all about him. At the same time if a doubt exists, and especially if he has bitten anybody or another dog, it is 160 
sest to secure him in a place from which escape is imossible, as the period during which the disease lies latent arely extends beyond six weeks, and certainly not for onger than twice that period, so that if acute symptoms lo not appear before that time has expired persons who ave been bitten may congratulate themselves upon being erfectly safe. Dumb madness is a form of rabies in which he lower jaw becomes paralysed, so that the animal canlot close its mouth, but the acuter form of rabies is soon eached, and the danger of being affected by the dog's aliva is not reduced.

Rampur Hound.-This is an Eastern breed which in hape and make resembles the greyhound, but he is built n more substantial lines. He is, moreover, a hairless dog y nature, but specimens kept in this country usually levelop a soft fluffy coat, owing doubtless to the coldness f our climate. Some excellent specimens of this breed vere brought home by his Majesty King Edward on his eturn from his tour of India in 1876 .

\section{Raw Meat. (See Feeding, Flesh.)}

Rearing Puppies.-After puppies are weaned there is ittle to be done beyond providing them with plenty of xercise and good food. It frequently occurs, however, hat they develop worms at a very tender age, the presence f these pests being indicated by the swelling and hardness f the stomachs. It is therefore a wise precaution to take o dose the puppies when they arrive at the age of a ouple of months with worm powder, and if this is done, $n$ the majority of cases the results will be satisfactory. Norms not only affect the growth of a puppy, but are iable to cause fits, and hence the wisdom of acting upon his advice. Puppies usually get their complete set of econd teeth at about nine months old, and consequently heir troubles commence before they arrive at that age. 
It is always best to remove the first set one by one as they become loose, else they are liable to interfere with the later ones as they come through the gum, and thereby cause them to be irregular. (See Puppies, Teeth, Weaning, Worms.)

Red Mange is a non-contagious form of mange which commences in the form of red patches on the body, these in time discharge and form scabs, and when these fall off the skin is very red and inflamed, hence the name red mange. The bowels should be kept well open with Epsom salts, and a dressing of some cooling lotion should be applied. (See Mange.)

Respiration.-In a healthy dog the respirations range from $I_{5}$ to 20 per minute. Quick, short breathing usually points to inflammation in the region of the bowels; short, difficult breathing to pneumonia; fast, difficult breathing to bronchitis; and thick, difficult breathing to asthma; all of which see.

Restoratives. - The best restoratives that can be given to a dog in a state of collapse are spirits, brandy preferably; and if he can be got to swallow an egg beaten up in brandy or port wine, will be found to be most effective. He may also be given ammonia to smell.

Retriever. (See Curly-coated Retriever, Flat-coated Retriever.)

Rheumatism is, unfortunately, by no means uncommon amongst dogs, the shoulders being more often attacked than the other parts of the body, but the loins and legs often suffer. It is not always an easy matter to detect the locality where it exists, but there is usually great tenderness if it is touched, and a considerable amount of heat. The best treatment to adopt is to place the dog in a warm kennel, and, as a preliminary measure, to administer a 162 
dose of opening medicine, after which the part affected should be well rubbed with Elliman's Embrocation; and the food should be of a non-heating character, and include plenty of boiled green vegetables.

Ribbed Up._A dog is said to be well ribbed up when his back ribs are long and his loins powerful and deep.

Ribs.-A dog possesses thirteen ribs on each side, nine of these being connected with the breastbone.

Ribs, Fracture of.-Dogs frequently have their ribs broken by blows, kicks, and other injuries, the result being great tenderness, and occasionally, but not always, a swelling over the seat of the fracture. If such signs appear the hand may be gently-very gently-passed over the swelling, or if this is not present, over the side of the dog to locate the pain, and if there is a fracture it will be felt; but should there be any doubt upon the subject, the dog may be held by an assistant and the ear placed against the place, when the two broken ends will be heard grating against each other when the ribs are moved, and sometimes as the dog breathes. The course to pursue, then, is to wrap a broad bandage (a linen one preferable, as this substance will not stretch) tightly round the body, and if a front rib is broken, round the chest as well, but not so tight as to interfere with the animal breathing. This bandage should be secured by large safety-pins, and it may be left on until the fracture unites, which will probably be in about three weeks or a month, if the dog is kept quite quiet and on cooling food. (See Fractures.)

Rice Water.-The water in which rice has been boiled will be found a very useful drink for a dog suffering from looseness of the bowels. (See Diarrhoea.) 
Rickets consists of diseased bones of the legs, and is usually the result of puppies being improperly reared, though the offspring of aged or unhealthy parents may suffer from it. The joints swell and the legs become crooked, the appearance of the dog being generally emaciated. Good feeding and fresh air, combined with a course of Parrishes' Food and Spratt's Patent Cod Liver Oil Biscuits, may possibly accomplish a cure; but this is doubtful, as when once limbs become twisted or out of shape, they very rarely ever come right.

Ringworm, fortunately for owners, does not often attack dogs, as it is most contagious; and if a case occurs in a large kennel, and its presence is not detected in time, every animal may become affected. It takes the form of a round patch, or patches, which form scabs. The latter in turn peel off, and leave unsightly bare spots. The treatment is to wash the dog well, and paint the patches twice a day with tincture of iodine. Care should be taken to thoroughly disinfect the kennel and every article which the dog has touched, and its bed should be burned. (See Contagious Diseases, Disinfectants.)

Roach Back.-An arched back which drops behind the shoulders and rises in the form of a curve to the top of the loins. It is also known as Wheel Back.

Roofs.-The best roofing for kennels are slates and tiles, the latter being excellent if well pointed and laid on boards as slates are, as they are very cool in summer and warm in winter. It is just the reverse with corrugated iron, which is the very worst of all roofs, even if laid on boards. Thatch possesses many admirable properties, but it harbours insects, and few district surveyors, excepting in remote rural places, would tolerate its use. The latter objection applies to felt laid on match-boarding and afterwards covered with pitch, and a roof of weather boarding 
might also be objected to by local authorities, though if carefully laid it answers its purpose well, in spite of its not being so warm as tiles or slates. (See Kennels.)

Rose Ear.-An ear which folds backwards so that the inner parts are exposed. This ear is a characteristic of the bulldog.

\section{Roseneath Terrier. (See West Highland Terrier.)}

\section{Round Worm. (See Worms.)}

Rounding Ears.-The operation performed on foxhounds in order to reduce the side of their ears, so as to prevent their being wounded by thorns.

\section{Ruby Spaniel. (See King Charles Spaniel.)}

Rupture.-Occasionally, but not often, puppies are ruptured from birth; but a rupture in the form of a swelling in the groin and other parts may appear in older dogs, either as the effects of an injury, as from a kick, or from severe constipation. In the case of the puppies the rupture sometimes disappears, but an operation provides the only possible cure when old animals are affected.

\section{S}

St. Bernard.-Unquestionably the St. Bernard owes much of his popularity to the sentimental reverence that is attached to the undoubtedly truthful tales that are told of his services to benighted travellers on the Alps. There is no doubt, moreover, that his immense size and dignified and majestic appearance would alone have fully justified the encomiums of his admirers; but it may be 
added that the modern St. Bernard as bred in England is a vast improvement upon the dogs of the famous hospice. No doubt some forty years ago, when the late Mr. J. Cumming Macdona and Mr. J. H. Murchison introduced their magnificent imported specimens of the breed into this country, the St. Bernard created a huge sensation, but British enterprise has accomplished much in the way of increasing size; and it is therefore not too much to say that such great heroes of the past as Tell, Thor, and Monarque would have great difficulty in holding their own with the champions of the present day if they revisited the scenes of their early triumphs. The monks of the hospice, however, have, through no fault of their own, been unlucky enough to lose their old blood, as their best animals were all wiped out in the discharge of their duties by a terrible storm on the Alps some years ago, and the breed of the hospice had to be resuscitated by blood from the plains below, which was of a very inferior quality.

The head of the St. Bernard is large, massive, broad, deep, and slightly rounded on the top; the muzzle being short, flat, square, of considerable substance, and well filled in under the eyes, which are dark in colour, small, rather sunken, and show the haw; the ears being rather small, set on high, and carried close to the sides of the head. The neck, which is of a good length, very powerful, and gracefully arched, carries a dewlap; the shoulders lay back well, and the chest is both wide and deep. The back is rather long, but very wide and muscular; the ribs being fairly rounded, and the loins deep and powerful. The fore-legs should be well set on under the dog, dead straight, muscular, and heavy in bone, with large compact feet; and the hind-legs very muscular at the thighs, and well bent at the hocks, which ought not to turn in, this being a point upon which modern breeders differ from many of the old ones. The tail is set on high, long, and carried low; the coat in the long-haired dogs being flat, rather I66 
thicker at the neck than elsewhere, whilst there is a feathering on the back of the fore-legs, thighs, and the tail; whilst in the smooths it is short and hound-like. The colours are orange and brindle mixed with white, great importance being attached to the markings, the white being distributed as follows-muzzle, blaze up face, broad white collar on neck, chest, fore-legs, feet, and tip of tail, whilst black shadings on the face and ears are much admired. As regards height, a dog should not stand less than 30 inches or a bitch less than 27. (See Feather, Haw.)

St. Hubert Hound.-A French breed, which is practically identical with the bloodhound, with which it has been frequently crossed. (See Bloodhound.)

\section{St. Vitus's Dance. (See Chorea.)}

Samoyede Dog.-The home of this variety is in the Siberian district of Russia, where he is used as a draught dog, as the Esquimaux is in Arctic circles. The head of this breed resembles that of the Esquimaux, but it is rather less massive, and the Samoyede is of a lighter build and more racy-looking than the latter, whilst his back is shorter, his loins more tucked up, and he is feathered a part of the way down on the back of the fore-legs. His height is also a little less than that of the Esquimaux, but he is a most active, willing worker, and has rendered excellent service to explorers in the North. (See Esquimaux Dog, Feather.)

Sand is occasionally used as a covering for the floors of indoor kennels; but even if it is spread thickly it is not recommended, as it is apt to get into the eyes, ears, and coats of the dogs.

Sarcoptic Mange. (See Mange.) 
Saturation.-The theory propounded by Mr. Bruce Lowe in connection with horse-breeding, to the effect that if a male and a female are constantly bred together, the latter in the course of time becomes so saturated with the blood of the former, through the medium of successive offspring, that the younger animals become more like the male parent at each successive birth, is no doubt believed in by some dog-breeders. At the same time, more will have to be known of the theory before it is generally accepted, but it unquestionably is subscribed to by many horse-breeders who have studied its possibilities, and if it is correct in the case of horses it is difficult to see why it should not apply to dogs. (See Back Blood.)

Savageness.-Undoubtedly some breeds are more pugnacious than others, and the different members of each breed, and often of the same litter, possess very different tempers. Many dogs become more or less quarrelsome and unreliable in disposition as they grow old, and therefore develop into dangerous companions for children; but a dog which is savage by nature is one which should not be allowed to live, as he is a perpetual source of danger to the public, and usually worthless for sporting purposes. If, however, he happens to be a particularly handsome specimen of his breed, he may be of some use for exhibition, but he should always be muzzled when taken out, even if led on a chain.

Sawdust.--Coarse sawdust is very useful as a covering for the floors of kennels if spread thickly on them. If not, it is liable to get blown about when the door is open and to get into the eyes, coats, and drinking vessels of the dogs.

Scalds, even if not of a serious nature, usually cause a great deal of pain, and are likely to leave unsightly scars behind them. The first thing to do is to exclude the air from the wound by covering it with oil and limewater in I 68 


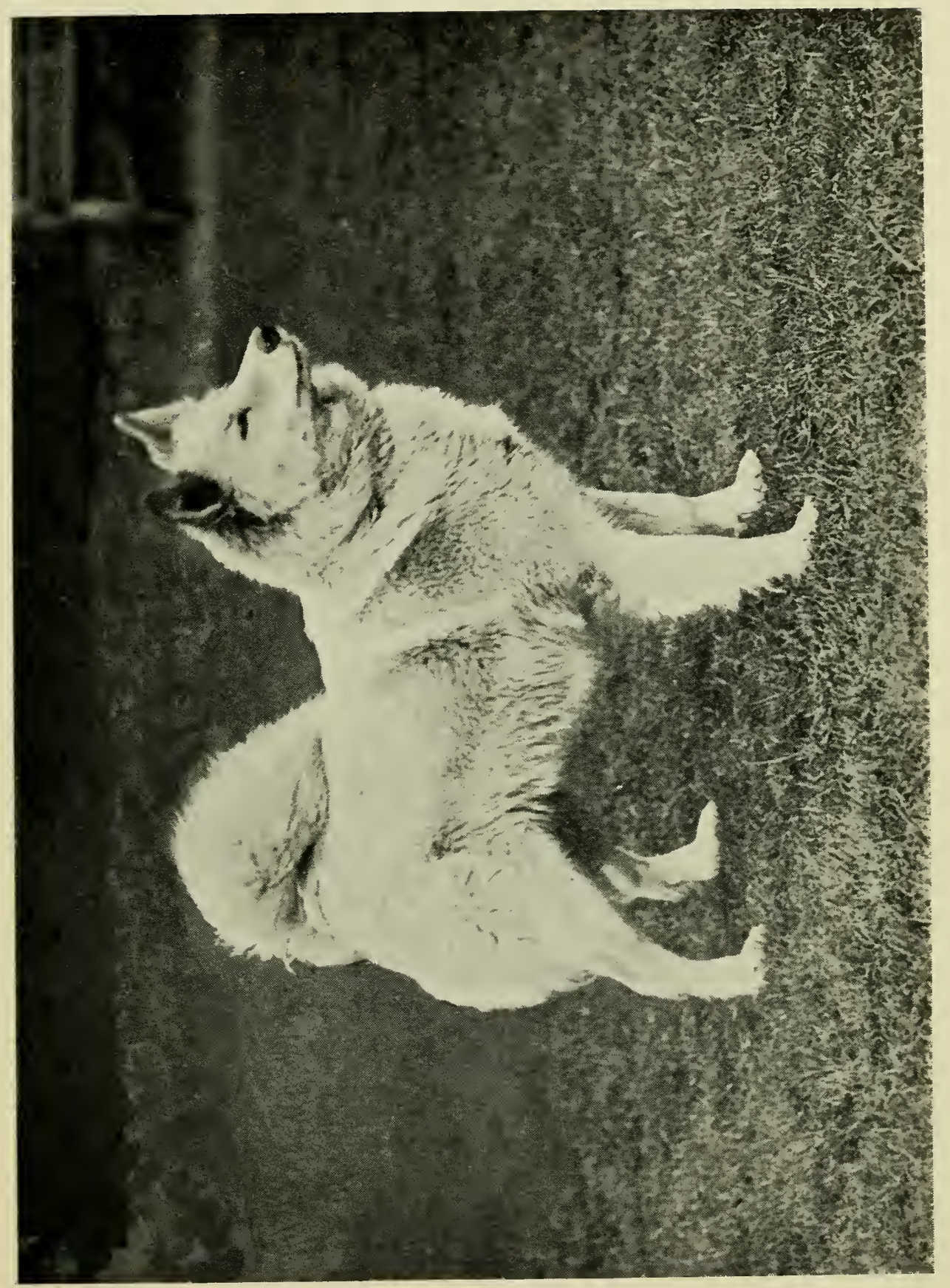



the proportion of two parts to one, to be followed by the application of a cooling ointment, such as zinc or boracic spread on lint, and kept in its place by bandages. Mild opening medicine may be given, and the dog should be allowed to rest quietly, no heating food being allowed him. (See Burns.)

Schipperke.-This intelligent, bright, and companionable little tailless variety of dog is a Belgian breed, and is largely used by the bargemen of Holland to protect the cargoes of their craft when they are navigating the canals. It goes without saying, therefore, that the Schipperke is a useful watch-dog; but as his size is small, his value lies more in his capacity for giving warning of the approach of strangers rather than in his ability to defend his master's property by force. In addition to his value as a guardian of his master's home and property, the Schipperke is a most companionable, good-tempered, and vivacious little dog, whilst the fact that he is indisposed to make friends with strangers endears him to many people who like to keep their dogs to themselves. With regard to the reference made above to the Schipperke as being a tailless breed, it may be observed that, as in the case of the bobtailed sheep-dog, many very good specimens of the variety came into the world with their caudal appendages fully developed. In such instances, again, as in the case of the bobtailed sheep-dog, breeders are permitted by the custom of the exhibiting community to remove the tails. The operation in the case of some Schipperkes is a very barbarous one, certain owners literally scooping out the root of the tail, so as to leave as little trace as possible of its having ever existed. It is not easy, moreover, to justify the encouragement of this form of mutilation in connection with fancy dogs, as either they should have tails or they should not. If they should, it appears to be an encouragement to fraud to permit a fancy point to be artificially produced in one 
breed and not in another, and therefore the position as it stands is far from satisfactory.

The head of the Schipperke closely resembles that of a fox, the muzzle being finer than that of a Pomeranian, to which it also bears a resemblance; the eyes should be a dark brown, round in shape, and very sharp looking; the ears being set on high, pointed at the tips, small in size, and carried perfectly erect. The neck is of fair length, but rather thick; the shoulders long and sloping; the chest wide and deep; the body short, broad, and deep at the brisket, and slightly tucked up, the fore-legs straight, the feet round and thick in the soles, the thighs very muscular. The coat is short and hard on the body, and still shorter on the head, but under the neck it is longer, forming a sort of mane, whilst on the chest there is a frill of longer hair, and the backs of the legs carry some feather. The recognised colour is black, but chocolate Schipperkes are also to be found, though they are not liked; the weight ranges from Io lbs. to $20 \mathrm{lbs}$. (See Docking Tails, Mutilation.)

Scurf rarely appears on the coats of healthy dogs if they are well groomed, and when it does it is usually the result of some skin trouble, which emanates from heat of the blood. A course of cooling medicine and plain food, combined with careful grooming, will remove the trouble. (See Brushing, Grooming.)

\section{Sealing-wax. (See Haw.)}

Second Mouth.-The term applied to the full second set of teeth which a dog usually possesses at the age of about nine months. (See Rearing Puppies, Teeth.)

Selection of Brood Bitch.-Most of what has been written below concerning the choice of a Stud-dog applies to the selection of a brood bitch; but it may be added that in the case of most breeds a bitch that is fairly long 
in the body is better for breeding from than a short-backed one, even though the latter property is a characteristic of the breed to which they belong. An old bitch, as a rule, should be mated with a young dog, and vice versâ, whilst middle-aged animals may be bred together; but though this is the usual and, generally speaking, wisest practice, there are exceptions to every rule. (See Brood Bitch, Selecting a Stud-dog, Sterility.)

Selecting a Stud-dog.-In selecting a dog to breed from, care should be exercised in deciding upon a healthy animal which is in full possession of all his faculties. An old or decrepit animal is rarely a successful sire, as his puppies, if they come, which is not always the case, are generally weakly, whilst any constitutional infirmities the parent may possess are liable to be inherited by them. It should be remembered, too, that there is always a liability of a throw-back to some remote ancestor, and this accounts for the disappointments experienced by many owners who breed puppies which do not resemble their parents at all. In short, the successful breeder should study pedigrees and carefully note the main characteristics which dominate each family before deciding upon a mate for each animal. Of course, a dog whose blood has crossed well with that of the bitch in other instances may be expected to suit her; but it is marvellous how often it occurs that one member of a litter is a most successful sire, whilst another one is absolutely valueless. On this ground it is safest to rely upon the services of the sire of a successful show-dog rather than upon those of the animal himself until the latter has proved his merits as a sire; and it may be added that, in the case of the sporting breeds, the offspring of parents which have been broken, and still more so if their forefathers have been broken as well, are more valuable for field purposes and easier trained than those which have never been broken. (See Back Blood, Brood Bitch, Sterility.) 
Selling.-It very often is a far harder matter to sell a good dog than people may believe when they hear of the prices which are alleged to have been paid for specimens of different breeds. Of course many-very many-of the transactions referred to are simply bogus, it being a case of $A$ purchasing a $\operatorname{dog}$ from $B$, and the two parties to the deal agreeing to state that a very much larger sum was paid than that which actually changed hands. Indeed, it often occurs that a cheque for a large amount is shown about, the amount stated thereon being supposed to represent what was paid for the dog, whereas the vendor agrees to return a considerable portion of the sum. Such transactions are merely regarded as tricks of the trade, as not merely do they gratify the vanity of the buyer and seller, but they serve to keep up the price of the variety the dog disposed of belongs to, as credulous reporters of newspapers contrive to get the sale published in their journals as news. The fancy prices put upon many showdogs by their owners and published in the catalogues are of course meant to be prohibitive, and are not taken seriously by practical men; but they, too, are often of use to a breeder in puffing his strain, as they are frequently the cause of a dog's likeness appearing in the illustrated papers, accompanied by the assurance that he is "valued" at a thousand pounds or more, whereas he would probably be dear at twenty. It is therefore necessary for a person with a dog for sale to disabuse his mind of the probability that he will be paid a long price for his animal. If the latter is well-bred, healthy, and good-looking, the best course for any one outside the dog world to take is to advertise it in such papers as The Field or Our Dogs, which enjoy wide circulations, and which occupy such high positions in canine circles that buyers and sellers may be reasonably certain that they will be protected against fraudulent persons. No owner of a good, well-bred dog, unless under very exceptional circumstances, need despair of disposing of his animal through such channels; and if 
he goes cautiously to work, and is not in too much of a hurry to accept the first offer he receives, he is likely to receive the fair market value of it. Another method of disposing of a dog is to enter it for a good show, and if it is a typical specimen of its breed it will possibly find a new owner; in fact, some of the great prize-winners have been thus purchased by experts, but it is unsafe for the amateur to trust to his own judgment at a show. (See Buying a Dog.)

Setter. (See English Setter, Gordon Setter, Irish Setter.)

Shavings are a good bed for dogs in hot weather, as they are cool, and the smell of turpentine in them, if they come from pinewood, assists in keeping insects away. The objection to the use of them is that, unless the bed is frequently renewed, they break up and become dusty. (See Bedding.)

Shedding Coat.-Dogs, like other animals, shed their coats at intervals, to the despair of their owners, if there is a show at hand at which it is desired that they should be exhibited. In the case of the long-coated breeds, the dead hair may be gently combed out in order to facilitate the growth of the new, whilst the jackets of the short-haired varieties a hard brush may be used. Wire brushes are often utilised for the purposes aforesaid with satisfactory results, but care must be taken to avoid injuring the new hair and skin. In cases where the coat comes off and leaves the dog practically bare, Spratt's Hair Stimulant may be used with advantage. (See Brushes, Combs, Grooming, Preparing for Show.)

\section{Sheep-dog. (See Bobtailed Sheep-dog, Collie.)}

Sheep-dog trials are held in many parts of the country, and invariably prove great attractions to the public. Their 
object is to test the working capacity of the dogs engaged, and the usual practice is to work each dog separately upon three strange sheep, and to decide the question of supremacy by the time he takes in fulfilling the conditions of the trial. These usually consist in driving the sheep round certain obstacles, between gaps in a short row of hurdles, and finally penning them in a small enclosure made of hurdles and provided with a very narrow entrance. The shepherd is allowed to accompany his dog and direct his movements-in short, to give him every assistance, but he may not touch the sheep, though he may help the dog by moving his arms when they are being driven into the pen.

Sheep's heads well boiled form a very excellent food for dogs, the broth being a welcome addition to the meal which is so much used in many kennels. (See Feeding.)

\section{Showing Dogs. (See Exhrbiting.)}

Shows.-The rage for dog-shows has extended during the past few years all over the country, with the result that almost every town enjoys an annual exhibition. No doubt these institutions bring a good deal of money into the district, but it is a matter of considerable doubt whether a multiplicity of shows is actually beneficial to the canine race. They certainly inflict a considerable hardship upon dogs which are hurried from town to town all through the summer months, and they have unquestionably been the means of producing the professional exhibitor, whose existence is a very doubtful blessing to the community and of more than questionable benefit to dog flesh. When shows were first established they were the mediums for attracting sportsmen who were genuinely desirous of comparing the merits of their respective animals, but now that they have become a business it can scarcely be denied that the commercial aspect is of paramount importance- 
indeed, it could not possibly be otherwise, when there are scores of people who earn their livelihood by exhibiting their dogs and the pecuniary increments derived therefrom. (See Exhibiting, Preparing for Show.)

Shy Breeders.-A stud-dog or brood bitch may easily acquire a reputation for being an unreliable breeder without being absolutely sterile, as health and condition have often a great deal to do with such matters. For instance, an animal which is very fat often fails to either beget or produce puppies, and it is just the same in the case of one which is in a debilitated state of health. It may be remarked, however, that many years ago The Field published a series of communications from a correspondent who endeavoured, by quoting instances in support of this theory, to show that some bitches which prove barren time after time can be got to breed if they are bled directly before the dog approaches them. The contention of the gentleman who wrote was, that if a bitch which is a shy breeder is suddenly rendered very weak before being served she will be likely to conceive, and he gave instances of several greyhounds which he had owned in order to support his statement. Whether his belief in the soundness of his views was justified, is a matter which those who care to make the experiment can decide for themselves. (See Sterility.)

Shy Feeder.-A dog is referred to as a shy feeder when either through ill-health or daintiness he refuses to eat. In such cases a tonic should be given, and he should be indulged by plenty of exercise and fresh air. (See Appetite, Feeding, Tonics.)

Sibbing.-Another term for In-breeding; which see.

Sight.-Some breeds, such as greyhounds, hunt their I75 
game by sight and not by scent, but they are the exceptions. (See Eyes, Greyhounds, Training Greyhounds.)

Sinews or Tendons are the bands which connect muscles with bones. They are extremely strong, but inelastic.

Size.-The size of dogs is ascertained both by taking their height or weight, sometimes by both, and in the latter case the results must obviously provide a better idea of the dog's bulk to a person who has never seen the animal than if only his height or weight are given; for a tall dog may be very deficient in substance and so weigh light, whilst a short one might weigh heavy if strongly built, thus giving a false impression of the symmetry and general appearance of the animal. Of course, in the case of toy dogs the question of weight is the most important point to study. (See Height.)

\section{Skin Diseases. (See Eczema, Mange.)}

Skye Terrier.-This is a most attractive member of the canine family, and certainly is deserving of more support than it receives; but no doubt its popularity has suffered from the attention bestowed upon the two other breeds of Scottish terriers, namely, the Dandie Dinmont and the hard-haired Scottish. There also remains the fact that the admirers of the Skye have incurred a certain amount of blame in the matter, as the majority of them appear to have only valued the dog because of his fancy points, and have in consequence devoted more attention to his coat than to his other merits. As a matter of fact, however, there is a working and most useful type of Skye well known in his native Scotland, of a similar shape to the show animals, which only differ from him in the matter of coat. There is no gamer or better vermin terrier than these Skyes of the working type, and this statement casts no reflection upon the show specimens, which are often plucky enough for anything; but the immense coats they carry 
render it impossible for them to do full merits to their hunting powers.

The head of the Skye terrier is long and flat, and it possesses the peculiarity of being narrower at the back than it is at the front. This is a point that is insisted upon by breeders, but it is not always an easy matter to see the formation, owing to the wealth of hair. On this account some people insist upon having the head thoroughly wetted before deciding as regards the merits of a Skye, as the hair will then cling to the skull and show its shape. There is a slight ridge between the eyes, and the muzzle, which is strong and well filled in beneath them, tapers gradually from this point to the nose. The teeth must be level; the eyes dark hazel in colour, set rather close together and of medium size, the working type showing very well-defined bristly eyebrows. The ears are of two kinds-namely, prick, which are carried erect, rather small in size, turned rather inwards at the tips, and showing plenty of hair ; or drop, in which case they are somewhat larger and lie flat to the sides of the head. The neck is gracefully arched and of fair length, but looks shorter than it really is on account of the coat it carries; the shoulders moderately sloping; the chest deep, but not too wide; the body very long indeed, with well-sprung ribs and powerful loins; whilst the back is slightly arched towards them. The fore-legs should be short, straight, and heavy in bone; the feet large, with thickly-padded soles, and the hind-legs very muscular at the thighs. The tail is of fair length, it is carried rather low and well feathered. The outer coat in the case of the show variety is long, free from curl, and harsh on the body, rather shorter on the head, but still long enough in the case of many dogs to quite conceal the eyes; whilst the under coat is short, close, and sealskin-like. In the working type the coat is short, very hard and close. The recognised colours are blue, grey, and fawn; the average weight being about I $8 \mathrm{lbs}$. in dogs and I $6 \mathrm{lbs}$. in bitches. 
Slab-sided.-A dog is thus described when his sides are flat, owing to his ribs not being sufficiently rounded. (See Sprung Ribs.)

Slack Loins.-A dog is said to be slack-loined when this part of his body is long and weak, which often causes him to move as though there were a joint at this point connecting his two ends.

Slate Roofs are expensive, but, with the possible exception of tiles, the best of all for kennels. (See Roofs.)

Slips.- (a) The name by which the leather strap used for leading dogs is known. (See Exercising:)

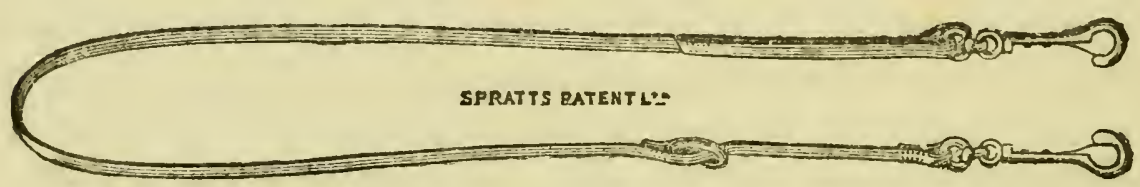

Double Lead.

(b) The leather couple used in coursing for keeping greyhounds under control before they are let go after their hare, which is known as "slipping" them. There is a cord running up the line, which is held in the slipper's hands, and when this is pulled by him it causes the collars round the greyhounds' necks to come open, so that they are free to commence coursing their hare.

\section{Snap Dog. (See Whippet.)}

Snipey Face.-A weak face which is not sufficiently developed to conform with the standard of the breed to which its possessor belongs.

Soap.-There are of course many sorts of dog soaps I 78 
in existence, but for ordinary purposes the old-fashioned blue curd is one of the best of all, if it can be procured. Wright's Coal-Tar Soap is also excellent, but a cake does not go very far when a big dog has to be washed; and carbolic soap is useful when there is a suspicion of skin trouble, but it is not good for the hair of delicate breeds, and leaves an unpleasant smell behind it. When the presence of fleas is suspected there is nothing to equal Spratt's Patent Dog Soap, which in addition to destroying the insects, effectually cleanses the skin. (See Washing Dogs.)

Soil.-A good deal more depends upon the nature of the soil upon which his kennel is erected than many breeders appear to imagine. It may therefore be pointed out that a heavy, damp, clay soil is very bad for dogs, whilst a chalky or sandy one is excellent. Of course it is not within the power of most people to select their residences so as to suit their dogs-although by doing so they will probably be benefiting themselves as well-but nevertheless, if they give the matter their consideration, they may avoid incurring unnecessary risks by selecting a hardy breed, if the soil is not well adapted for their purpose.

Sore Feet.-Dogs frequently get sore or raw places on their feet or between their toes, these being usually the result of some skin trouble which is affecting, or about to affect, other parts of their bodies. In such cases some cooling medicine and plain non-heating food should be given, whilst a washing or two in warm water, using tar or carbolic soaps, may do good in slight cases. (See Eczema, Mange, Soap.)

Sortiness. (See Sorty.)

Sorty.-A term applied to two or more dogs which are 
of identically the same type and appearance, in fact, well matched.

Soundness. - The question of a dog's soundness must depend in a measure upon the purposes to which he will be put; but of course this statement must not be taken as implying that an animal is absolutely sound if he happens to be suffering from some minor or obscure infirmity, which though it might be serious in the case of a field-dog, would be a matter of no importance in a domestic pet. Possibly, therefore, it would have been better to have adopted the expression "practically sound," for, as in the case of human beings, there must be very few dogs which would pass the scrutiny of a keen examination by a professional man without a slight weakness being detected somewhere. It may however be suggested that impaired vision or hearing, decayed teeth, chronic lameness or rheumatism, chorea, indigestion, a weak heart, phthisis, diseased bones, contorted limbs, a tendency to epilepsy, chronic skin disease, sterility, and imperfect formation of the generative organs, all constitute unsoundness, and should deter any one from knowingly purchasing an animal afflicted by any of them. Of course a weak heart, a crooked limb, chorea, or sterility, might not be a serious objection against a dog which has only to be kept as a pet about the house, but it is always wiser to avoid an animal with an "if " about it when possible; but naturally in the case of an old favourite which is attacked by disease or misfortune the case is different. On the other hand, there are hundreds of sound, or practically sound, healthy dogs which labour under a disability to do the work which some owners require of them, and yet be quite well adapted for the purposes of others. Thus a gun-dog which is deficient in scenting powers or gun shy, a greyhound or whippet which is troubled with the slows, a terrier which is deficient in courage, or an animal with a slight deformity, might be I 80 
readily purchased by some people though useless for others. Moreover, some of the above defects cannot strictly be included in the category of either soundness or unsoundness, but as they affect the working capacity of a dog, it may be permissible to refer to them here. It may be added that no dog which is suffering from any temporary disease or illness can be regarded as sound, even though he be on the high road to recovery, as relapses may occur, or convalescence be retarded, by a change of food or kennel.

Spaniels.-The spaniel family is a very large one, and consists of four divisions-namely, the Springers, by which name the larger-sized field spaniels, including the Clumber, Sussex, Field, Norfolk, and Welsh, are known; the Cockers, or smaller-sized field varieties; the water-spaniels, English and Irish; and toy spaniels. The above breeds are referred to under their respective headings.

Spanish Bulldog.-A big, coarse dog, somewhat of the bull-mastiff type, and possessing few points in common with the show bulldog of the present day. An ineffectual attempt was made to popularise the variety in this country some forty years ago.

\section{Spanish Fly. (See Cantharides.)}

Spitz Dog.-The German name for the Pomeranian.

Splay Feet.-Open, flat feet.

Splints.-(a) The narrow, flat pieces of thin board, or possibly stout cardboard, which are used in cases of fractured limbs, to keep them in position after being set.

(b) Small bony lumps which occasionally, but infreI8I 
quently, appear on the fore-legs of dogs, such as greyhounds, which undergo much hard work. They create inflammation of the sinews and ligaments, and lameness usually follows. Rest, cooling medicine, and food, and painting with iodine twice a day, usually causes them to disappear ; if not, professional advice should be obtained.

Sports.-In breeding there is always a chance, more or less remote, of a puppy displaying some peculiarity, such as a lemon-coloured retriever being born of black parents. This does not necessarily betoken any impurity of blood, though it may possibly be due to the impressiveness of an ancestor, and as a rule the sports are fairly safe to breed from, as their offspring usually revert to the type of the parents of the sports, though there are instances of their peculiarities being perpetuated in their puppies. (See Back Blood.)

Sprains, which consist of the straining of a muscle or tendon, are by no means uncommon amongst dogs, and in some cases are apt to be mistaken for rheumatism, as the symptoms, which consist of tenderness and fever, occasionally accompanied by lameness, are somewhat similar. Hot fomentations often bring temporary relief, and the part affected may subsequently be gently rubbed with Elliman's Embrocation, soap liniment, or some stimulating lotion. Absolute rest should also be allowed the dog. (See Counter-Irritants.)

Springer.-The name given to the larger varieties of field spaniels. (See Spaniels.)

Spring Hooks.-There should be a strong spring hook at the end of every chain or lead, and a swivel which works easily should be attached to it, lest the chain gets twisted up and the animal strangled. Show chains possess two spring hooks, one at each end-this being an admirable 
arrangement, as it enables the chain to be easily shortened. (See Chains, Leads, Swrvels.)

Sprung Ribs.-Ribs are said to be sprung when they are nicely rounded. (See Slab-sided.)

Sterility.-Occasional instances are known of dogs and bitches being absolutely sterile, but they are not common; and it is a fact well within the knowledge of most breeders that a dog or a bitch may produce puppies by one animal and not by another. (See Selecting a Brood Bitch, Shy Breeder, Selecting a Stud-dog.)

Stern.-A name by which the tail is often referred to. It is generally applied in referring to hounds.

Stifle.-The upper joint of the hind-leg.

Stitching Wounds.-A little nerve is required in stitching up a wound, but the operation is not a particularly difficult one as a rule. The needle to be used should be slightly bent, and it is best to thread it with a thin silver wire. The point of the needle should be inserted a little way from the side of the wound, and passed along so as to come out on the other side of it in such a manner that the two sides can be drawn together. The wire can then be secured so as to prevent them coming apart, and may be left in for a few days until the healing process has well advanced. It is necessary to examine the stitches at least once a day in case inflammation sets in, as if it does the stitches must be temporarily removed. The number of stitches will depend upon the nature of the wound, but each one must be made separately and independently of its neighbour, at intervals of about one inch according to circumstances.

Stone--Dogs sometimes, but not very often, suffer from stone in the bladder, the symptoms of which are 183 
frequent attempts to pass water with small results, the urine being almost black when it does appear. If the stones are small they may be passed, but usually an operation is necessary, and hence the advice of an experienced veterinary surgeon should be obtained with as little delay as possible, as the presence of the stones inflicts considerable suffering upon the dog. (See Calculus.)

Stop.-The indentation in the skull between the eyes of some breeds, notably the bulldog.

Stoves.-Speaking generally, stoves are not only unnecessary but injurious adjuncts to a kennel, besides which they are a constant source of danger, owing to the possibility of their setting fire to the place. Very few healthy dogs, unless under very exceptional circumstances, are benefited by being kept in an artificially warmed atmosphere, but in the case of delicate toys and sick animals it is different. (See Hospital.)

\section{Strains. (See Sprains.)}

Straw is the best bedding that a dog can have, and wheaten straw is preferable to either barley or oat. (See Bedding.)

\section{Stud-dog. (See Selection of Stud-dog.)}

Sulphur, in the form of flowers or milk of sulphur, is a most excellent medicine for use when the blood is heated, and may be given internally in milk, the dose being about a teaspoonful for a large dog. Sulphur is also used successfully as an ointment when mixed with lard, and often with other materials, in cases of eczema and mange; which see.

Suppositories are cone-shaped mixtures of cocoa-butter and oil mixed with drugs, and made sufficiently hard to 


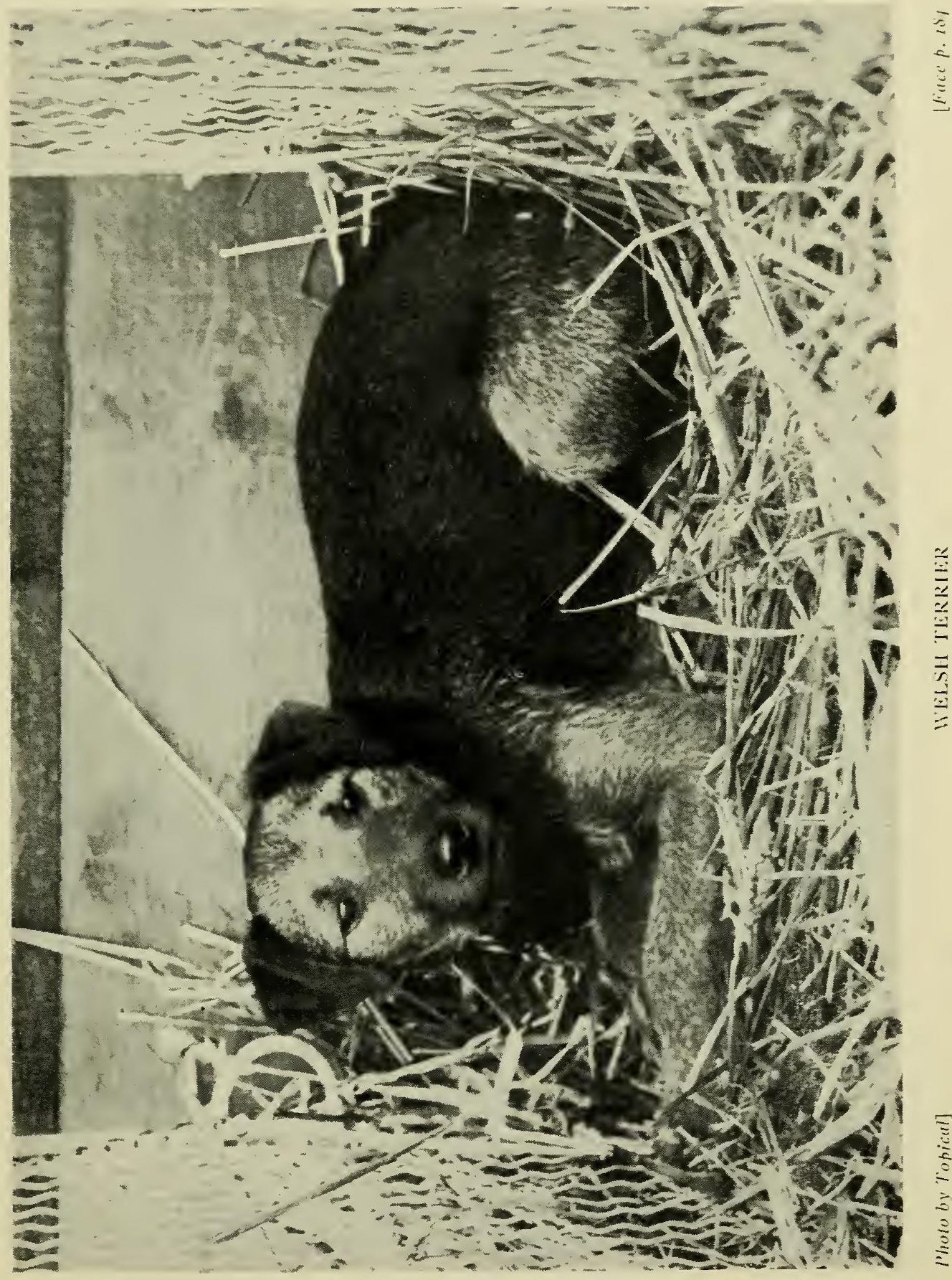



enable them to be forced up the rectum in cases where it is necessary to adopt the method of administering medicine by the bowel. They are also used in cases of inflammation of the rectum, piles, and hæmorrhoids; which see.

Surfeit is the result of injudicious feeding and the want of proper exercise, which combine in upsetting the stomach and heating the blood, with the result that inflamed patches break out all over the body, and from these a disagreeable, sticky discharge appears. Subsequently scabs form, and when these come off bare patches are left. The treatment is similar to red mange; which see.

Sussex Spaniel.-This variety is no doubt one of the most ancient of the British breeds, and in the opinion of several writers of authority the taproot from which the setter originated. For many years the Rosehill strain was the source from which the finest Sussex spaniels of the day had sprung, but the fortunes of the breed began to decline more than a generation ago, with the result that few really typical specimens of the old type, and still fewer pure-bred Sussex spaniels, can be found. This is greatly to be regretted, as they were first-rate working, intelligent, and keen-nosed dogs, and hence the practical extinction of the race leaves the canine world distinctly poorer.

The head of the Sussex spaniel is rather heavy, and the forehead somewhat projecting; the muzzle being long and square, the nose liver-coloured, the eyes soft and hazelcoloured; the ears, which are low set, being long, narrower at the setting on than at the tips, and well fringed with hair. The neck is slightly arched and very strong-looking; the shoulders sloping, the chest deep, and the body long, with well-sprung ribs and powerful loins. The fore-legs are short, straight, and well-feathered down to the ground; the feet being large and carrying plenty of hair, and the hind-legs being very muscular about the thighs. The tail, which is docked, is feathered and carried low ; the coat being 
thick and soft, but weather-resisting, and for preference it should be quite flat, but a slight wave is permissible. The colour is a rich golden liver, any approach to a puce or muddy shade being a bad fault, and the average weight is about 40 lbs.

\section{Sutures. (See Stitching-up Wounds.)}

Swivels.-Every chain or lead used for dogs should have a swivel which works easily close to the spring hook which is attached to the collar, and the addition of one at the middle and a third one at the other end, if that has a sprink hook on it, is a very wise arrangement, which is cordially recommended to the consideration of dog-owners. All properly constructed show chains are thus designed, as a protection against the dog being strangled on the bench or whilst travelling. (See Chains, Slips, Spring Hooks.)

\section{$\mathrm{T}$}

Table Scraps form an excellent food for dogs, and especially those of the toy varieties, provided that the green vegetables are not omitted and that the amount of meat fat and greasy substances is strictly limited, as too much stimulating food is certain to heat the blood of animals which do not get much exercise. (See Feeding.)

Tailless Dogs.-It is rather a moot question whether there are any varieties of dogs in existence which are naturally tailless, but certainly there are some breeds, many representatives of which are born with no tails or else very short ones. Probably this may be the result of a long-continued custom of removing the caudal appendages of the breeds in question, and if so it is an illustration of heredity. On the other hand, if it were so, there would be I 86 
surely many cases occurring of fox-terriers or spaniels coming into the world with abbreviated tails, but such are very rare. It may be remarked, too, that there is an Oriental breed of tailless dogs.

Tan is sometimes used as a covering for the floors of kennels, but is not by any means an ideal substance for the purpose, as though to a certain extent it may be a disinfectant, it soon becomes dry and dusty; whilst if it is kept damp, it obviously is calculated to produce rheumatism amongst the dogs, which constantly move about and lie upon it.

Tape Muzzle.-A serviceable emergency muzzle can be made out of strong, wide tape, or even thick string, by doubling the tape and then by placing one end of the loop so formed just behind the dog's ears and passing the tape along the top of the skull and muzzle to about half-way along the latter, so as to get the length from that point to the back of the ears. A knot is then made at that point, and the two loose ends of the tape are allowed to hang down, one on each side of the muzzle. They are next knotted again below it in such a manner that the loop thus formed will fit tightly enough round the muzzle to prevent the dog from opening his jaws further than is desired. The ends are then passed backwards under his head until they come to the part of the neck under the ears, where a third knot is made, and the ends being then passed up each side of the neck to meet the other end of the loop to which they are fixed. (See Muzzles.)

\section{Tape-worm. (See Worms.)}

Tar in one form or another is valuable in treating cases of skin diseases, and it is also a very good dressing for the outsides of wooden kennels, as it is disliked by insects. If 
by any accident it should get on the coats of dogs, tar can be removed by rubbing grease or butter on the place.

\section{Tartar Emetic. (See Antimony.)}

Tartar on Teeth is a frequent cause of suffering to dogs which are constantly fed on soft food, as this sort of diet provides no means for cleansing the teeth, and therefore the tartar accumulates, and in the end produces inflammation of the gums. If large bones or Spratt's biscuits, given whole and dry, are occasionally provided the animals to gnaw, the growth of tartar will be checked; but when it once has formed it will be necessary to have the teeth scraped by a professional man. A course of cooling medicine should be administered if there is inflammation of the gums. (See Teeth.)

Technical Terms.-The following are the technical terms most in use amongst dog-breeders :-

Apple-head.-A round head. This appearance is sometimes produced by the ears being set on low, and not by the roundness of the skull.

Beefy.-The term applied to heavy quarters.

Brush.-The tail; generally applied to that of the collie.

Business-dog.-A fighting dog.

Butterfy Nose.-A parti-coloured nose.

Button Ears.-Ears, the flap of which hang down wards, so as to conceal the interior.

Cát-foot.-A round foot.

China Eye.-A wall eye.

Cloddy.-Thickly built.

Cobby.-Compactly built.

Couplings. - The body and loins which couple the fore-end and hind-quarters.

Cow Hocks.-Hocks which turn inwards, so that the stifles and feet turn out. 
Dish-faced.-A dog is said to be dish-faced when the end of his muzzle turns up higher than the part of it nearest to the eyes.

Down-face.-A face which does not turn upwards, as it should do in some breeds.

Dudley Nose.-A light-coloured nose.

Face.-The muzzle.

Feather.--The hair which runs down the back of the legs and below the tails of some breeds.

Flag.-WThe tail, usually applied to that of the setter. Frill.-The growth of hair on the chest.

Frog-face.-A long, down-face in a short-faced breed. Furnished.-A dog is said to be furnished when he has matured.

Hare-foot.-A long foot.

Haw.-The red inner membrane of the eye.

Lay-back is formed by the upper jaw and nose receding.

Leather.-The fleshy part of the ear.

Made Up. (See Furnished.)

Old Man.-A matured dog.

Overshot.-The formation caused by the upper teeth projecting beyond the lower ones.

Pig Eyes.-Small, deeply-set eyes.

Pig Jaw.-An upper jaw which projects in front of the lower one.

Pincher Jaw. (See Pig Jaw.)

Reachy.-A lathily built, long-framed dog is thus described.

Roach Back.-A back which is arched from the shoulders to the top of the loins.

Rose Ears.-Ears, the tips of which lay back, so as to show the interior.

Slab Sides.-Flat sides.

Sorty.-A term applied to two or more dogs of exactly similar appearance.

Splay Feet.-Flat, open feet. 
Stern.-The tail, usually applied to hounds.

Stop.-The indentation in the skull between the eyes of some breeds.

Thumb Marks.-The dark patch on the head of a pug, and the legs of black-and-tan terriers.

Tulip Ears.-Upright ears.

Undershot.-A dog is said to be undershot when his lower teeth project in front of the upper ones.

Up-face.-A term applied to a nose and upper jaw which recede.

Wheel-back.-Another term for a roach-back.

Teeth.-A dog possesses forty-two teeth-namely, twelve incisors or front-teeth, four canines or eye-teeth, and twenty-six molars or back-teeth. By the time the puppy has arrived at the age of about nine months he will usually have got his second or permanent set, which under ordinary conditions should last him until he is six years old, when they begin to become loose and fall out. Much, however, will depend upon the manner in which a dog has been treated, as injudicious feeding will undoubtedly affect his teeth; and if he is allowed to carry stones in his mouth and encouraged to gnaw hard sticks they are sure to suffer. Occasionally dogs lose their teeth at quite an early age through the effects of canker and other causes, in which event their digestions become impaired. One case at least, however, of a dog wearing a complete set of false teeth with evident satisfaction has been known, the animal in question being a schipperke, the property of an enterprising West-end dentist, who exhibited him at a show held at the Westminster Aquarium some twenty years ago. (See Canker in the Mouth, Rearing Puppies, Teething.)

Teething.-Many puppies suffer a good deal from the effects of teething, and in severe cases fits may be the result of their doing so. The first milk-teeth usually appear through the gum when the pups are about three weeks 
or a month old, and if there is at this or any future time a difficulty in cutting them, which will be found by a swelling and redness of the gums and evident pain in sucking and eating, it may be necessary to use a lancet or very sharp penknife, which must be absolutely clean. The second teeth are generally in their places when the dog arrives at about the age of nine months; and whilst the milk-teeth are being shed and the later ones cut, it is necessary to inspect the condition of the mouth pretty frequently, so that loose teeth may be extracted if necessary, as if they remain in for too long they are very likely to affect the regularity of the second set, and thereby ruin the appearance of the dog's mouth. (See Fits, Full-mouth, Rearing Puppies.)

\section{Telegony. (See Back Blood.)}

Temperature.-The temperature of a dog varies slightly according to where it is taken, but the usual and best course to pursue is to place the thermometer in the rectum, where the normal temperature is $\mathrm{IOI}^{\circ}$ to $\mathrm{IO}_{4}{ }^{\circ}$. Under the forearm it is practically the same, but it is not so easy to keep the thermometer in its place. (See Thermometer.)

\section{Tendons. (See Sinerws.)}

Terrier.-The expression terrier is unquestionably derived from the Latin word terra, which signifies "earth," and consequently is applied to such varieties of dogs as are used for going to ground after vermin. Apart from that absolutely indispensable characteristic-gameness, a terrier must be structurally fitted for this sort of work, and he must not therefore be of too large a size or too wide in the chest, else he could never enter some drains or narrow earths. His height at shoulder is not so much a matter of importance-although of course there must be some limit imposed upon it-as narrowness of chest, as the terrier 
enters the earth with his front legs in front of him, and therefore a taller dog with a narrow chest can do so far easier than a shorter one with a broad chest.

Thatched Roof.-This sort of roof is warm in winter, cool in summer, and attractive in appearance; but it is apt to harbour insects, and its use is prohibited by most local authorities. (See Roofs.)

Thermometer.-A clinical thermometer should be included in the medical stores of every kennel, as its use is a sure guide in cases of fever. It is quite easy to read, and when properly used will often be of great assistance to an owner when attempting to ascertain what ails his dog. (See Temperature.)

Thibet Mastiff.--These dogs are largely used in their native country for the purposes to which mastiffs were devoted by our forefathers, and prove themselves most reliable guardians of life and property. In disposition they are unreliable, and certainly the majority of the few specimens seen in this country have been more or less dangerous animals for strangers to approach. The Thibet mastiff is, however, a most handsome, imposing-looking dog, his size being rather less than that of the mastiff.

The head in this breed is rather narrow in comparison to the size of the dog, domed on the top, of moderate length, and carries some heavy wrinkling of skin on the forehead, which; combined with the small sunken eyes and the display of some haw in the corners of these, gives the animal a very ferocious expression. The ears are of medium size, and set low; the neck, body, and legs resemble those of the mastiff; but the tail, which is very bushy, is carried high; and the coat is very much longer. The recognised colour is black, with a tan muzzle and tan spots over the eyes. 
Thick Head.-A coarse, heavy head.

Thorns, if they penetrate a sensitive part, are liable to cause lameness, and possibly abscesses to form. The only precaution that can be taken against such occurrences is to examine the feet and legs of any dogs which have been running amongst bushes when they come in from exercise, and to remove the thorns, if any are found, with a pair of pincers. (See Abscess, Exercise, Lameness.)

Throaty.-A dog is described as such when he has a superfluity of loose skin on his throat.

\section{Throw Back. (See Back Blood.)}

Thumb-mark.-The dark patch on the head of a pug, and the marks above the pasterns on the legs of black-and$\tan$ terriers are referred to as thumb-marks. (See Blackand-Tan Terrier, Pug.)

Ticks are the objectionable, bluish-coloured parasites which attach themselves to the skin of dogs. A good dressing of paraffin, if the dog belongs to one of the larger varieties, but not if he is a toy as it is too strong for them, will usually clear the ticks away, unless they have established themselves securely and in numbers. If so, they will have to be cut in halves with sharp scissors. Dogs which have gone over land over which sheep have been are especially liable to be attacked by ticks. (See Fleas, Lice.)

Tile Roofs form a very good covering for kennels, provided they are well pointed and laid on boards, as they are warm in winter and cool in summer. (See Roofs.)

Tongue.-As in the human being, so it is in the case of dogs which are sick-the tongue usually supplies some 
indications of the nature of the ailment. Thus a hot, dry, and very red tongue is associated with inflammation of the stomach; a white, dry tongue with poverty of the blood; a furred, yellowish tongue with liver troubles; a furred, white one with indigestion; and a dark-brown, swollen tongue with rabies. Paralysis of the tongue occurs when the muscles become affected, so that the dog is unable to draw it back, and it therefore hangs out of the mouth at one corner, and usually becomes dry and hard. There is no cure for a paralysed tongue, which is usually met with amongst the short-faced varieties of toy dogs.

Tonics are useful in building up dogs which have got run down through the effects of an illness or constitutional weakness.

Tourniquet.-In cases of severe wounds which cause much bleeding it is sometimes necessary to apply a tourniquet, if the injury is in such a position that one can be used. A tourniquet consists of a bandage, which in cases of emergency may be a pocket-handkerchief, wrapped very tightly either above or below the wound -sometimes it is necessary to fix one in both positions. In cases of an artery being severed it should be above the wound, but when veins are cut it should be below it. (See Arteries, Bleeding, Veins.)

Toy Bulldogs. - The rehabilitation of the toy bulldog in this country has been accomplished within the past few years. Half a century ago and less he was well known in England; but his admirers fell off, and the best specimens found their way to France, where they became great favourites. French breeders, however, began to introduce points of their own, and the result was that unsightly bat-ears and frog-faces became the fashion amongst them. These hideous properties, however, have now been 
pretty well bred out by English breeders, and in consequence some very good specimens of the bulldog, weighing about 22 lbs., are now to be seen. (See Bulldog, Frog-face.)

Toy Dogs.-The expression toy dog is rather an elastic one, as for all practical purposes some of the larger varieties are to all intents and purposes toys. Still, properly speaking, the toy breeds may be summed up as being King Charles, Blenheim, Japanese, and Pekinese spaniels, blackand-tan and bull terriers under ro lbs. weight, Italian greyhounds, Maltese, pugs, and Yorkshire terriers. The accompanying illustration shows an admirably designed basket for

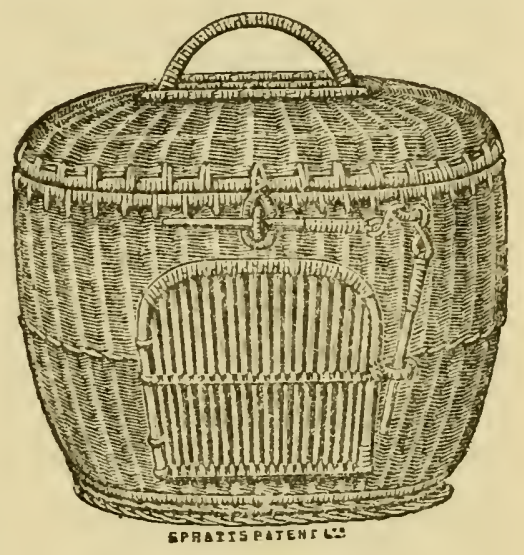
the use of toy dogs. Not merely does it serve as a travelling basket, if necessary, but it will be found most useful for shutting the little dogs in during cold weather.

Toy Terrier is the name usually applied to the dwarf black-and-tan terrier of from 5 lbs. to Io lbs. weight, which has been produced by a course of in-breeding from the larger-sized dogs of the same variety. The toys are desired to resemble the heavier dogs as closely as possible in appearance, but they are usually much rounder in their skulls, larger in the eye, and not so good in colour and markings. (See In-breeding.)

Trace.-The black line which runs down the backs of pug dogs is called the trace. (See $P u g$.)

Training Greyhounds.-There is not much difficulty in getting a greyhound into condition if the time can be spared to do so, and the animal is properly fed; but both 
experience and good judgment are of course necessary when a high-class greyhound is being trained for an important stake. It is, however, quite within the power of most people who are fond of sport to get their dogs fit enough to run at any local private meeting, and many winners at these most enjoyable little fixtures are trained by their owners. As is the case in almost everything that is connected with the health and well-being of dogs, the questions of food and exercise are matters of paramount importance in connection with the preparation of a greyhound, as there is no chance whatsoever of his laying on muscle and getting into proper condition unless he has good food and possesses a good appetite to eat it. The exercise should mainly consist of daily long, slow walksit being the custom for a trainer to take his dogs out well clothed, in leather leads, in batches of five or six, each batch being entrusted to the care of a separate attendant, as no man can look after more than the above number at most; and besides this, different animals may require different exercise, so each batch has its own daily course of work, and it is possible to keep apart any members of the kennel which may bear animosity towards each other. The daily exercise should take the form of long walks, in the course of which the greyhounds may be loosed from their leads and allowed a gallop in a meadow or on a common, but they should not be encouraged to cover long distances at top speed, but merely to frolic about.

In the case of an owner who is only training one or two dogs, and who cannot personally superintend all their requirements, the question of proper exercise is not an easy one, as the animals have to be entrusted to the charge of a man who may not care to walk the distances along the road which are regarded as necessary for their wellbeing. This difficulty can, however, be surmounted by giving the man a letter to deliver to a friend of the owner's who lives some miles away, and if a reply is sent stating Ig6 
the time at which the man arrived and left, a check upon shirking the walk will have been arrived at.

Of course greyhounds in training require a certain amount of fast work to clear their wind; but it need not be given them too frequently else they may grow stale, and on no account should they see a hare too often, else they are certain to get cunning sooner or later and begin to cut corners when slipped instead of keeping as close to the scut of their hare as they can. The best way to indulge them with the necessary fast gallop is for the trainer, or somebody the dogs are fond of, to leave them in charge of another man whilst he proceeds the required distance away, and then calls to them. On being released the greyhounds will always make the best way they can to their trainer, and hence the gallop will come off all right. It may be added that it is necessary to strip the dogs of the clothing they usually wear when taking walking exercise before they are galloped; and with reference to this clothing, it may be added that it is customary to protect them with a waterproof sheet if the weather is wet.

As regards feeding arrangements, it may be observed that Spratt's greyhound biscuits, or Rodnim soaked in the broth of bullocks' or sheep's heads, is a very excellent staple food if some of the meat from the heads is cut up small and mixed with the stew, and a few green vegetables which have been boiled separately can also be added. Oatmeal, treated similarly to the biscuits, may be given as an alternative; but it heats the blood of some dogs and causes looseness in the bowels of others when first given them, and therefore it is not wise to commence feeding greyhounds in training upon oatmeal just before they are expected to run. As the eventful day approaches a larger allowance of meat should be given them, lean mutton being the best, as it is both nutritious and easy of digestion, two feeds a day being amply sufficient in the case of healthy animals; but bad doers which require to be coaxed may be fed oftener and in smaller quantities. 
Sloppy food, provided that it is made so by good strong broth, is preferable to dry, as it tends to reduce the dog's thirst, and the less water they get the better, as it is bad for the wind of a dog in training. It may here be observed that many greyhounds which are regularly fed on sloppy food will drink next to no water, and sometimes none at all.

On coming in from exercise the feet of the dogs should be carefully examined, lest they should have been cut, and then washed. It is also most essential that a dog in training should be well groomed each day to keep his skin in good condition. In conclusion, it may be pointed out that there is no unvarying rule for regulating the amount of food and exercise which each animal should be allowed, as individual dogs differ very widely in appetite and constitution; so that food and exercise which would be far too much for one dog would not nearly suffice for another. (See Clothing, Exercising, Feeding, Grooming.)

\section{Travelling. (See Journeys.)}

Trimming is so nearly allied to the nefarious practice of faking, that it may honestly be said that there is very little distinction that can be drawn between the two. Trimming, however, has more by custom than by right come to be regarded as a minor form of faking, which is winked at by persons who would throw up their hands in horror at the bare idea of an exhibitor dying his dog's coat, though they themselves do not scruple to employ a professional "handler" to pluck the coats of their long or wire-haired dogs if they should be too profuse, and their own servants are not proficient in the art. It is, in fact, safe to assert that the coats of almost half of the wire-haired fox terriers and Irish terriers which are exhibited are more or less plucked and trimmed before they are shown, and in the case of Bedlington terriers matters are even worse; yet exhibitors of the latter are 198 
often disqualified, whilst owners of the former go free, for the simple reason that they may not require so much doing to them. If the statement as regards the trimming of the breeds mentioned, and of other varieties also, is doubted, let any of those who are disposed to do so endeavour to get a quiet look at a few of the crack prize dogs a few weeks before the show season commences and a similar time after it concludes, and they will scarcely be able to recognise some of the animals, as many persons who have purchased a dog at a show has discovered to his cost. (See Exhibiting Dogs, Faking.)

\section{Tripe. (See Paunches.)}

Truffle Dog.-This breed of dog, if it really is a distinct breed, as it doubtless originated in a cross between the poodle and the terrier, which appears to have been very carelessly kept up, is rarely seen in this country; but in parts of the Continent it is used for the purposes of locating truffles, which it accomplishes by its powers of scent.

Tucked Up.-When a dog's back ribs are short, so that his loins are slender, or when he is temporarily drawn up at this point through illness or cold, he is described as being tucked up.

Tulip Ear.-An erect ear. The term is usually applied to bulldogs whose ears stand up straight. (See Bulldogs.)

Tumours are slow-growing growths which attack old dogs as a rule, but are also not infrequently the result of a blow. They appear on different parts of the body, and if taken in time are sometimes amenable to treatment; but as a rule a surgical operation is the only remedy that is likely to prove efficacious. Hence the advice of a 
veterinary surgeon should be obtained. Tumours are of various sorts-viz. fatty tumours, which usually attack old dogs; fibrous tumours, generally to be seen on the limbs and jaws as a result of some injury; fibro-cystic tumours, which are mostly situated on the elbows, and are caused by the dog lying on a hard bed; and osseous tumours which are hard, bony growths on the hocks and forejoints.

Twitch. (See Chorea, Distemper.)

\section{U}

Underhung. - When the lower row of front teeth project in front of the upper ones the dog is said to be underhung.

\section{Undershot. (See Underhung.)}

\section{Unsoundness. (See Soundness.)}

Up-face.-The formation which results from the nose receding, as in the case of the bulldog. (See Lay-back.)

Urinary Troubles occasionally affect the dog, the most common being an inability to hold water. This is occasionally due to timidity, but may be caused by a weakness of the bladder, in which case a reference to "The Dog's Medical Dictionary" (Routledge \& Sons) will provide some very useful information. It may also be a symptom of stone, in which case it must be regarded as serious.

If there is a difficulty in passing water, and this increases, it may be necessary to pass a catheter up the penis in order to allow it to escape, and for this professional advice should be secured without delay. When 


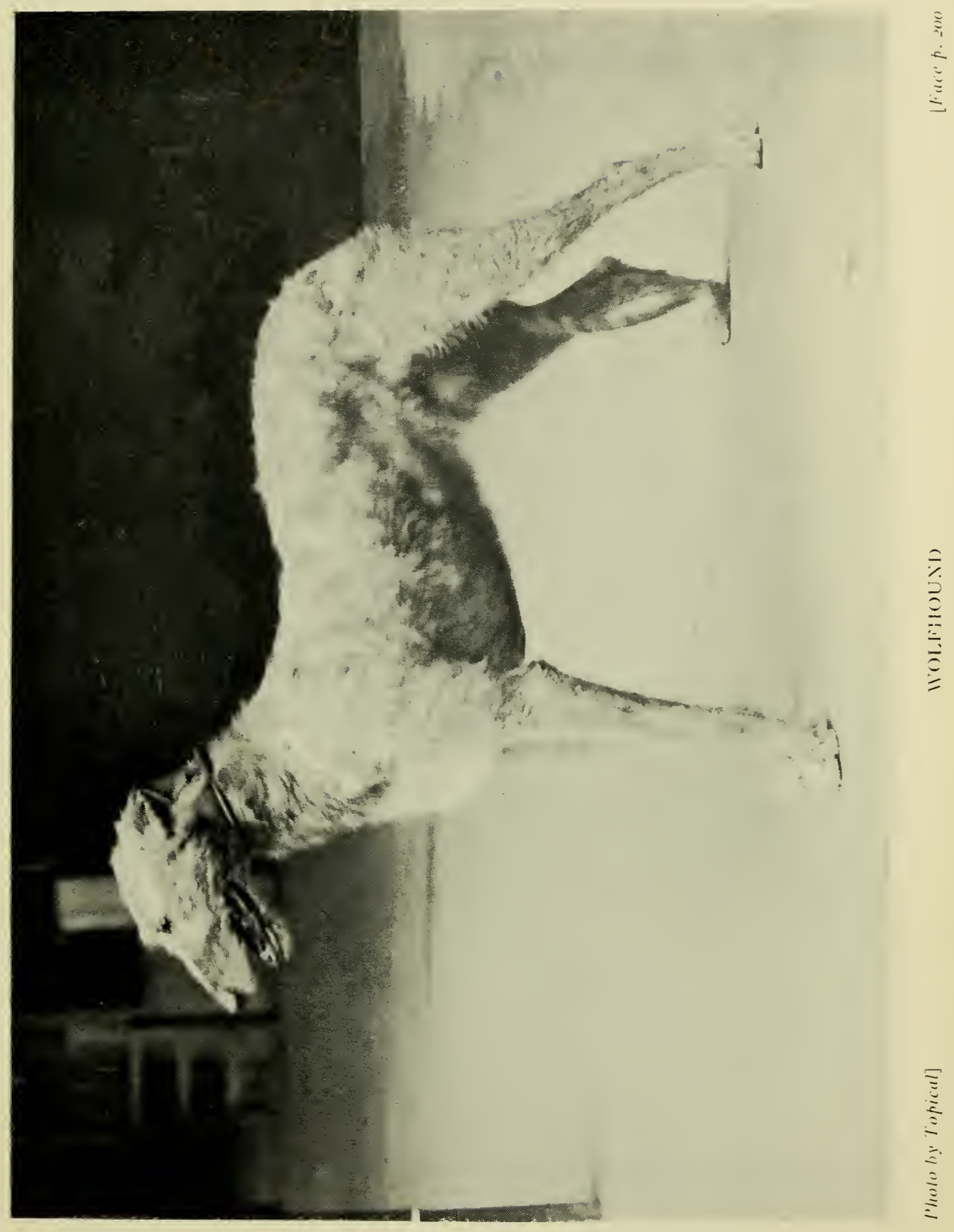



there is much pain in the region of the top of the loins and stomach, and especially if the urine which passes is tinged with blood, the presence of a stone may be suspected; but under any circumstances the bowels should be well opened by a dose of castor oil, and opium should be administered every six hours in doses of from $\frac{1}{2}$ grain to 2 grains, according to the size of the dog. Linseed poultices on the parts where the pain exists will also bring relief.

Inflammation of the kidneys, or nephritis, also creates a difficulty in passing water. It may be the result of cold, a stone, or some direct injury. The symptoms are : great pain at the loins, an arched back, and a difficulty in walking, whilst the urine is generally bloody. Hot fomentations will relieve the pain; but this is both a dangerous and a painful disease, so a veterinary surgeon should be called in. (See Linseed, Nursing, Stone.)

\section{V}

Vagina.-The organ of sex in the bitch.

Value of Dogs.-As a rule the value of a dog is what he will fetch, but of course some quite fancy prices are occasionally paid. (See Buying a Dog, Selling.)

Vegetables.-Green vegetables, such as cabbages, are necessary for the well-being of dogs, which should be taught to eat them from puppyhood; and of course they should always be well boiled, but not in the water in which meat is being cooked. A very excellent green food consists of the shoots of nettles well boiled, and spinach is also good; but as a rule roots are not to be recommended, though potatoes, if mashed up, form an agreeable change when mixed with broth and a little flesh, but they should not be given too often. (See Feeding.) 
Veins are the blood-vessels which carry the blood back to the heart after it has passed through the arteries. The blood which comes from a severed vein trickles out, and is darker in colour than that which spurts from the arteries if they are cut. (See Arteries, Bleeding, Capillaries, Stitching-up Wounds.)

Ventilation.-All kennels should be well ventilated if the dogs inhabiting them are expected to thrive; but adequate ventilation and draughts are two very different things, and hence the ventilators should be placed up high over the heads of the dogs at the top of the kennel. A very good ventilator is formed by a piece of bent iron piping, so arranged that the water cannot enter it, which can easily be effected by fitting it with a cowl. By such means the impure air will be able to escape and the kennels kept sweet. Another good arrangement is a sliding panel at the top of each of the sides of the kennel, something after the design of the ventilators in railway carriages. By this the amount of ventilation can be regulated, as it will not be necessary to open more than one ventilator in bad weather, and that only at the side away from the direction of the wind; whilst in hot weather they can all be pushed as far back as possible, thus allowing a current of cool air to pass over the heads of the dogs. (See Hospital, Kennels.)

\section{Vermin. (See Fleas, Lice, Ticks.)}

Veterinary Surgeons.-Both dogs and their owners have every cause to feel thankful that the health of the one and the property of the other are now in the hands of a very different class of practitioner to many of the illiterate, ignorant men who used to pose as dog doctors in the past. The modern canine specialist is a gentleman who has studied his subject, and is not merely guided by the principles of rule of thumb and a smattering of a know- 
ledge of dogs' diseases, associated with an acquaintance with the ailments of cows. Hence the extraordinary cures which have been effected, and the immense value of the works which have been published on the subject of canine diseases and their successful treatment, conspicuous amongst the series being “The Dog's Medical Dictionary," by Mr. A. J. Sewell, and published by George Routledge \& Sons, Ltd.

Vomiting.-Owing to the fact that dogs frequently vomit from very trivial causes, the possibility that the act may be a symptom of serious disease is apt to be overlooked. It is therefore an act of wisdom on the part of an owner to endeavour when his dog vomits to ascertain whether the act is accompanied by further symptoms of diseases described on other pages of this work.

\section{$\mathrm{W}$}

Wall Eye. (See China Eye.)

Warm Tan._A deep, rich coloured shade of tan.

\section{Warragal. (See Dingo.)}

Warts are rather common amongst dogs, and appear on all parts of their bodies, but most frequently on the mouth and lips. There are three ways of dealing with them-namely, by cutting them out, by applying caustic, or, if their shape and position will permit it to be done, by tying a piece of silk thread tightly round the necks of the warts, and allowing it to remain on until they drop off.

Washing Dogs.-The right way to wash a dog is to place him in a tub that is large enough to accommodate him comfortably, and if this is made of wood, and there 203 
is a hole at the bottom which can be stopped by a cork, it will save a good deal of trouble and mess by standing it on trestles over a drain or gutter, so that it can be emptied easily. Fill the bath full enough to reach almost up to the dog's belly, with water hot enough to let the hand be put into it comfortably, having previously placed at hand a piece of soap, a sponge, or washing glove, a couple of towels, and a can of cold, or in the winter tepid, water, whilst a little common soda may be placed in the bath. Then lift the dog in gently, having first removed his

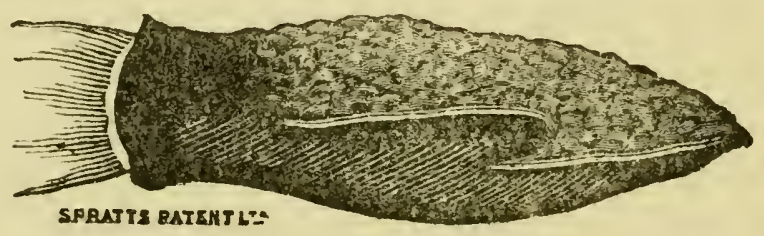

Washing Glove.

collar, supplying its place with a piece of clean cord if he tries to escape. First thoroughly soak his head and face with water by the assistance of the sponge or glove; then apply the soap and wash it off, rinsing with a little cold or tepid water out of the can at hand. Then deal with all the other parts of his legs and body in turn in a similar manner, taking care to sluice the soap well out of his coat by means of the sponge or glove; the last stage being to douche him with the clean water out of the can, as this will assist the former operation, and also reduce the chances of his taking cold. Then squeeze the water out of his coat and feet, and rub him dry in the towels. He should not be allowed to run loose directly after a bath, as he is sure to roll on the ground and soil his coat, but should be tied up near a fire if delicate, or else put back in his kennel on a clean bed.

It may be added that the washing glove, if used, should be specially designed for the purpose, else it will be useless. (See Soap.) 
Watch-dogs.-Of late years the large-sized watch-dog, such as our forefathers used to rely upon for the guardianship of their lives and property, has fallen out of fashion, the result being that such varieties as the mastiff have found their occupation gone. No doubt this in a great measure is due to the methods of housebreakers having undergone a change, but be this as it may the watch-dog of the period is one of the smaller breeds, which is kept indoors in order to arouse the household by his barking should intruders appear upon the scene. For this purpose there are no better breeds than the Pomeranian or the Schipperke, but most of the terrier varieties are alert and reliable; whilst for outdoor work of the kind a retriever will usually be found to be very useful. A good deal will, however, depend upon how an animal is brought up and managed; as a dog which is pampered and coddled cannot reasonably be expected to have his wits about him, and will possibly be lying fast asleep on his luxurious bed whilst burglars are rifling his master's house. In short, it is a very bad plan to make a watch-dog too comfortable or to feed him too late of a night. A hearty morning meal may be given him, and of course a run, and then he should be shut up in a quiet kennel to sleep for the rest of the day, and be brought indoors at night. The best place to locate him is in the passage, and he should be chained up, as if he is allowed to run loose he may select more comfortable sleeping quarters, far removed from the part of the house at which burglars may enter. It is always a great mistake to allow your watch-dog, whatever his breed may be, to be made a fuss of by strangers, and care should be taken to keep him during the day out of the way of tramps, who may lay pieces of poisoned meat about the premises in the interests of their accomplices, the housebreakers.

Water.-Most dogs drink far more water than is good for them, and the habit is one that increases unless the propensity is controlled. It is noticeable, too, that dogs 205 
which get a good deal of sloppy food care very little for water, which rather goes to prove that excessive drinking is an acquired habit. Of course it is not suggested that dogs should be kept short of water, but it is recommended that when puppies they should only have it placed before them at intervals, and if this rule is carried out they will not drink much when they grow up. (See Training Grevhounds.)

Water-dogs.-Apart from the water-spaniels, which take to water like ducks, the best water-dogs are the Labrador, the field-spaniels, the retriever, the Newfoundland, and most breeds of terrier. Some of these animals, however, possess a great dislike to entering a stream or pond, and these rarely, if ever, can be made to conquer this aversion. On the other hand, there are many representatives of other varieties which take water well.

Water Troughs should always be kept clean, and out of the rays of the sun in summer. They are best made of enamelled iron of a pattern that cannot be overturned, and their contents should be frequently changed.

\section{Waterside Dog. (See Airedale Terrier.)}

Wavy-coated Retriever.-This variety is not encouraged nowadays, though he was in favour some years ago. (See Flat-coated Retriever.)

Weaning Puppies.-Puppies should be weaned gradually, their dam being taken away from them for an hour or two a day when they are a little over a month old, by which time they should have been taught to feed a little by themselves. The period of separation should be gradually extended during the daytime, the dam being left with them of a night until they arrive at the age of six weeks, when she may be finally removed from them. Of course there are exceptional circumstances which may render it desir206 
able to keep the puppies longer with their dam, such as if they are weakly, or if the weather is very cold. (See Breeding, Brood Bitch, Puppies, Rearing Puppies, Teething.)

Welsh Heeler.-A title by which mirled collies are sometimes described, but the derivation of the expression is unascertainable. (See Collie, Mirle.)

Welsh Hound.-This is a wire-haired variety of the foxhound, which was used promiscuously for hunting the fox, the otter, and the hare in Wales. His merits as a hunter were undoubtedly high, but the breed has almost died out.

Welsh Spaniels. - The Welsh springer has of late years been resuscitated, to the satisfaction of sportsmen in different parts of the country who desire to possess a working spaniel which stands on higher legs than the modern show springers; and of him it may be said that no member of the family is a better and more reliable worker.

The head in this variety is only of moderate length and width; there should be a stop between the eyes, and a distinct drop at the setting on of the muzzle, which is of fair length, neither too long or too short, and rather narrow. The eyes are dark hazel in colour, and not too sunken; the ears smaller than those of the English springers, set on low, fairly feathered, and lie close to the sides of the head. The neck is powerful, and shows no superabundance of loose skin, it is nicely set on long, sloping shoulders; the body being of moderate length, with well-sprung ribs and powerful loins. The fore-legs are longer than those of the English springers, quite straight, and carry a fair amount of feather, and round feet, whilst the hind-legs, which are feathered down to the hocks, must not be too much bent at the stifles; and the tail, which is carried straight, is nicely feathered, The 
coat is very thick and flat, the accepted colours being red and white, or orange and white, the former for choice; and the average weight about 36 lbs. (See Feather, Spaniels, Stop.)

Welsh Terrier.-This breed has sprung into favour during the last twenty years, but previous to its merits being recognised in England it was well known and a general favourite in Wales. There can be no doubt that on its first appearance this breed was a good deal hampered in the course of its struggle for popularity by the disposition to confound it with another rough-coated dog, which was styled by its admirers "the Old English terrier," and which it was attempted to push to the front at the expense of the Welsh one. That there was a certain similarity of appearance between the two cannot be denied-indeed, a judge has been known to award honours at the same show to a dog which was entered both as an Old English and Welsh terrier; but an expert on the subject of terriers could never have made such a mistake, as the former variety was clearly mongrel, and of late has disappeared. The Welsh terrier, however, has become very popular, and fully deserves all the support he receives, as he is an active, intelligent, game, and companionable dog; and since the variety has been taken seriously in hand by scientific breeders there is much more sortiness observable amongst its members.

The head of the Welsh terrier is flat and moderately wide between the ears, with a slight stop between the eyes, and a long, powerful muzzle, set on a lower level than the skull. The eyes, which are rather small, must not be too deeply set, and are of a dark hazel colour; the ears being $\mathrm{V}$-shaped, set on fairly high, moderately thick in leather, and carried close to the sides of the head. The neck is rather long and slightly arched; the shoulders well laid back; the back short and flat, rounded at the ribs, and powerful at the loins. The fore-legs are fairly long, set on 208 
right under the dog, quite straight, and should show good bone, the hind ones being strong and muscular, and not too much bent at the stifles; the tail, which it is the custom to dock, being set on high. The coat is very close and wiry, the colours being black-and-tan, or grizzle and $\tan$; whilst the average weight is about 20 lbs. (See Docking Tails.)

West Highland Terrier.-This breed is to all intents and purposes a white-coloured, hard-haired Scottish terrier; which see.

\section{Wheel Back. (See Roach Back.)}

Whippet.-The whippet, or snap-dog, is used for dogracing purposes, and is in great request in many parts of the country where this sport is popular. In appearance he is simply a miniature greyhound, the popular weight being about $20 \mathrm{lbs}$; but some well-known performers-the famous Cowboy, for instance, who ran at about 40 lbs.are considerably heavier. (See Dog Racing, Greyhound, Training Greyhounds.)

Whips.-If it is necessary to correct a dog, the chastisement should always be administered with a whip, and a short-handled one with a fairly stout thong is the best to use for the purpose. A stick should never be applied to a dog, as it is apt to cause serious, and possibly permanent, injuries to bones.

White English Terrier--It is a subject of regret to many dog-lovers of the old school that this most beautiful and engaging breed of dog should have been allowed to become practically extinct. This, however, is the case, and it is almost to be feared that a similar fate will overtake the black-and-tan terrier-of which he is an exact replica in white-if more patronage is not bestowed upon him. (See Black-and-Tan Terrier.) 
Windows.-When dogs are confined in large kennels the latter should always be fitted with windows, so as to admit light and air. It is necessary, however, that they should be well protected by wire on both sides, unless they are situated very high up, in order to prevent the dogs breaking the glass and thereby cutting themselves. (See Kennels.)

Wire Brushes are used for the purpose of removing the dead hair when dogs are changing their coats. Their use is, however, often abused by people who are desirous of reducing a superabundance of coat in their show dogs. (See Brushes, Faking, Grooming, Preparing for Show, Trimming.)

Worms are terrible pests to many dogs, and in addition to causing them a good deal of suffering at times, the presence of these parasites invariably affects their health, coat, and general condition. There are three varieties of worms-the maw-worm, which is to be found in the rectum, the round-worm, and the tape-worm, which inhabit the bowels. The maw-worms resemble grains of rice, and are in reality particles of a tape-worm, which create great irritation of the part; whilst the round-worms are about four inches long and of a pinkish colour. The worst of all is the tape-worm, which resembles a long piece of whitish-coloured tape, with a diamond-shaped head, and until the latter is got away the dog will not be freed from the objectionable presence of this loathsome creature. Unfortunately it is by no means easy to remove the head, as the body breaks up in pieces and comes away, leaving the head behind it to create trouble inside the dog. Consequently, however large the pieces that are passed may be, the tape-worm remains unless the head comes with them, and hence it is always desirable to give at least two doses of medicine at intervals of about a week. Unless the dog is very delicate or quite young, if so the period 210 
must be reduced, he should be fasted for twenty-four hours before being given his medicine, and during this fast not a grain of food or drop of water should be given him. An hour afterwards, if the medicine has not worked, he may be given a dose of castor oil ; but if it has, a basin of hot broth will do him good, and this should be allowed him the same time after the oil if he has to take the latter. A run, too, will expedite his motions, which should be inspected, if it is a case of a tape-worm, to ascertain if the head has been passed. The most common and one of the most efficacious remedies for worms is freshly grated areca-nut, the dose of which is two grains for every pound the dog weighs, the maximum dose being two drams for such breeds as the mastiff or St. Bernard, according to the weight and age of the dog. Santonine, in doses from one-eighth to one-half a grain, is also an efficacious remedy, and so too are oil of male-fern, turpentine, and Indian pink ; but the two last named are most dangerous, and their use should be avoided. Favourable reference may also be made to Spratt's Worm Powders, which have succeeded in cases where other remedies have failed, and which contain nothing that can prove injurious to the dogs. The presence of worms can be detected by loss of flesh or skin troubles, a staring coat, and a general air of languor and discomfort about the dog. In the case of small puppies the bellies are hard and distended, and sometimes the presence of the pests is associated with fits. (See Puppies.)

Wounds. (See Bites, Bleeding, Cuts, Stitching-up Wounds.)

\section{$\mathrm{Y}$}

Yellows. (See Jaundice.)

Yorkshire Terrier.-There is no such beautiful dog in the world as a really fine specimen of this breed in firstrate condition, but unfortunately good specimens are not 
easy to find, and when they are their coats are most difficult to keep in order. Indeed, no variety requires more assiduous attention, and many are the devices resorted to and prescriptions used to accomplish that result. Cocoaoil is a very good thing for the long, silken jackets of these little dogs, which are usually kept shut up in glass-fronted boxes, as their constitutions are so delicate; whilst soft wash leather coverings are kept upon their feet to prevent them scratching and tearing the hair. It is usual also to keep the luxurious hair which grows upon their heads tied back, in order that they can see, and their jackets, which should be of exuberant length, require frequent attention from a long but soft-bristled brush, else they will become matted and the dog's beauty will be lost.

The head is small and flat, the muzzle delicate and not too long; the eyes rather small and deeply set, dark in colour and sparkling; the ears small, and carried semi-erect, the hair on them being short and of a very deep tan colour. The neck is fairly long, the shoulders sloping, and the body moderately long and level, the ribs being flat and loins strong. The fore-legs must be quite straight, and they are covered with short hair of a deep tan shade, the feet being round, and the tail docked. The coat is a great point, as it must be long on the body, almost reaching to the ground and perfectly flat, whilst on the head it is also of considerable length. The colour is a lovely steel-blue of a dark shade on the body, whilst the long hair on the head, and also on the chest, is of a rich, deep $\tan$ hue, but on the neck it is the same colour as on the body, all the tan hair being darkest at the roots. Weights vary considerably, being from $5 \mathrm{lbs}$. to I $2 \mathrm{lbs}$. (See Brushes.)

Printed by Ballantyne, Hanson \& Co.

Edinburgh \& London 


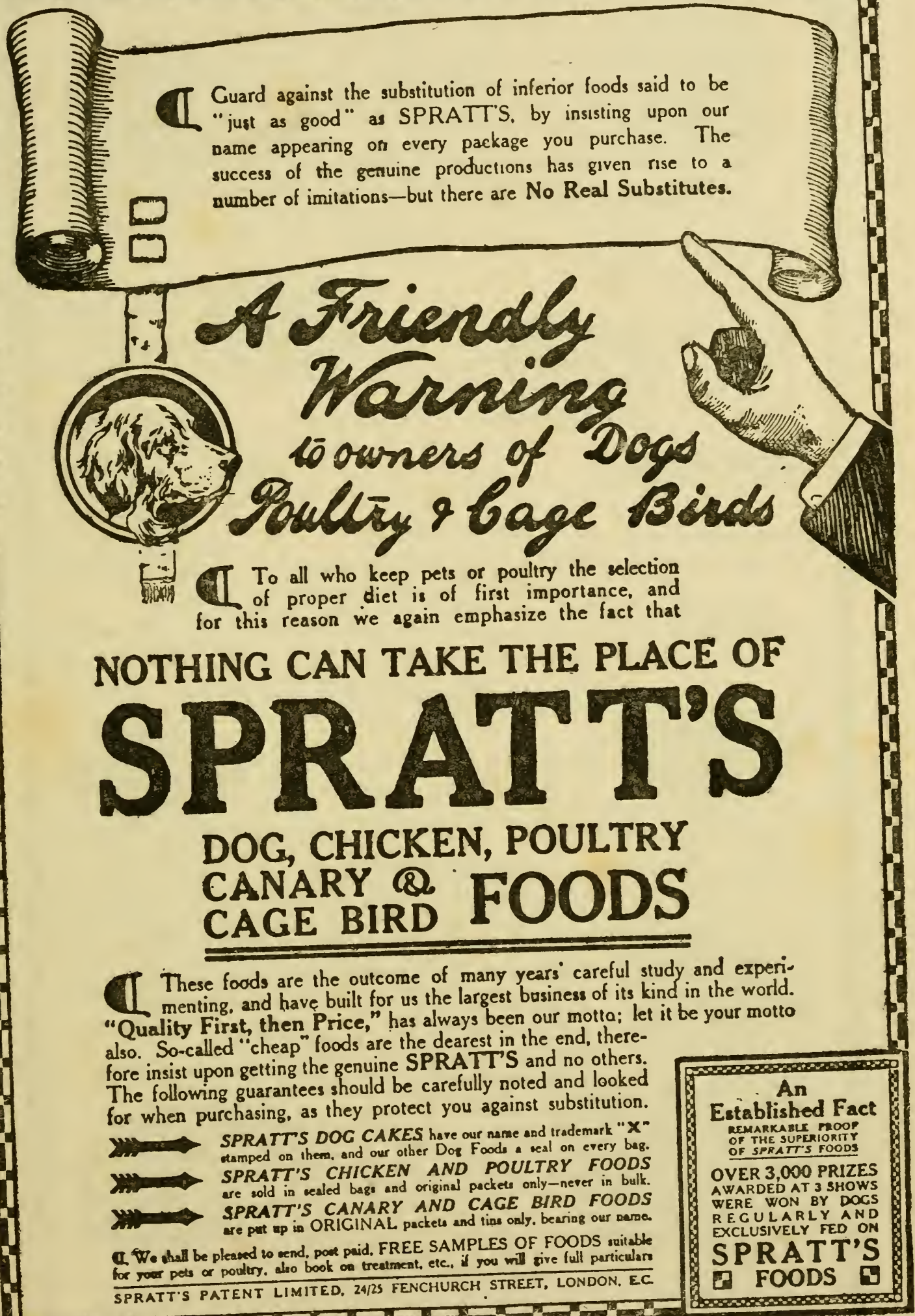




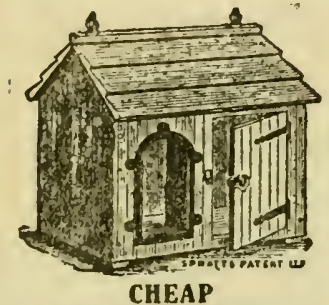

PORTABLE KENNEL

Mode io sectloos to boll togetser.

Terrier Size - $£ 136$

Bulldog Size - $\$ 190$

Retriever Size - $£ 1170$

Great Danes - $\$ 2176$

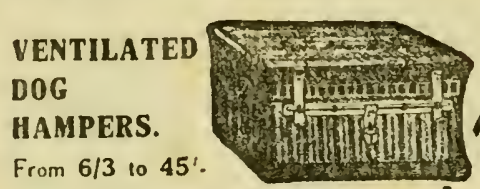

From $6 / 3$ to $45^{\prime}$.

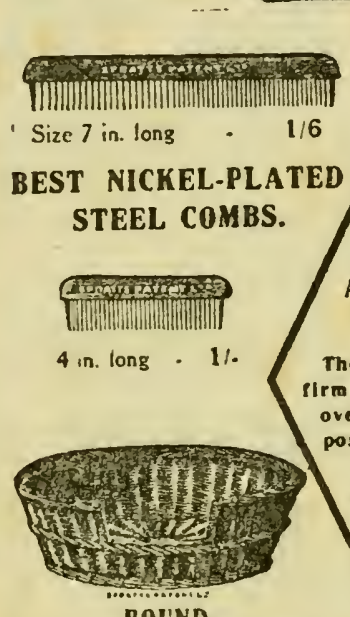

ROUND

SLEEPING BASKETS

arowa Wickerwork sod Varsisbed.

From 2.3 to $6 /$.
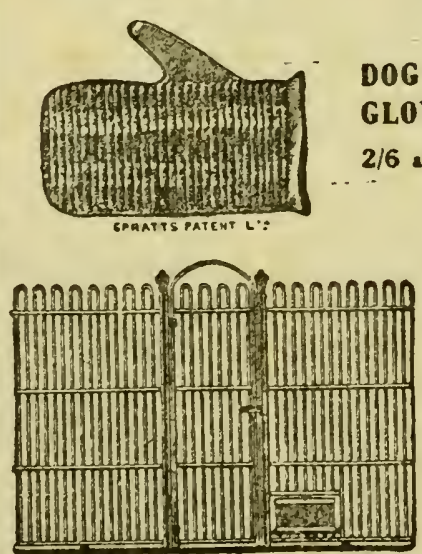

WROUGHT IRON KENNEL RAILING.
WE RAVE A VERY LARCE ASSORTMENT OF :

COLLARS CHAINS LEA D S

AKD SBALL DE PLEASED TO SEND' PRICES ON APPLICATION. SPRATT'S PATENT LIMITED. 24/25 Fencharch St., London,

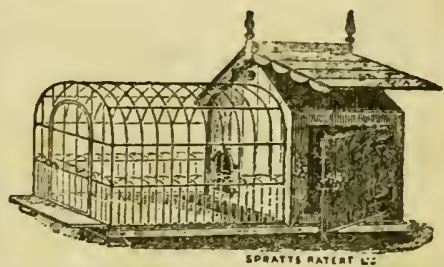

TOY DOG KENNEL \& RUN.

For Indoor use, mounted on Castors. Prices $47 / 6$ and 57/6 E.C.

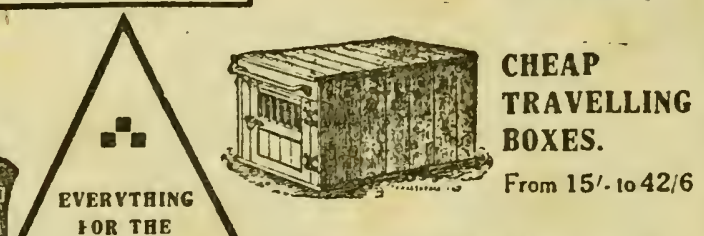
EVERYTHING
DOG -

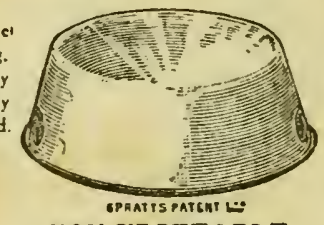

NON-UPSETABLE DOG DISH.

Are the most Durable. Reliable and Up-to-Date on the Market.

Galvanized-

6d., 9d.. 1/. \& 1/6 each

Enamelled-

$1 /-.1 / 6,2 /-\& 2 / 6$ each

They are made by a flra wirs a. reputation-a

who bave studied the requiremeats of dogs for

position to know exactly the appliances necessary

Whetber you are requiring a range of kennels or a dog collar, write for onr lllustrated list, but don't be guided by the price only. Spratt's Ouatity is above the average. and has to be

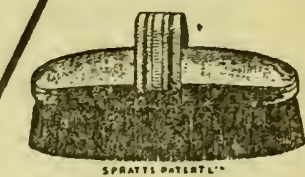
BRUSHES OF ALL DESCRIPTIONS \& SIZES. REMEMBER From 6d. 10 $6 / 6$
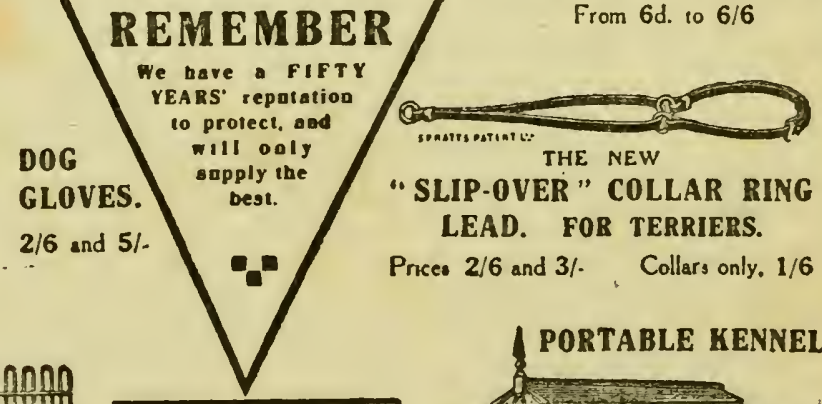

"SLIP-OVER" COLLAR RING LEAD. FOR TERRIERS.

Prices $2 / 6$ and 3/. Collars only, 1/6

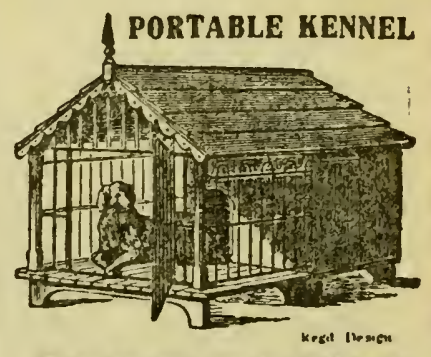

With Oatside Covered Bencb. 


\section{RACKHAM'S DISTEMPER BALLS}

The only remedy for Distemper that has never failed to effect a perfect cure. No matter what the breed of the dog, they are a certain cure. With full directions. Prices, $1 /-, 26,5 /-, 10 /$, and 20'- per box. Postage 2d. extra.

\section{RACKHAM'S JAPANESE WORM} BALLS OR POWDERS

This is the widely celebrated cure. For expelling Worms of all kinds from Dogs. No other medicine, oil, or frequent dosing necessary. "ONE DOSE SUFFICIENT." Prices 1/., 26,5-, 10/-, and 20/- per box. Postage 2d. extra.

\section{RACKHAM'S TONIC CONDITION BALLS}

are Invaluable for Weak and Ailing Pups, Greyhounds and Whippets in Training, Exhibition, Sporting, and Stud Dogs. Bring them into the bighest state of condition of health. Prices, 1/-, 2/6, 5/-, 10/-, and 20/-. Postage 2d. extra.

\section{RACKHAM'S KATALEPRA}

The only acknowledged cure in the world for Red Mange, Eczema, and the various troublesome skin diseases to which most dogs are subject. It cures these diseases rapidly, its use injures neither the dog's constitution nor general health. Prices, $1 /-, 26,5 /-, 10 /-$, and 20/-. Postage 2d. extra.

\section{RACKHAM'S DACTYLA} (Registered)

The Finest Food in the World

"The New Food for Dogs." Contains our Dried Meat Powder; also a scientifically prepared admixture of Dates and other Eastern Fruits. Keeps system and skin cool, healthy, free from Mange and Eczema, and coat glossy. Prices, 19/6 cwt., 9/9 $\frac{1}{3}-\mathrm{cwt}$., 5/. 1-cwt., and $2 / 6$ I4 lb.

\section{RACKHAM'S JAPAN SOAP}

For Washing Dogs. Prevents Mange, Eczema, Scurf, \&c. Kills Lice, Ticks, and Fleas instantaneously. Cleanses, disinfects and beautifies. Tablets, $6 \mathrm{~d}$. and $1 \mathrm{~s}$. Post free, 2d. extra.

\section{RACKHAII \& CO. (Dept. V.S.E.), St. Peters, NORWICH} Telegraphic Address: "DISTEMPER, NORWICH."

\section{BOOKS FOR THE STABLE AND KENNEL}

" STONEHENGE." The HoRse, IN THE Stable and IN THE FieLd : his Varieties, Management in Health and Disease, Anatomy, Physiology, \&c. Sixteenth Edition. Revised and partly re-written by HAROLD LeEney. Two vols., royal 8vo, cloth. With 4 Coloured Plates, and 23 I Illustrations. 30s.

HORSES, HORSEMEN AND STABLE-MANAGEMENT. By Godfrey Bosvile. 8 Plates and numerous Illustrations. Demy 8vo, half-roan, 5 s.

DOGS: THEIR MANAGEMENT IN HEALTH AND DISEASE. By the late EDWARD MAYHEw. Re-written by A. J. SEwELL, M.R.C.V.S. 20 Plates and many cuts. Crown 8vo, half-roan, 5 s. THE DOG'S MEDICAL DICTIONARY. By A. J. Sewell, M.R.C.V.S. Third Edition, with Plates. Demy 8vo, half-roan, 5s.

THE BOY FANCIER. By F. T. BARTon, M.R.C.V.S. A Complete Manual for all who keep Domestic Pets for Pleasure or Profit ; Ponies, Dogs, Cats, Rabbits, Guinea-Pigs, Ferrets, Fancy Mice, Squirrels, Hedgehogs, Poultry, Pheasants, Cage-Birds, Pigeons, \&c. With I 43 Illustrations. $8 \mathrm{vo}$, cloth extra, 5 s.

\section{List of Books on Country Life free on request}

GEORGE ROUTLEDGE \& SONS, LTD. BROADWAY HOUSE, 68-74 CARTER LANE, LONDON, E.C. 


\section{THE HUNTING MAN'S LIBRARY}

\section{With Coloured Plates and other Illustrations}

Printed uniformly in large, clear type. Size of Volumes,

$$
10 \frac{3}{4}+7 \frac{1}{2} \text { in. }
$$

I. THE NOBLE SCIENCE OF FOX-HUNTING. By F. P. Delmé Radcliffe, and enlarged by W. C. A. Blew. Fifth Edition, edited by CuthBert BRAdley, "Whipster" of The Field. Two vols., 2IS. net.

II. NOTITIA VENATICA: A Treatise on Fox-Hunting, embracing the General Management of Hounds. By RoBerT T. VyNER, and enlarged by W. C. A. Blew. Eighth Edition, edited by CUthbert BRAdley. Two vols., 2IS. net.

III. GOOD SPORT SEEN WITH SOME FAMOUS PACKS: I885-1910. By Cuthbert BRADley; with a Hunting Note by the Right Hon. Henry Chaplin, M.P., Ex-M.F.H. Blankney. I2s. 6d. net.

IV. FOX-HUNTING FROM SHIRE TO SHIRE, with many Noted Packs. A companion volume to the above. By the same Author. With Introductory Note by Captain E. PENNELL ELMHiRst, Ex-Master of the Woodland Pytchley and "Brooksby" of The Field. I2s. 6d. net.

Illustrated Prospectus of above, free on request.

\section{MR. HALFORD'S BOOKS FOR THE ANGLER}

MODERN DEVELOPMENT OF THE DRY-FLY. By Frederic M. Halford, "Detached Badger" of The Field. With 9 Coloured Plates of Flies, I 7 Photogravure Plates, and 18 Colourstandards. Medium 8vo, buckram, I5s. net.

THE DRY-FLY MAN'S HANDBOOK: A Complete Manual, including the Fisherman's Entomology and the Making and Management of a Fishery. By the same Author. With 43 Plates and numerous Illustrations in the Text. Uniform with above. 2IS. net.

"Nothing has done more to revolutionise our trout fishing than the modern development of the dry-fly. And just as no other fashion in fishing has been productive of more far-reaching changes, so no other man has done so much to advance this highest expression of the angler's art as Mr. Halford, whose beautiful books, at once practical and poetic, have made known its possibilities and its practice to so many grateful epigoni." Morning Post.

GEORGE ROUTLEDGE \& SONS, LTD.

BROADWAY HOUSE, 68-74 CARTER LANE, LONDON, E.C. 


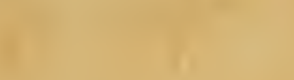

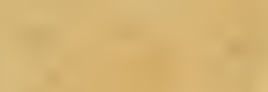

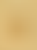
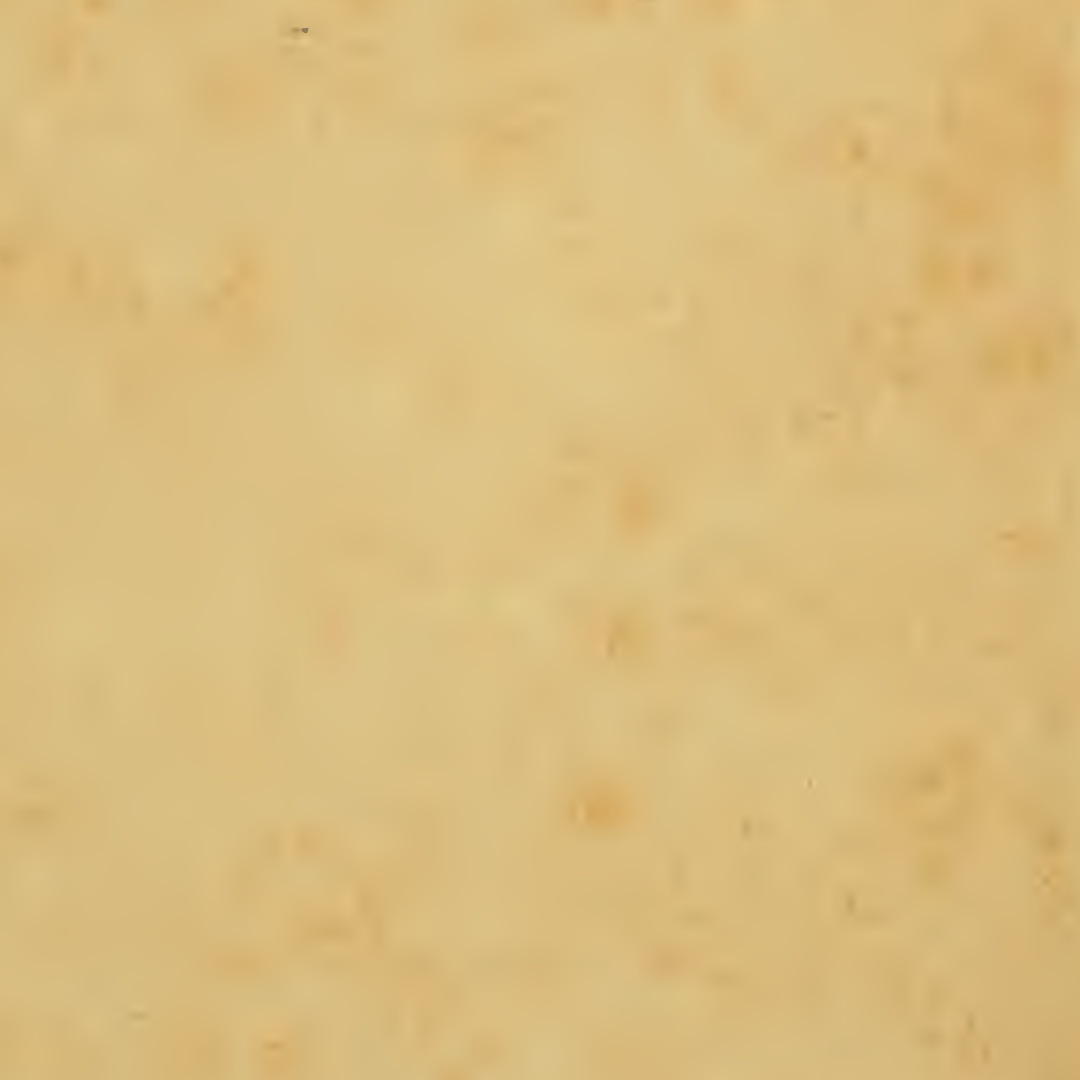

y
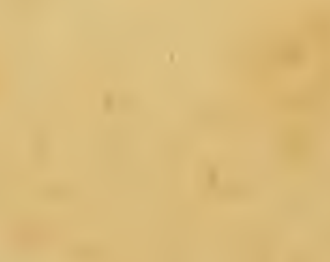

r

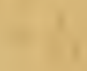

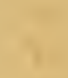

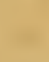

(

(1)

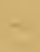


Nobster Family Library of Veterinary Medicine unmings School of Veterinary Medicine at

utis University 


$$
\text { of }{ }_{5}
$$


